\title{
Ability of Compressed-Air Foam to Absorb Heat \\ and \\ Mitigate Gas Propagation
}

\author{
By \\ Paul Lhotsky, P. Eng.
}

A thesis submitted to the Faculty of Graduate and Postdoctoral Affairs in partial fulfilment of the requirements for the degree of

\author{
Doctor of Philosophy \\ in Civil Engineering
}
Department of Civil and Environmental Engineering
Carleton University
Ottawa, Ontario

May 2013

(C) Copyright 2013

Paul Lhotsky 
Library and Archives

Canada

Published Heritage

Branch

395 Wellington Street

Ottawa ON K1A ON4

Canada
Bibliothèque et

Archives Canada

Direction du

Patrimoine de l'édition

395 , rue Wellington

Ottawa ON K1A ON4

Canada
Your file Votre référence

ISBN: 978-0-494-94553-7

Our file Notre référence

ISBN: 978-0-494-94553-7
NOTICE:

The author has granted a nonexclusive license allowing Library and Archives Canada to reproduce, publish, archive, preserve, conserve, communicate to the public by telecommunication or on the Internet, loan, distrbute and sell theses worldwide, for commercial or noncommercial purposes, in microform, paper, electronic and/or any other formats.

The author retains copyright ownership and moral rights in this thesis. Neither the thesis nor substantial extracts from it may be printed or otherwise reproduced without the author's permission.
AVIS:

L'auteur a accordé une licence non exclusive permettant à la Bibliothèque et Archives Canada de reproduire, publier, archiver, sauvegarder, conserver, transmettre au public par télécommunication ou par l'Internet, prêter, distribuer et vendre des thèses partout dans le monde, à des fins commerciales ou autres, sur support microforme, papier, électronique et/ou autres formats.

L'auteur conserve la propriété du droit d'auteur et des droits moraux qui protege cette thèse. $\mathrm{Ni}$ la thèse ni des extraits substantiels de celle-ci ne doivent être imprimés ou autrement reproduits sans son autorisation.
In compliance with the Canadian Privacy Act some supporting forms may have been removed from this thesis.

While these forms may be included in the document page count, their removal does not represent any loss of content from the thesis.
Conformément à la loi canadienne sur la protection de la vie privée, quelques formulaires secondaires ont été enlevés de cette thèse.

Bien que ces formulaires aient inclus dans la pagination, il n'y aura aucun contenu manquant. 


\section{ABSTRACT}

Despite their limited use, compressed-air foam systems (CAFS) have important benefits for firefighting, life safety and fire control including reducing water demand, limiting damage and mitigating adverse effects on the environment.

The objectives of this study were to:

- determine the heat absorption capacity of compressed-air foam, and

- determine the foam's ability to mitigate gas propagation.

As compressed air-foam's (CAF) ability to extinguish a fire within one to two minutes is well documented, in this research, the immediate post-fire conditions were simulated by applying a heat source to the bottom of a foam layer to determine CAF's ability to cool hot surfaces.

A method of calculation was developed and validated to determine the convective heat transfer coefficient between steel and CAF in contact with a horizontal surface that is applicable for surface temperatures above $100^{\circ} \mathrm{C}$.

The heat transfer coefficient was then used to calculate the optimal application density of CAF to provide the maximum rate of cooling. 
The ability of CAF to mitigate the transfer of hot gases was studied by first measuring the concentrations of $\mathrm{CO}_{2}$ that were generated by burning propane and subsequently propagated through the foam layer. It was concluded that, as long as the foam cover is intact, the propagation of $\mathrm{CO}_{2}$ is substantially reduced.

The results can be used to predict the ability of CAF to control products of combustion crossing a foam layer after the initial cooling of the surface. CAFSs could be used to control the spread of flammable vapours and therefore minimize the possibility of explosion in case of a flammable liquid spill. CAF could also provide a temporary control of gas evaporation of dangerous materials to ensure adequate environmental protection until specialized decontamination equipment can arrive at the site. 


\section{ACKNOWLEDGEMENTS}

I thank my thesis director, Professor George Hadjisophocleous, for his guidance throughout my research and thesis preparation. I admire Dr. Hadjisophocleous for his unparalleled devotion to fire protection and his leadership for developing a fire protection graduate program at Carleton University.

Thank you to Dr. Jim Mehaffey for his help throughout my research and the preparation of my thesis as well as for convincing me to take part in the graduate studies program at Carleton University.

I thank Dr. Steve Craft for his valuable input and counsel.

To Mr. George Crampton and the National Research Council, thank you for giving me access to the compressed-air foam generator. I also thank Modern Sprinkler Company, especially Mr. Ron Cornelow, for the use of their facilities. I thank Mr. Simon Turenne for assembling the specialized foam container.

I thank Dr. Steve Bodzay for guiding me in my thesis as well as providing me with the moral support throughout my studies. I also thank Dr. Joseph Brody for his direction and encouragement. 
A heartfelt thank you to my team at Civelec, and especially to my business partner, $\mathrm{Mr}$. Carlo Mastroberardino, for supporting me in times when the office work and studies overlapped. I thank Mr. Nick Cronin and Mr. Jonathan Linteau who helped me prepare the experiments and collect data.

I am grateful to Anne, Sarah and Bryn Burnell for their help and support through the studies and the editing of this report.

I dedicate this work to the memory of my mother, Mila, and my father, Dr. Stefan Lhotsky who guided me throughout my life and whom I miss very much. 
TABLE OF CONTENTS

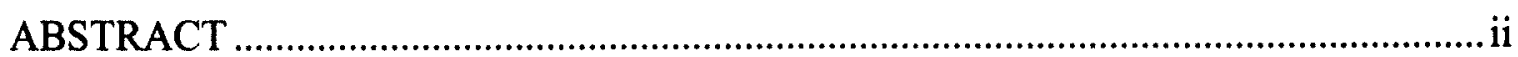

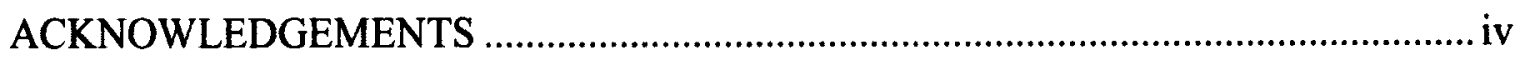

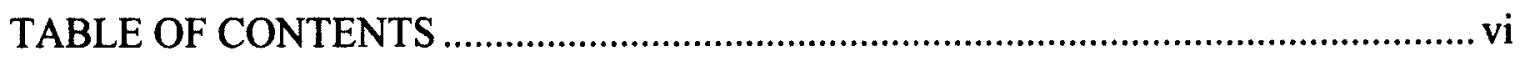

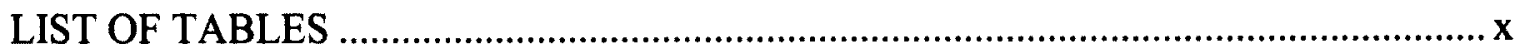

LIST OF FIGURES

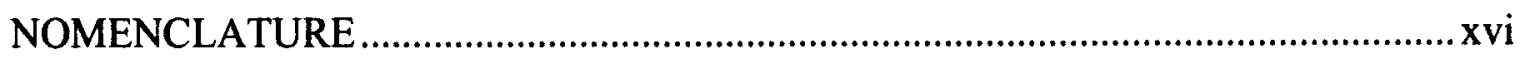

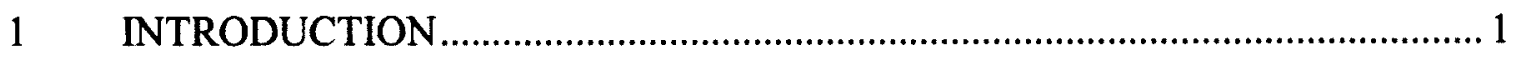

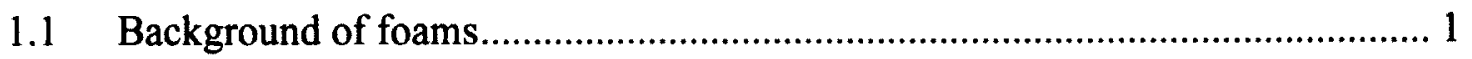

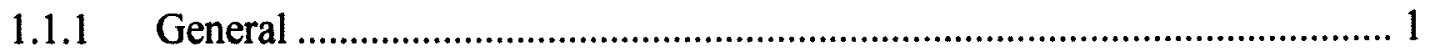

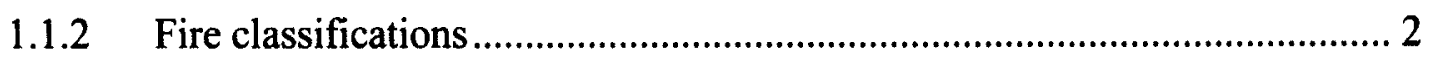

1.1.3 Foams - Types of expansion ............................................................. 3

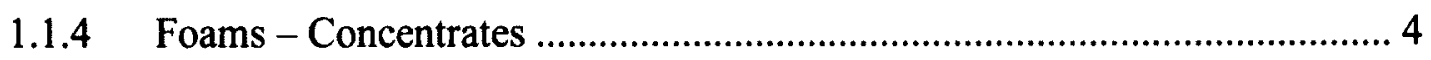

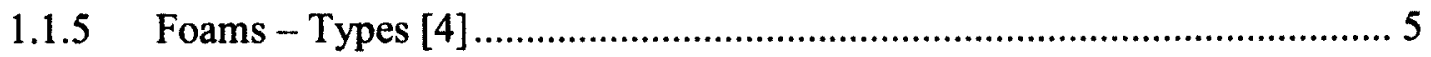

1.1.6 Foams - Environmental concerns ...................................................... 7

1.2 Background for compressed-air foam systems - CAFS [7] ................................ 8

1.3 Applicable scenario for the use of CAFS - heat control .................................... 9

1.4 Applicable scenarios for the use of CAFS - gas control ................................. 11

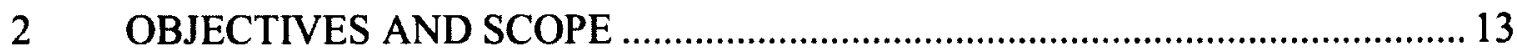

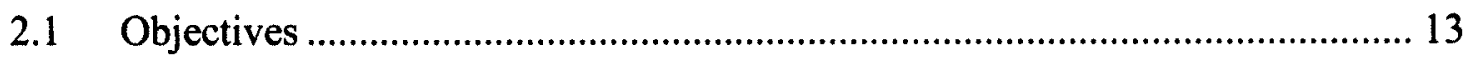

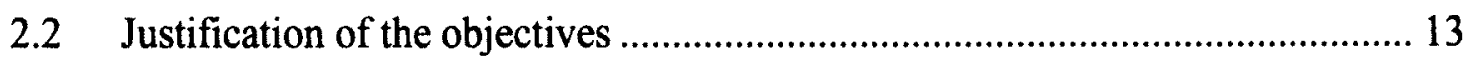

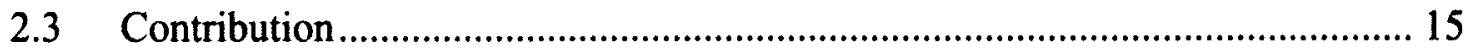




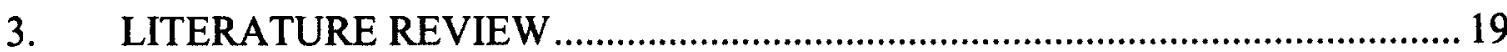

3.1 Effects of heat and smoke on electronics ................................................... 19

3.2 Typical use of fire extinguishing foams ....................................................... 19

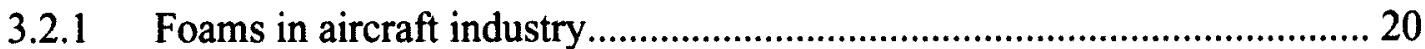

3.2.2 Foams for the protection of flammable liquids ...................................... 22

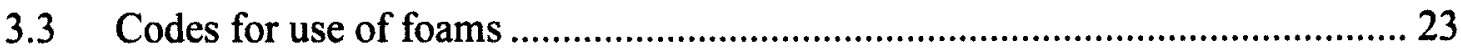

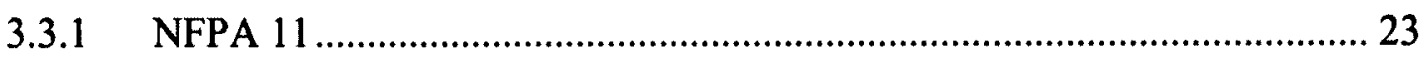

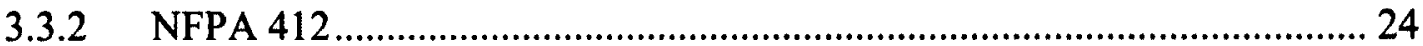

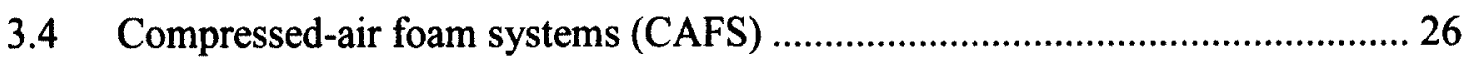

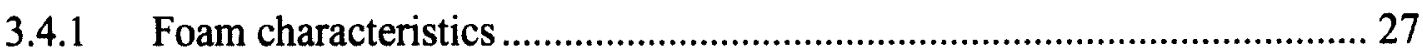

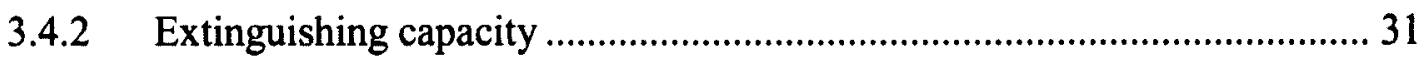

3.4.3 Foam's ability for the mitigation of thermal radiation.................................40

3.5 Summary of the Findings of the Literature Review ........................................ 42

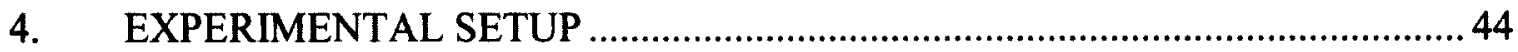

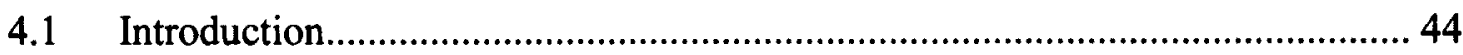

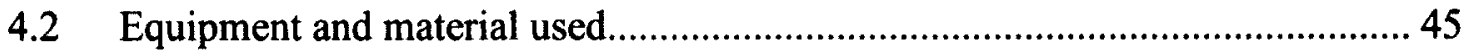

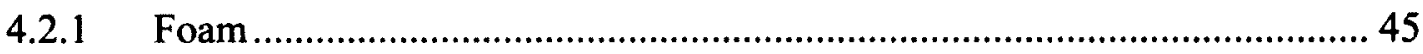

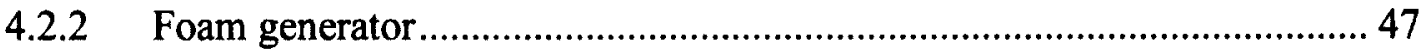

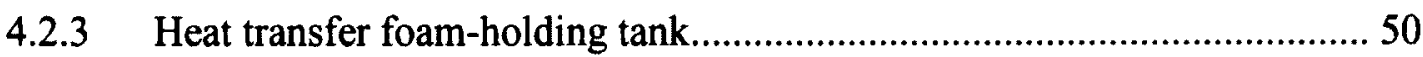

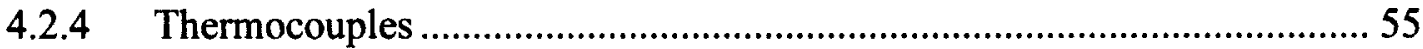

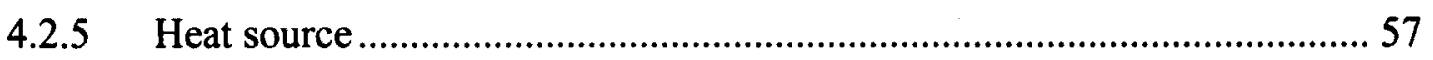

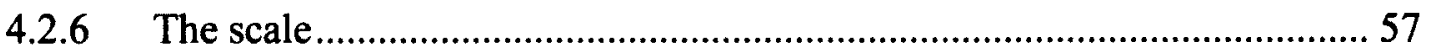




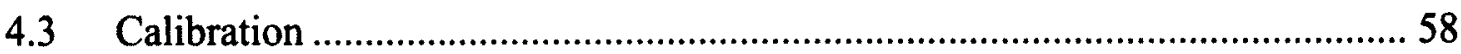

4.3.1 Foam water - foam concentrate calibration ................................................ 58

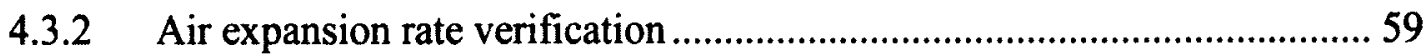

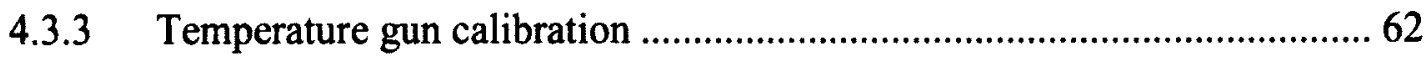

5. HEAT TRANSFER EXPERIMENTS AND ANALYSES ....................................

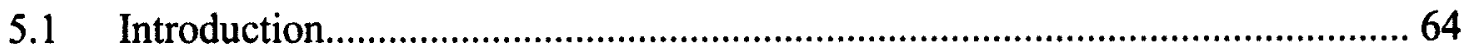

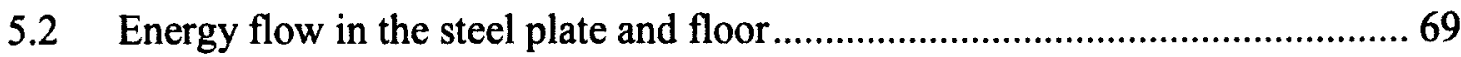

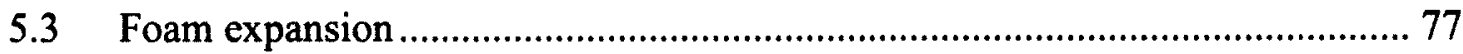

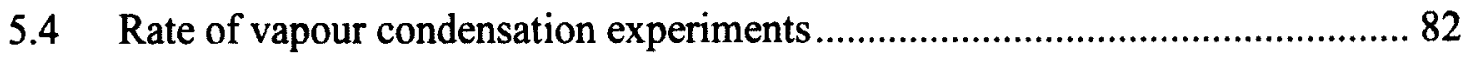

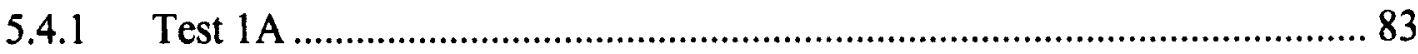

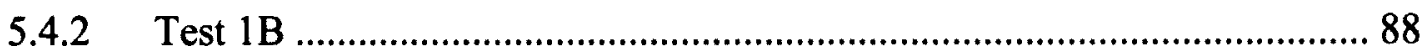

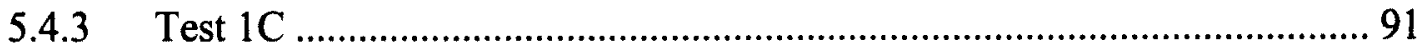

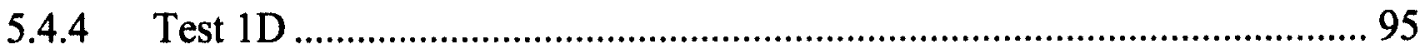

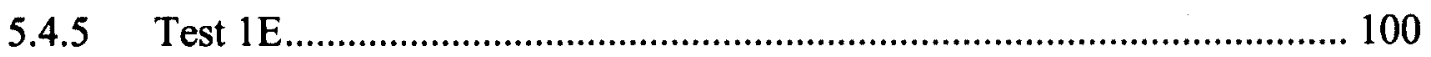

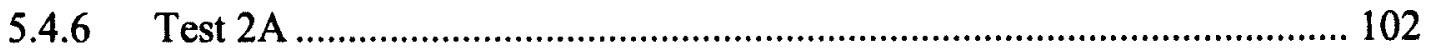

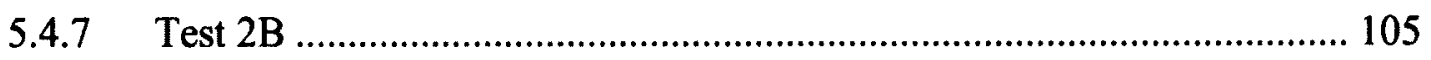

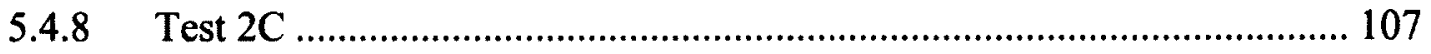

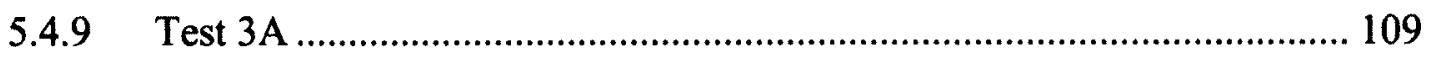

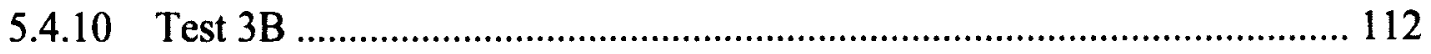

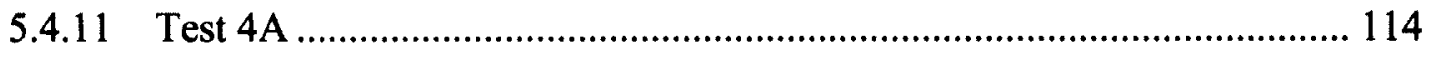

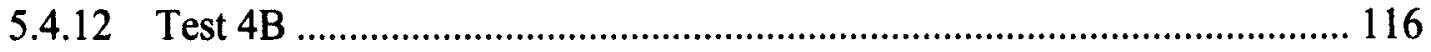

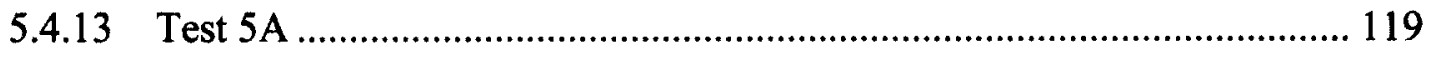


5.5 Condensation of vapour in the foam layer analyses ....................................... 121

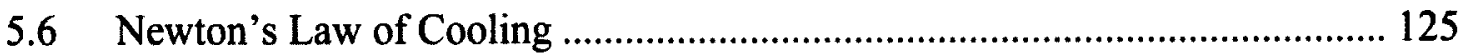

5.7 Convective Heat Transfer Coefficient for Surface Temperature above $100^{\circ} \mathrm{C} 127$

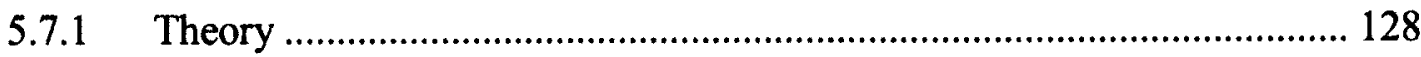

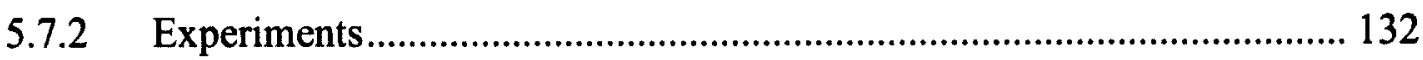

5.7.3 Verification of the validity of the convective heat transfer coefficient.... 137

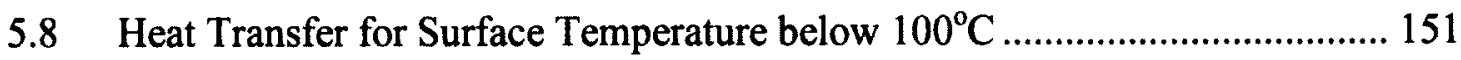

5.9 Use of steel to foam convective heat transfer coefficient................................. 156

6. EXPERIMENTAL - GAS PROPAGATION ….............................................. 161

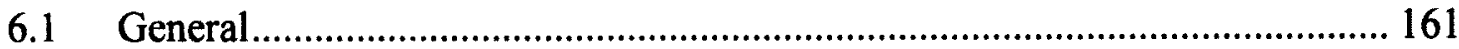

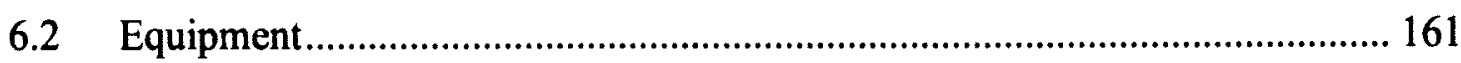

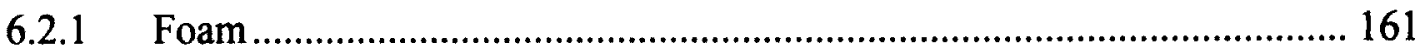

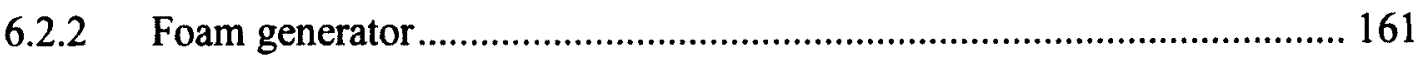

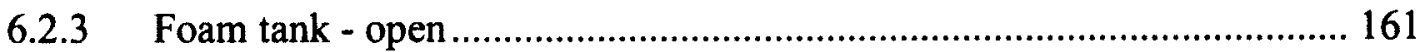

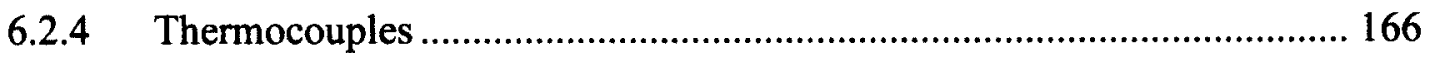

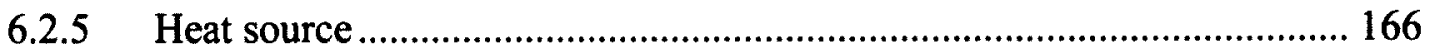

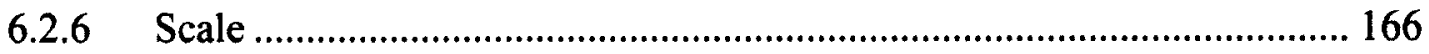

6.2.7 $\quad \mathrm{CO}_{2}$ detection .............................................................................. 166

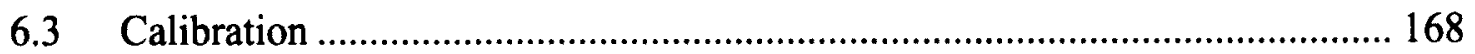

6.3.1 Foam water - foam concentrate calibration ............................................. 168

6.3.2 Expansion rate verification.................................................................... 168

6.4. Gas mitigation experiment - procedure ……............................................... 168 


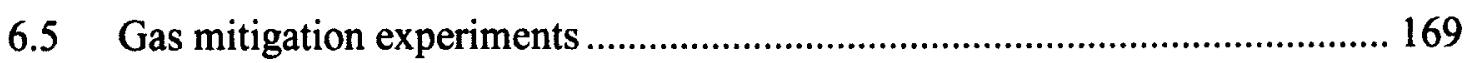

6.5.1 Gas mitigation experiment - reference test - G1 ..................................... 169

6.5.2 Gas mitigation experiments - Test G2, G3, G4 and G5 ........................ 170

6.5.3 Unheated foam experiments - Test G6 .............................................. 177

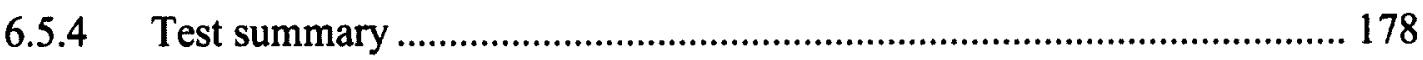

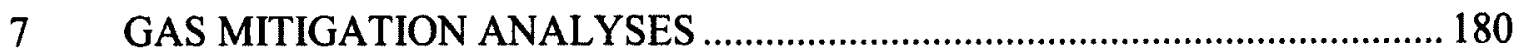

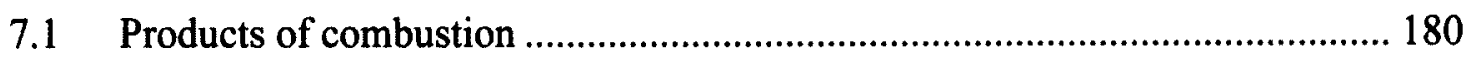

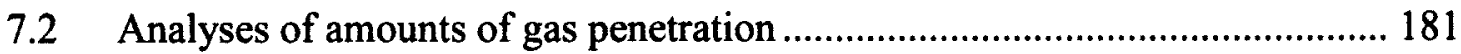

8. CONCLUSIONS AND RECOMMENDATIONS .............................................. 187

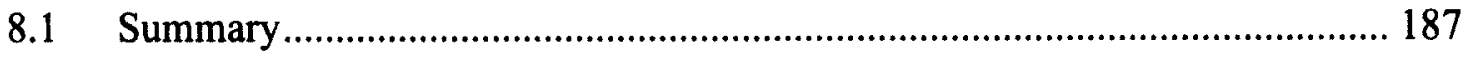

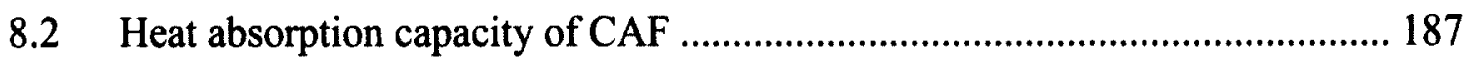

8.3 Foam's ability to mitigate gas propagation ....................................................... 189

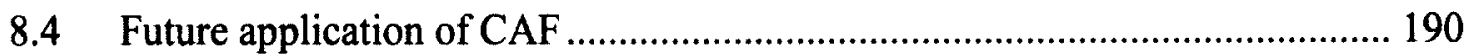

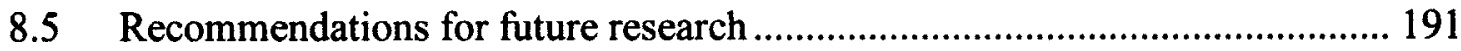

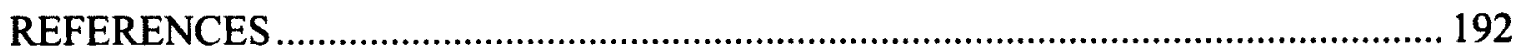

\section{LIST OF TABLES}

Table 3.4.2-1 Electrical conductivity of CAFS ………................................................. 34

Table 3.4.2-2 Test results - CAFS extinguishing capacity of Power Transformer Fires ................................................................................. 36

Table 3.4.2-3 Results of foam water sprinkler system vs CAFS.................................... 37

Table 4.2.2-1 Foam generator foam specifications ……….........................................5 50

Table 4.3.2-1 Foam expansion measurements .............................................................62

Table 5.5-1 Condensation of vapour experiments data ........................................... 123 
Table 5.7.2-1 Test 6-1 - Calculation of heat transfer foam coefficient ....................... 136

Table 5.7.3-1 Tests to determine the steel to foam convective heat transfer coefficient

Table 5.7.3-2 Test 6-2 - $100 \mathrm{cc}$ of foam over steel plate at $200^{\circ} \mathrm{C}$ expansion 1:25

Table 5.7.3-3 Test 6-3 - $60 \mathrm{cc}$ of foam over steel plate at $200^{\circ} \mathrm{C}$ expansion 1:25

Table 5.7.3-4 Test 6-4 - $60 \mathrm{cc}$ of foam over steel plate at $175^{\circ} \mathrm{C}$ expansion 1:8.7

Table 5.7.3-5 Test 6-5-60 cc of foam over steel plate at $150^{\circ} \mathrm{C}$ expansion $1: 8.7$

Table 6.5.4-1 Gas mitigation data 179

\section{LIST OF FIGURES}

Fig. 3.2.1-1 Floor grate nozzle used in CalmAir Hangar - Winnipeg.......................2 21

Fig. 3.2.1-2 High Expansion Foam Discharge Test - Air Tassili............................. 22

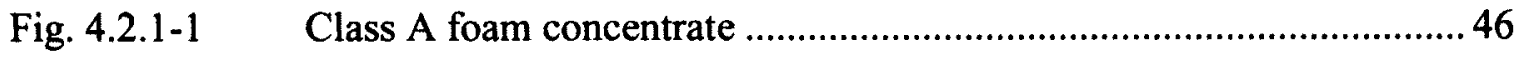

Fig. 4.2.1-2 Class B foam concentrate..............................................................4 47

Fig. 4.2.2-1 Foam generator ............................................................................ 48

Fig. 4.2.2-2 Foam generator and attached compressor ............................................... 48

Fig. 4.2.2-3 Foam generator detail......................................................................... 49

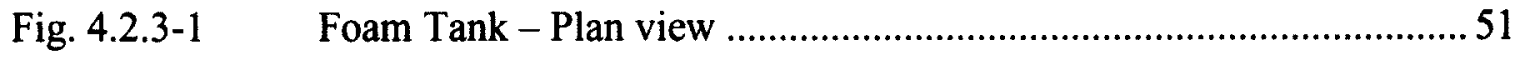

Fig. 4.2.3-2 Foam tank - Cross Section AA ……….............................................. 51

Fig. 4.2.3-3 The foam holding tank ...................................................................... 53

Fig. 4.2.3-4 Foam tank with $6.35 \mathrm{~mm}$ steel plate only at the bottom. ..................... 54

Fig. 4.2.3-5 Thermocouple attachment mechanism.................................................5 55 
Fig. 4.2.4-1 Thermocouples used inside the foam layer.......................................... 56

Fig. 4.2.4-2 Thermocouple multiplex reader ........................................................... 56

Fig. 4.2.5-1 Burner...........................................................................................

Fig. 4.3.2-1 Water foam solution preparation............................................................6 60

Fig. 4.3.2-2 Foam expansion measurement .............................................................61

Fig. 5.1-1 Heat flow in the system.....................................................................6

Fig. 5.2-1 Test 1 - Container heated to $200^{\circ} \mathrm{C}$ with no foam................................. 70

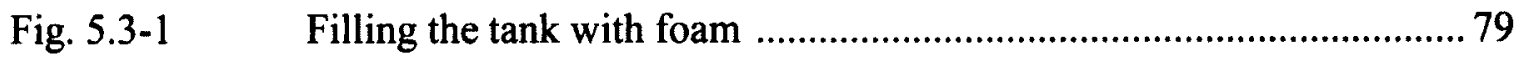

Fig. 5.3-2 Foam temperatures - vapour test …………........................................... 80

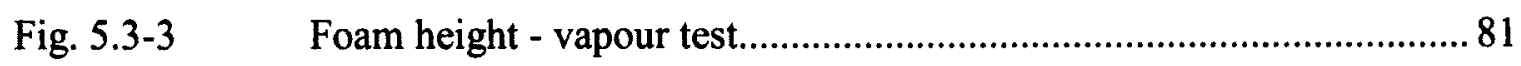

Fig. 5.4-1 Filling the tank with foam ………..................................................... 83

Fig. 5.4.1-1 Test $1 \mathrm{~A}-200 \mathrm{cc}$ of AFFF AR, 3\%, expansion ratio

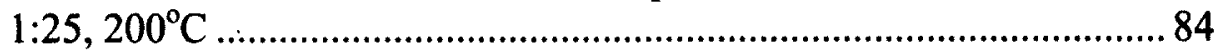

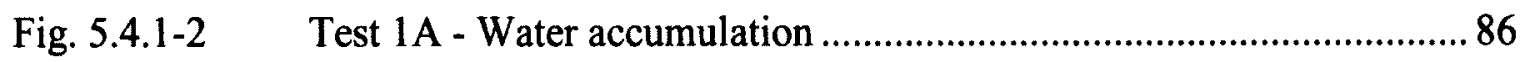

Fig. 5.4.1-3 Test 1A - Foam water drainage rate...................................................... 87

Fig. 5.4.2-1 Test 1B -400 cc of AFFF AR, 3\%, expansion ratio

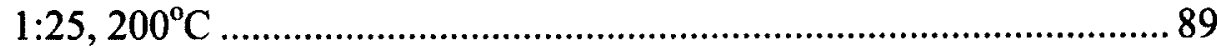

Fig. 5.4.2-2 Test 1B - Water accumulation ...........................................................90

Fig. 5.4.2-3 Test 1B - Foam water drainage rate ……………................................... 91

Fig. 5.4.3-1 Test $1 \mathrm{C}-600 \mathrm{cc}$ of AFFF AR, 3\%,expansion ratio 1:25, $200^{\circ} \mathrm{C}$

Fig. 5.4.3-2 Test 1C - Water accumulation ............................................................ 93

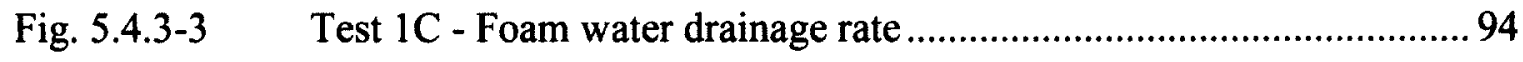

Fig. 5.4.4-1 Test 1D - 400 cc of AFFF AR, 2\%, expansion ratio

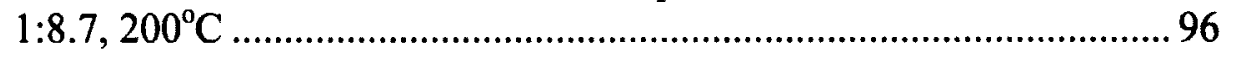

Fig. 5.4.4-2 Test 1D - Water accumulation ......................................................... 97 
Fig. 5.4.4-3 Test 1D - Foam water drainage rate.................................................. 98

Fig. 5.4.4-4 Test 1D - Temperatures below and above the floor ............................... 99

Fig. 5.4.5-1 Test 1E - $600 \mathrm{cc}$ of AFFF AR, 2\%, expansion ratio

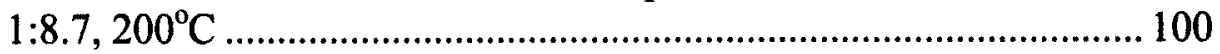

Fig. 5.4.5-2 Test 1E - Water accumulation........................................................... 101

Fig. 5.4.5-3 Test 1E - Foam water drainage rate ................................................... 102

Fig. 5.4.6-1 Test $2 \mathrm{~A}-200 \mathrm{cc}$ of AFFF AR, 3\%, expansion ratio $1: 25,175^{\circ} \mathrm{C}$

Fig. 5.4.6-2 Test IE - Foam water drainage …………........................................... 104

Fig. 5.4.7-1 Test 2B - 400 cc of AFFF AR, 3\%, expansion ratio 1:

$25,175^{\circ} \mathrm{C}$

Fig. 5.4.7-2 Test 2B - Foam water drainage rate ..................................................... 107

Fig. 5.4.8-1 Test $2 \mathrm{C}-600 \mathrm{cc}$ of AFFF AR, 3\%, expansion ratio

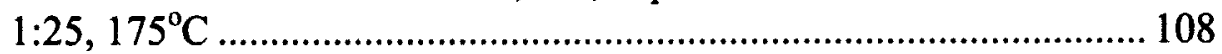

Fig. 5.4.8-2 Test 2C - Foam water drainage …………........................................... 109

Fig. 5.4.9-1 Test $3 \mathrm{~A}-200 \mathrm{cc}$ of AFFF AR, 3\%, expansion ratio $1: 25,150^{\circ} \mathrm{C}$

Fig. 5.4.9-2 Test 3A - Foam water drainage rate.................................................... 111

Fig. 5.4.10-1 Test 3B - 400 cc of AFFF AR, 3\%, expansion ratio $1: 25,150^{\circ} \mathrm{C}$

Fig. 5.4.10-2 Test 3B - Foam water drainage …………............................................ 113

Fig. 5.4.11-1 Test $4 \mathrm{~A}-200 \mathrm{cc}$ of AFFF AR, $3 \%$, expansion ratio $1: 25,125^{\circ} \mathrm{C}$

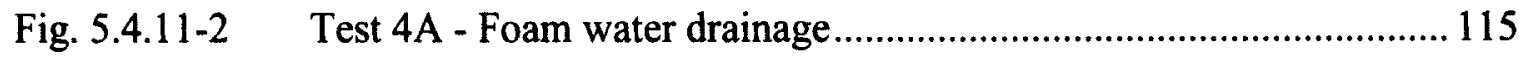

Fig. 5.4.12-1 Test $4 \mathrm{~B}-400 \mathrm{cc}$ of AFFF AR, 3\%, expansion ratio $1: 25,125^{\circ} \mathrm{C}$

Fig. 5.4.12-2 Test 4B - Foam water drainage ……………..................................... 118 
Fig. 5.4.13-1 Test 5A - $100 \mathrm{cc}$ of AFFF AR, 3\%, expansion ratio $1: 25,100^{\circ} \mathrm{C}$

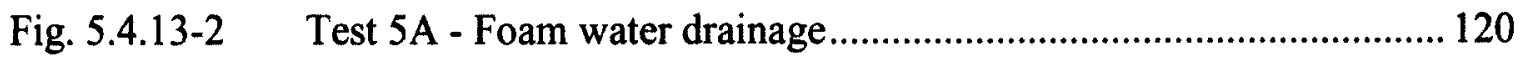

Fig. 5.7.2-1 Test 6-1 - $80 \mathrm{cc}$ of foam over steel plate at $200^{\circ} \mathrm{C}$, expansion ratio $1: 25$

Fig. 5.7.2-2 Test 6-1 - $80 \mathrm{cc}$ of foam over steel plate at $200^{\circ} \mathrm{C}$ detailed.

Fig. 5.7.3-1 Test 6-2 - $100 \mathrm{cc}$ of foam over steel plate at $200^{\circ} \mathrm{C}$ expansion ratio $1: 25$

Fig. 5.7.3-2 Test 6-3 - $60 \mathrm{cc}$ of foam over steel plate at $200^{\circ} \mathrm{C}$ expansion $1: 25$

Fig. 5.7.3-3 Test $6-4-60 \mathrm{cc}$ of foam over steel plate at $175^{\circ} \mathrm{C}$ expansion 1:8.7.

Fig. 5.7.3-4 Test 6-5 - $60 \mathrm{cc}$ of foam over steel plate at $150^{\circ} \mathrm{C}$ expansion 1:8.7

Fig. 5.8-1 Test 7-1 - heat transfer without foam ................................................. 152

Fig. 5.8-2 Temperature drop of top of steel plate from $100^{\circ} \mathrm{C}$ to $80^{\circ} \mathrm{C}$ for Tests $1,1 \mathrm{~A}, 1 \mathrm{~B}, 1 \mathrm{C}, 1 \mathrm{D}$ and $1 \mathrm{E}$.

Fig. 5.8-3 Temperature drop of top of steel plate from $100^{\circ} \mathrm{C}$ to $80^{\circ} \mathrm{C}$ for Tests $1,2 \mathrm{~A}, 2 \mathrm{~B}$ and $2 \mathrm{C}$

Fig. 5.8-4 Temperature drop of top of steel plate from $100^{\circ} \mathrm{C}$ to $80^{\circ} \mathrm{C}$ for Tests $1,3 \mathrm{~A}, 3 \mathrm{~B}, 4 \mathrm{~A}, 4 \mathrm{~B}$ and $5 \mathrm{~A}$.

Fig. 6.2.3-1 Foam tank - open floor - plan view ................................................ 162

Fig. 6.2.3-2 Foam tank - open floor - cross section AA ...................................... 163

Fig. 6.2.3-3 Foam tank - with open floor grate ................................................... 164

Fig. 6.2.3-4 Plywood hood for high temperature tests ........................................... 165

Fig. 6.2.3-5 Plywood hood with plexiglass windows.............................................. 165

Fig. 6.2.7-1 $\quad \mathrm{CO}_{2}$ probes with accessories ........................................................... 167

Fig. 6.5.1-1 The $\mathrm{CO}_{2}$ foam container setup ……................................................. 169 
Fig. 6.5.2-1 Gas mitigation experiment set up................................................ 171

Fig. 6.5.2-2 Test $\mathrm{G} 2-\mathrm{CO}_{2}$ concentration vs Time - Foam A expansion $1: 25$.................................................................... 172

Fig. 6.5.2-3 Test $\mathrm{G} 3$ - Temperature and $\mathrm{CO}_{2}$ concentration vs Time .................. 174

Fig. 6.5.2-4 Test $\mathrm{G} 4-\mathrm{CO}_{2}$ concentration vs Time ......................................... 175

Fig. 6.5.2-5 Test G5 - Temperature and $\mathrm{CO}_{2}$ concentration vs Time .................. 176

Fig. 6.5.3-1 Test G6 - Foam height vs Time............................................... 178

Fig. 7.2-1 Test G2 - Gas flow across the foam layer .................................. 185 


\section{NOMENCLATURE}

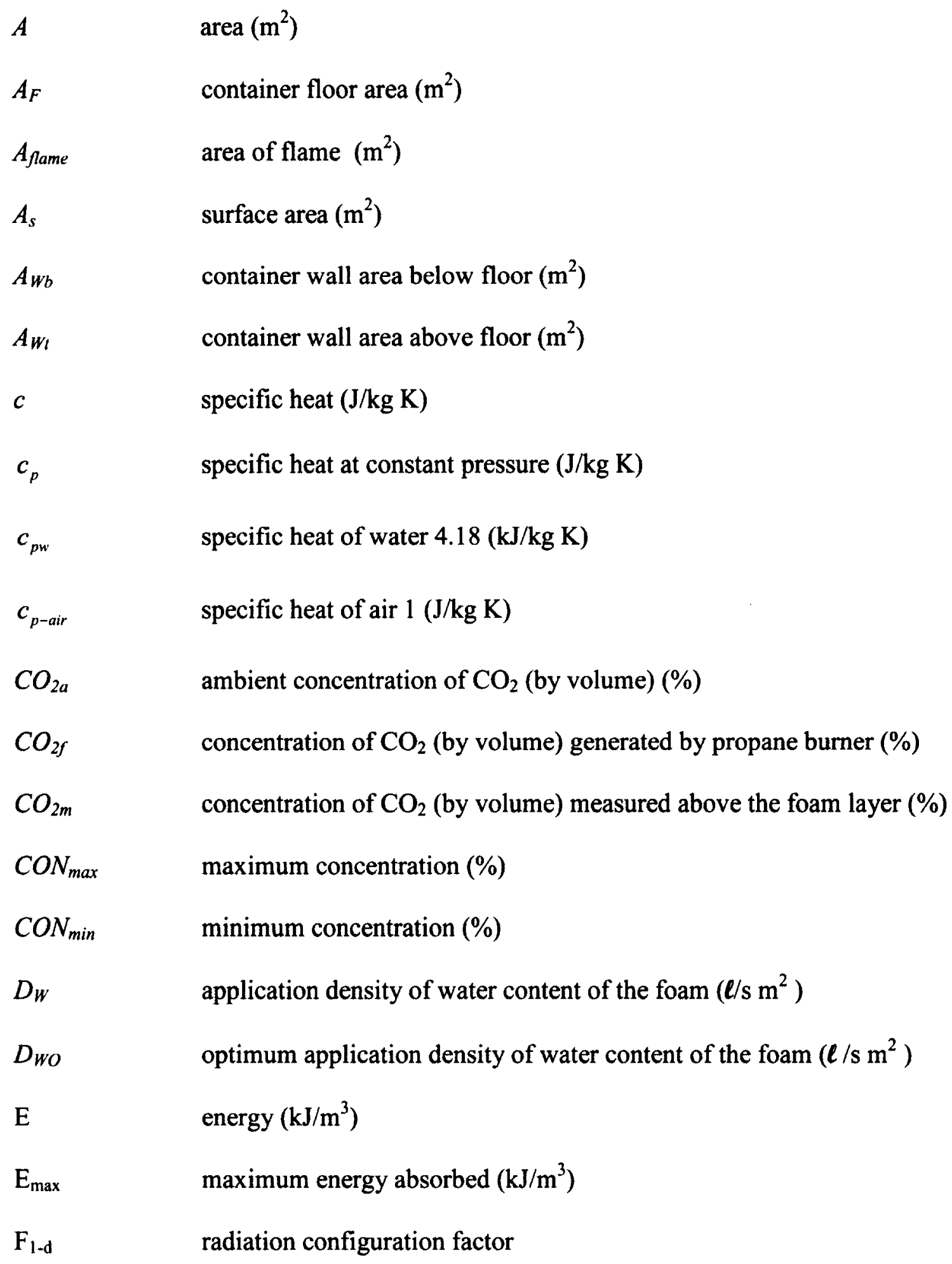




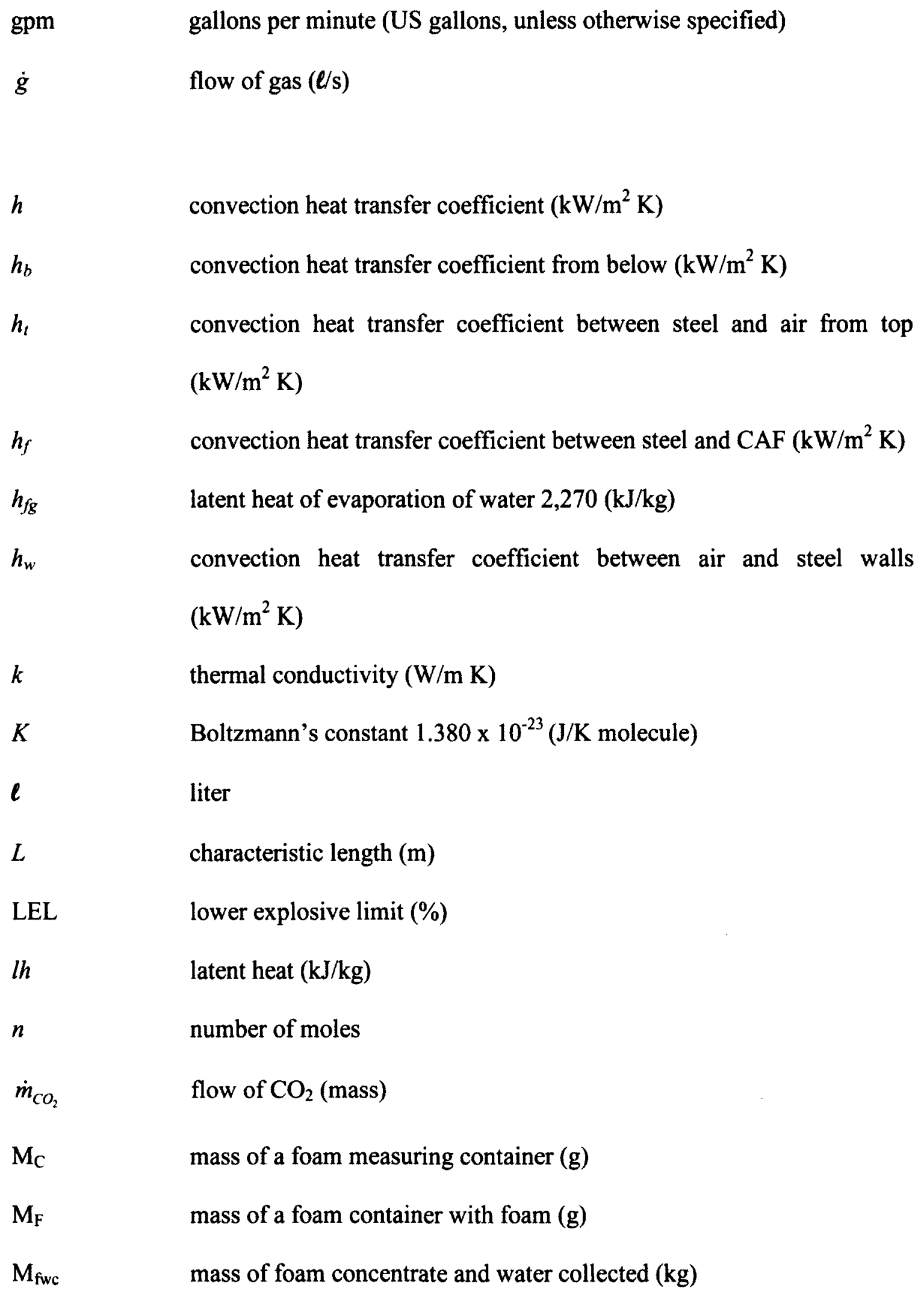




\begin{tabular}{|c|c|}
\hline $\mathrm{M}_{\text {fwi }}$ & initial mass of foam concentrate and water $(\mathrm{kg})$ \\
\hline $\mathrm{M}_{\mathrm{v}}$ & mass of evaporated water $(\mathrm{kg})$ \\
\hline $\mathrm{M}_{\mathrm{f} 1000}$ & mass of $1000 \mathrm{cc}$ of foam $(\mathrm{kg})$ \\
\hline $\mathrm{M}_{\mathrm{w}}$ & mass of liquid $(\mathrm{kg})$ \\
\hline$\dot{v}(t)$ & rate of gas flow as a function of time $(\ell / s)$ \\
\hline$P$ & pressure $(\mathrm{Pa})$ \\
\hline$q "$ & heat flux (sub script indicates direction) $\left(\mathrm{kJ} / \mathrm{sm}^{2}\right)$ \\
\hline$\dot{q}$ & rate of energy flow $(\mathrm{kJ} / \mathrm{s})$ \\
\hline$\dot{q}_{\mathrm{c}}$ & rate of energy flow into the container $(\mathrm{kJ} / \mathrm{s})$ \\
\hline$\dot{q}$ cond-foam & rate of energy flow due to conduction across foam $(\mathrm{kJ} / \mathrm{s})$ \\
\hline$\dot{q}_{\text {cond-steel }}$ & rate of energy flow due to conduction across steel $(\mathrm{kJ} / \mathrm{s})$ \\
\hline$\dot{q}_{\text {condensation }}$ & rate of energy flow from vapour due to condensation $(\mathrm{kJ} / \mathrm{s})$ \\
\hline$\dot{q}_{\text {conv-air }}$ & rate of energy flow due to convection from foam to air $(\mathrm{kJ} / \mathrm{s})$ \\
\hline$\dot{q}_{\text {conv-gas }}$ & rate of energy flow due to convection from gas to steel $(\mathrm{kJ} / \mathrm{s})$ \\
\hline$\dot{q}_{\text {rad-gas }}$ & rate of energy flow due to radiation from flame to steel $(\mathrm{kJ} / \mathrm{s})$ \\
\hline$\dot{q}_{\text {water }}$ & rate of energy flow accumulated and carried in the water $(\mathrm{kJ} / \mathrm{s})$ \\
\hline Q & energy $(\mathrm{kJ})$ \\
\hline$Q_{c}$ & energy accumulated in the container $(\mathrm{kJ})$ \\
\hline$Q_{v}$ & energy to convert liquid to vapour $(\mathrm{kJ})$ \\
\hline Qw & energy in draining water $(\mathrm{kJ})$ \\
\hline$R$ & universal gas constant, $8.314\left(\mathrm{JK}^{-1} \mathrm{~mol}^{-1}\right)$ \\
\hline$R_{c}$ & refractive index of foam concentrate \\
\hline
\end{tabular}




$\begin{array}{ll}R_{s} & \text { refractive index of foam solution } \\ R_{w} & \text { refractive index of water } \\ t & \text { time (in seconds unless otherwise specified) } \\ \mathrm{t}_{0} & \text { time at the insertion of the foam (unless otherwise specified) } \\ \mathrm{t}_{1} & \text { time at the end of evaporation of the foam (unless otherwise specified) } \\ T & \text { temperature }\left({ }^{\circ} \mathrm{C} \text { unless otherwise specified) }\right. \\ T_{0} & \text { temperature of the surface of the steel plate }\left({ }^{\circ} \mathrm{C}\right) \\ T_{A b} & \text { air temperature below the floor }\left({ }^{\circ} \mathrm{C}\right) \\ T_{A 10} & \text { air temperature } 10 \mathrm{~mm} \text { above the floor }\left({ }^{\circ} \mathrm{C}\right) \\ T_{A 20} & \text { air temperature } 20 \mathrm{~mm} \text { above the floor }\left({ }^{\circ} \mathrm{C}\right) \\ T_{A 30} & \text { air temperature } 30 \mathrm{~mm} \text { above the floor }\left({ }^{\circ} \mathrm{C}\right) \\ T_{A 40} & \text { air temperature } 40 \mathrm{~mm} \text { above the floor }\left({ }^{\circ} \mathrm{C}\right) \\ T_{a v} & \text { average temperature } \\ T_{F b} & \text { temperature bottom of the floor }\left({ }^{\circ} \mathrm{C}\right) \\ T_{F t} & \text { temperature of the wall top of the floor }(\mathrm{K}) \\ T_{F l a m e} & \text { temperature top of the floor }\left({ }^{\circ} \mathrm{C}\right) \\ T_{s} & \text { temperature top of the flame }\left({ }^{\circ} \mathrm{K}\right) \\ T_{s-o} & \text { temperature of the surface }\left({ }^{\circ} \mathrm{C}\right) \\ T_{W t} & \text { initial temperature of the surface of object }\left({ }^{\circ} \mathrm{C}\right) \\ T_{F b} & \text { templosive limit }\end{array}$




$\begin{array}{ll}V_{s} & \text { volume of steel }\left(\mathrm{m}^{3}\right) \\ V & \text { volume }\left(\mathrm{m}^{3}\right) \\ V_{f} & \text { volume of foam }\left(\mathrm{m}^{3}\right) \\ V_{v} & \text { volume of vapour }\left(\mathrm{m}^{3}\right) \\ V_{c o n} & \text { volume of foam measuring container }(\ell) \\ V_{c o n c} & \text { volume of foam concentrate (ml) } \\ V_{F W} & \text { volume of water and foam concentrate mix (ml or cc) } \\ V_{H 2 O} & \text { volume of water }(\ell) \\ W_{P} & \% \text { of water content }\end{array}$

\section{Greek letters}

$\alpha$

$\Delta$

$\Delta \mathrm{t}$

$\varepsilon$

$\varepsilon_{\text {fire }}$

$\varepsilon_{a-s}$

$\theta$

$\rho$

$\rho_{\text {air }}$

$\rho_{c a f-a i r}$

$\rho_{\text {caf }-w}$ thermal diffusivity $\left(\mathrm{m}^{2} / \mathrm{s}\right)$

difference (change of value)

time change ( 2 seconds)

emissivity

emissivity of flame

emissivity (combined for steel and air)

temperature difference $\left({ }^{\circ} \mathrm{K}\right)$

mass density $\left(\mathrm{kg} / \mathrm{m}^{2}\right)$

density of air $\left(\right.$ at $\left.20^{\circ} \mathrm{C}\right)-1.205\left(\mathrm{~kg} / \mathrm{m}^{3}\right)$

density of air content of CAF $\left(\mathrm{kg} / \mathrm{m}^{3}\right)$

density of water content of CAF $\left(\mathrm{kg} / \mathrm{m}^{3}\right)$ 


$\begin{array}{ll}\rho_{F W} & \text { foam-concentrate and water mix density }\left(\mathrm{kg} / \mathrm{m}^{3}\right) \\ \rho_{s} & \text { density of steel }-7854\left(\mathrm{~kg} / \mathrm{m}^{3}\right) \\ \rho_{v} & \text { density of vapour }\left(\text { at } 100^{\circ} \mathrm{C}\right)-0.625\left(\mathrm{~kg} / \mathrm{m}^{3}\right) \\ \rho_{w} & \text { density of water }-1,000\left(\mathrm{~kg} / \mathrm{m}^{3}\right) \\ \sigma & \text { Stefan-Boltzmann constant } 5.67 \times 10^{-8}\left(\mathrm{Wm}^{-2} \mathrm{~K}^{-4}\right)\end{array}$

\section{Subscripts}

$\max$

maximum

S

surface conditions

$\infty$

free stream conditions

\section{Fire Fighting Foams}

FP fluoroprotein foam

FFFP film-forming fluoroprotein foam

AR FFFP alcohol resistant film-forming fluoroprotein foam

AFFF aqueous film-forming foam

AR AFFF alcohol resistant aqueous film-forming foam

HX high expansion foam

CAF compressed-air foam

CAFS compressed-air foam system

TAR turbine action rotary nozzle

GDR gear drive rotary nozzle 


\section{INTRODUCTION}

\subsection{Background of foams}

\subsubsection{General}

Fire protection plays a critical role in life, building, property and environmental safety. Fire protection systems can be automatic (sprinkler systems), or manual (standpipe systems). The majority of fire fighting systems use water as the extinguishing agent.

When water is used as the sole extinguishing agent, a relatively small portion of the water is involved in extinguishing the fire. Some of the water is evaporated, some is sprayed over an area that is not involved in the fire and some of the water flows away from the target on fire.

When flammable liquids are involved in a fire, the efficiency of water to extinguish a fire is reduced even more. This is because most flammable liquids have a lower density than water, so they float above the water surface. To increase the efficiency of fighting fires involving flammable liquids, firefighting foams are used as stand-alone systems or as additives to water extinguishing systems.

The use of foams in firefighting reduces the time to extinguish the fire, reduces the water required to extinguish the fire, and therefore reduces the damage caused by the fire and by firefighting. 


\subsubsection{Fire classifications}

Fires are divided into different classes that are based on the types of combustibles involved. Fire protection and firefighting varies for each class. The National Fire Protection Association (NFPA) 10 - Standard for Portable Fire Extinguishers, art. 5.2, [1] defines the classes of fires as follows:

- "Class A Fires

Class A fires are fires that involve ordinary combustible materials, such as wood, cloth, paper, rubber, and many types of plastics."

- "Class B Fires.

Class B fires are fires that involve flammable liquids, combustible liquids, petroleum greases, tars, oils, oil-based paints, organic solvents, lacquers, alcohols, and flammable gases."

- “Class C Fires.

Class $\mathrm{C}$ fires are fires that involve energized electrical equipment."

- "Class D Fires.

Class D fires are fires that involve combustible metals, such as magnesium, titanium, zirconium, sodium, lithium, and potassium." 
- "Class K Fires.

Class $\mathrm{K}$ fires are fires that involve combustible cooking media (vegetable or animal oils and fats)."

\subsubsection{Foams - Types of expansion}

Fire extinguishing foams are divided into three general categories based on their expansion ratio (the volume of foam solution to the resultant foam volume). These are described as follows in NFPA 11 - Standard for Low-, Medium-, and High-Expansion Foam, art. 3.3 [2]:

- Low-expansion - expansion ratio of 1:1 to 1:20.

Low-expansion foams are generally used on flammable liquid fires where the foam provides a thin film over the combustibles. This foam has a good spreading capacity.

- Medium-expansion - expansion ratio of 1:20 to 1:200.

Some literature states that medium-expansion foam provides a good barrier against the spread of hot gases and other products of combustion. Very limited test results have been found and these tests measured the concentration of explosive vapours when the foam was sprayed over a flammable liquid spill and the surface was at ambient temperature [3]. Most medium-expansion foam systems are manually operated.

- High-expansion - expansion ratio of 1:200 to 1:1000.

High-expansion foam provides good extinguishing capacity for three dimensional fires. A three dimensional fire is understood as a fire that, as in 
conventional fires, propagates upward and also has notable downward propagation due to dripping of burning materials or spillage of flammable liquids.

\subsubsection{Foams - Concentrates}

Foam is generated by combining a foam concentrate with water, and then the mixture is expanded with air as it is discharged. A typical example is an air aspirating sprinkler head. The type of concentrate refers to the percentage of foam concentrate required in the mix (foam solution). For example, a $1 \%$ concentrate is normally combined with 99 parts of water. Similarly, a 3\% concentrate normally is combined with 97 parts of water. As the $1 \%$ concentrate is 3 times more concentrated than $3 \%$ concentrate, in general the final foam solution will be same. [2]

NFPA 11 - Standard for Low-, Medium, and High-Expansion Foam [2] defines:

- Foam concentrate - a concentrated liquid foaming agent as received from manufacturer

- Foam solution - a homogeneous mixture of water and foam concentrate in correct proportions.

Typically, the researched literature refers to the solution that drains from the aerated foam as drained water. 


\subsubsection{Foams - Types [4]}

Foams are divided into two main groups: protein-based foams and synthetic-based foams.

- Protein-based foams

○ Protein

Protein foams consist of hydrolysed natural protein with added salts. Protein foams are environmentally-friendly and are used mostly in marine environments and for firefighting training purposes. Protein foams are effective in extinguishing fires involving hydrocarbon fuels. Protein foams are available in $3 \%$ or $6 \%$ concentrate.

○ Fluoroprotein - FP

Fluoroprotein foams use telomer-based fluorocarbon surfactants. These foams are effective in extinguishing hydrocarbon-based combustibles. Fluoroprotein foams are available in a $3 \%$ or $6 \%$ concentrate.

- Film-Forming Fluoroprotein - FFFP

FFFP is a blend of hydrolysed natural proteins with telomer based fluorocarbon surfactants. This foam is mostly used in aviation applications and is available in a $3 \%$ or $6 \%$ concentrate.

- Alcohol Resistant Film-Forming Fluoroprotein - AR FFFP

AR FFFP is a multi-purpose natural protein based foam for use on both hydrocarbon fuels and polar solvent fires. Two grades are provided, 1) a $3 \times 3$ type for use at $3 \%$ on hydrocarbon and $3 \%$ on polar solvent 
fuels, and 2) a $3 \times 6$ grade that is effective at $3 \%$ concentration on hydrocarbon fuels but requires $6 \%$ concentration for polar solvent chemicals.

- Synthetic foams

- Class A foam

A Class A synthetic foam lowers the surface tension of water which helps in wetting the surface of combustibles. Class A foam was developed for extinguishing Class A type fires. It can also be used in compressed-air foam systems.

$\circ$ Aqueous Film-Forming Foam - AFFF

AFFF contains fluorinated surfactants that cause low surface tension (15 to $17 \mathrm{dynes} / \mathrm{cm}$ ) as well as a positive spreading coefficient that enables film formation on top of lighter fuels. AFFF is a synthetic detergent that uses a blend of fluorocarbon and hydrocarbon surfactants. The foam has a high fluidity that facilitates film formation. It is effective in extinguishing most hydrocarbon fuels. The typical use is in refineries, oil and gas rigs, airports and marine applications. AFFF is available in $1 \%, 3 \%$ and $6 \%$ concentrate.

- Alcohol Resistant Aqueous Film-Forming Foam - AR AFFF

AR AFFF is a synthetic detergent-based aqueous film-forming foam with a water soluble polymer that is used on a wide range of hydrocarbon and polar solvent fires. 
$\circ$ High-expansion - HX

High-expansion foams are a mixture of synthetic foaming agents that perform well when used at medium- or high-expansion. HX can be used at expansion ratios ranging from 1:10 to $1: 1,000$.

- Class A versus Class B foams

In many cases, foam type classification refers only to the foam types as Class A or Class B. Class A foam is as described above, while Class B foam usually refers to any of FFFP, AFFF, AR FFFP or AR AFFF foams. Class A foam is generally used on Class A fires and Class B foams are usually used on Class B fires.

- Standard foams versus military specification foams [5]

Firefighting foams are available in two grades: standard grade and military grade. The military grade foam has stricter quality control and tolerance levels.

\subsubsection{Foams - Environmental concerns}

Most firefighting foams are biodegradable and pose a minimal threat to the environment. The exception is one of the two fabricated versions of aqueous film forming foam; note that AFFF can be produced by electrochemical fluorination or by telomerization. 
The fluorochemical raw material produced by electrochemical fluorination is perfluorooctane sulfonyl fluoride (POSF). The degradation of POSF-derived fluorochemicals as well as the hydrolysis or neutralization of POSF results in the formation of perfluorooctyl sulfonate (PFOS). The negative impact on the environment of PFOS is currently a major focus of the U.S. Environmental Protection Agency (EPA) regulatory activities $[6]$.

Telomer-based AFFF does not contain PFOS or any other compound currently considered by regulatory agencies as a possible environmental threat. There is no known biological pathway by which telomer-based AFFF can be oxidized or metabolized into PFOS. Telomer-based AFFF agents contain 30-60\% less fluorine than AFFF based on POSF-derived fluorosurfactants.

\subsection{Background for compressed-air foam systems - CAFS [7]}

The use of foams in firefighting dates back to 1877. The first CAFS experiments started in 1930 and the United States Navy began to use CAFS in 1940 as fixed systems. In 1994, a firefighting vehicle equipped with a CAFS was demonstrated by manufacturers of CAFS with a mobile unit [8] in order to promote the use of this system.

A CAFS delivers foam in consistencies that depend on the foam concentrate and expansion ratio used. The consistency of foams is known as dry or wet and is generally classified from 1 to 5 with 1 being the driest and 5 being the wettest. 
Dry foams have longer drain times and the bubbles break down faster in the presence of heat. In general, a CAFS can use Class A, AFFF, AR FFF, FFFP or AR FFFP concentrates. Typically the bubbles generated by the CAFS are less than $50 \mu \mathrm{m}$ in diameter and differ in size by less than one order of magnitude.

The review of the existing literature as is described in Chapter 3 of this thesis indicates that research, to this date, on compressed-air foam systems has principally focused on its extinguishing capability.

\subsection{Applicable scenario for the use of CAFS - heat control}

The ability of CAFS to extinguish fires involving flammable and combustible liquids has been demonstrated by a number of experiments that are described in Chapter 3 of this thesis $[9,10,11,12$ and 13$]$.

The standard for protection of flammable liquids is provided in NFPA 30 - Flammable and Combustible Liquid Code, art. 16.5 [14]. Typical storage of flammable or combustible liquids is in double row racks with or without solid shelves as described in NFPA 13 - Standard for the Installation of Sprinkler Systems, art 3.9 [15]. In general, fire protection consists of ceiling sprinkler protection as well as in-rack sprinkler protection as described in NFPA 30, art. 16.5.1.2 [14]. The industry tendency is to use plastic containers for storing flammable and combustible liquids. A number of fire tests 
conducted at the Factory Mutual Test Centre resulted in the development of a protection scheme using closely-spaced sprinklers and solid barriers. The results were published in FM Global fire protection data sheets, art. D2.2 [16]. The fire protection scheme is designed to use a combination of solid barriers and a very high sprinkler density to prevent the heat, generated by burning flammable liquids, from affecting the flammable liquids and the containers stored in the tiers above the fire. This protection ensures the control of the fire within one storage level. This protection scheme is now part of NFPA 30, art. 16.6.1 [14] and is limited to containers having a volume of less than $24.6 \ell$ (6.5 gal (US)). The protection of plastic containers with a volume over $24.6 \ell$ stored in racks is not a part of any recognized standard. If CAFs can be shown to effectively control the heat so that the plastic containers will not rupture due to the fire, a new method of protection for flammable liquids in plastic totes in racks can be developed.

The National Fire Code of Canada requires that flammable and combustible liquids as well as water used in fire protection be prevented from contaminating the environment and be prevented from entering a sewage system [17]. Hence, the typical required on site water and flammable combustibles retention capacity is $700,000 \ell$ to $1,000,000 \ell$. This is based on water demands for firefighting in NFPA 30 , art. 16.7 [14].

The research in this thesis investigates the ability to reduce the surface temperature of objects near the fire immediately after the fire is extinguished by the foam. 
Based on calculations using required flows and duration as specified in NFPA 11, art. 7.16 [2], the required containment volume when compared with conventional firefighting methods that use only water or foam-water (low-expansion foam normally generated by a sprinkler system) would be greatly reduced. When water or foam-water is used, the required containment volume is approximately $140,000 \ell$ while when CAFS is used, the required containment volume is reduced to approximately $1,000 \ell$.

Recognized standards are available for the protection of flammable liquids using waterfoam systems but they do not include CAFS. If a CAFS is to be used as a replacement for approved fire protection systems, an alternative solution (a code equivalency) acceptable to the authorities having jurisdiction would have to be used. The data and analyses from this thesis could be used to prepare the necessary alternative solution.

\subsection{Applicable scenarios for the use of CAFS - gas control}

A second focus of this study considers two scenarios: 1) the products of combustion affect the operation of electronic equipment [18], and 2) the products of combustion are transported within the room by the air flows due to the fire and potentially by the ventilation system [19]. The CAFS experiments were designed to determine the efficiency of the foam layer to limit the propagation of the products of combustion and thereby prevent the occurrence of these two scenarios. 
In case of a spill of flammable liquids, flammable liquids will evaporate and if an airflammable liquid gas mixture concentration is between the lower explosive limit (LEL) and the upper explosive limit (UEL), an ignition source may cause an explosion [20]. A layer of CAF on top of the spilled flammable liquids may prevent the flammable liquid vapours from reaching concentrations above the LEL. 


\section{OBJECTIVES AND SCOPE}

\section{$2.1 \quad$ Objectives}

The objectives of the research described in this thesis are to:

- determine the heat absorption capacity of compressed-air foam, and

- determine the foam's ability to mitigate gas propagation.

More specifically, the purpose of this study is to develop methods that can be used to evaluate the energy absorption ability of CAF as well as the gas transfer through the foam layer and ultimately to help predict the effectiveness of a foam layer to reduce the heat and smoke effects on the surrounding environment. The findings in this study can assist in developing improvements to CAFS applications.

\section{$2.2 \quad$ Justification of the obiectives}

Information obtained from this study can be used in modeling fire scenarios to determine the effects of fire on the environment, equipment and personnel. Fire modeling is being used more frequently as building codes and fire codes now provide an option to design safety features to address the objectives listed below.

In Canada, the National Building Code (NBC) of Canada provides requirements for fire protection. A design done using the objective-based provisions of the NBC of Canada (2010) [21] is referred to as an alternative solution. The objectives that would be applicable are: 
- "To minimize the risk of accidental ignition."

- "To limit the severity and effects of fire or explosions."

- "To retard the effects of fire on areas beyond its point of origin."

- "To limit the spread of hazardous substances beyond their point of release."

- "To minimize the risk of injury to persons as a result of contact with hot surfaces or substances."

In some cases, the NBC references National Fire Protection Association (NFPA) codes. The NBC does not have very detailed objectives for automatic suppression systems but the NFPA codes do provide detailed objectives. The following is a typical objective for a fire protection system required for telecommunication equipment taken from the NFPA 76 code [19]

- "Where telecommunications equipment is exposed to a worst credible fire scenario, the facility design shall limit temperatures in a manner that protects against unacceptable network failure."

- "Where telecommunications equipment is exposed to a worst credible fire scenario, the facility design shall limit the effects of products of pyrolysis or combustion in a manner that protects against unacceptable network failure."

The objectives of this thesis are to provide the tools for assessing whether heat and products of combustion will affect the surrounding area of the fire when a CAFS has been used to extinguish a fire. 
For example:

- If the CAFS is used in the protection of telecommunication systems, the maximum temperature and smoke concentration affecting the telecommunication equipment can be predicted using the information developed in this thesis and it can be determined whether the equipment can operate without unacceptable network failure.

- If the CAFS is used in protecting rack storage of flammable liquids, the developed information can be used to predict the cooling effects of the foam on the flammable liquid storage containers.

The information from this study can be used for the development of future codes for fire protection, such as the development of fire protection for the storage of flammable liquids in plastic containers in racks.

\subsection{Contribution}

The use of plastic containers to store flammable liquids is becoming more prevalent in industry. Standards for fire protection of flammable liquids in plastic containers limit the size of the containers and the storage configuration. Temperature control is essential to keep the containers from bursting, and to control and extinguish a fire. This study provides data that could be used to predict the ability of the CAFS to control heat and 
that could be used to develop new fire protection standards for the storage of flammable liquids.

Recognized standards are available for the protection of flammable liquids using water foam systems (sprinklers with AFFF, sprinklers and high expansion foam, etc.) but they do not include CAFS [2]. If a CAFS is to be used as the only fire protection system, an alternative solution (a code equivalency) would have to be prepared and the alternative solution would have to be accepted by the authorities having jurisdiction [22]. The data and analyses from this report may be used to prepare the required alternative solution.

Presently, the majority of fire-protection extinguishing systems used in areas that are sensitive to heat and smoke damage are based on gas extinguishing systems. Once the fire is detected, the gas is released in order to extinguish the fire. The efficiency of the gas system depends on the ability to maintain the required gas concentration in the room. In general, the gas system does not prevent the heat nor the products of combustion released from the fire from causing damage to equipment. Most of the gases used in these extinguishing systems are halogenated compounds that are considered dangerous to the environment due to their ozone-depleting characteristics. The potential of ozone depletion and global warming by gases used in firefighting was described in a report prepared by Andrew Kim [23]. In addition, when these gases are exposed to high temperatures, the gas can decompose and cause oxidation of metal surfaces [24]. 
Some materials release highly toxic gases when they are involved in a fire [25]. If the CAFS can efficiently control gas propagation, a higher level of life safety will be provided.

Environmental contamination is also a major concern and contaminated water must be prevented from entering the environment [17]. By reducing the amount of water used in firefighting, decontamination costs can be reduced. CAF is able to extinguish fires in a relatively short period of time and with notably less water compared with conventional extinguishing systems, thus reducing the generation of all contaminants.

The increase of knowledge about the heat transfer across the CAF and the mitigation of gas transfer when the foam layer is exposed to fire from below will contribute to the development of a CAFS to protect sensitive equipment and the surrounding environment.

This study provides data that can be used in determining the use of CAFS to protect exposed equipment that is sensitive to heat and to the products of combustion, and to assist in the development of new methods of protection using CAFS that could also provide a more efficient use of the foam by reducing the required foam quantity. NFPA 412 states that foam performance is judged based on two criteria: (1) ability for quick knockdown of flames and (2) ability to keep the fuel area secure against re-ignition [26]. These systems could have important benefits for firefighting, life safety and fire control 
including reducing water demands, decreasing costs, limiting damages and mitigating the adverse effect on the environment. 
3. LITERATURE REVIEW

\subsection{Effects of heat and smoke on electronics}

A study of the effects of heat and smoke on telecommunication equipment was conducted by Carlo Mastroberardino and Paul Lhotsky [18] for a telecommunication equipment facility. The study demonstrated that the smoke and decomposition of halogen-based gas from Halon extinguishing systems react with the contact surfaces of the electronic component causing major damage. The study also showed that the use of gas extinguishing systems does not provide cost-effective fire protection. The objectivebased codes recommend smoke control using specially designed ventilation systems. This study validated the need for protection from heat and smoke for telecommunication and computer equipment. It also demonstrated that fine mist can provide efficient cooling of hot surfaces.

The report does not cover the critical levels of smoke or heat as that depends on the individual equipment.

\subsection{Typical use of fire extinguishing foams}

The use of fire protection foams has been proven to be very effective in extinguishing fires, particularly fires involving hydrocarbon fuels. (See section 3.3.2 for details.) To provide effective fire suppression, fires involving water-miscible and polar flammable liquids require the use of foam that is alcohol-resistant. The majority of foam-based fire 
protection systems are used in the aircraft industry and for the protection of flammable liquids.

\subsubsection{Foams in aircraft industry}

The following types of systems are generally used for the protection of aircraft hangars:

- Foam water sprinkler deluge systems that use AFFF foam, generally 3\% concentrate. (This design is slowly being phased out as the wet sprinkler system is now part of the codes.) [27]. The wet sprinkler system uses closed sprinkler heads and only the sprinklers above the fire are expected to open thus generally reducing the water demand and the water damage.

- Closed-head sprinkler system at roof level and monitor nozzles using AFFF to cover the entire hangar floor within 3 minutes. This design was first used in Canada in 2003 at an Air Transat Hangar in Dorval, Quebec. The system was designed by Civelec Consultants (P. Lhotsky and C. Mastroberardino) [28].

- Closed-head sprinkler system at roof level and floor grate nozzles (a special grate nozzle developed by Viking Corporation [29]) using AFFF that covers the entire hangar within 3 minutes. The photograph in Fig, 3.1-1 was taken at the CalmAir Hangar in Winnipeg in 2005. The system installed at this hangar was designed by Civelec Consultants Inc. (P. Lhotsky and C. Mastroberardino) [30]. 


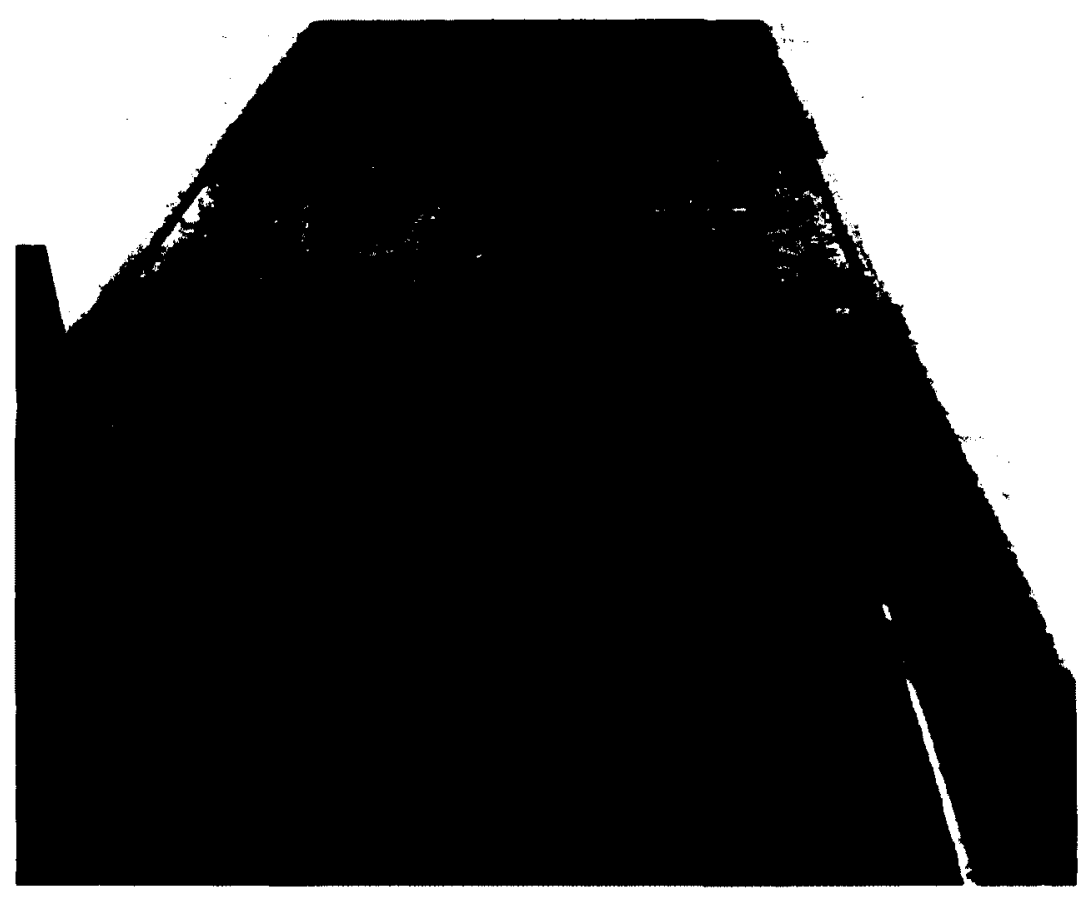

Fig. 3.2.1-1 Floor grate nozzle used in CalmAir Hangar - Winnipeg

- Closed head sprinkler system and high expansion foam system using HX foam. A discharge test at the Air Tassili hangar designed by Civelec Consultants Inc., Paul Lhotsky and Carlo Mastroberardino [31] is described in the discharge test report and a picture of the test is shown in Fig. 3.2.1-2. 


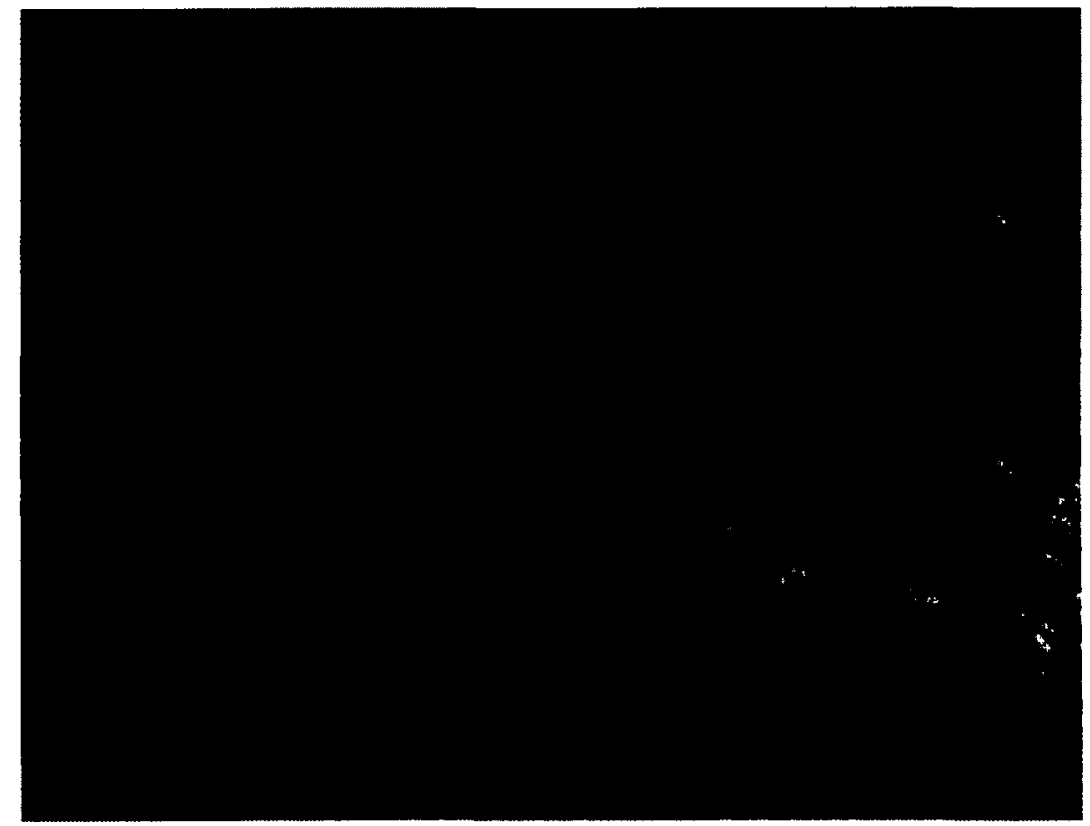

Fig. 3.1-2 High Expansion Foam Discharge Test - Air Tassili

\subsubsection{Foams for the protection of flammable liquids}

NFPA 30 - Flammable and Combustible Liquid Code, art. 16.8 [14] is the standard for protection of flammable liquids used in North America and is often referenced in codes and national standards throughout the world. NFPA 30 requires foam protection for warehouses storing flammable liquids in containers over 7.571 (2 US gal) if the facility is not equipped with a special drainage system.

Generally, these systems use standard sprinkler systems that also distribute foam for the initial extinguishing phase (typically 15 minutes) [14]. Foams used in such applications are typically AFFF or AR AFFF depending on the combustibles. The use of foam does not modify the applied density of water required to control the fire, but reduces the area 
of operation. That is, the number of sprinkler heads required to control the fire is reduced [14].

Foam systems can reduce the fire intensity and fire effects, and have been used as part of alternative solutions (code equivalencies) to provide the required level of fire safety. For example, a foam system was used to reduce the fire hazard as part of an alternative solution for the protection of an oil-based paint and thinners storage warehouse in Delta, British Columbia [32].

\subsection{Codes for use of foams}

\subsubsection{NFPA 11}

NFPA 11 - Standard for Low-, Medium- and High-Expansion Foam, art. 7.15 [2] is a standard for the design and use of low-, medium-, and high-expansion foams. NFPA 11 provides information about the required discharge density for CAFS as well the duration of application. Below is an excerpt from NFPA 11:

\section{- "Discharge density.}

The design discharge density shall be in accordance with the applicable occupancy standards and in accordance with the manufacturer's listing but in no case less than $1.631 / \mathrm{min} / \mathrm{m}^{2}\left(0.04 \mathrm{gpm} / \mathrm{ft}^{2}\right)$ for hydrocarbon fuel applications and $2.3 \mathrm{l} / \mathrm{min} / \mathrm{m}^{2}\left(0.06 \mathrm{gpm} / \mathrm{ft}^{2}\right)$ for alcohol and ketone applications. Where fixed spray-type systems are used to protect three-dimensional equipment, the 
minimum density shall be applied over the projected area of a rectangular prism envelope for the equipment and its appurtenances."

- “Discharge duration.

The system shall be designed to discharge compressed-air foam for a minimum period of 10 minutes over the entire area for deluge-type systems and a minimum of 5 minutes for fixed spray-type systems and shall be in accordance with the manufacturer's listing."

\subsubsection{NFPA 412}

NFPA 412 - Standard for Evacuating Aircraft Rescue and Fire-Fighting Foam Equipment, [26] is the NFPA standard for foam equipment.

The most common use of firefighting foams is in aircraft protection and NFPA 412 contains most of the industry standards as they apply to firefighting foams. Some of the applicable NFPA 412 definitions are listed below:

- “Foam drainage time (quarter life)

The time in minutes that it takes for 25 percent of the total liquid contained in the foam sample to drain from the foam".

- "Foam solution

The solution that results when the foam concentrate and water are mixed in designated proportions prior to aerating to form foam". 
- "Foam expansion

The ratio between the volume of the foam produced and the volume of solution used in its production".

- "Foam stability

The degree to which a foam resists spontaneous collapse or degradation caused by external influences such as heat or chemical action."

NFPA 412 does not provide any information how to rate or measure the foam stability. NFPA 412 also provides information for the determination of the concentration of the foam solution and the foam expansion ratio, as described below.

\section{- Foam solution concentration determination}

NFPA 412 requires that foam concentration be tested and provides two methods.

- The first method uses a refractometer or conductivity meter. Samples of foam solution are tested and compared to test curves of known concentrations.

- The second method uses a refractometer only. The refractive index of the water is taken $\left(R_{W}\right)$, the foam concentrate refractive index is taken $\left(R_{C}\right)$, and the foam solution refractive index $\left(R_{S}\right)$ is taken. The foam concentration can then be calculated using the following formula:

$\%$ foam solution concentration $=\frac{R_{S}-R_{W}}{R_{C}-R_{W}} 100$ 


\section{- Expansion determination}

To determine the expansion ratio, the foam is collected in a $1000 \mathrm{cc}$ graduated container that is cut-off at the $1000 \mathrm{cc}$ level. The mass of the container $M_{C}$ is measured to the nearest gram. The container is filled with foam and the excess foam is removed by sliding a straight edge over the top of the container. The full container mass $M_{F}$ is measured. The mass of $1000 \mathrm{cc}$ of foam is calculated using the following equation:

$M_{f 1000}=\left(M_{F}-M_{C}\right)$

The expansion ratio is expressed as 1:(1000/Mf1000) This works when $M_{F}$ and $M_{C}$ are measured in grams and should be multiplied by $\rho$ (density) of the solution in $(\mathrm{g} / \mathrm{cc})$. Assuming that the density is close to $1 \mathrm{~g} / \mathrm{cc}$, not multiplying by the density will not change the result.

The use of the test procedures described above is essential to ensure that the foam solution has the right proportion of the concentrate as most of the foam concentrate and mixing is done by the use of proportioners or dosing pumps.

\subsection{Compressed-air foam svstems (CAFS)}

CAFS are mostly manual systems. An advantage of this system is the ability to project the CAF over a long distance. The stability of the foam has led to the development of CAFS for use in forest firefighting. [7] 
The National Research Council of Canada (NRC) is active in research involving CAFSs and has developed two new distribution nozzles: Turbine Action Rotary (TAR) and Gear Drive Rotary (GDR). Both were patented to be used with fixed pipe systems [33].

In cooperation with the NRC, Fire Flex Systems has developed a complete preengineered CAFS. Fire Flex Systems has installed CAFSs protecting entire buildings that replaced sprinkler protection. The use of CAFS in the protection of entire buildings is relatively expensive but can be advantageous in areas with poor water supplies. Fire Flex Systems has also developed a proprietary method for friction-loss calculations of the CAF flows through fixed piping [34].

\subsubsection{Foam characteristics}

A number of researchers have experimented with foam to predict foam behaviour. The following list is a summary of research on determining characteristics of CAFSs.

- B.S. Gardiner, B.Z. Dlugogorski and G.J. Jameson.

In order to deliver foam from the generator to the fire, the foam has to travel through piping. A number of studies have been made to determine friction loss. An equation for predicting the pressure loss flowing in straight pipes was developed and is described by B.S. Gardiner, B.Z. Dlugogorski and G.J. Jameson. [35] 
The foam flow through the pipe is dependent on wall slip. Two methods for predicting wall slip have been developed. One is by Oldroyed-Jastrzebski [9] and the other by Mooney [10]. B.S. Gardiner, B.Z. Dlugogorski and G.J. Jameson [11] suggest that the method described by Oldroyed-Jastrzebski is more appropriate than the Mooney method.

A study of three-dimensional wet foams was also performed by B.S. Gardiner, B.Z. Dlugogorski and G.J. Jameson [36]. This study helped predict bubble packing and foam decomposition. The foam configuration and volume depends on the efficiency of the bubble packing. The efficiency is reduced when insufficient time is available for packing of the bubbles.

\section{- B.S. Gardiner, B.Z. Dlugogorski , G.J. Jameson and R.P. Chhabra}

A study was made to determine the yield stress of aqueous foams. It was found that the foam actually has a measurable stress (yield stress) when the bubbles separate. This structural force is due to the internal structure of the foam that consists of bubbles form by thin films. The knowledge of yield stress can be used to determine the foam distribution over the fire and the flow behaviour outside the piping. B.S. Gardiner, B.Z. Dlugogorski, G.J. Jameson and R.P. Chhabra [12] have concluded that there exists a true yield stress in aqueous foams at the dry foam limit. 


\section{- S.A. Magrabi, B.Z. Dlugogorski and G.J Jameson}

A study of bubble size distribution of CAFs was conducted to predict the foam bubble behaviour with respect to time. S.A. Magrabi, B.Z. Dlugogorski and G.J Jameson [37] concluded in this study that wet foams have a fast initial drainage and deterioration of the foam bubble sizes. After the wet foam drains (dries out), its deterioration rate is comparable to that of dry foams.

A model for free drainage in aqueous foams was also developed by S.A. Magrabi, B.Z. Dlugogorski and G.J Jameson [38]. They found that the drain rates depend substantially on bubble size variations. As the bubble size variation increases, the drainage rates also increase.

A study of drainage characteristics of AFFF and FFFP in CAF was performed by S.A. Magrabi, B.Z. Dlugogorski and G.J Jameson [39]. It was found that surface tension and bulk viscosities of AFFF and FFFP generated by CAFS were comparable. The FFFP foam coarsening (bubble size increasing) was significantly slower than for the AFFF foam. The AFFF foam drained significantly faster than the FFFP foam. In addition to the foam stability, the extinguishing capability of foams also depends on the spreadability of the foam and evaporation of the water from the foam. 


\section{- B.Y. Lattimer, C.P. Hanauska, J.L. Scheffey and F.W. Williams}

The use of small-scale test data to characterize some aspects of fire fighting foam for suppression modeling was investigated by B.Y. Lattimer, C.P. Hanauska, J.L. Scheffey and F.W. Williams [13]. They developed a test apparatus to measure evaporation rate, foam mass, drainage rate, foam height and foam temperature. The test apparatus used a radiant heater that applied radiation to the top of the foam. At a very high radiation level $\left(50 \mathrm{~kW} / \mathrm{m}^{2}\right)$, a small expansion of the foam was noticed.

\section{- A. Saint-Jalmes and D. Langevin}

The time evolution of aqueous foams; that is drainage and coarsening, was studied by Armaud Saint-Jalmes and Dominique Langevin. Their study demonstrated that the foam coarsens due to the pressure difference between bubbles of different sizes. It also concluded that drainage is enhanced as a result of coarsening, that is when the bubbles break and combine to form larger bubbles. This explains the efficiency of the CAF as most of the bubbles in the compressedair foam have more uniform sizes. [40].

\section{- H. Persson}

A number of tests to determine the resistance against heat radiation were conducted by Henry Persson [3]. Similar to other experiments a radiation heat flux was applied to the top of the foam. The foams used had relatively low 
expansion ratios (between $1: 6.5$ to $1: 11.5$ ). The tests did not include any compressed-air foams.

An interesting experiment was conducted by Persson [3], where the foam was discharged over a flammable liquid and the air above the foam was tested using an explosimeter. The tests indicated that the foams were able to maintain the volatile vapour level at less than $10 \%$ of LEL for at least 30 minutes with temperatures of the flammable liquid at $50^{\circ} \mathrm{C}$. However, these experiments were done at room temperature and no heat was applied to the foam during this experiment. No quantitative results were reported.

\subsubsection{Extinguishing capacity}

The extinguishing effectiveness of compressed-air foam systems has been tested by a number of research teams. A major advancement for the application of CAFS was done by NRC: rotary distribution nozzles for fixed CAFSs was developed and patented (TAR and GDR nozzles). A summary of principal research on the extinguishing ability of CAFSs is described below.

\section{- Andrew K. Kim and Bogdan Dlugogorski}

A study on the effectiveness of CAFSs was conducted by Andrew K Kim and Bogdan Dlugogorski [41]. The performance of a CAFS was compared with water mist and sprinkler systems. It was found that CAFS performs much better than 
water mist in extinguishing wood crib and flammable liquid pool fires in open spaces. In enclosed spaces the ability of the CAFS in extinguishing flammable liquid pool fires is comparable to a water mist system. The performance of CAFS in extinguishing fires involving a large wood crib was much better than that of a sprinkler system.

The time to extinguish a fire using CAF was generally below 30 seconds for heptane and diesel fuel fires, and about 7 minutes for a large wood crib fire. They also found that the decay of foam increased with the presence of different sizes of foam bubbles. There is, thus an advantage in the slower decay of compressed-air foams (since CAF has relatively consistent bubble size [38]).

Class A foam was used with a concentration of $0.3 \%$. The Class B foam used AFFF concentrates from 1 to $3 \%$ rates and the expansion ratios used were 1:4 and 1:10. With an expansion ratio of $1: 4$, the spray density depending on location varied between $2 \ell\left(\mathrm{min} / \mathrm{m}^{2}\right)$ to $28 \ell\left(\mathrm{min} / \mathrm{m}^{2}\right)$. For an expansion ratio of $1: 10$ the spray density depending on location varied between $1 \ell\left(\mathrm{min} / \mathrm{m}^{2}\right)$ to $10 \ell\left(\min / \mathrm{m}^{2}\right)$. The study raised a concern that high expansion foams, over 1:10, may not be as efficient in penetrating the fire plume. 


\section{- Andrew K. Kim and George Crampton}

The efficiency of CAFS to extinguish Class C fires was tested by Andrew K. Kim and George Crampton [42]. The CAFS was used to extinguish fires involving cable trays. In general, after the application of the foam, the fire was controlled within 1 minute and was extinguished within 1 minute 30 seconds to 2 minutes 10 seconds. The delivery density was at least $1.63 \mathrm{1} / \mathrm{min} / \mathrm{m}^{2}$, using Class A foam with an expansion ratio of 1:11 after a 10 minute drain. The foam was left standing for a period of 10 minutes, water that drained from the foam was discarded and then the foam expansion ratio was measured. See table 3.3.2-1.

A conductivity test was also performed to determine if the CAFS could be used on Class $\mathrm{C}$ fires (electrical equipment). The electrical conductivities measured at $25^{\circ} \mathrm{C}$ as presented in the paper are summarised in Table 3.4.2-1. 
Table 3.4.2-1 Electrical conductivity of CAFS

\begin{tabular}{|c|c|c|c|}
\hline $\begin{array}{c}\text { Electrical } \\
\text { conductivity } \\
\text { MicroS/cm }\end{array}$ & Solution type & Concentration & Expansion \\
\hline 1346 & Tap water & 0 & 0 \\
\hline 640 & $\begin{array}{c}\text { Fire protection } \\
\text { water }\end{array}$ & 0 & 0 \\
\hline 6.7 & Distilled water & 0 & 0 \\
\hline 337 & Rain water & 0 & 0 \\
\hline 1560 & Distilled water & $1 \%$ Class A & 0 \\
\hline 77 & Tap water & $1 \%$ Class A & $1: 11.5$ \\
\hline 27 & Tap water & $1 \%$ Class A & $\begin{array}{c}1: 12.5 \text { after } 10 \\
\text { min }\end{array}$ \\
\hline 915 & Distilled water & $2 \%$ Class B & 0 \\
\hline 17 & Distilled water & $2 \%$ Class B & $1: 12.5$ \\
\hline 6.7 & Distilled water & $2 \%$ Class B & $\begin{array}{c}12.5 \text { after } 10 \\
\text { min }\end{array}$ \\
\hline 1221 & Distilled water & $3 \%$ Class B & 0 \\
\hline 61 & Tap water & $3 \%$ Class B & $1: 12.5$ \\
\hline 34 & Tap water & $3 \%$ Class B & $\begin{array}{c}5: 12 \text { after } 10 \\
\text { min }\end{array}$ \\
\hline
\end{tabular}

The measurements show that the conductivity was substantially reduced when the water foam mix was converted into compressed-air foam. 
The efficiency of a CAFS for the protection of power transformers was studied by Andrew K. Kim and George Crampton [43]. The standard protection of power transformers usually involves a deluge sprinkler system. The transformer insulating oil used in the test was Voltesco 35 produced by Imperial Oil. (density $=877 \mathrm{~kg} / \mathrm{m}^{3}$ at $15^{\circ} \mathrm{C}$, flash point $=150^{\circ} \mathrm{C}$.) The oil was pre-heated to $75^{\circ} \mathrm{C}$. Immediately after the fire was extinguished, the contents of a $300 \mathrm{~mm}$ diameter burn-back pan was ignited and placed gently into the middle of the large test pan. The time for the small fire to break down the foam blanket and burn back $25 \%$ of the large pan area was recorded as burn-back time. Table $3.4 .2-2$ provides a summary of the test data.

The test results demonstrated that the CAFS is more efficient than sprinkler deluge systems in extinguishing fires involving cooling oils of power transformers and uses considerably less water. The interesting part of this experiment is that the combustible liquids were pre-heated prior to the start of the fire which provided a better simulation of actual field conditions. 
Table 3.4.2-2 Test results - CAFS extinguishing capacity of Power Transformer Fires

\begin{tabular}{|c|c|c|c|c|c|c|c|c|c|}
\hline System & Nozzle & $\begin{array}{l}\text { Foam } \\
\text { type }\end{array}$ & $\begin{array}{c}\text { Foam } \\
\text { conc. }(\%)\end{array}$ & $\begin{array}{l}\text { Flow } \\
\text { (U/min) }\end{array}$ & Fuel & $\begin{array}{l}\text { Pre-heat } \\
\left({ }^{\circ} \mathrm{C}\right)\end{array}$ & $\begin{array}{c}\text { Burn-Back } \\
\text { (min:s) }\end{array}$ & $\begin{array}{c}99 \% \\
\text { suppression } \\
\text { (min:s) }\end{array}$ & $\begin{array}{c}100 \% \\
\text { extinguish } \\
\text { ment }\end{array}$ \\
\hline Deluge & sprinkler & none & none & 910 & Oil & 75 & $1: 20$ & $2: 05$ & $3: 53$ \\
\hline CAF & TAR & Class A & 1 & 88 & Oil & 76.5 & $1: 21$ & $1: 09$ & $1: 24$ \\
\hline CAF & TAR & Class A & 1 & 66 & Oil & 76 & $1: 27$ & $2: 16$ & $4: 02$ \\
\hline CAF & TAR & Class B & 2 & 66 & Oil & 77 & $1: 20$ & $0: 10$ & $0: 25$ \\
\hline CAF & TAR & Class B & 2 & 66 & Oil & 77 & $2: 26$ & 1:21 & $2: 52$ \\
\hline CAF & TAR & Class B & 2 & 66 & Diesel & 32 & $1: 17$ & $1: 40$ & $2: 55$ \\
\hline CAF & GDR & Class A & 1 & 160 & Diesel & 33 & $1: 17$ & $0: 56$ & $1: 40$ \\
\hline CAF & GDR & Class B & 2 & 160 & Diesel| & 41 & 1:04 & $1: 30$ & $1: 45$ \\
\hline CAF & GDR & Class B & 2 & 160 & Oil & 75 & $1: 25$ & $1: 33$ & $1: 58$ \\
\hline CAF & TAR & Class B & 2 & 160 & Oil & 75 & $1: 15$ & $1: 13$ & $1: 29$ \\
\hline
\end{tabular}

A series of full-scale tests demonstrating the effectiveness of a CAFS in extinguishing fires in a residential occupancy was completed by Andrew K. Kim and George Crampton. [44] The tests demonstrated that the CAFS is more efficient than a sprinkler system. It was noted that the temperature readings after the suppression discharge were considerably lower when the CAFS was used. For the CAFS, the temperatures were between $78^{\circ} \mathrm{C}$ and $82^{\circ} \mathrm{C}$, while for the sprinkler system, they were between $240^{\circ} \mathrm{C}$ and $437^{\circ} \mathrm{C}$. 
- Andrew K. Kim, George Crampton and J.P. Asselin

A number of tests were performed by Andrew K. Kim, George Crampton and J.P. Asselin [45] to determine the performance of a CAFS relative to the performance of foam water sprinkler system. UL 162 [46] prescribes Class B fire tests using three different foam discharge methods: an overhead fixed piping system using sprinklers or spray nozzles, subsurface injection devices and topside discharge devices. Only the overhead fixed piping fire test was used in this research. The following table provides the results of the tests:

Table 3.4.2-3 Results of foam water sprinkler system vs CAFS

\begin{tabular}{|c|c|c|c|c|c|}
\hline System & $\begin{array}{c}\text { Foam } \\
\text { water } \\
\text { sprinklers }\end{array}$ & CAFS & CAFS & CAFS & CAFS \\
\hline Foam type & Class B & Class B & Class B & Class A & Class A \\
\hline $\begin{array}{l}\text { Flow rate gpm } \\
\qquad(1 / \mathrm{min})\end{array}$ & $\begin{array}{l}61.8 \\
(234)\end{array}$ & $\begin{array}{l}24.3 \\
(92)\end{array}$ & $\begin{array}{l}24.3 \\
(92)\end{array}$ & $\begin{array}{l}24.0 \\
(91)\end{array}$ & $\begin{array}{l}24.0 \\
(91)\end{array}$ \\
\hline Foam conc. $(\%)$ & 3 & 2 & 2 & 1 & 1 \\
\hline Expansion ratio & $1: 3.5$ & $1: 10$ & $1: 10.9$ & $1: 10$ & $1: 8.62$ \\
\hline $\begin{array}{l}\text { Extinguishment } \\
\text { time (min:s) }\end{array}$ & $2: 32$ & $0: 50$ & $0: 49$ & $0: 59$ & $1: 16$ \\
\hline $\begin{array}{l}\text { Burn-back time } \\
\text { (min:s) }\end{array}$ & $9: 00$ & $23: 35$ & $17: 15$ & $10: 10$ & $6: 15$ \\
\hline
\end{tabular}


The research used different types of delivery nozzles and different distances of the nozzles from the combustibles were investigated. The extinguishing ability was not affected by the increase of distance from $4.42 \mathrm{~m}(14.5 \mathrm{ft})$ to $7.62 \mathrm{~m}$ ( $25 \mathrm{ft})$ but, in some instances, the burn-back time was decreased. In general, the CAFS was more efficient than the foam water system.

\section{- George Crampton}

The performance of a CAFS, when used simultaneously with a sprinkler system was tested by George Crampton [47]. A number of tests demonstrated that there is no serious degradation in extinguishment and in burn-back protection when the two systems are used together.

A series of full-scale tests on Class B fires were conducted by George Crampton [48] to establish a safety factor and establish the minimum and maximum densities of the compressed-air foam by varying the water supply pressures. As the water pressure was reduced and air pressure was maintained constant, the generated foam expansion increased. The water content of the foam was used in the determination of the foam application density. It was found that the extinguishing times were not significantly affected by the change in water pressure. 


\section{- George Crampton and Andrew K. Kim}

A number of full-scale tests were conducted by George Crampton and Andrew Kim to compare the performance of a CAFS with a foam water sprinkler system when used on a flowing heptane fire [49]. The results show that the CAFS was able to control and extinguish the fire while the foam water sprinkler system was able to control the fire but was not able to extinguish the fire.

The test used 2\% Class B foam for CAFS and 3\% Class B foam for the foam water sprinkler system. A military specification foam was also tested and the performance of the Class B military specification foam was slightly better than the standard $\mathrm{CAF}$.

An evaluation of the fire suppression effectiveness of manually applied CAF was done by Andrew K. Kim and George P. Crampton [50]. Their research demonstrated that the CAF is more efficient than water or low-expansion foam (foam water) in manual fire fighting. CAF used substantially less water and was more efficient in controlling the temperature in the fire compartment.

\section{- J.W. Fleming and R.S. Sheinson}

A bench-scale high-expansion aqueous foam generator integrated into a traditional cup burner apparatus was developed by James W. Fleming and Ronald S. Sheinson [51]. The tests demonstrated that high-expansion foams are very 
efficient in extinguishing fires. The test apparatus enabled testing of the efficiencies of high-expansion foam with expansion ratios from 1:50 up to 1:590.

\section{- A.J. Laudness, M.S. Rayson, B. Z. Dlugogorski and E.M. Kennedy}

An experimental program to develop a novel foam involved the use of a chemical reaction between dissolved species to generate inert nitrogen gas in situ, hence the name in situ generated nitrogen foams (ISNF). Tests comparing the ISNF to the performance of CAF were conducted by A.J. Laudness, M.S. Rayson, B. Z. Dlugogorski and E.M. Kennedy [52]. The tests showed that the ISNF fire fighting capacity is similar to that of CAF. Further research was recommended.

\subsubsection{Foam's ability for the mitigation of thermal radiation}

The ability of compressed-air foam to absorb thermal radiation was the subject of fire spread research in Australia. The objective of that study was to determine the ability of the foam to provide exposure protection.

\section{- S.A. Magrabi, B.Z. Dlugogorski and G.J. Jameson}

The performance of aqueous foams in mitigating thermal radiation was studied by S.A. Magrabi, B.Z. Dlugogorski and G.J. Jameson [53]. The study was performed to determine the effectiveness of pre-sprayed foam to absorb and resist heat exposure from an advancing fire. A typical application would be a forest fire. 
In the research, Class B AFFF foam at 3\% was used with expansion ratios from 1:5 to 1:30. The foam was sprayed into a container and the radiation source was applied to the top surface of the foam. The foam mass and the drained water mass were separately monitored to determine the foam drainage.

The performance in attenuating thermal radiation energy was evaluated by analysing the underlying physical phenomena in the foam layer, namely drainage, evaporation and collapse. The results showed that, for an extended period of time, the foam consistency was different depending on location. The top of the foam layer had a very dry consistency, while near the bottom, the concentration was that of the original foam solution. It was determined that aged foams are less stable and drain faster than non-aged foams. This was assumed to be due to a narrower bubble-size distribution.

A uniform bubble distribution in freshly made foam requires greater energy to break up the foam and initiate drainage, than foam that has variable bubble size. It was noted that the application of radiation to the top of the foam as well as the gravity force and drainage at the bottom of the foam increased the drainage of the foam. In fact, the drainage was increased by heat and by the drainage itself. The evaporation rates of the foam were noted to be linear up to a heat flux of $20 \mathrm{~kW} / \mathrm{m}^{2}$. It was found that the foam layer cannot, for any length of time, withstand high evaporation rates caused by thermal heat fluxes above $20 \mathrm{~kW} / \mathrm{m}^{2}$ 
and disintegrates rapidly. It was concluded that an increasingly larger amount of heat was conducted downwards through the foam layer as the intensity of the incident radiant exposure was increased.

The experiment showed that water drainage from the foam is largely dependent on heat exposure.

It was deduced that the presence of wetter foam at the top of the freshly-made foam delayed water drainage. The water drainage was attributed to the thinning of the film forming the bubble (the film-thinning process) that eventually led to the rupture of the bubble. The report concluded that the most cost-effective approach for protection against thermal radiation is the use of freshly-made foam with an expansion ratio of 1:30.

\subsection{Summary of the Findings of the Literature Review}

The literature review did not reveal any research on the performance of CAF when subjected to heating from below, which is the topic of the research presented in this thesis.

From the literature review, it can be observed that there has been little research done in investigating the ability of a CAFS to minimize the transfer of heat from a hot surface to 
the environment as well as the ability of a CAFS to prevent the flow of gases when the foam is sprayed over a hot surface. 


\section{EXPERIMENTAL SETUP}

\subsection{Introduction}

The objective of this study is to simulate the ability of the foam to reduce the effects of the fire on the surrounding areas and to obtain means to determine the optimal rate of application (density) of the foam.

The experiments were designed to simulate the heat absorption capacity of CAF following extinguishment of fire. In all the experiments, the foam used was compressedair foam. In these experiments, the floor of the container was heated and then the foam was sprayed onto the hot floor. The temperature of the foam was monitored at given depths within the foam. The water drainage was also monitored.

The importance of installing instrumentation so as not to affect the test behaviour was taken into consideration when deciding the type of instrumentation and the location of the thermocouples. 


\subsection{Equipment and material used}

\subsubsection{Foam}

Two types of foam concentrate were used: Class A and Class B - AR-FFF. Two different expansion ratios were also tested. Class B - AR-FFF was used as this type of foams are most effective for extinguishing flammable or combustible liquid fires. Class A foams were used for their extinguishing qualities on Class A fires. CAFs with an expansion ratio of 1:25 to $1: 30$ are relatively dry and stick to the surface. CAFs with an expansion ratio of $1: 8$ to $1: 10$ are relatively wet and will float across the surface and provide wetting of the surface. The four combinations of compressed-air foam used in these experiments were:

- Type A foam solution mixed at $0.3 \%$ with an expansion ratio of $1: 8.5$

- Type A foam solution mixed at $1 \%$ with an expansion ratio of 1:23.4

- Type B foam solution mixed at $2 \%$ with an expansion ratio of $1: 8.7$

- Type B foam solution mixed at 3\% with an expansion ratio of 1:24.8

\section{Class A foam}

The Class A concentrate used was Silv-ex concentrate made by Ansul (see Fig. 4.2.1-1). The concentrate was listed as $0.3 \%$ to $1 \%$ depending on the expansion ratio. A solution of $0.3 \%$ of foam concentrate for the $1: 8.5$ expansion ratio and $1 \%$ for the $1: 23.4$ expansion ratio were used. 


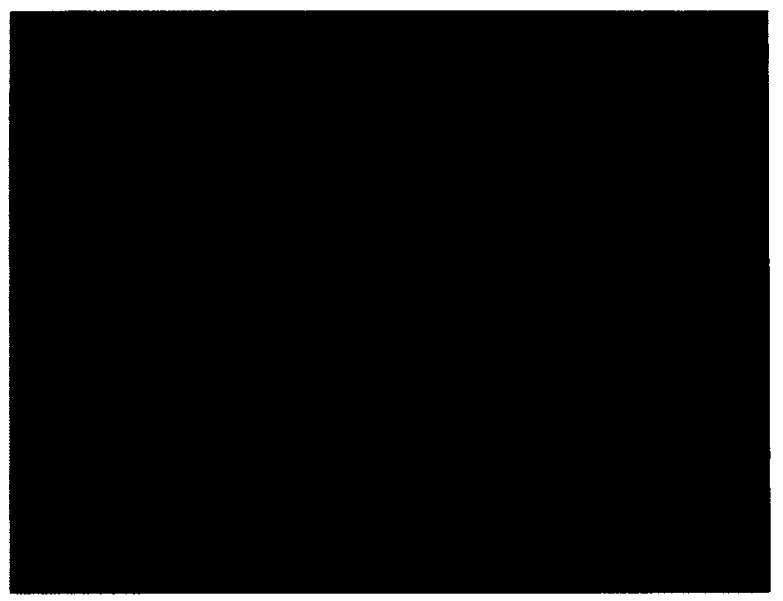

\section{Fig. 4.2.1-1 Class A foam concentrate}

\section{Class B concentrate}

The Class B concentrate used was Alcoseal Film Forming Alcohol Resistant Fluoroprotein Foam concentrate made by Angus (see Fig. 4.2.1-2). The concentrate was listed as $3 \%$ for non-alcohol combustibles and $6 \%$ for alcohol-based combustibles. The concentrate was listed as $0.3 \%$ to $1 \%$ depending on the expansion ratio. A solution of $2 \%$ of foam concentrate for the $1: 8.7$ expansion ratio and $3 \%$ for the $1: 24.8$ expansion ratio were used. The listing of the foam was for use by air aspirating or air non-aspirating systems: typically this would be used in a sprinkler system.

A solution using $2 \%$ of concentrate with expansion ratio of $1: 8.7$ was used to produce CAF. 


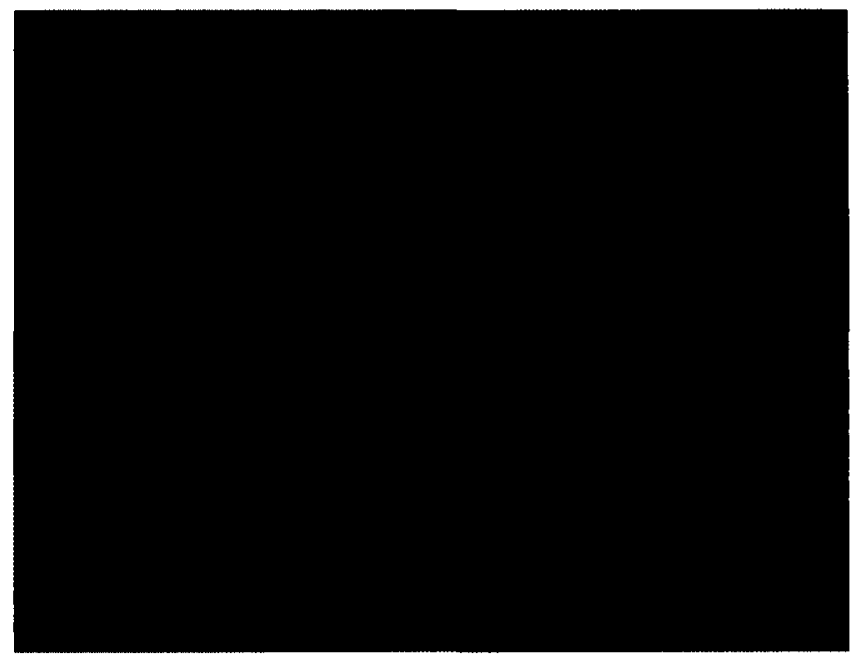

\section{Fig. 4.2.1-2 Class B foam concentrate}

\subsubsection{Foam generator}

An experimental portable foam generator that was designed by NRC was used in these experiments (see Figs. 4.2.2-1 and 4.2.2-2). The use of the generator was graciously offered by the NRC. The generator consisted of a metal tank, control valve and air intake. The tank had a capacity of $3 \ell$. The tank was filled with a pre-mixed foam solution. 


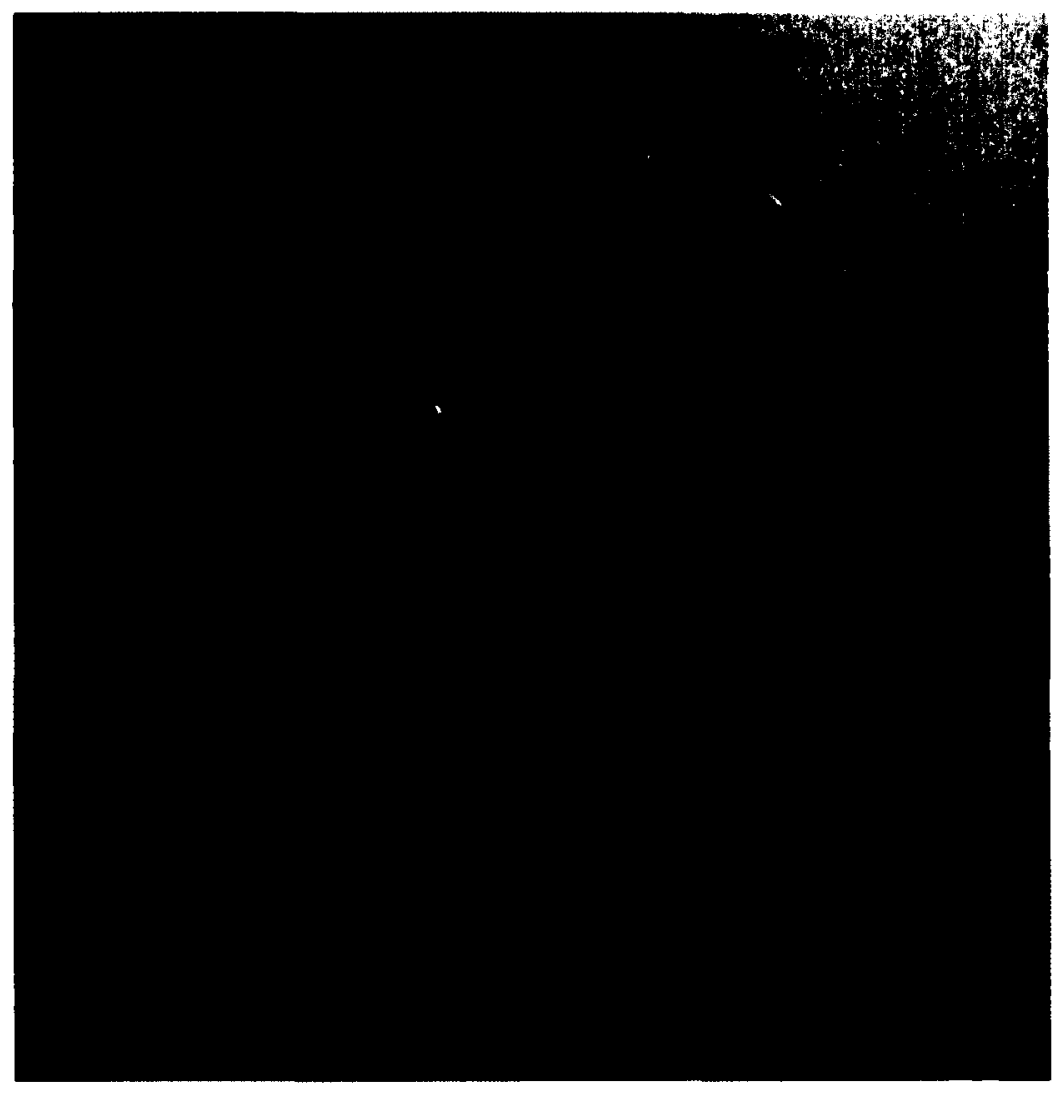

Fig. 4.2.2-1 Foam generator

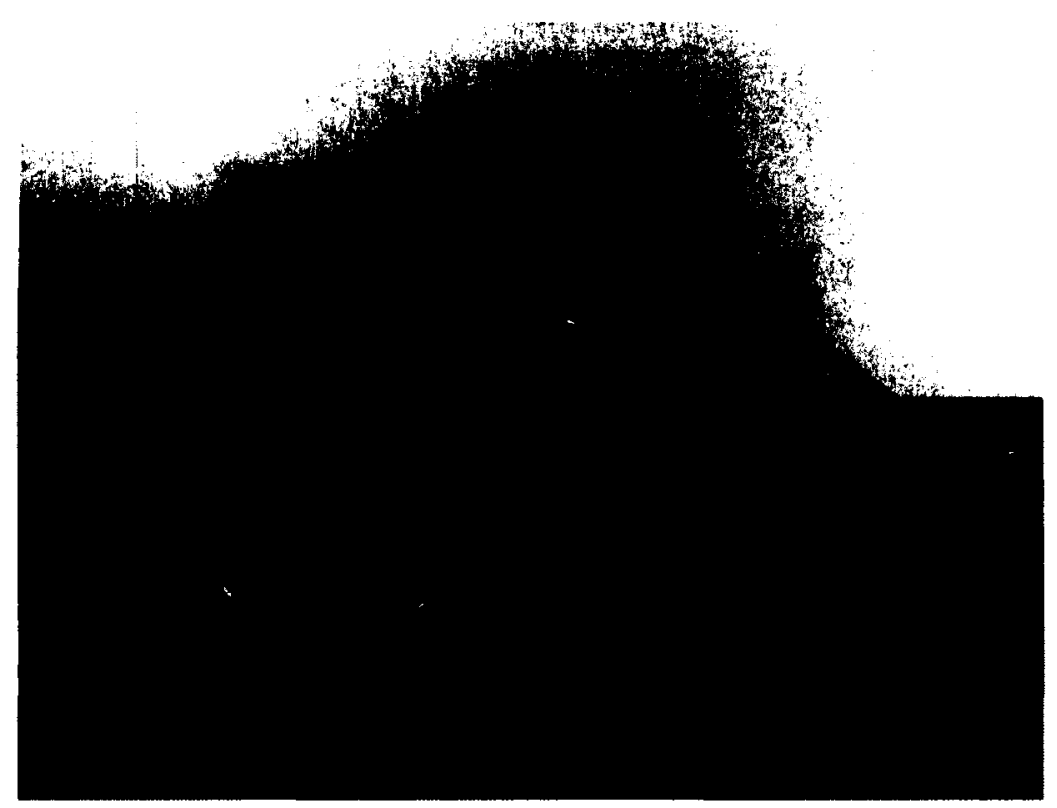

Fig. 4.2.2-2 Foam generator and attached compressor 
The tank was pressurized with compressed-air at approximately $620 \mathrm{kPa}(90 \mathrm{psi})$. The compressed-air occupied the space above the pre-mixed foam solution. The pressurized pre-mixed foam solution was forced into a tube that led from the control valve to the bottom of the tank. A calibrated reduced orifice was installed near the control valve and a small hole was drilled above the reduced orifice. See Fig. 4.2.2-3.

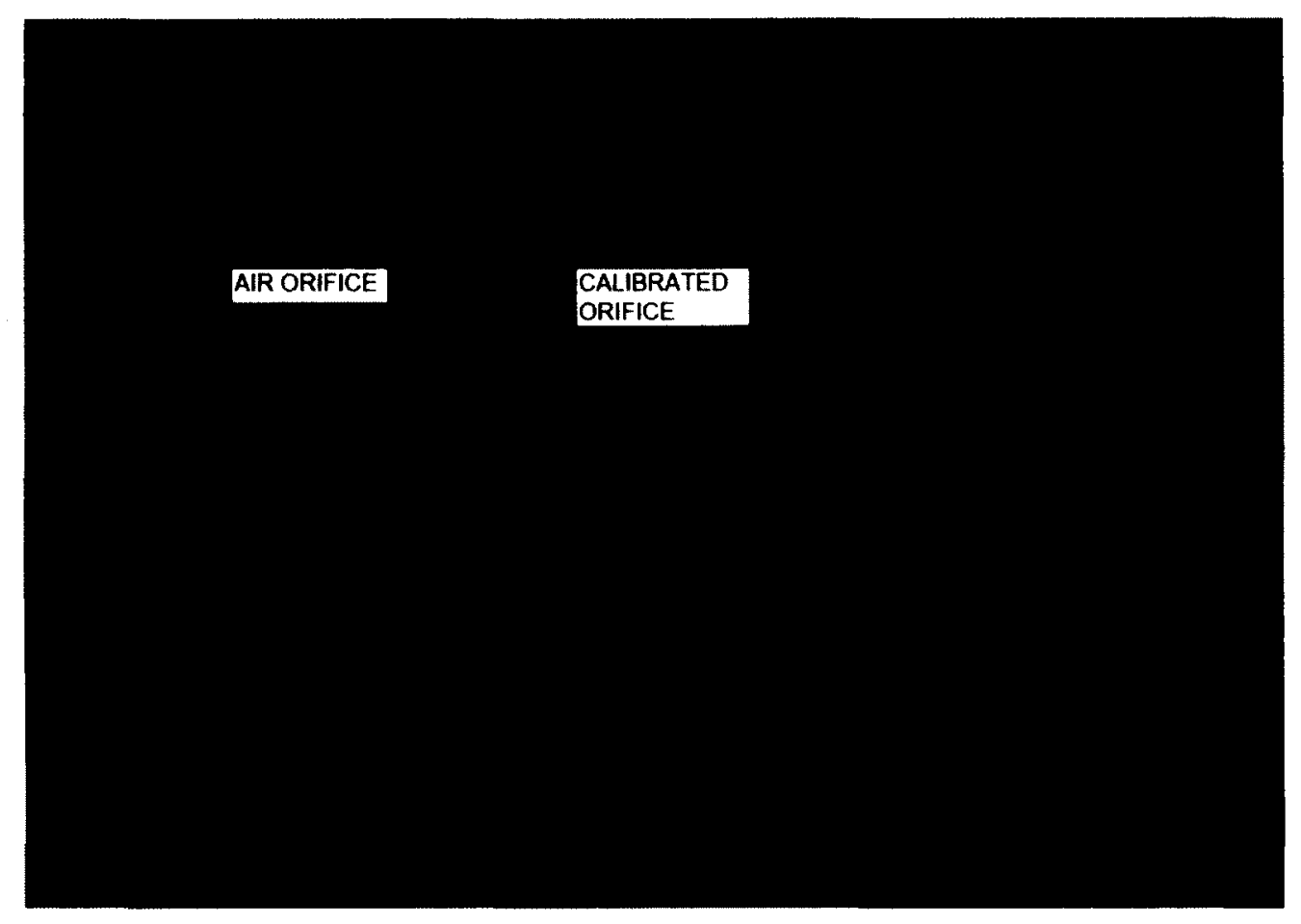

Fig. 4.2.2-3 Foam generator detail

The pre-mixed foam solution was forced into the tube by air pressure, passed through the calibrated orifice and was mixed with air using the Venturi principle. The bubbles were then improved as they passed through the tubing attached to the control valve located outside of the tank. 
The generator was designed to generate compressed-air foam with the characteristics given in Table 4.2.2-1 and these expansion ratios are commonly used in practice.

Table 4.2.2-1 Foam generator foam specifications

\begin{tabular}{|c|c|c|c|}
\hline Foam type & Concentrate mix \% & Expansion ratio & Orifice \\
\hline Class A & $0.3 \%$ & $1: 8.5$ & Large \\
\hline Class A & $1 \%$ & $1: 23$ & Small \\
\hline Class B & $2 \%$ & $1: 9$ & Large \\
\hline Class B & $3 \%$ & $1: 25$ & Small \\
\hline
\end{tabular}

\subsubsection{Heat transfer foam-holding tank}

The test apparatus for the heat transfer tests consisted of a foam-holding tank, a propane burner, thermocouples and a temperature measuring gun. The temperature reading is based on infrared radiation.

The foam-holding tank (see Figs 4.2.3-1 and 4.2.3-2) for the heat transfer tests was constructed of stainless steel with internal dimensions of $310 \mathrm{~mm}$ x $310 \mathrm{~mm}$ x $310 \mathrm{~mm}$. The walls were $500 \mathrm{~mm}$ high and $50 \mathrm{~mm}$ thick with insulation between the stainless steel plates. The floor of the holding tank was located at approximately $190 \mathrm{~mm}$ from the bottom of the walls and was slightly sloped to one side to permit drainage of the liquid from the foam. 


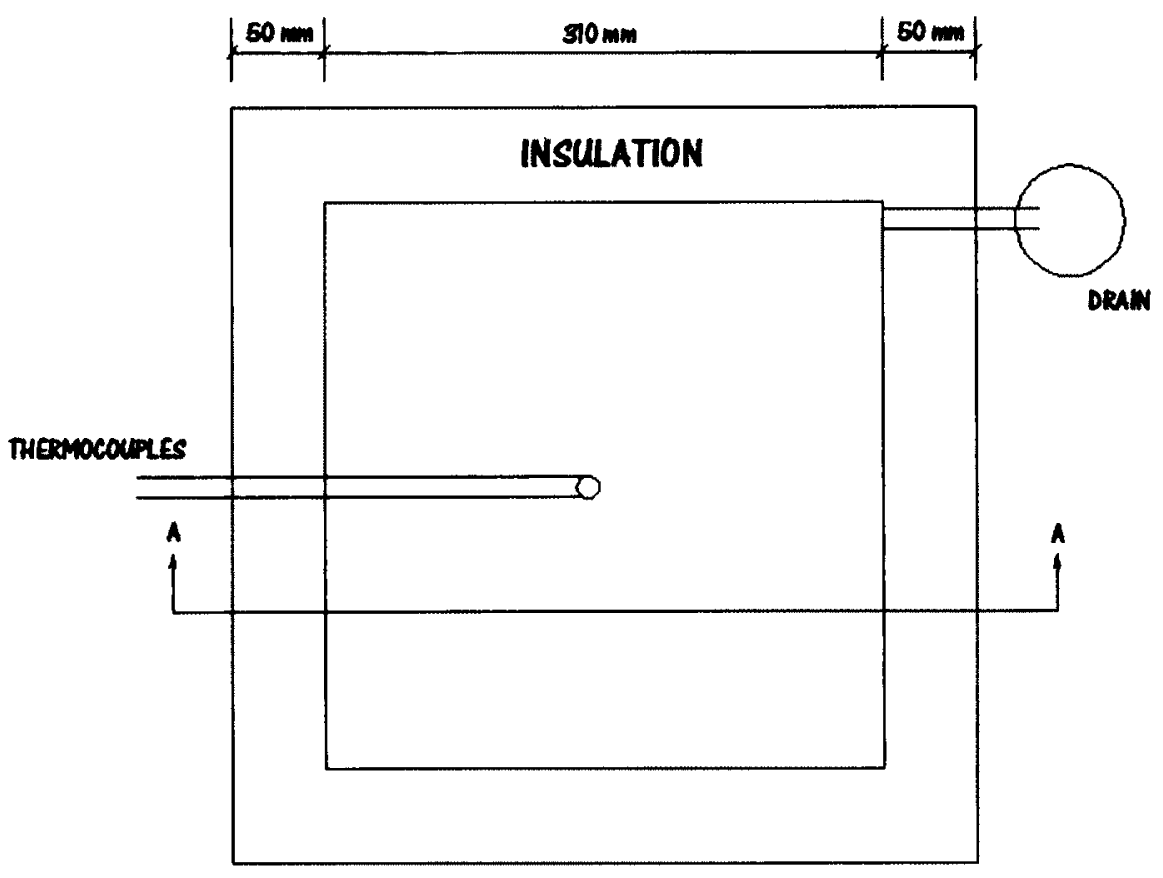

Fig. 4.2.3-1 Foam Tank - Plan view

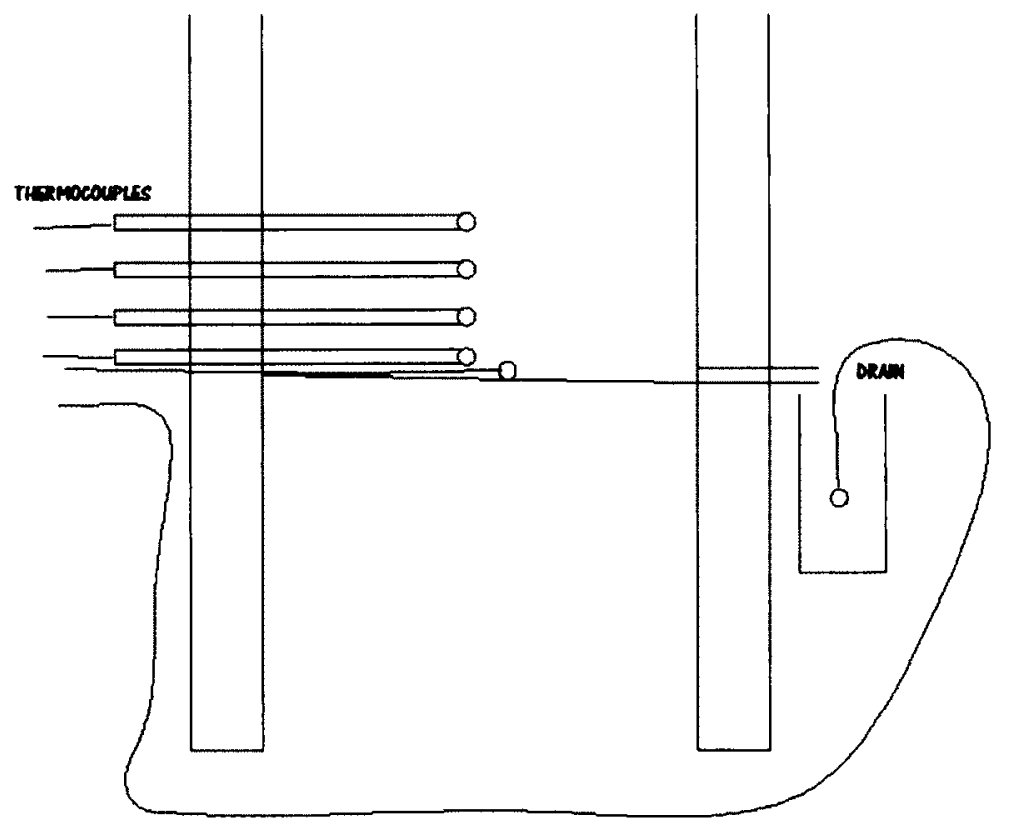

Fig. 4.2.3-2 Foam tank - Cross Section AA 
The holding tank was designed to simulate typical fire conditions where the foam is sprayed over the hot (burning) surface. As a typical surface is not flat and assumed not to absorb water, the holding tank was designed to simulate a real situation where the foam drainage cools the floor surface and is also able to partially drain as it would in the open fire area. The walls of the holding tank were insulated to represent boundary conditions that minimize the effect of heat loss to the walls. The walls of the holding tank were extended $190 \mathrm{~mm}$ below the bottom of the tank floor to allow hot air accumulation under the floor. This wall extension allowed the floor to be further from the burner flames and therefore, reduced the temperature variation in the plane of the floor of the tank. See Fig.4.2.3-3.

Thermocouples were placed:

- In contact with a steel plate sitting on the floor

- $10 \mathrm{~mm}$ above the floor

- $20 \mathrm{~mm}$ above the floor

- $30 \mathrm{~mm}$ above the floor

- $40 \mathrm{~mm}$ above the floor

- In the water drainage pipe 


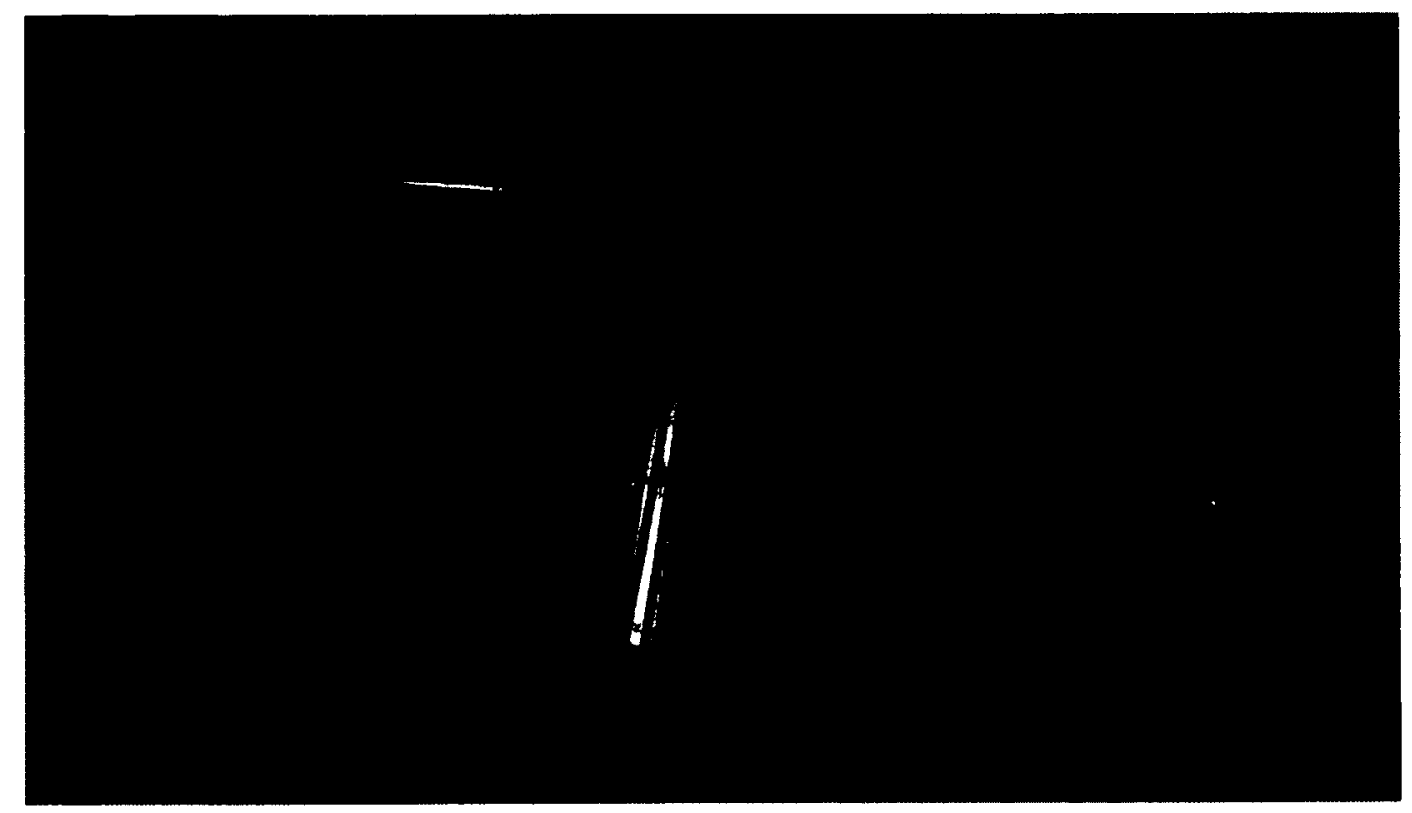

Fig. 4.2.3-3 The foam holding tank

To be able to evaluate the cooling ability of the CAF, a $6.35 \mathrm{~mm}$ thick steel plate was installed on top of the floor of the foam holding tank. See Fig. 4.2.3-4. The steel plate was heated to the desired starting (initial) temperature and then the burner was extinguished. The cooling of the plate using the CAF could then be compared to the cooling of the plate without the foam cover. 


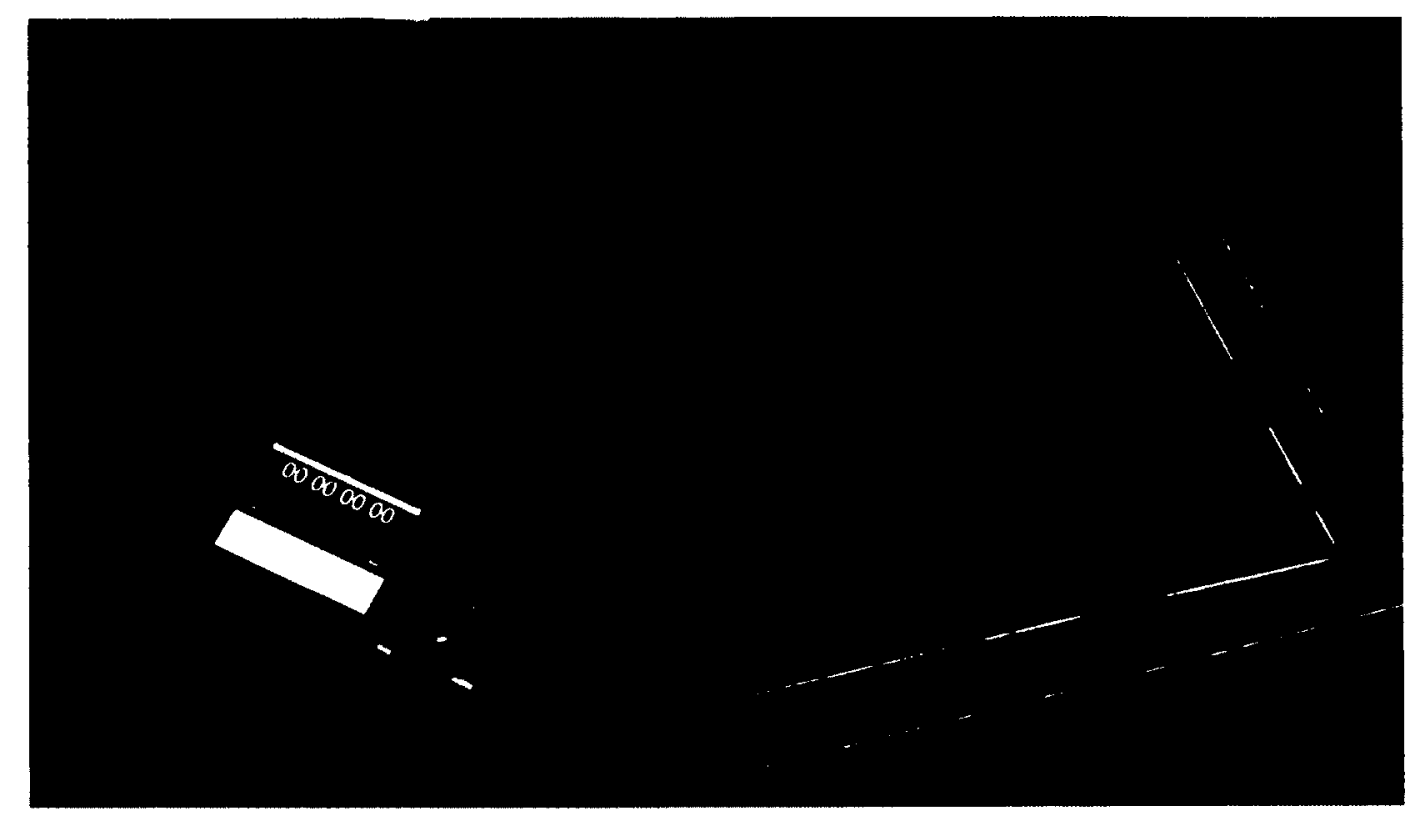

Fig. 4.2.3-4 Foam tank with $6.35 \mathrm{~mm}$ steel plate only at the bottom.

The surface temperature of the foam was measured with a temperature gun as this method did not affect the foam surface and did not have to move with the foam change of height.

For some experiments, additional thermocouples were added to measure the temperature of gas below the floor, the temperature of the bottom of the floor, as well as temperatures of foam or air at any selected level.

A tape measure was attached to the side of the wall to allow measurement of the foam level. See Fig 4.2.3-5 


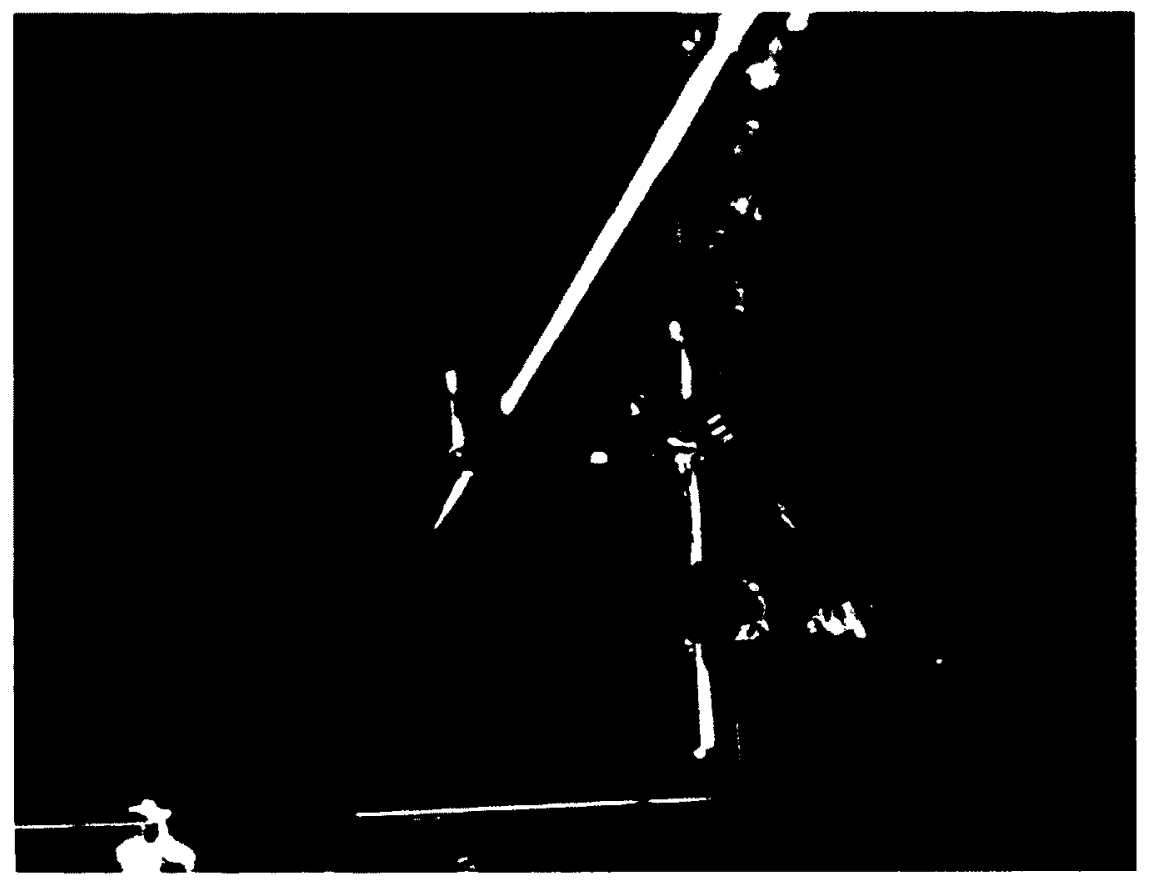

Fig. 4.2.3-5 Thermocouple attachment mechanism

\subsubsection{Thermocouples}

The foam tank was designed to hold Type $\mathrm{K}$ thermocouples distributed by Controls Intempco Ltd. See Fig. 4.2.4-1. The thermocouples were connected to a National Instruments multiplexer (see Fig. 4.2.4-2) that was interfaced with a computer running Labview that recorded temperature readings every two seconds. 


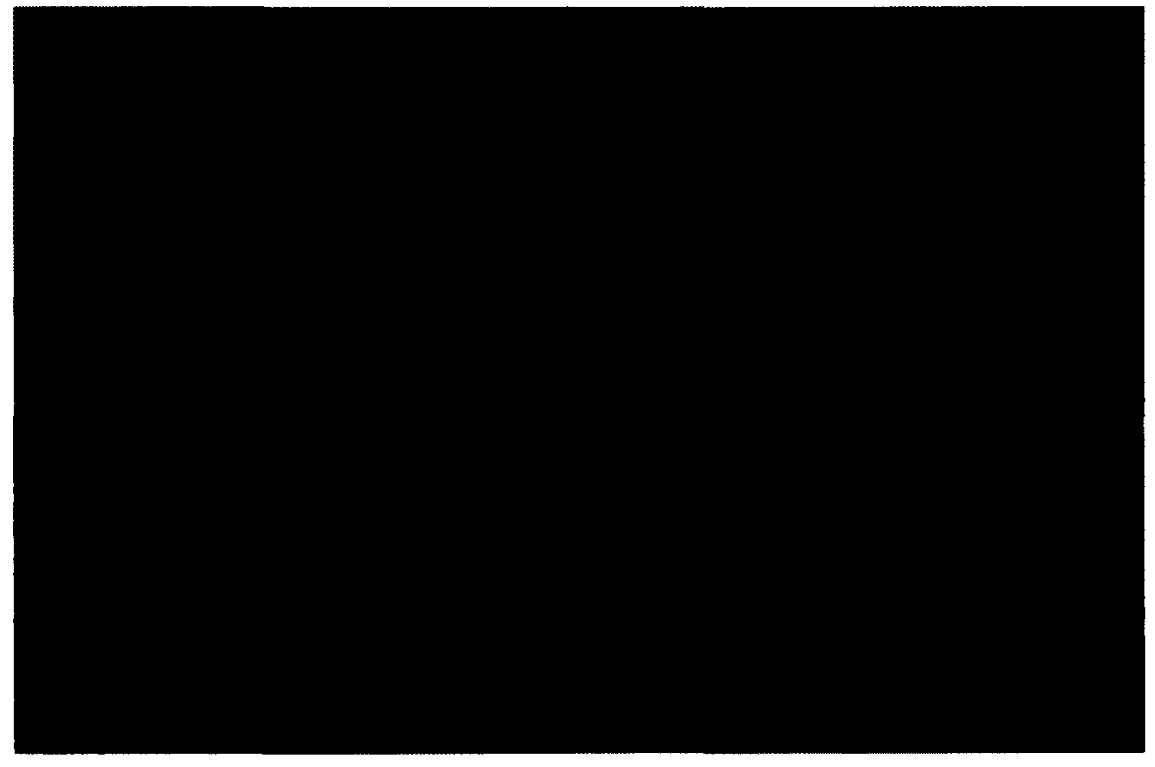

Fig. 4.2.4-1 Thermocouples used inside the foam layer

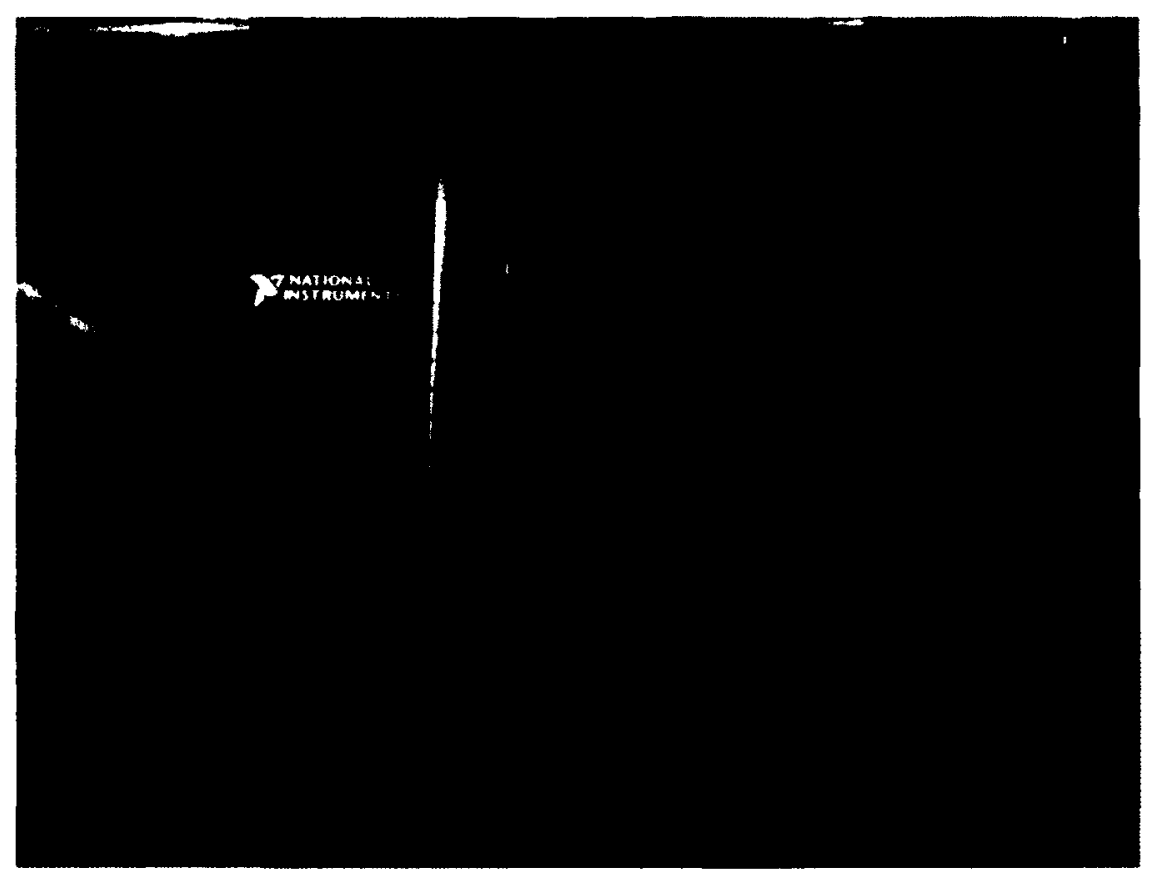

Fig. 4.2.4-2 Thermocouple multiplex reader 


\subsubsection{Heat source}

An outdoor cooker model \# 009008 imported by S.R.Potten Ltd was used to simulate fire conditions (see Fig. 4.2.5-1). The output was rated at $21.1 \mathrm{~kW}(72,000 \mathrm{BTU} / \mathrm{hr})$. The burner was designed to use propane gas.

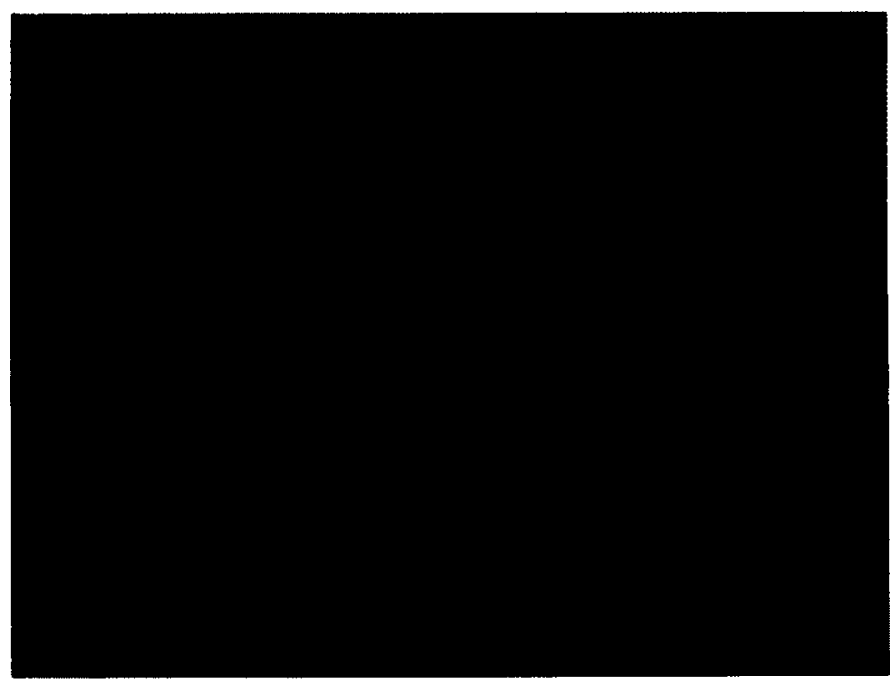

Fig. 4.2.5-1 Burner

\subsubsection{The scale}

A Symmetry - Cole-Parmer portable series digital balance model ECII-400 was used to measure the foam expansion and accumulation of the drainage water. The scale precision was $\pm 0.2 \mathrm{~g}$. The scale had the ability to set zero weight with an empty container (tare) and to display the net weight. 


\subsection{Calibration}

\subsubsection{Foam water - foam concentrate calibration}

To make a pre-mixed foam solution, the exact amount of water was measured by using a calibrated cylinder. The foam concentrate was added to the water using a calibrated syringe or calibrated cylinder and mixed to provide a homogenous solution.

The water measurement precision was approximately $\pm 10 \mathrm{~m} \ell$. The concentrate measurement precision was $\pm 0.5 \mathrm{~m} \ell$. The precision of the foam concentrate can be calculated as follows.

The lower limit of the concentration can be calculated by the following equation based on uncertainty analyses procedures as described in the Reference Manual for the P.E. exam in fire protection engineering [54]:

$$
C O N_{\min }=100 \frac{V_{\text {conc }}-\Delta V_{\text {conc }}}{\left(V_{\mathrm{H}_{2} \mathrm{O}}+\Delta V_{\mathrm{H}_{2} \mathrm{O}}\right)+\left(V_{\text {conc }}-\Delta V_{\text {conc }}\right)}
$$

The upper limit of the concentration can be calculated by the following equation:

$$
C O N_{\max }=100 \frac{V_{\text {conc }}+\Delta V_{\text {conc }}}{\left(V_{\mathrm{H}_{2} \mathrm{O}}-\Delta V_{\mathrm{H}_{2} \mathrm{O}}\right)+\left(V_{\text {conc }}+\Delta V_{\text {conc }}\right)}
$$

For a $3 \ell$ solution using $2 \%$ concentrate the limits are:

$$
\begin{aligned}
& C O N_{\min }=100 \frac{60-0.5}{(2940+10)+(60-0.5)}=1.977 \% \\
& C O N_{\max }=100 \frac{60+0.5}{(2940-10)+(60+0.5)}=2.023 \%
\end{aligned}
$$


For a $3 \ell$ solution using $3 \%$ concentrate the limits are:

$$
\begin{aligned}
& C O N_{\min }=100 \frac{90-0.5}{(2910+10)+(90-0.5)}=2.974 \% \\
& C O N_{\max }=100 \frac{90+0.5}{(2910-10)+(90+0.5)}=3.0262 \%
\end{aligned}
$$

For a $3 \ell$ solution using $0.3 \%$ concentrate the limits are:

$$
\begin{aligned}
& \operatorname{CON}_{\text {min }}=100 \frac{9-0.5}{(2991+10)+(9-0.5)}=0.282 \% \\
& C O N_{\text {max }}=100 \frac{9+0.5}{(2991-10)+(9+0.5)}=0.318 \%
\end{aligned}
$$

For a $3 \ell$ solution using $1 \%$ concentrate the limits are:

$$
\begin{aligned}
& C O N_{\min }=100 \frac{30-0.5}{(2970+10)+(30-0.5)}=0.980 \% \\
& C O N_{\max }=100 \frac{30+0.5}{(2970-10)+(30+0.5)}=1.020 \%
\end{aligned}
$$

The error in concentrate is more important for low concentrations. The $0.3 \%$ concentration error can be up to $6 \%$. In the high concentration mix, the error is reduced to less than $1.5 \%$.

\subsubsection{Air expansion rate verification}

The foam water mix density $\rho_{\mathrm{FW}}$ was determined by measuring the mass of a container, $\mathrm{M}_{\mathrm{C}}(\mathrm{g})$, of a volume of $1000 \mathrm{~m} \ell$. Then $1000 \mathrm{~m} \ell$ of water foam mix, $\mathrm{V}_{\mathrm{FW}}$, was added into the container and the resultant mass of the foam solution and the container was measured, $\mathrm{M}_{\mathrm{F}}$. See Fig. 4.3.2-1. 


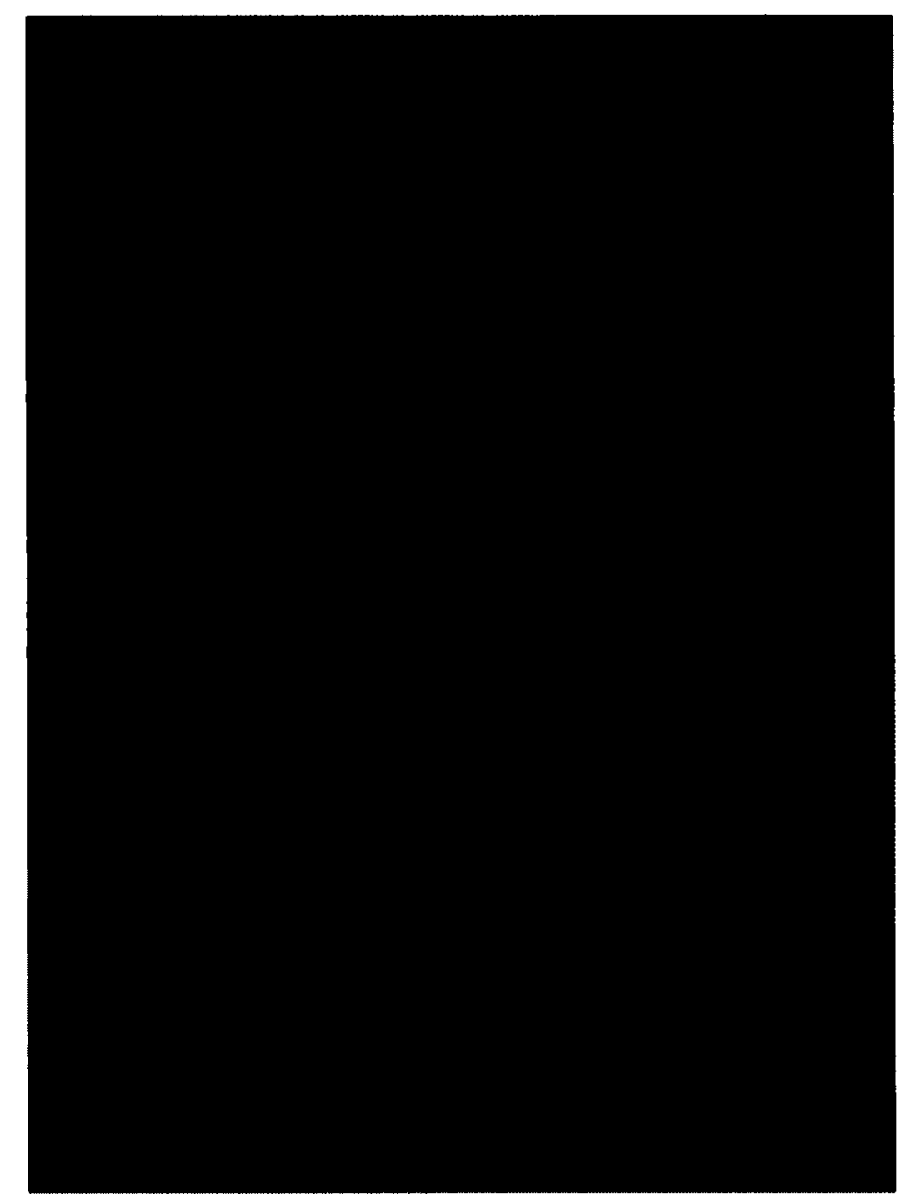

\section{Fig. 4.3.2-1 Water foam mixture preparation}

The volume accuracy was measured to $\pm 10 \mathrm{~m} \ell$. The foam-water density was calculated by using:

$\rho_{F W}=\frac{M_{F}-M_{C}}{V_{F W}}(\mathrm{~g} / \mathrm{m} \ell)$

A container (expansion measuring container) having a volume of $3680 \mathrm{~m} \ell$ was measured to determine the exact volume, $V_{c o n}(\mathrm{~m} \ell)$. The volume accuracy was measured to $\pm 20 \mathrm{~m} \ell$. The mass of the container, $M_{C}(\mathrm{~g})$, was measured at $107.7 \mathrm{~g}$. The container was 
filled with foam and the excess foam was removed by sliding a straight edge over the top of the container. The full container mass, $M_{F}(\mathrm{~g})$, was then measured. See Fig. 4.3.1-2.

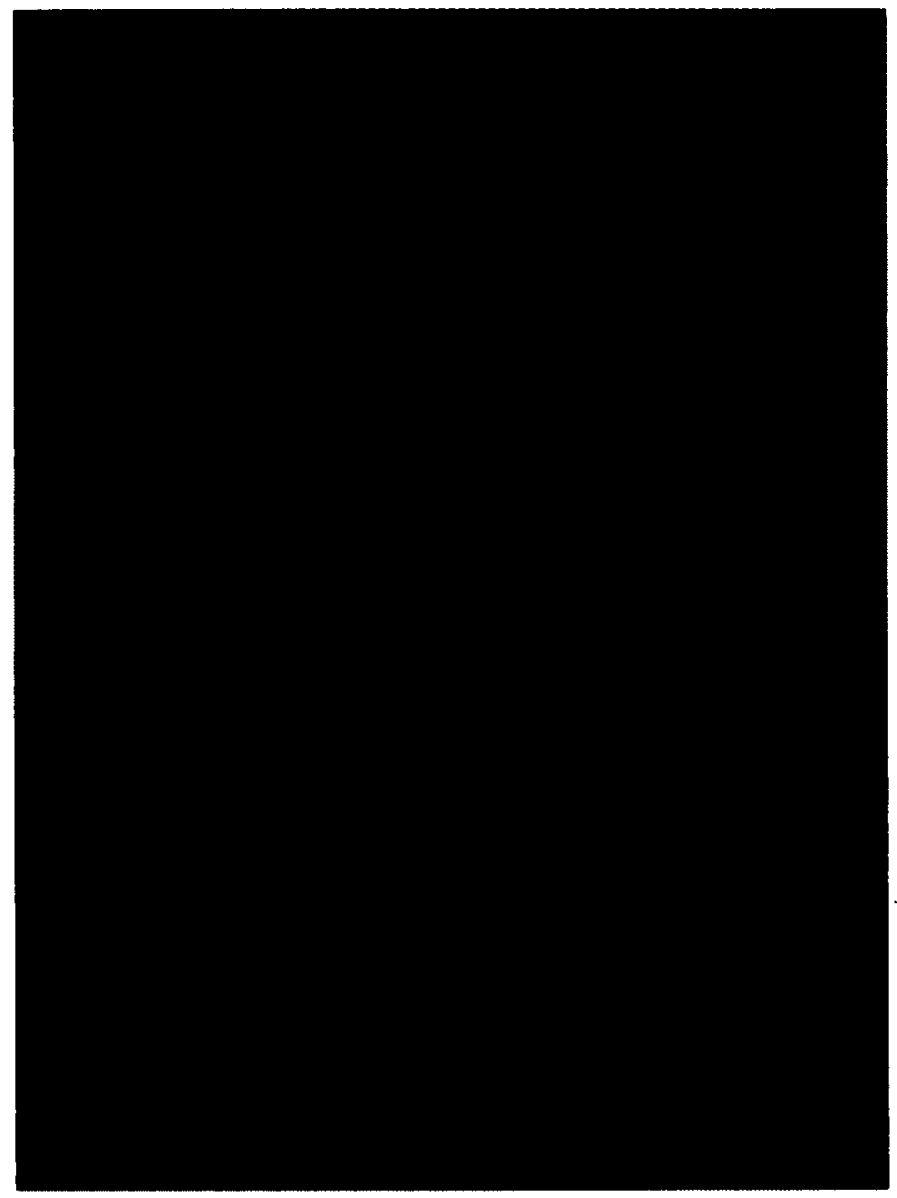

Fig. 4.3.2-2 Foam expansion measurement

The expansion ratio was calculated using the following equation:

Expansion ratio $=\rho_{F w} \frac{V_{c o n}}{\left(M_{F}-M_{C}\right)}$ (no units)

The mass measurements had a minimum precision $\pm 1 \mathrm{~g}$.

The following table provides a summary of foam expansion measurements. 
Table 4.3.2-1 Foam expansion measurements

\begin{tabular}{|c|c|c|c|c|c|c|}
\hline $\begin{array}{c}\text { Type of } \\
\text { foam }\end{array}$ & Concentrate & $M_{C}(g)$ & $M_{F}(g)$ & $V_{F W}(m \ell)$ & $\begin{array}{c}\rho_{F W} \\
(g / m \ell)\end{array}$ & Expansion ratio \\
\hline Class A & $0.3 \%$ & 107.7 & 433.6 & 3680 & 0.430 & $1: 8.5$ \\
\hline Class B & $2 \%$ & 107.7 & 425.4 & 3680 & 0.422 & $1: 8.71$ \\
\hline Class A & $1 \%$ & 107.7 & 158.6 & 3680 & 0.157 & $1: 23.4$ \\
\hline Class B & $3 \%$ & 107.8 & 149.4 & 3680 & 0.148 & $1: 24.8$ \\
\hline
\end{tabular}

\subsubsection{Temperature gun calibration}

To measure the surface temperature of the foam, an infrared heat gun was used. To calibrate the temperature gun, foam at room temperature was discharged into a container. Water was placed in a container and slowly heated. A thermocouple was placed near the top surface. Temperature readings of the thermocouple and the water surface temperature taken by the temperature gun were compared at $5^{\circ} \mathrm{C}$ intervals.

In addition, a thermocouple was placed near the top surface of the foam. A temperature reading of the foam surface was taken with the heat gun and the temperature reading of the heat gun was compared to the temperature reading of the thermocouple. This was 
done in order to determine if the readings of the temperature gun were affected by the foam surface.

The temperature readings were consistent with the readings of the thermocouples to within $\pm 1.5^{\circ} \mathrm{C}$. 


\section{HEAT TRANSFER EXPERIMENTS AND ANALYSES}

\subsection{Introduction}

The objective of this study is to evaluate how CAF absorbs heat and to develop tools to help estimate the optimal foam application density. Contrary to previous experiments described in the literature review where heat was applied only to the top of the foam, in the experiments described herein, heat was applied to the bottom of the foam. The application of heat to the bottom of the foam simulates conditions where the foam is sprayed over the fire as an extinguishing agent. The foam reduces the temperature of the burning surface and the surfaces adjacent to the fire. As the foam is applied to a surface of the target that is to be protected. The surface of the foam application is normally larger than the fire. The foam also provides protection of the target from heat exposure coming from the side or from below the target. A typical example of this is a fire in a storage system where the fire is beside or below the stored products.

This study focuses on the cooling ability of the foam rather than the extinguishing ability.

In the experiments that are the subject of this thesis, the tests were designed to simulate the conditions where the CAF is discharged at the early stages over the burning object, extinguishing the fire and controlling the temperature of the object as well as limiting the effects on the immediate surroundings. A typical application would be a fire in rack 
storage of flammable liquids in containers where the $\mathrm{CAF}$ is applied in a similar manner as water from sprinkler protection using in-rack sprinklers. [55]

The general application of CAF in extinguishing fires is a foam discharge that lasts several minutes. Based on the literature review, the majority of fires that are fought using compressed-air foam are extinguished within 1 to 3 minutes. Cooling the burning and adjacent surfaces is a critical factor in extinguishing the fire, and controlling the fire spread to surrounding areas. For example, in the case of a fire involving the storage of flammable or combustible liquids in plastic containers, cooling the hot containers will prevent the containers located beside or above the fire from overheating and bursting, thus preventing the fire spread and facilitating the extinguishing of the fire.

The expected energy flows in the experiments are summarized as follows:

- Energy flow from the heat source to the bottom of the container in the form of convection and radiation. (The heated bottom of the container could represent a mass that accumulated energy from a fire or a mass that is being heated by a fire below)

- Energy flow in the form of conduction across the metal floor of the container and the steel plate.

- Energy flow in the form of convection from the steel plate to the foam.

- Energy absorption causing the phase change of water to vapour (evaporation). 
- Energy flow in the form of conduction and due to mass transfer across the foam. There may also be condensation as the vapour travels from the bottom of the foam layer to the top.

- Energy flow in the form of convection and radiation from the foam to the air.

- Energy flow to the environment by the vapour as vapour rises above the foam.

- Energy accumulated in the drained water.

See Fig. 5.1-1 for a graphical representation of the modes of heat and mass transfer..

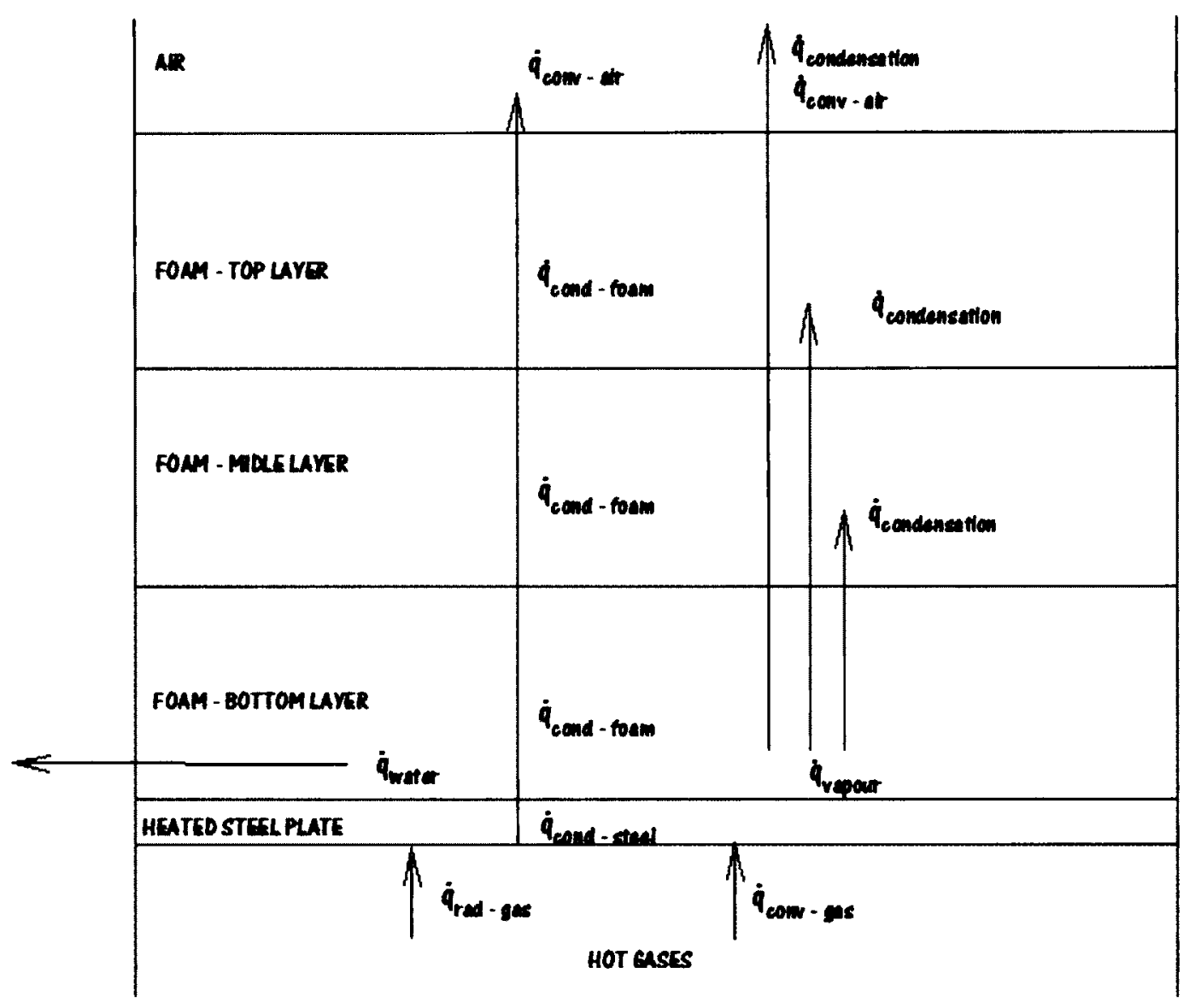

Fig. 5.1-1 Heat flow in the system 
The prediction of heat transfer through the CAF is not straightforward because the foam is not stable with respect to time. The bubble size changes and part of the water content in the foam drains. Some energy is absorbed by the water that is drained. When the temperature of the hot surface is at or above $100^{\circ} \mathrm{C}$, energy is absorbed by the draining water that then changes from liquid to vapour. Small portions of water vapour condense inside the foam layer at temperatures below $100^{\circ} \mathrm{C}$ and release latent energy as they change from vapour to liquid.

If the foam layer is deep, the water evaporation and condensation would act as a heat pump, where the energy would be absorbed by the change of state from water to vapour. The energy would be transported by the water vapour into the foam layer and be released as it condenses.

If most of the vapour condenses within the foam layer, the heat released due to the change of state of vapour to water would be absorbed by the foam. As the energy release is relatively high when water condenses, it is important to determine to what extent the "heat pump" type of energy transfer affects the overall energy flows.

The following physical properties [56] were used for analyses and calculations:

- Water - vapour

$$
\begin{array}{ll}
\text { Specific heat of water } & \mathrm{c}_{\mathrm{pw}}=4.18(\mathrm{~kJ} / \mathrm{kgK}) \\
\text { Latent heat of evaporation } & \mathrm{h}_{\mathrm{fg}}=2,270(\mathrm{~kJ} / \mathrm{kg})
\end{array}
$$


Density of water $\quad \rho_{\mathrm{w}}=1,000\left(\mathrm{~kg} / \mathrm{m}^{3}\right)-\left(1 \mathrm{~g}\right.$ of water occupies $\left.1 \mathrm{~cm}^{3}\right)$

Density of vapour at $100^{\circ} \mathrm{C} \quad \rho_{v}=\left(0.625 \mathrm{~kg} / \mathrm{m}^{3}\right)-(1 \mathrm{~g}$ of vapour occupies $\left.1,600 \mathrm{~cm}^{3}\right)(1 \mathrm{~g}$ of water vapour occupies $1,600 \mathrm{~m} \ell)$ at atmospheric pressure.

- Air

Specific heat of air $\quad c_{p-a i r}=1(\mathrm{~kJ} / \mathrm{kg} \mathrm{K})$

Density of air at $20^{\circ} \mathrm{C} \quad \rho_{\text {air }}=1.205\left(\mathrm{~kg} / \mathrm{m}^{3}\right)$

- CAF

Expansion rate of 1:25 was used in the calculations below:

Water content of CAF $\quad \rho_{\text {caf }-\mathrm{w}}=40\left(\mathrm{~kg} / \mathrm{m}^{3}\right)$

Air content of CAF $\quad \rho_{\text {caf-air }}=1.16\left(\mathrm{~kg} / \mathrm{m}^{3}\right)$

The CAF contains water (including foam concentrate) and air. If $1 \mathrm{~m}^{3}$ is filled with foam, $1 / 25$ of the volume is occupied with water and $24 / 25$ is occupied by air. Therefore :

$$
\rho_{\text {caf -air }}=\rho_{\text {air }}(24 / 25)=1.2059(24 / 25)=1.16\left(\mathrm{~kg} / \mathrm{m}^{3}\right)
$$

The maximum capacity of the energy absorption of the foam is reached when all the water contained in the foam has vaporized. This can be calculated simply as:

$E_{\max }=\Delta T_{100} \rho_{C A F-W} c_{p w}+h_{f g} \rho_{C A F-W}$

As $1 \mathrm{~m}^{3}$ of CAF with an expansion ratio of 1:25 has a mass of approximately $40 \mathrm{~kg}$, for $\mathrm{CAF}$ at initial temperature of $20^{\circ} \mathrm{C}$ the maximum absorption energy is:

$E_{\max }=80 \times 40 \times 4.18+2270 \times 40=13,376+90,800=104,176 \mathrm{~kJ} / \mathrm{m}^{3}$ 
When comparing the energy required to increase the temperature of water from $20^{\circ} \mathrm{C}$ to $100^{\circ} \mathrm{C}$ (the first term in Equation 5.1-2) to the energy required to change the water to vapour at $100^{\circ} \mathrm{C}$ (the second term), it is clear that the evaporation of the foam will play a major part of the heat absorption. What is not clear, is whether the vapour will condense while crossing the foam layer and cause heat transfer to the upper layer of the foam, or whether the vapour will penetrate across the foam layer and escape into the atmosphere.

\subsection{Energy flow in the steel plate and floor}

The energy of the steel floor and the steel plate at ambient temperature is considered as a reference. Energy increase or decrease is with respect to the ambient energy level unless otherwise indicated.

This study concentrates on an automatic discharge of foam over a fire area. The automatic discharge is normally initiated during the early stages of the fire at typical activation times of a sprinkler system. The foam activation is expected within 5 minutes. Tests described in NFPA 13 [15] show that the typical surface temperature of objects affected by the fire was below $200^{\circ} \mathrm{C}$. If not rapidly reduced, these temperatures can damage electronic equipment and can cause overheating and bursting of containers.

Test 1 was conducted to calculate the heat absorption by the container and the steel plate. The steel plate was initially at an ambient temperature of $25^{\circ} \mathrm{C}$ and was heated to $200^{\circ} \mathrm{C}$ and then left to cool. The temperature of the bottom of the floor and the temperature of 
the air below the floor were measured. The temperature of the top of the steel plate, and the air temperature at $10 \mathrm{~mm}, 20 \mathrm{~mm}, 30 \mathrm{~mm}$ and $40 \mathrm{~mm}$ above the floor were also measured. See Fig. 5.2-1 for the test results.

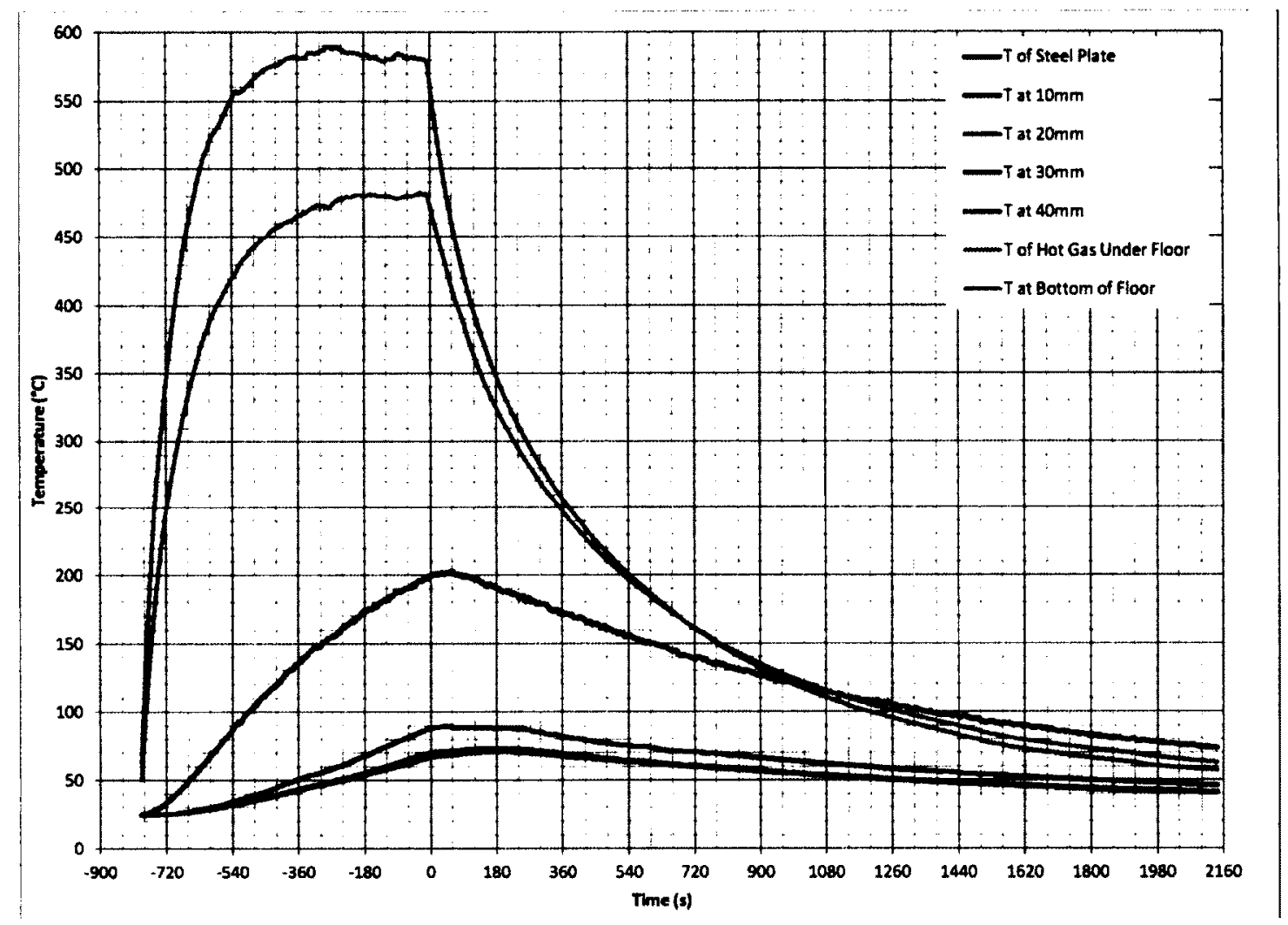

Fig. 5.2-1 Test 1 - Container heated to $200^{\circ} \mathrm{C}$ with no foam

When the floor of the container was heated, the container and the steel plate absorbed energy (heat) by convection and radiation. Heat was then conducted across the steel floor and steel plate resulting in a large temperature gradient across the floor during the heating phase of the experiment. When the temperatures of the container floor, walls and the steel plate temperature were higher than the surrounding air, heat was convected to 
the surrounding air. The temperatures measured at the bottom of the floor and below the floor dropped below the temperatures measured at the top surface of the steel plate after $t=1000$ seconds. This is due to the large surface area of the floor and walls, air gap between the floor and the steel plate and the large thermal mass of the steel plate.

To simplify the calculations, the following approximations were made:

- It was assumed that the temperature below the floor was uniform.

- It was assumed that the temperature of the floor was uniform, which is consistent with the assumption above.

- The wall temperatures were measured at different heights above the floor and the average of these temperatures was used (approximately $30^{\circ} \mathrm{C}$ lower than the temperature of the top of the floor).

- The wall temperatures were measured at different heights below the floor and the average of these temperatures was used (approximately $10^{\circ} \mathrm{C}$ lower than the temperature of the bottom of the floor).

- The air temperature measured at $20 \mathrm{~mm}$ above the steel plate was used for the calculations of the heat convection from the top of the steel plate to the air above the steel plate. From Figure 5.2-1 it is observed that temperatures above $20 \mathrm{~mm}$ are outside of the summit so that they are above the boundary level.

- The air temperature measured at $20 \mathrm{~mm}$ above the floor was also used for the calculations of the heat convection from the walls above the floor to the air above the steel plate. 
- The temperature measured at the top of the steel plate was used for the calculation of the heat convection from the steel plate to the air above the steel plate.

- Propane flame temperature of $1,600 \mathrm{~K}$ was used for the calculations. The literature gives values of $1,600 \mathrm{~K}$ for a propane flame. [57]

- The flame diameter was estimated at $95 \mathrm{~mm}$, hence the area for radiation was assumed to be the surface of the flame diameter $-0.0072 \mathrm{~m}^{2}$. The flame was approximately $50 \mathrm{~mm}$ from the bottom of the wall.

- Emissivity used was: of the flames 0.70 , of walls 0.90 and of air 0.7 [58].

- To determine the amount of radiation from the flame that affects the impact surface depends on the geometry and is referred to as configuration factor. If the container would surround the flame, the configuration factor would be 1 . The $50 \mathrm{~mm}$ space between the bottom of the wall and the flame was approximated by a cylinder having a radius of $150 \mathrm{~mm}$ and a height of $50 \mathrm{~mm}$. The area was calculated to be $2 \pi \mathrm{rh}=47,123 \mathrm{~mm}^{2}$. The total area with configuration factor of 1 was estimated by a half sphere having a radius of $150 \mathrm{~mm}$. The area of the half sphere was calculated to be $4 \pi^{2} / 2=141,373 \mathrm{~mm}^{2}$. The configuration factor is :

$$
F_{1-2}=\frac{2 \pi r h-4 \pi r^{2} / 2}{2 \pi r^{2}}
$$

The percentage of area exposed to radiation was approximately $67 \%$. Therefore, a configuration factor of 0.67 was used.

- The radiation absorption through hot air was ignored due to short distances between the flame and the container. 
The transient energy flows inside the steel plate were not calculated but the energy transfer in and out of the container and the steel plate was approximated by calculating energy gained and lost by radiation and convection using the following equation:

$$
\begin{aligned}
& \dot{q}_{c}(t)=\left\{A_{F} h_{b}\left[T_{A b}(t)-T_{F b}(t)\right]\right\}+\left\{A_{W b} h_{w}\left[T_{A b}(t)-T_{W b}(t)\right]\right\} \\
& -\left\{A_{F} h_{t}\left[T_{F t}(t)-T_{A 20}(t)\right]\right\}-\left\{A_{w_{t}} h_{w}\left[T_{w b}(t)-T_{A 20}(t)\right]\right\} \\
& +\left\{F_{1-d} \varepsilon_{\text {flame }} \sigma A_{\text {flame }}\left[T_{\text {flame }}^{4}\right]\right\}+\left\{\varepsilon_{a-s} \sigma A_{W b}\left[T_{W b}^{4}-T_{A b}^{4}\right]\right\}+\left\{\varepsilon_{a-s} \sigma A_{F}\left[T_{F b}^{4}(t)-T_{A b}^{4}(t)\right]\right\} \\
& -\left\{\varepsilon_{a-s} \sigma A_{F}\left[T_{F t}^{4}(t)-T_{A 20}^{4}(t)\right]\right\}-\left\{\varepsilon_{a-s} \sigma A_{W t}\left[T_{W t}^{4}(t)-T_{A 20}^{4}(t)\right]\right\}
\end{aligned}
$$

Where:

$\dot{q}_{c}=$ rate of heat (energy) accumulation in the container floor and the steel plate $(\mathrm{kJ} / \mathrm{s})$

$A_{F}=$ container floor area $\left(\mathrm{m}^{2}\right)=0.961 \mathrm{~m}^{2}$

$A_{W b}=$ container wall area below floor $\left(\mathrm{m}^{2}\right)=0.248 \mathrm{~m}^{2}$

$A_{W t}=$ container wall area above floor $\left(\mathrm{m}^{2}\right)=0.372 \mathrm{~m}^{2}$

$A_{\text {flame }}=$ area of flame diameter $\left(\mathrm{m}^{2}\right)=0.0072 \mathrm{~m}^{2}$

$h_{b}=$ convection heat transfer coefficient for air affecting bottom (ceiling) $\left(\mathrm{kW} / \mathrm{m}^{2} \mathrm{~K}\right)=$ $9.0 \mathrm{~W} / \mathrm{m}^{2} \mathrm{~K}$

$h_{w}=$ convection heat transfer coefficient for air affecting walls $\left(\mathrm{kW} / \mathrm{m}^{2} \mathrm{~K}\right)=8 \mathrm{~W} / \mathrm{m}^{2} \mathrm{~K}$ $h_{t}=$ convection heat transfer coefficient for air affecting top (roof) $)\left(\mathrm{kW} / \mathrm{m}^{2} \mathrm{~K}\right)=9$ $\mathrm{W} / \mathrm{m}^{2} \mathrm{~K}$

$T_{A b}=$ air temperature below the floor $(\mathrm{K})$

$T_{A 20}=$ air temperature $20 \mathrm{~mm}$ above the floor $(\mathrm{K})$

$T_{A 40}=$ air temperature $40 \mathrm{~mm}$ above the floor $(\mathrm{K})$ 
$T_{F b}=$ temperature bottom of the floor $(\mathrm{K})$

$T_{F t}=$ temperature top of the floor $(\mathrm{K})$

$T_{\text {Flame }}=$ temperature top of the flame $(\mathrm{K})$

$T_{W t}=$ temperature of the wall top of the floor $(\mathrm{K})$

$T_{F b}=$ temperature of the wall bottom of the floor $(\mathrm{K})$

$F_{l-d}=$ configuration factor -0.67

$\varepsilon_{\text {flame }}=$ emissivity of flame $=0.70$

$\varepsilon_{a-s}=$ effective emissivity combined of steel plate and air $=0.65$

$\sigma=$ Stefan Boltzmann constant $=5.67 \times 10^{-8}\left(\mathrm{Wm}^{-2} \mathrm{~K}^{-4}\right)$

$t_{0}=$ time of ignition of the burner

$t_{1}=$ time when the burner is turned off

$t_{2}=$ time when the temperature of steel plate drops to $75^{\circ} \mathrm{C}$

$\Delta \mathrm{t}=$ time $\operatorname{step}(2 \mathrm{~s})$

The air flows above the steel plate were not expected to be turbulent. The radiant heat flow was much greater than the heat flow due to convection Therefore values for convection heat transfer for laminar flows were used to simplify the calculations. The values used for heat transfer coefficient were taken from "Fire dynamics 1" [59].

Therefore, the energy accumulated in the container and the steel plate can be calculated by integrating equation $5.2-1$ : 


$$
\begin{aligned}
& \dot{q}_{c}(t)=\left\{A_{F} h_{b} \int_{t_{0}}^{t_{2}}\left[T_{A b}(t)-T_{F b}(t)\right] d t\right\}+\left\{A_{W b} h_{w} \int_{t_{0}}^{t_{2}}\left[T_{A b}(t)-T_{W b}(t)\right] d t\right\} \\
& -\left\{A_{F} h_{t} \int_{t_{0}}^{t_{2}}\left[T_{F t}(t)-T_{A 20}(t)\right] d t\right\}-\left\{A_{W t} h_{W} \int_{t_{0}}^{t_{2}}\left[T_{W t}(t)-T_{A 20}(t)\right] d t\right\} \\
& +\left\{F_{1-d} \varepsilon_{\text {flame }} \sigma A_{f l a m e} \int_{t_{0}}^{t_{1}}\left[T_{f l a m e}^{4}\right] d t\right\}+\left\{\varepsilon_{a-s} \sigma A_{W b} \int_{t_{0}}^{t_{2}}\left[T_{A b}^{4}(t)-T_{W b}^{4}(t)\right] d t\right\} \\
& +\left\{\varepsilon_{a-s} \sigma A_{F} \int_{t_{0}}^{t_{2}}\left[T_{A b}^{4}(t)-T_{F b}^{4}(t)\right] d t\right\}-\left\{\varepsilon_{a-s} \sigma A_{F} \int_{t_{0}}^{t_{2}}\left[T_{F t}^{4}(t)-T_{A 20}^{4}(t)\right] d t\right\} \\
& -\left\{\varepsilon_{a-s} \sigma A_{W t} \int_{t_{0}}^{t_{2}}\left[T_{W t}^{4}(t)-T_{A 20}^{4}(t)\right] d t\right\}
\end{aligned}
$$

The integral can be approximated by a sum of average temperature differences over a short period of time and the equation 5.2-2 can be re-written as:

$$
\begin{aligned}
& Q_{c}=\left\{A_{F} h_{b} \sum_{i=t_{0}}^{t_{2} / 2}\left[T_{A b}(2 i)-T_{F b}(2 i)\right] \Delta t\right\}+\left\{A_{W b} h_{w} \sum_{i=t_{0}}^{1 / 2}\left[T_{A b}(2 i)-T_{W b}(2 i)\right] \Delta t\right\} \\
& -\left\{A_{F} h_{t} \sum_{i=t_{0}}^{2 / 2}\left[T_{F t}(2 i)-T_{A 20}(2 i)\right] \Delta t\right\}-\left\{A_{W t} h_{w} \sum_{i=t_{0}}^{t / 2}\left[T_{W t}(2 i)-T_{A 20}(2 i)\right] \Delta t\right\} \\
& +\left\{F_{1-d} \varepsilon_{\text {flame }} \sigma A_{\text {flame }} \sum_{i=t_{0}}^{t_{1}^{\prime 2}}\left[T_{\text {flame }}^{4}(2 i)\right] \Delta t\right\}+\left\{\varepsilon_{a-s} \sigma A_{W b} \sum_{i=t_{0}}^{t^{\prime 2}}\left[T_{W b}^{4}(2 i)-T_{F b}^{4}(2 i)\right] \Delta t\right\}+ \\
& \left.+\left\{\varepsilon_{a-s} \sigma A_{F}\right) \sum_{i=t_{0}}^{2^{\prime 2}}\left[T_{A b}^{4}(2 i)-T_{F b}^{4}(2 i)\right] \Delta t\right\}-\left\{\varepsilon_{a-s} \sigma A_{F} \sum_{i=t_{0}}^{z^{\prime 2}}\left[T_{F t}^{4}(2 i)-T_{A 20}^{4}(2 i)\right] \Delta t\right\} \\
& -\left\{\varepsilon_{a-s} \sigma A_{w t} \sum_{i=t_{0}}^{t^{\prime 2}}\left[T_{W t}^{4}(2 i)-T_{A 20}^{4}(2 i)\right] \Delta t\right\}
\end{aligned}
$$

The energy accumulated in the container and the steel plate was calculated using an Excel spread sheet from $t_{0}=-788$ seconds to $t_{1}=0$ seconds. As the burner was shut at $t=0$ the calculations for radiation from the flame were executed from $t_{0}=-788$ seconds to $t_{1}=0$ seconds. The calculated absorbed heat was $834 \mathrm{~kJ}$. 
Once the burner was shut off, the radiation was no longer present and the calculation of heat loss did not contain the flame radiation term and the calculation was terminated when the steel plate temperature dropped to $75^{\circ} \mathrm{C}$.

The heat loss from $t_{1}=0$ seconds to $t_{2}=2142$ seconds was calculated to be $562 \mathrm{~kJ}$.

The energy remaining in the container and the steel plate was calculated using the following equation:

$\mathrm{Q}=\mathrm{c}_{\mathrm{p}} \rho_{s} \mathrm{v}_{\mathrm{s}} \Delta \mathrm{T}$

where

$\mathrm{c}_{\mathrm{p}}=$ specific heat of steel $=434\left(\mathrm{~J} \mathrm{~kg}^{\circ} \mathrm{K}\right)$

$\rho_{\mathrm{s}}=$ steel density $=7854 \mathrm{~kg} / \mathrm{m}^{3}$

$v_{s}=$ volume of steel $\left(\mathrm{m}^{3}\right)$

$\Delta \mathrm{T}=$ change of temperature $\left({ }^{\circ} \mathrm{C}\right.$ or $\left.\mathrm{K}\right)$

The volume of container $=$

$(0.5 \times 0.31 \times 4 \times 0.0016)+(0.31 \times 0.31 \times 0.0016)=0.0011 \mathrm{~m}^{3}$

The volume of steel plate $=0.3 \times 0.3 \times 0.00635=0.0006 \mathrm{~m}^{3}$

The total volume is $0.0017 \mathrm{~m}^{3}$

The energy left in the container is:

$\mathrm{Q}=\mathrm{c}_{\mathrm{p}} \rho_{\mathrm{s}} \mathrm{v}_{\mathrm{s}} \Delta \mathrm{T}=434 \times 7854 \times 0.0017 \times 50=292,675 \mathrm{~J}=293 \mathrm{~kJ}$ 
The total energy gain and loss should be the same. In this case the energy summary is:

\begin{tabular}{ll} 
Energy gained from $25^{\circ} \mathrm{C}$ to $200^{\circ} \mathrm{C}$ & $839 \mathrm{~kJ}$ \\
Energy loss from $200^{\circ} \mathrm{C}$ to $75^{\circ} \mathrm{C}$ & $-562 \mathrm{~kJ}$ \\
\hline Energy left in the system & $-293 \mathrm{~kJ}$ \\
\hline Total / error & $-16 \mathrm{~kJ}$
\end{tabular}

As the calculations included a number of approximations, the proximity of the result to meet the energy conservation principle, demonstrated that the assumptions and approximations were within an acceptable range.

\section{$\underline{5.3 \quad \text { Foam expansion }}$}

Usually the disintegration of the foam is due to the collapsing of foam bubbles and can be explained using the ideal gas law [57]. The air temperature increases, the air volume also increases and the bubble expands. The increase of volume causes the bubble to burst and the wall of the bubble to collapse when the strength and elasticity (surface tension) of the bubble is exceeded. [11]

The change of air pressure in the bubble can be calculated using the following expression:

$P V=n R T$

For a temperature change from $20^{\circ} \mathrm{C}\left(293.5^{\circ} \mathrm{K}\right)$ to $80^{\circ} \mathrm{C}\left(353.5^{\circ} \mathrm{K}\right)$, the change of pressure and volume can be calculated as shown in equation 5.3-1: 
$\mathrm{PV}_{353} / \mathrm{PV}_{293}=(353.5 / 293.5)=1.2$

The pressure times the volume is directly proportional to the change of temperature in degree $\mathrm{K}$. As the pressure that the bubble surface can withstand is relatively small, the volume change will play a role in the disintegration of the foam.

If the drained water is heated and evaporates, than the vapour will also affect the foam. When the water is evaporated, the volume of vapour is approximately 1,600 times greater than it's volume when in liquid form.

In case of foam having a volume $\left(\mathrm{V}_{\mathrm{f}}\right)$ and an expansion ratio of $1: 25$, if $\mathrm{X \%}\left(\mathrm{W}_{\mathrm{p}}\right)$ of water would drain and evaporate, the volume of vapour $V_{v}$ would be:

$$
V_{v}=\left(V_{f} / 25\right)\left(W_{p} / 100\right) 1600=V_{f} W_{p} 0.64
$$

For example, if $10 \%$ of water drains and evaporates, the volume of generated vapour is 6.4 times greater than the original volume of the foam. This causes the vapour penetration across the foam layer.

To investigate the vapour absorption ability of the foam, the steel plate was removed from the floor and a thin layer of insulation was installed under the floor to reduce the 
rate of temperature rise of the floor of the container. The container was filled with foam and the floor of the container was slowly heated to maintain the floor temperature at approximately $100^{\circ} \mathrm{C}$. The foam used was CAF made of $3 \%$ AR-FFF concentrate with expansion ratio of $1: 25$.

In the experiment, as the heat started to affect the foam, water started draining from the foam and the volume of the bubbles and the foam started to increase. In Fig 5.3-1, the initial foam height was $70 \mathrm{~mm}$ and the expansion caused the height to increase to a maximum of $300 \mathrm{~mm}$. The foam surface temperature did not exceed $55^{\circ} \mathrm{C}$.
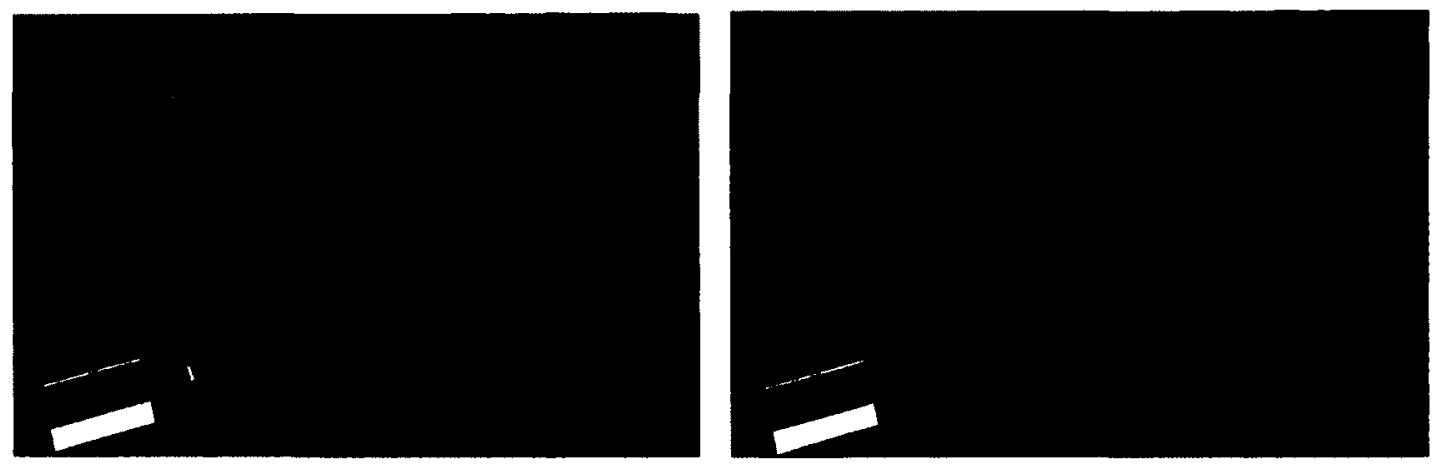

Fig. 5.3-1 Foam height expansion example

See Figure 5.3-2 for the graph of recorded temperatures and Figure 5.3-3 for the graph of foam height. 


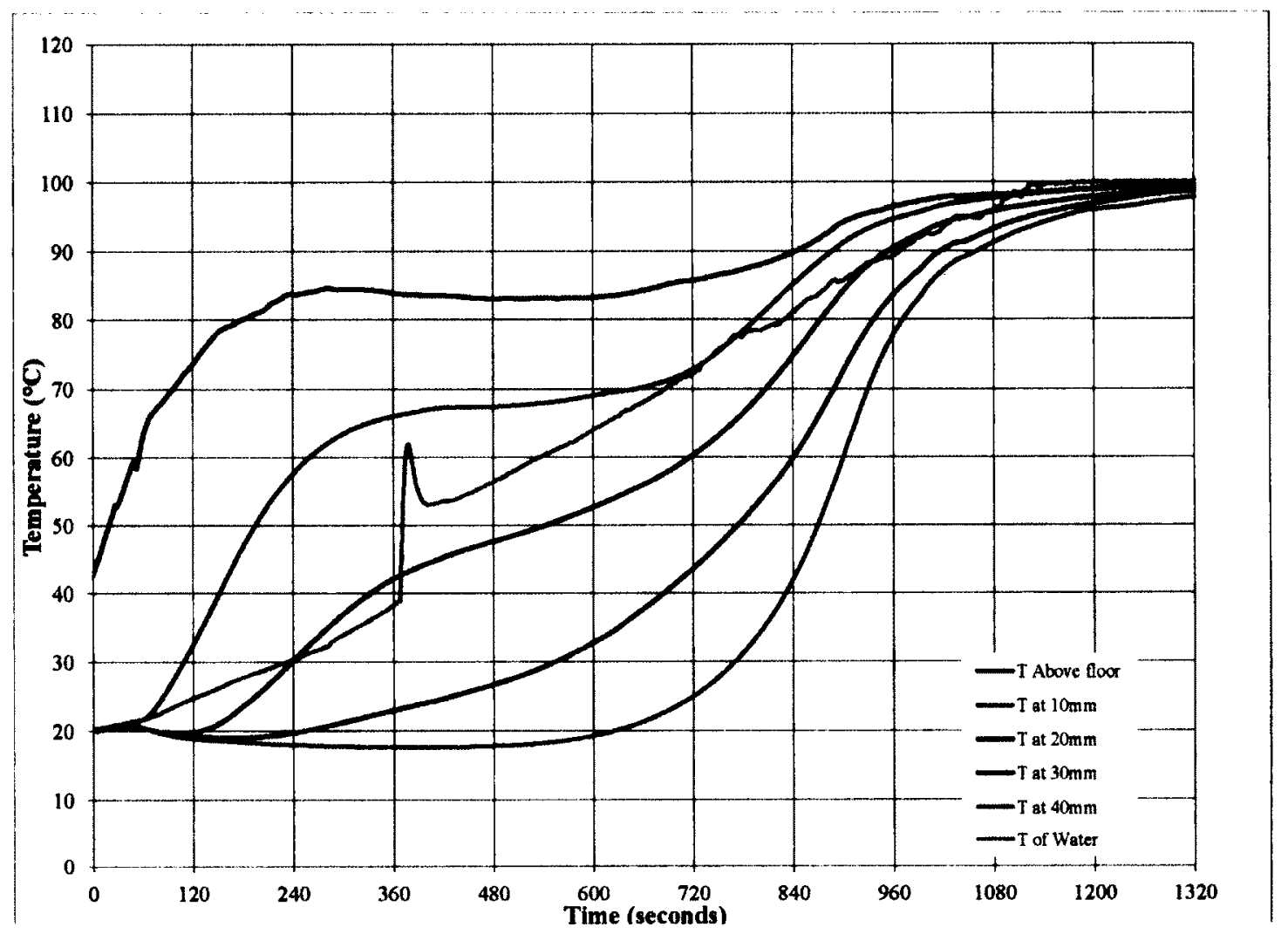

Fig. 5.3-2 Foam temperatures - vapour test

At approximately 360 seconds, foam started to disintegrate and water started to drain. This can be observed on Fig 5.3-2 by a sharp increase in temperature measured at the water drain outlet. ("T of water"). As the floor temperature was approaching $100^{\circ} \mathrm{C},(760$ seconds) the foam height increased linearly to a maximum height of $300 \mathrm{~mm}$ as can be observed on Fig. 5.3-3. 


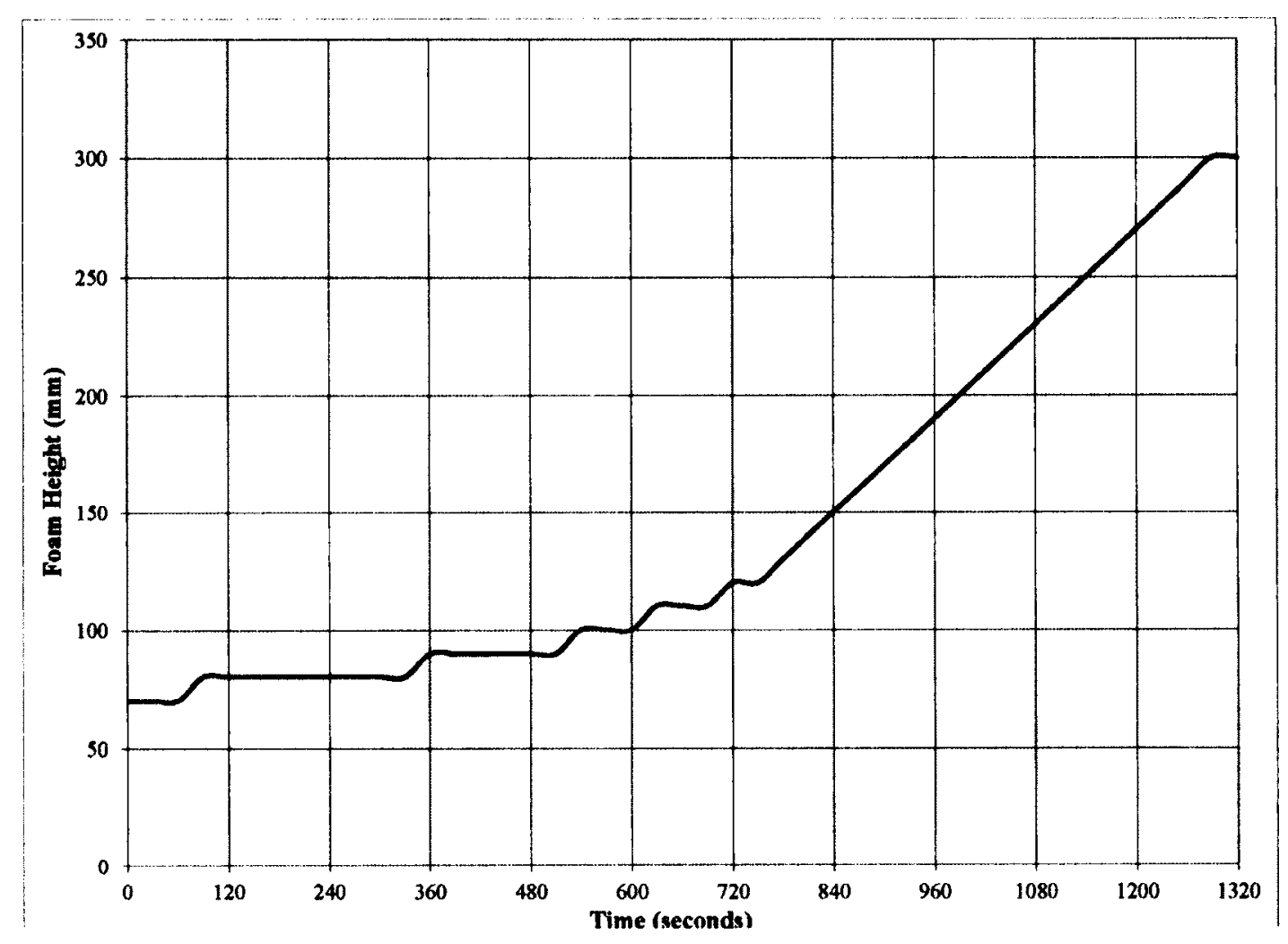

Fig. 5.3-3 Foam height - vapour test

Based on the above described experiment the maximum foam absorption of the vapour can be calculated. The expansion due to the air temperature and foam collapsing was considered negligible when compared with the expansion caused by the vapour.

$V_{f}=70 \times 310 \times 310=6,727,000 \mathrm{~mm}^{3}$

$V_{f}+V_{v}=300 \times 310 \times 310=28,830,000 \mathrm{~mm}^{3}$

$\mathrm{V}_{\mathrm{v}}=28,830,000-6,727,000=22,103,000 \mathrm{~mm}^{3}$

$\mathrm{W}_{\mathrm{p}}=\mathrm{V}_{\mathrm{v}} /\left(0.64 \mathrm{~V}_{\mathrm{f}}\right)=5.1 \%$

The maximum vapour captured in the foam, when the foam is heated slowly was determined to be $5.1 \%$. 


\subsection{Rate of vapour condensation experiments}

To determine whether the vapour is absorbed by the foam and condenses within the foam layer, the following experiments were carried out.

The foam holding tank as described in section 4.2 .3 was used. A $6.35 \mathrm{~mm}$ thick steel plate was placed directly on the floor of the heat transfer foam holding tank. A thermocouple was attached to the top surface of the steel plate. The floor of the tank was heated with a gas burner and the temperature on the top of the steel plate was monitored. When the desired temperature was reached, the burner was shut off. The temperature on the top of the steel plate surface continued to climb several degrees due to the heat conduction from the bottom of the steel plate. The climb of temperature measured at the top of the steel plate is represented by a curve "T of steel plate" on Fig. 5.2-1. ("T of steel plate" refers to temperature measured at the top of the steel plate for all experiments.) After reaching the maximum temperature, the temperature of the steel plate surface started to decrease, and when the surface temperature reached the desired temperature, all the foam produced from the pre-measured water and foam concentrate mix was sprayed over the hot steel plate. See Fig. 5.4-1

The temperature of the steel plate was monitored. The foam was left to disintegrate completely, and all liquid (foam solution) drained from the foam was collected and the mass of the liquid was measured. 


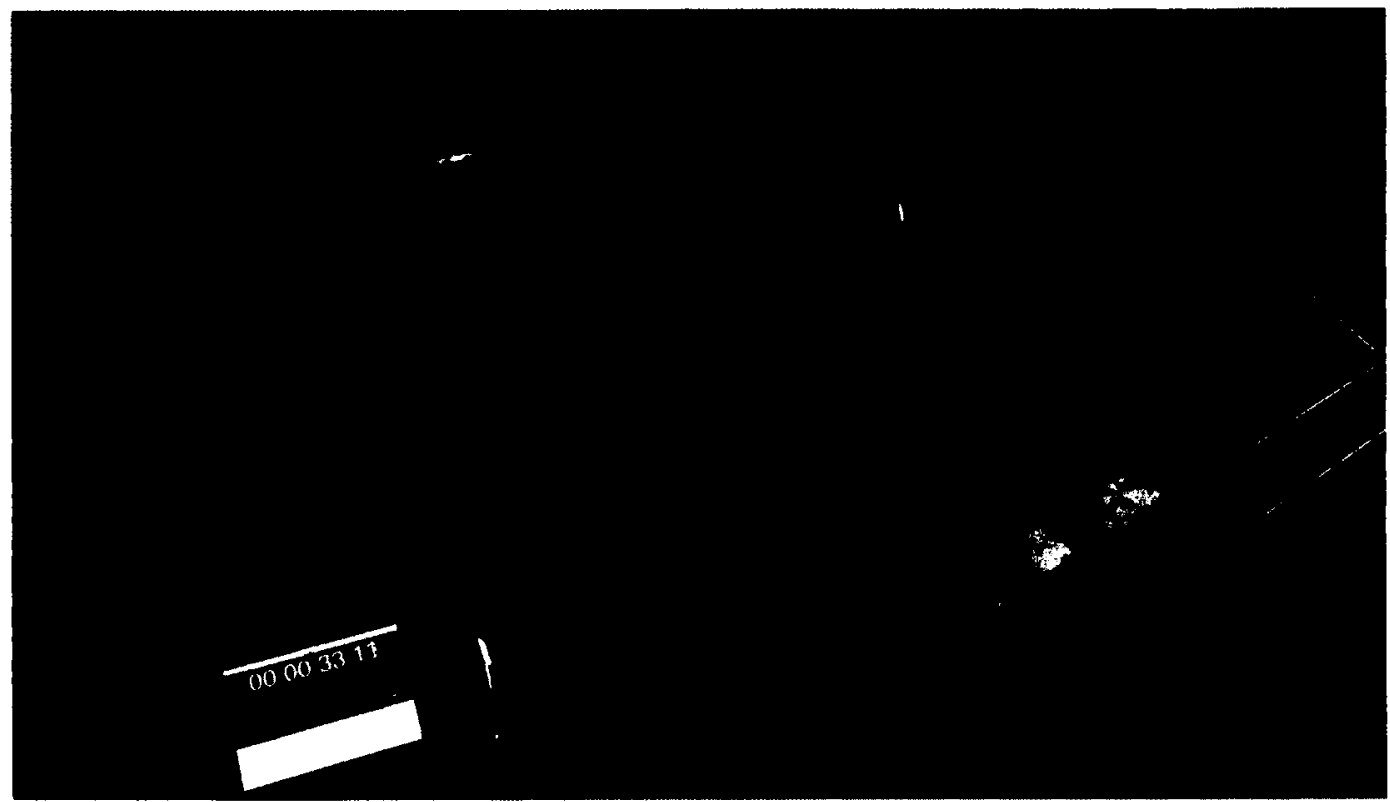

\section{Fig. 5.4-1 Filling the tank with foam}

\subsubsection{Test 1A}

In Test $1 \mathrm{~A}, 200 \mathrm{cc}$ of water foam solution was used and its mass was measured to be $197.8 \mathrm{~g}$. The foam was CAF using 3\% AFFF AR foam concentrate and an expansion ratio of $1: 25$. The foam was sprayed over the $6.35 \mathrm{~mm}$ thick steel plate that was at $200^{\circ} \mathrm{C}$ at the time that the foam was inserted. Fig. 5.4.1-1 shows the temperatures being recorded during the test. As the thermocouple that measured the temperature of the drained water was located inside the drain pipe and the drain pipe was located below the container floor, the temperature surrounding the thermocouple was affected by the heating of the container. 
The burner was ignited at $t=-600$ seconds and the steel plate temperature started climbing. The burner was turned off at $t=-150$ seconds. The surface temperature continued to climb to $206^{\circ} \mathrm{C}$, then started to drop and reached $200^{\circ} \mathrm{C}$ at $\mathrm{t}=0$ seconds. At that time, the foam was inserted into the container. The initial foam height was $40 \mathrm{~mm}$. The steel plate surface temperature dropped rapidly and almost instantly after the insertion of the foam, vapour started bubbling and escaping through the top of the foam layer. The bubbling and escaping of the vapour from the foam layer stopped after approximately 180 seconds.

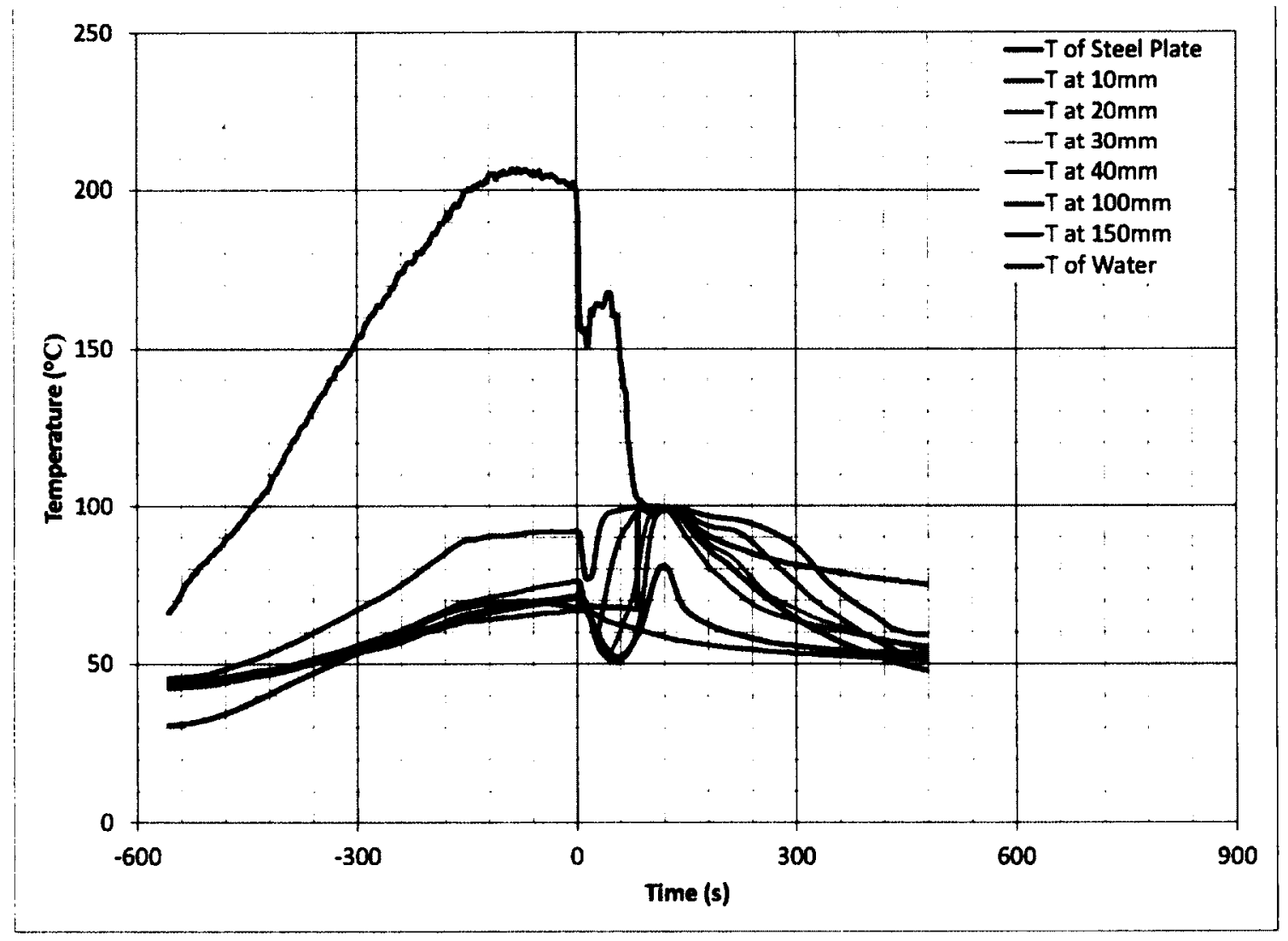

Fig. 5.4.1-1 Test $1 \mathrm{~A}-200$ cc of AFFF AR, 3\%, expansion ratio 1:25, $200^{\circ} \mathrm{C}$ 
As the drainage rate from the foam was limited, and when rate of evaporation was higher than the drainage rate, the surface temperature increased then dropped until the surface temperature reached $100^{\circ} \mathrm{C}$. This was represented by a temperature peak within $\mathrm{t}=0$ seconds to $t=60$ seconds of the recorded temperature at the top of the steel plate. The evaporation rate was slower after the surface temperature descended to $100^{\circ} \mathrm{C}$ and some of the drained liquid no longer evaporated, but started to flow from the floor drain and, as a result, the temperature measured at the outlet of the drain increased sharply. This was represented by a sharp increase of temperature taken at the drain and represented by a curve "T of water". As the floor surface dropped to $100^{\circ} \mathrm{C}$, the foam height started to increase and in approximately 1 minute reached a height of $100 \mathrm{~mm}$. This explains the peak in temperature $100 \mathrm{~mm}$ above the floor.

Small amounts of vapour remained trapped by the foam, which was represented by the temperatures at $10 \mathrm{~mm}$ and $20 \mathrm{~mm}$ being actually higher than the temperature of the steel plate from $120 \mathrm{~s}$ until about $300 \mathrm{~s}$. As the foam disintegrated the trapped vapour escaped to the atmosphere.

At approximately 2 minutes, the foam started to collapse and the temperatures started to decrease. The floor surface temperature remained relatively high due to the heat flow across the steel plate from below. Most of the foam had evaporated by approximately $\mathrm{t}=330$ seconds. 


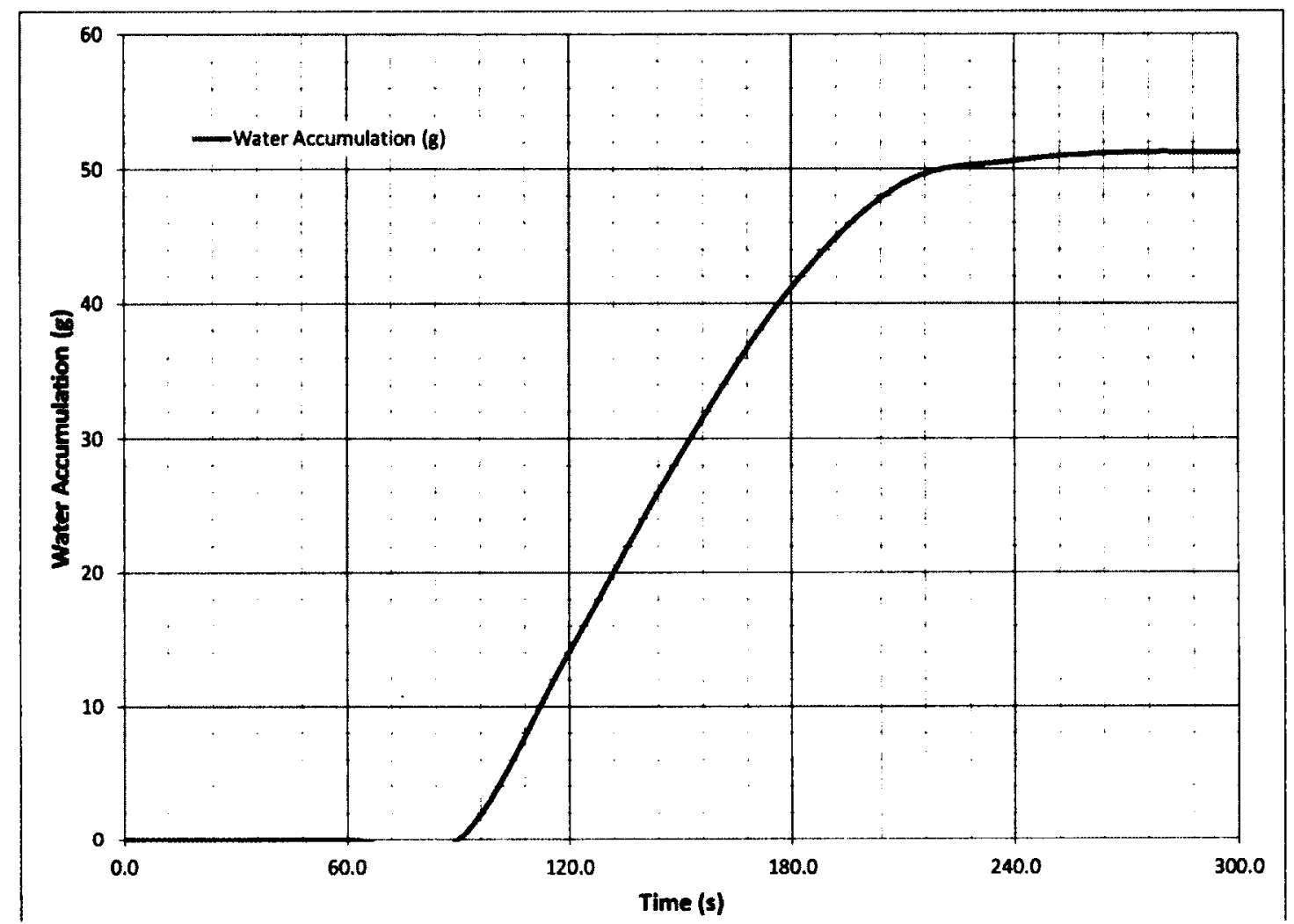

\section{Fig. 5.4.1-2 Test 1A - Water accumulation}

The mass of the water drained was measured during the experiment and plotted. See Figure 5.4.1-2. The water accumulation was recorded in 30 second intervals. The flow rate in $\mathrm{ml} / \mathrm{s}$ was calculated and plotted with respect to time. See Fig. 5.4.1-3. As the flow rates were calculated using water accumulation at 30 second intervals, the graphs of the flow rate are approximations.

At approximately $t=240$ seconds most of the water content of the foam had drained and the foam collapse rate increased. At that time the foam surface dropped to $40 \mathrm{~mm}$ above the steel floor. This can be seen by a faster rate of temperature decrease measured at 
$10 \mathrm{~mm}, 20 \mathrm{~mm}$ and $30 \mathrm{~mm}$ heights from the floor in Fig 5.4.1-1. The curves measuring temperatures above the foam level ( $\mathrm{T}$ at $40 \mathrm{~mm}, \mathrm{~T}$ at $100 \mathrm{~mm}$ and $\mathrm{T}$ at $150 \mathrm{~mm}$ ) did not show a faster rate of temperature decrease after 240 seconds.

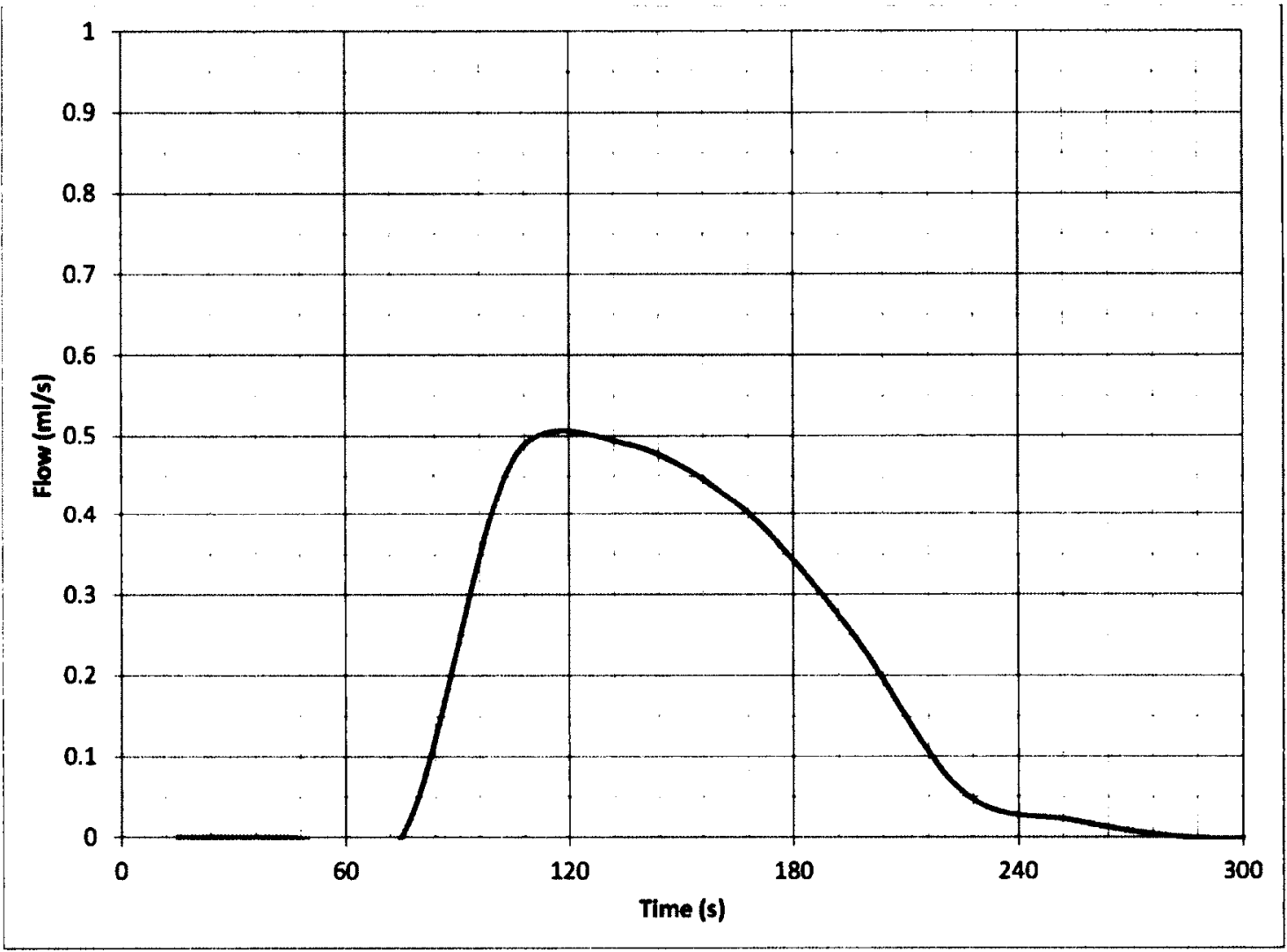

Fig. 5.4.1-3 Test 1A - Foam water drainage rate

The mass of the drained water that was collected was measured at $51.2 \mathrm{~g}$. As the initial mass of the liquid was $197.8 \mathrm{~g}$, the mass of the vapour that escaped through the foam was calculated to be $146.6 \mathrm{~g}$. 
It should be noted that the drained water causes wetting of some combustibles and therefore may be very important in firefighting of combustibles that absorb water.

The following tests 1B to 5A were similar to 1A with the exception of foam type, foam quantity and initial steel plate temperature. The measurements were same.

\subsubsection{Test 1B}

In Test $1 \mathrm{~B}, 400 \mathrm{cc}$ of water foam solution was used. The weight was measured to be 396.1 g. The foam was CAF using 3\% AFFF AR foam concentrate and an expansion ratio of 1:25. The foam was sprayed over the $6.35 \mathrm{~mm}$ thick steel plate that was at $200^{\circ} \mathrm{C}$ at the time that the foam was inserted. Fig. 5.4.2-1 shows the temperatures recorded during the test. The burner was turned off at $t=-380$ seconds. The steel temperature did not climb to $200^{\circ} \mathrm{C}$ so the burner was restarted at $\mathrm{t}=-240$ seconds and turned off again at $t=-160$ seconds. The foam was inserted at $t=0$ seconds. It was noticed that the vapour penetration through the top of the foam had stopped after approximately 180 seconds. This was similar to the results of Test $1 \mathrm{~A}$ where half of the foam volume was used. The foam level immediately after the insertion of the foam was $80 \mathrm{~mm}$.

The foam behavior was very similar to Test $1 \mathrm{~A}$. The floor temperature dropped and then fluctuated due to the limited available water drainage. The water flow through the floor drain started approximately 1.5 minutes after the insertion of the foam as can be observed by a sharp increase in the temperature of the drained water. See Fig. 5.4.2-2 for the measured water drainage and the rate of drainage on Fig. 5.4.2-3. 


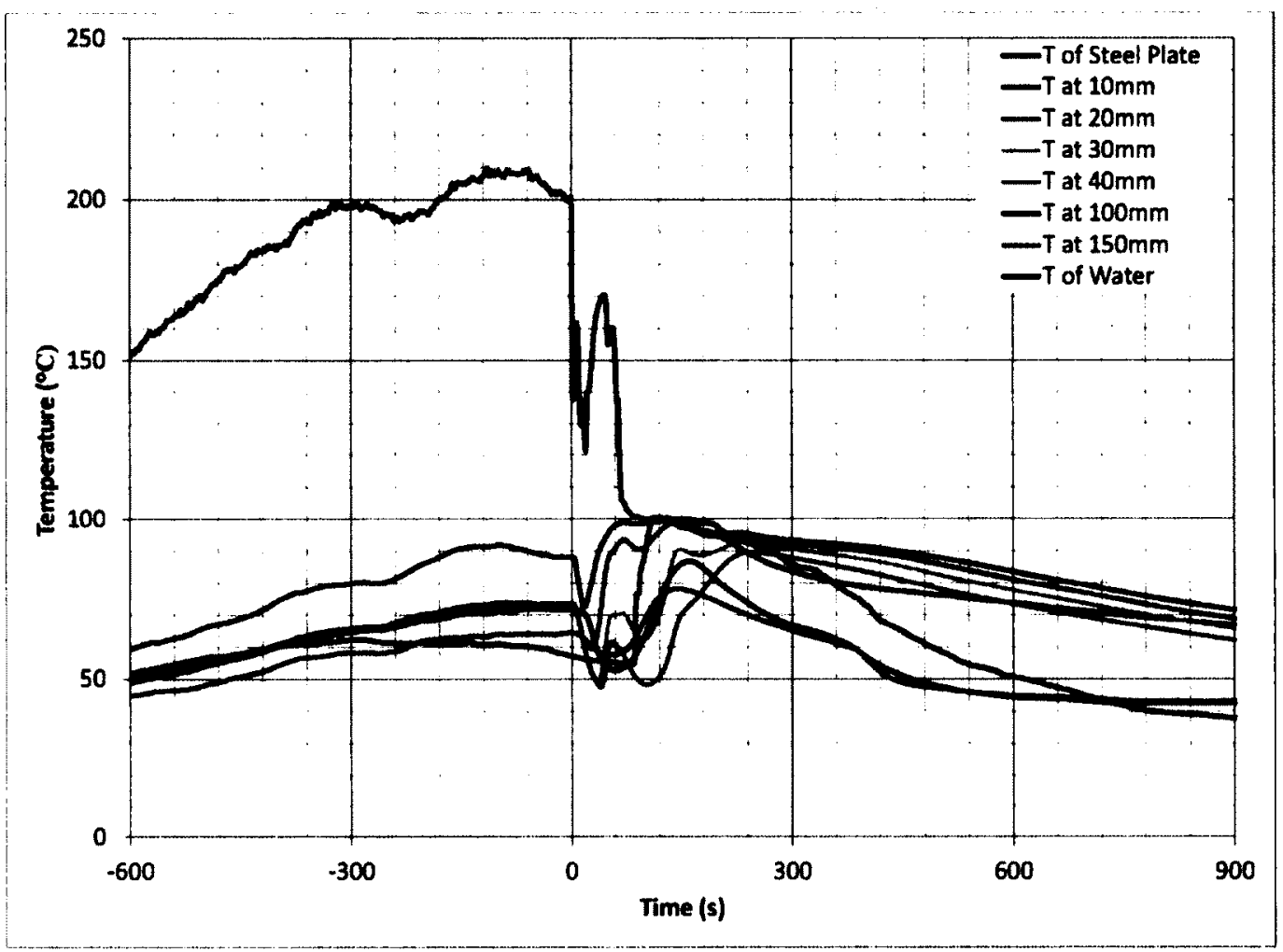

Fig. 5.4.2-1 Test $1 B-400$ ce of AFFF AR, $3 \%$, expansion ratio $1: 25,200^{\circ} \mathrm{C}$

Small amounts of vapour remained trapped by the foam, which explains the temperature of the steel plate being lower than the temperatures measured in the foam layer for times greater than 180 seconds. Similarly to Test $1 \mathrm{~A}$, as the water drainage significantly decreased at $t=420$ seconds. The rate of temperature decrease measured at $10 \mathrm{~mm}, 20$ $\mathrm{mm}$ and $30 \mathrm{~mm}$ above the floor was greater. As the amount of foam in this test was double than in Test $1 \mathrm{~A}$, the rate of water drainage increased substantially. 


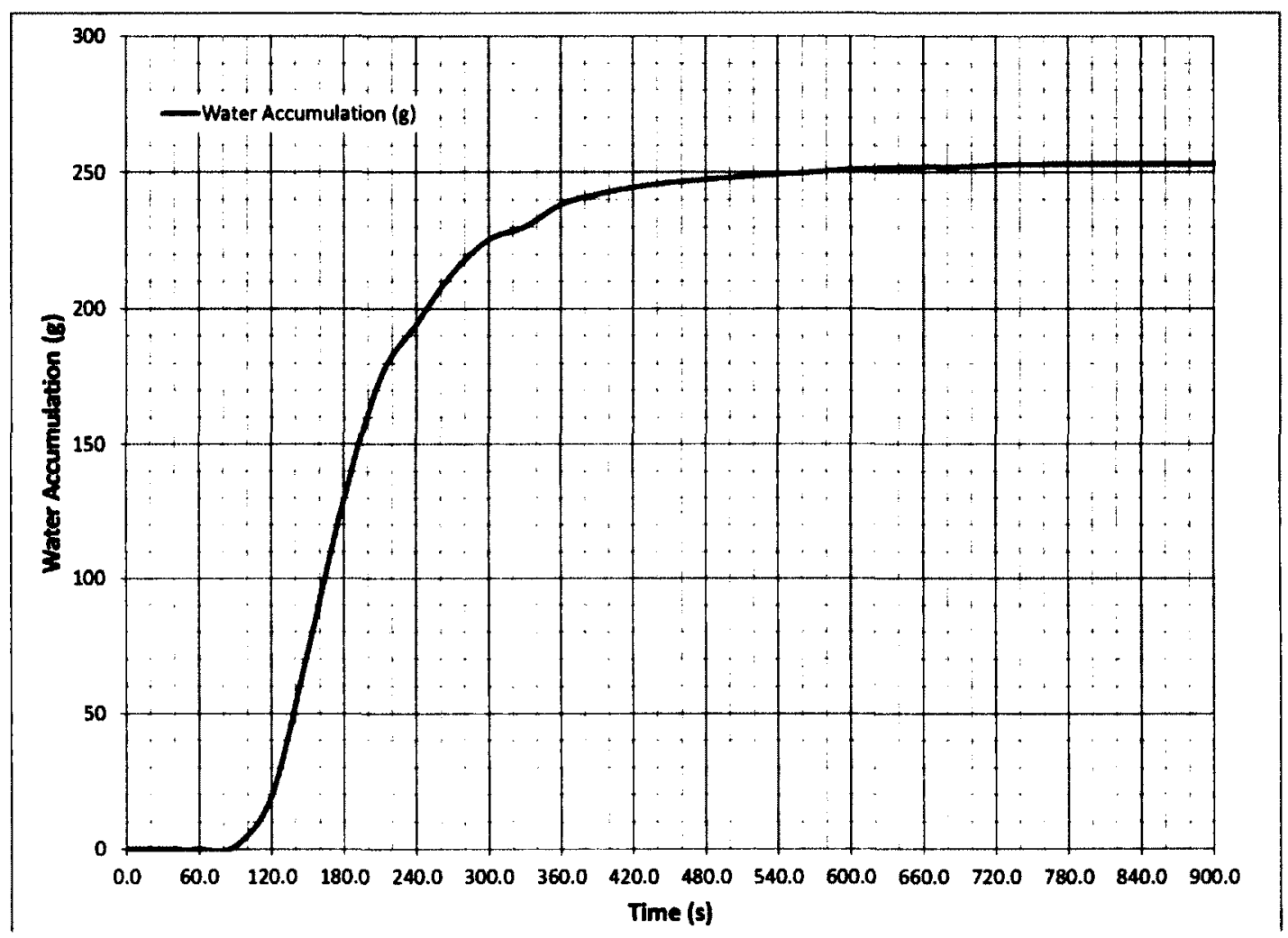

Fig. 5.4.2-2 Test 1B - Water accumulation

The mass of the drained water that was collected was $255.4 \mathrm{~g}$. As the initial mass of the liquid was $396.1 \mathrm{~g}$. the escaped vapour mass was $140.7 \mathrm{~g}$. 


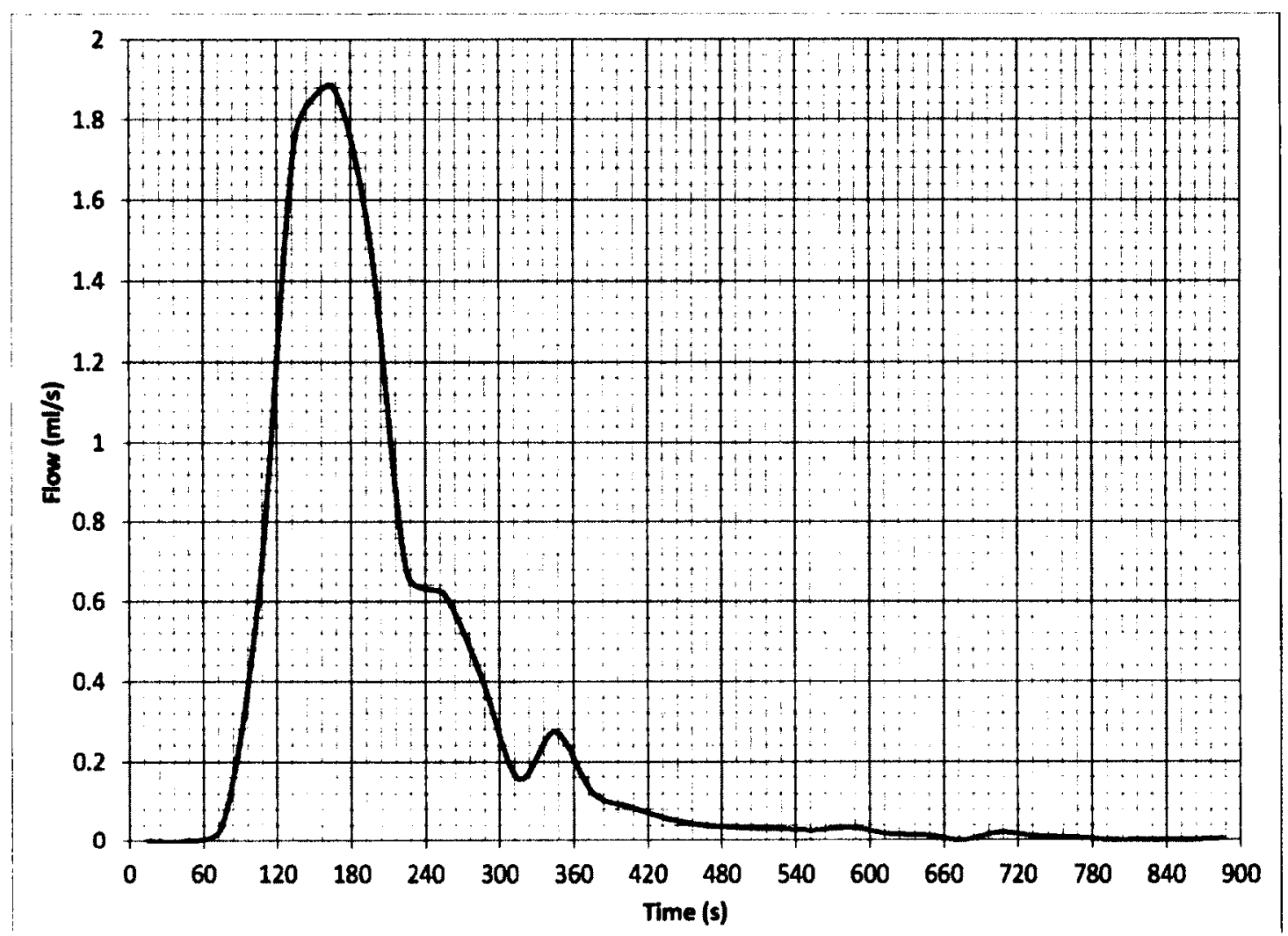

Fig. 5.4.2-3 Test 1B - Foam water drainage rate

\subsubsection{Test 1C}

In Test $1 \mathrm{C}, 600 \mathrm{cc}$ of water foam solution was used. The weight was measured to be $591.7 \mathrm{~g}$. The foam was CAF using 3\% AFFF AR of foam concentrate and an expansion ratio of $1: 25$. The foam was sprayed over the $6.35 \mathrm{~mm}$ thick steel plate that was at $200^{\circ} \mathrm{C}$ at the time that the foam was inserted. Fig. 5.4.3-1 shows the temperatures recorded during the test. 


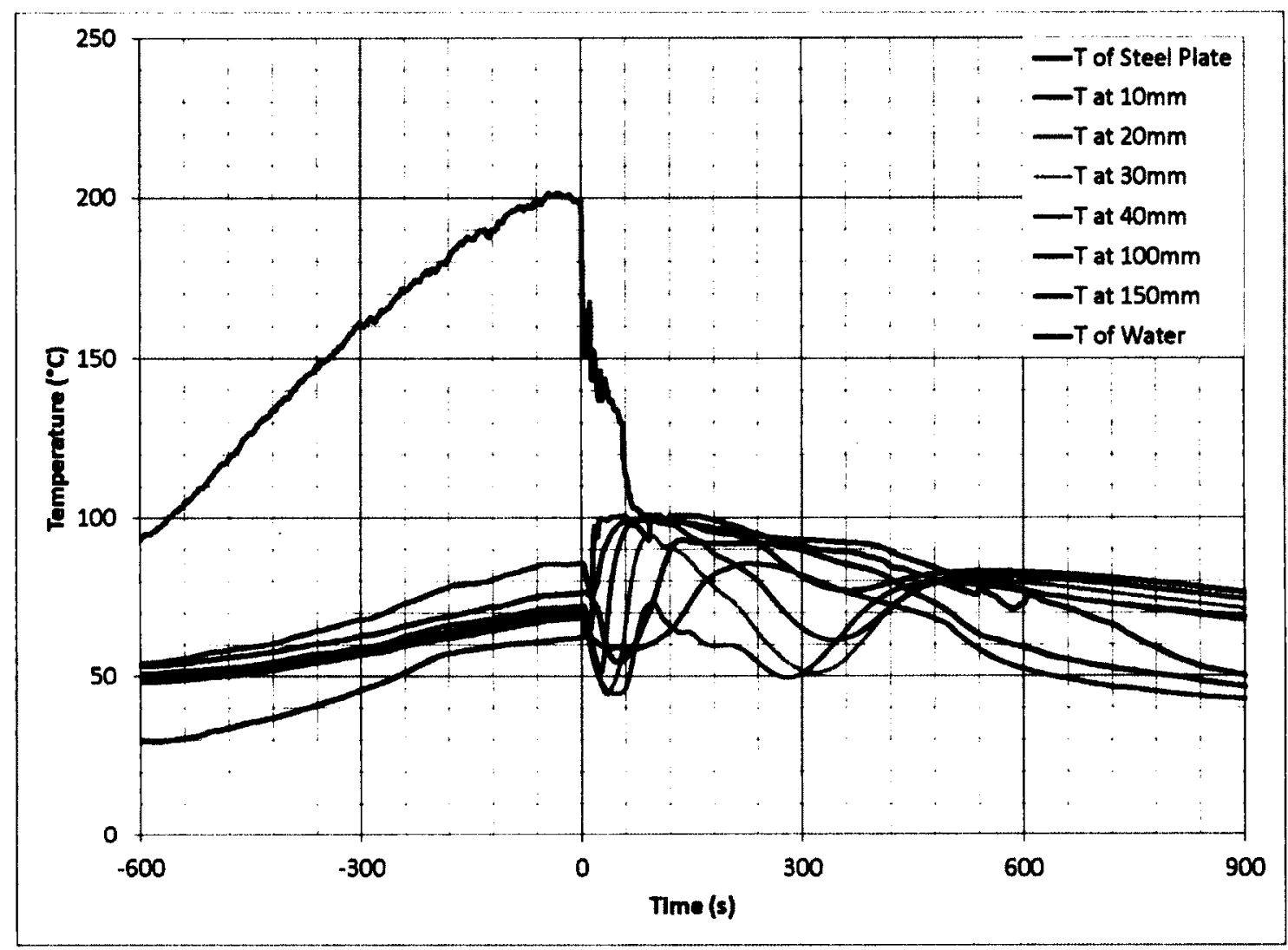

Fig. 5.4.3-1 Test $1 \mathrm{C}-600 \mathrm{cc}$ of AFFF AR, $3 \%$,expansion ratio 1:25, $200^{\circ} \mathrm{C}$

The foam was introduced at $t=0$ seconds. Similarly to Tests $1 \mathrm{~A}$ and $1 \mathrm{~B}$, the vapour penetration through the foam lasted approximately 180 seconds and the duration was not affected by the amount of foam coverage. The foam level immediately after the insertion of the foam was $120 \mathrm{~mm}$. The foam behaviour was similar to Tests 1A and 1B. The floor temperature dropped and then fluctuated due to the limited available water drainage. The water flow through the floor drain started almost immediately at a very low rate (few drops), and the sustained flow started at approximately 1.5 minutes after the insertion of the foam as can be observed by a small increase in the temperature of the drained water. See Fig. 5.4.3-2 for the measured water drainage and the rate of drainage on Fig. 5.4.3-3. 
The maximum water drainage rate was similar to the drainage rate in Test 1B. Starting at $t=60$ seconds, large vapour bubbles were noticed trapped within the foam layer. This was measured by the thermocouples that were located at $100 \mathrm{~mm}$ and $150 \mathrm{~mm}$ levels and can be seen on curves "T at $100 \mathrm{~mm}$ " and "T at $150 \mathrm{~mm}$ ". This explains why temperatures are higher at the upper level than the temperatures measured at the lower levels.

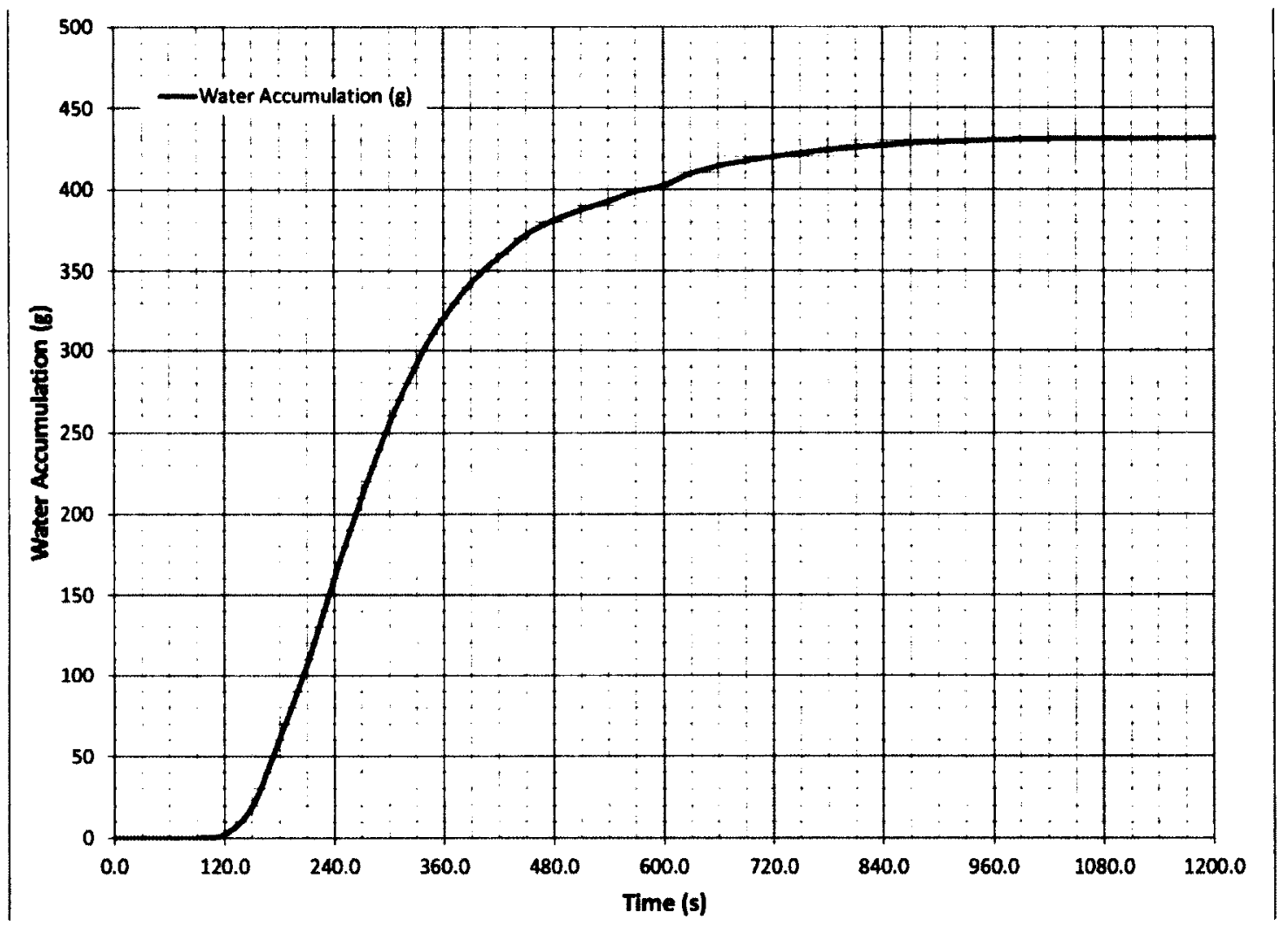

\section{Fig. 5.4.3-2 Test 1C - Water accumulation}




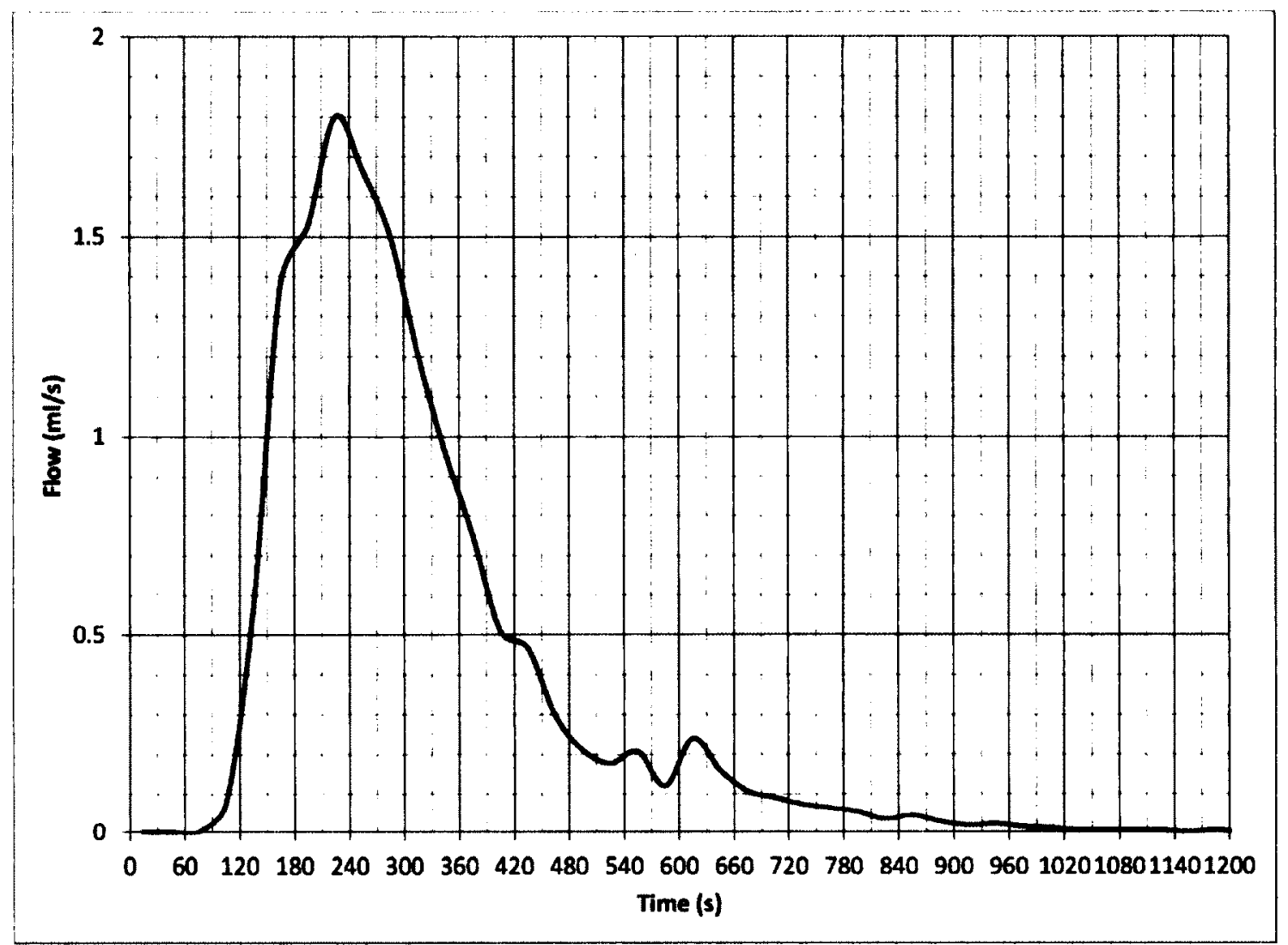

Fig. 5.4.3-3 Test 1C - Foam water drainage rate

The mass of the drained water that was collected was $431.4 \mathrm{~g}$. As the initial mass of the liquid was $591.7 \mathrm{~g}$, the escaped vapour mass was $160.3 \mathrm{~g}$. When all of the foam was evaporated or drained, the top of the steel plate temperature decreased to approximately $75^{\circ} \mathrm{C}$. The top of the steel plate decreased to approximately the same temperature as in Test 1 where no foam was used in the experiment and at which point the container and the steel plate temperature was reduced by convection to air. 


\section{Heat balance calculations for Test 1C}

At the insertion of the foam, the average temperature of the air content of the foam and the foam concentrate was $25^{\circ} \mathrm{C}$. The energy required to increase the temperature of the water content of the foam from $25^{\circ} \mathrm{C}$ to $100^{\circ} \mathrm{C}$, evaporate $160 \mathrm{~g}$ of water and to increase the temperature from $25^{\circ} \mathrm{C}$ to $95^{\circ} \mathrm{C}$ of $431 \mathrm{~g}$ of water is (for details see section 5.4):

$$
\begin{aligned}
& Q=Q_{V}+Q_{W}=\left(\Delta T\left(c_{P W}\right) M_{v}\right)+\left(h_{f g} M_{v}\right)+\left(\Delta T\left(c_{P-W}\right) M_{f w c}\right) \\
& Q=(75 \times 4.18 \times 0.160)+(2270 x 0.160)+(70 x 4.18 x 0.431)= \\
& 414+126=540(K J)
\end{aligned}
$$

The heat transfer from the steel plate to the foam was $540 \mathrm{~kJ}$. This energy gain was similar to the energy loss of $562 \mathrm{~kJ}$ for the container and the steel plate for the same temperature drop (from $200^{\circ} \mathrm{C}$ to $75^{\circ} \mathrm{C}$ ) calculated in subsection 5.4.1.

\subsubsection{Test 1D}

In Test 1D, $400 \mathrm{cc}$ of water foam solution was used. The mass of the foam water content was $399.4 \mathrm{~g}$. The foam was CAF using $2 \%$ AFFF AR of foam concentrate and an expansion ratio of $1: 8.7$. The foam was sprayed over the $6.35 \mathrm{~mm}$ thick steel plate that was at $200^{\circ} \mathrm{C}$ at the time that the foam was inserted $(t=0$ seconds). Fig. $5 \cdot 4.4-1$ shows the temperatures recorded during the test. When compared to Test 1B, the surface temperature of the steel cooled faster. This was due to higher water content in the foam 
and the ability to release the water faster than foam with a higher expansion ratio. The initial foam height was only $30 \mathrm{~mm}$ as the foam expansion was lower than in the previous tests. As the foam temperature increased, the foam expanded and covered the thermocouple located at $40 \mathrm{~mm}$ height within 30 seconds. When the foam was inserted into the container, the spray covered all thermocouples; this explains the drop of temperature on the thermocouples located at $10 \mathrm{~mm}, 20 \mathrm{~mm}, 30 \mathrm{~mm}$ and $40 \mathrm{~mm}$ from the floor. As in the previous tests, the upper layer of the foam was affected by the vapour bubbles causing the higher temperatures measured by the thermocouples located at $40 \mathrm{~mm}$ and $30 \mathrm{~mm}$ when compared to the temperatures measured at $10 \mathrm{~mm}$ and $20 \mathrm{~mm}$ levels.

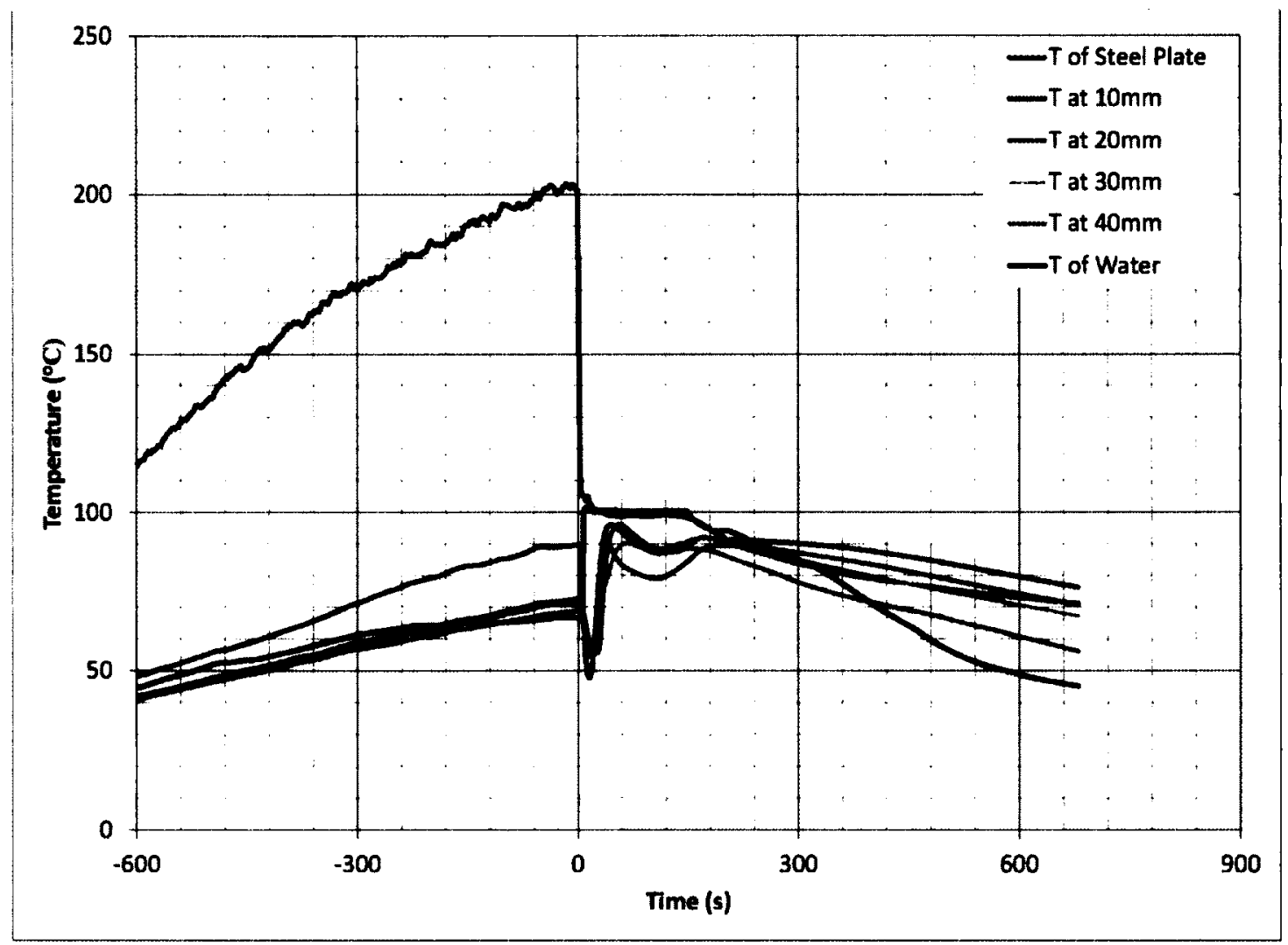

Fig. 5.4.4-1 Test $1 D-400$ cc of AFFF AR, $2 \%$, expansion ratio 1:8.7, $200^{\circ} \mathrm{C}$ 
The mass of the drained water that was collected was $232.9 \mathrm{~g}$. As the initial mass of the liquid was $399.4 \mathrm{~g}$. the escaped vapour weight was $166.5 \mathrm{~g}$. The water accumulation and the rate of the water drainage is represented in Fig. 5.4.4-2. and Fig. 5.4.4-3 respectively. The rate of water drainage was higher than in Test 1B. This was expected due to the lower expansion ratio of the foam.

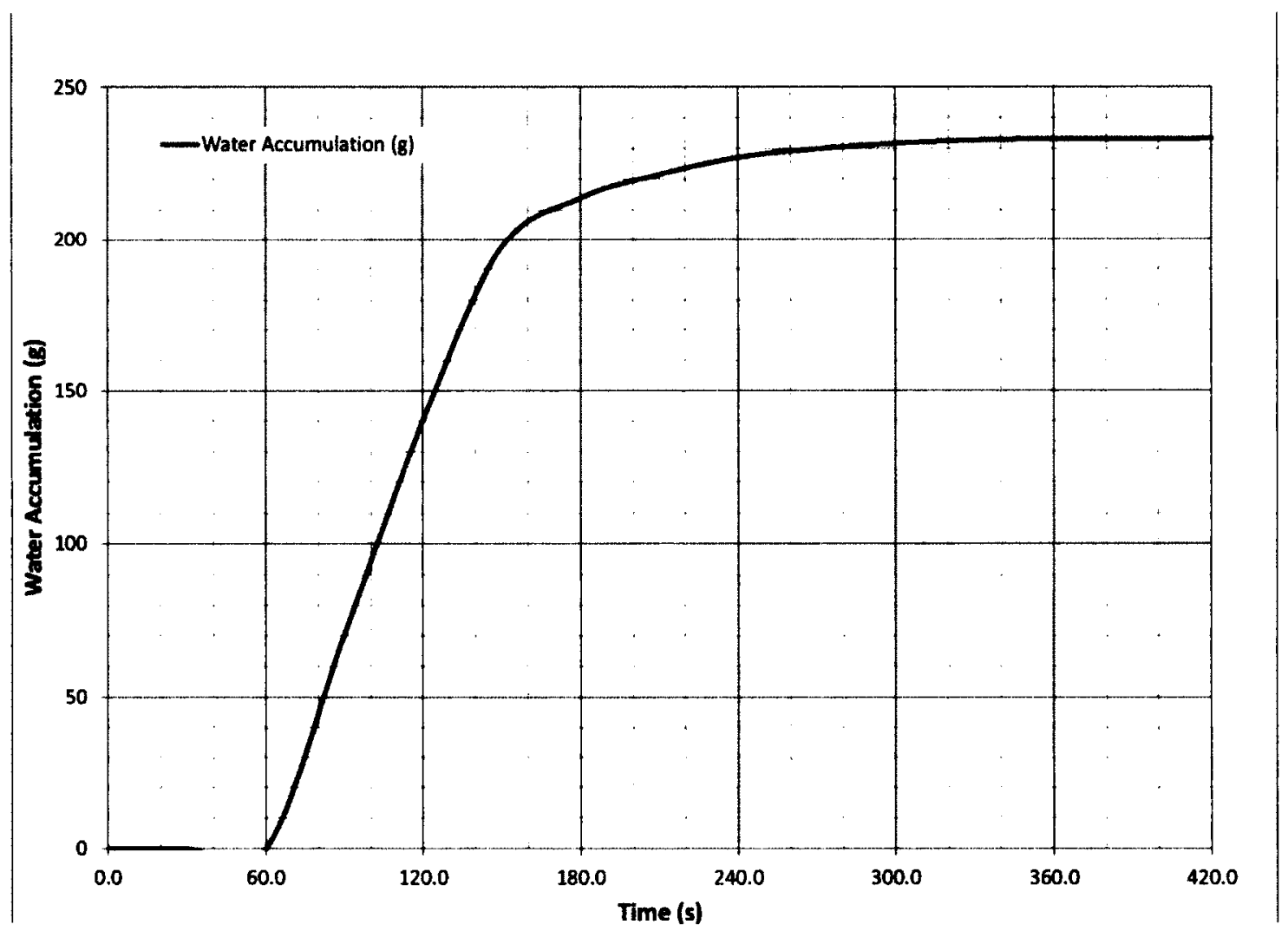

Fig. 5.4.4-2 Test 1D - Water accumulation 


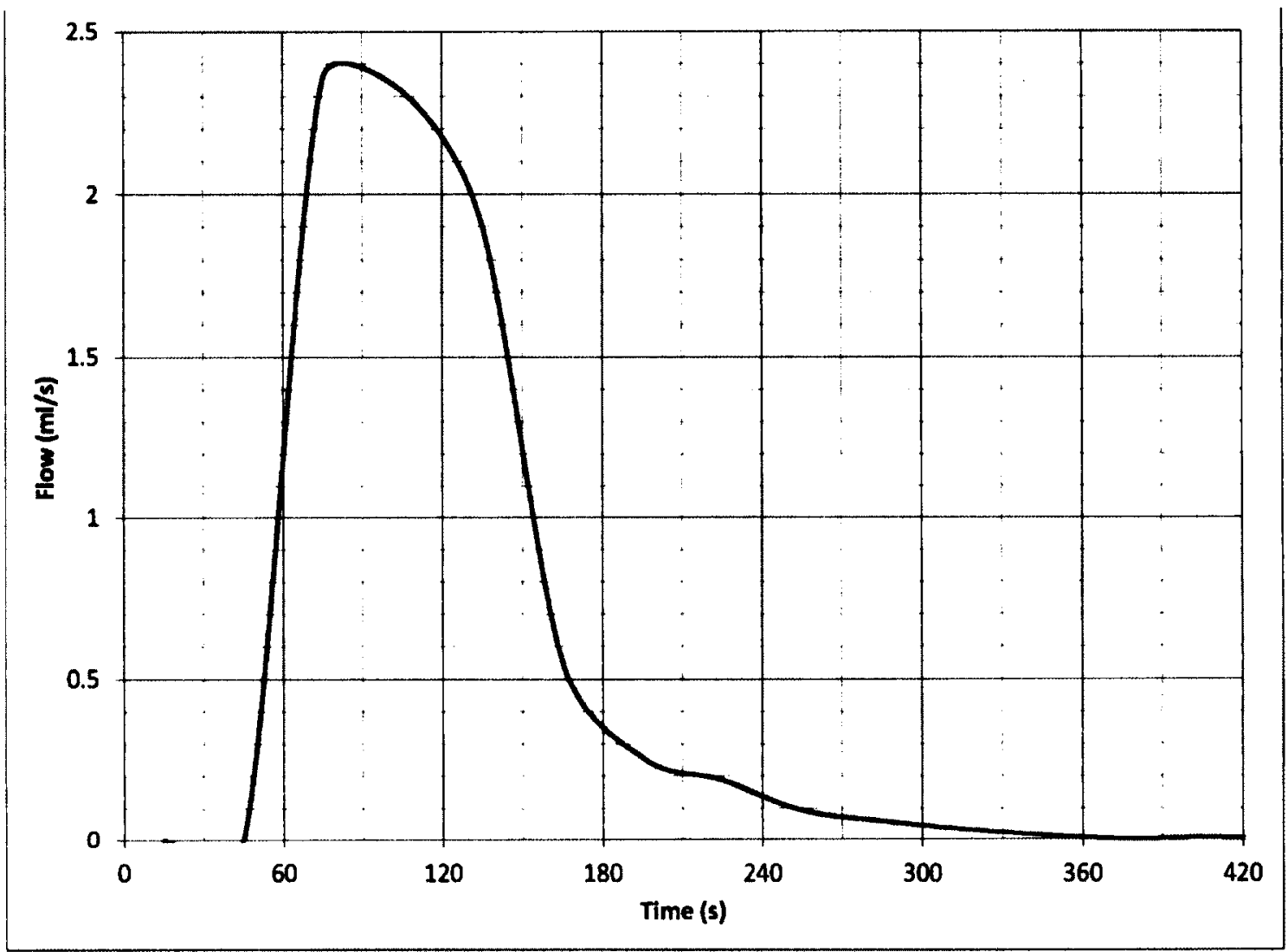

Fig. 5.4.4-3 Test 1D - Foam water drainage rate

In Test 1D, one thermocouple was placed at the bottom of the floor and one thermocouple was located $20 \mathrm{~mm}$ below the floor. Fig. 5.4.4-4 shows the temperatures measured below the floor and at the bottom of the floor during Test 1D. 


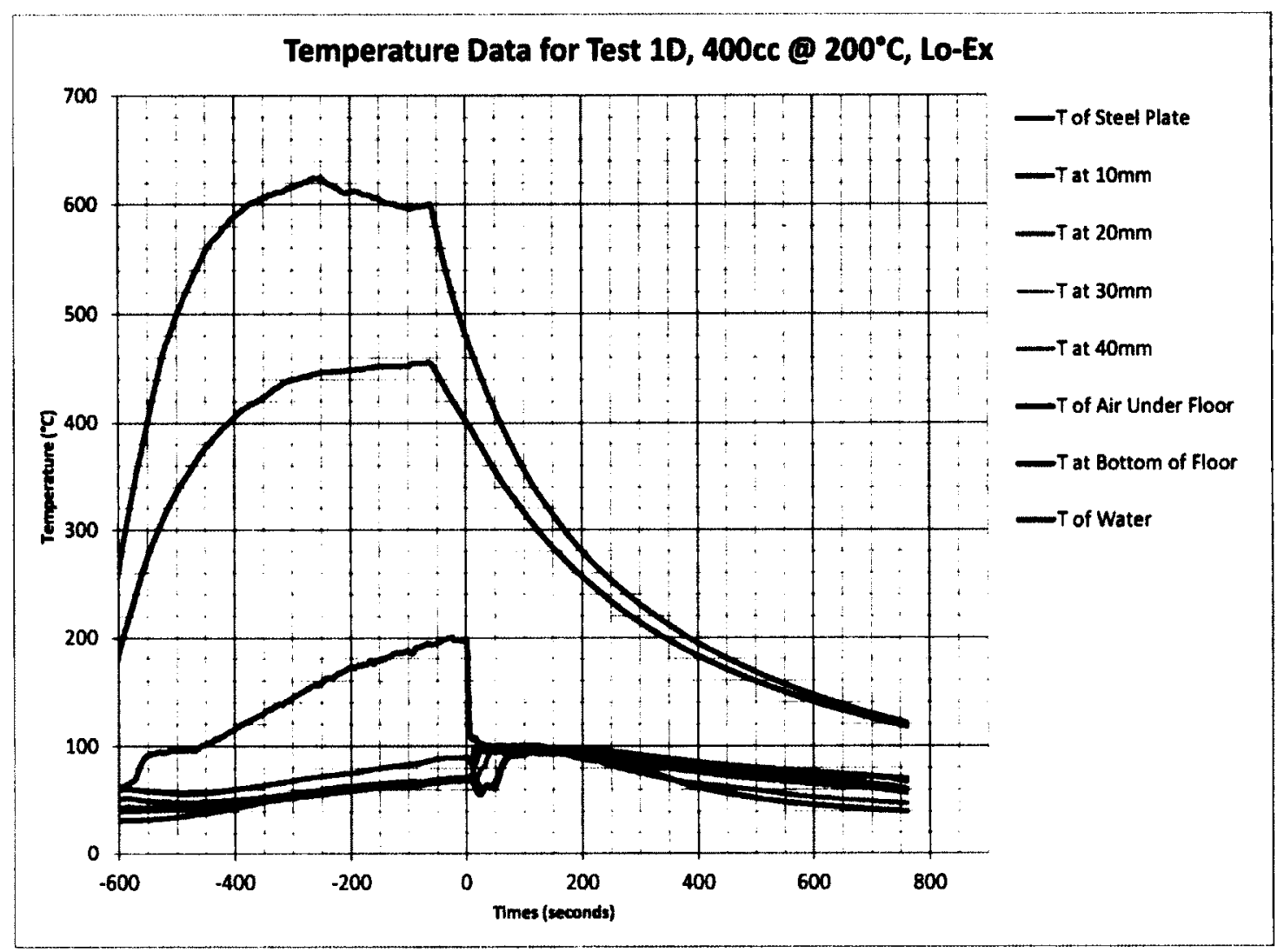

Fig. 5.4.4-4 Test 1D - Temperatures below and above the floor

The temperature measurements below the floor were similar to the temperatures measured in Test 1 (section 5.2). The burner was lowered at approximately $t=-250$ and shut off at $t=-60$ seconds. The effect can be seen by the drop in temperature below the floor on curve $\mathrm{T}$ of air under the floor. The gradual cooling of the bottom of the floor can be observed when compared with the sharp drop of temperature from $200^{\circ} \mathrm{C}$ to $100^{\circ} \mathrm{C}$ at the top of the steel plate at the time when the foam was introduced.

During Test $1 \mathrm{D}$, the gas temperature below the steel plate was $600^{\circ} \mathrm{C}$ and the bottom of the floor temperature when the foam was inserted was $458^{\circ} \mathrm{C}$. 


\subsubsection{Test 1E}

In Test $1 \mathrm{E}, 600 \mathrm{cc}$ of water foam solution was used and the mass was measured at 597.7 g. As in Test 1D, foam was CAF using $2 \%$ AFFF AR of foam concentrate and an expansion ratio of $1: 8.7$. The foam was sprayed over the $6.35 \mathrm{~mm}$ thick steel plate that was at $200^{\circ} \mathrm{C}$ at the time that the foam was inserted (at $\mathrm{t}=0$ seconds). Fig. 5.4.5-1 shows the temperatures recorded during the test. The initial foam height was $45 \mathrm{~mm}$. The results of Test 1E were similar to those of Test 1D as these tests use the same foam expansion rate.

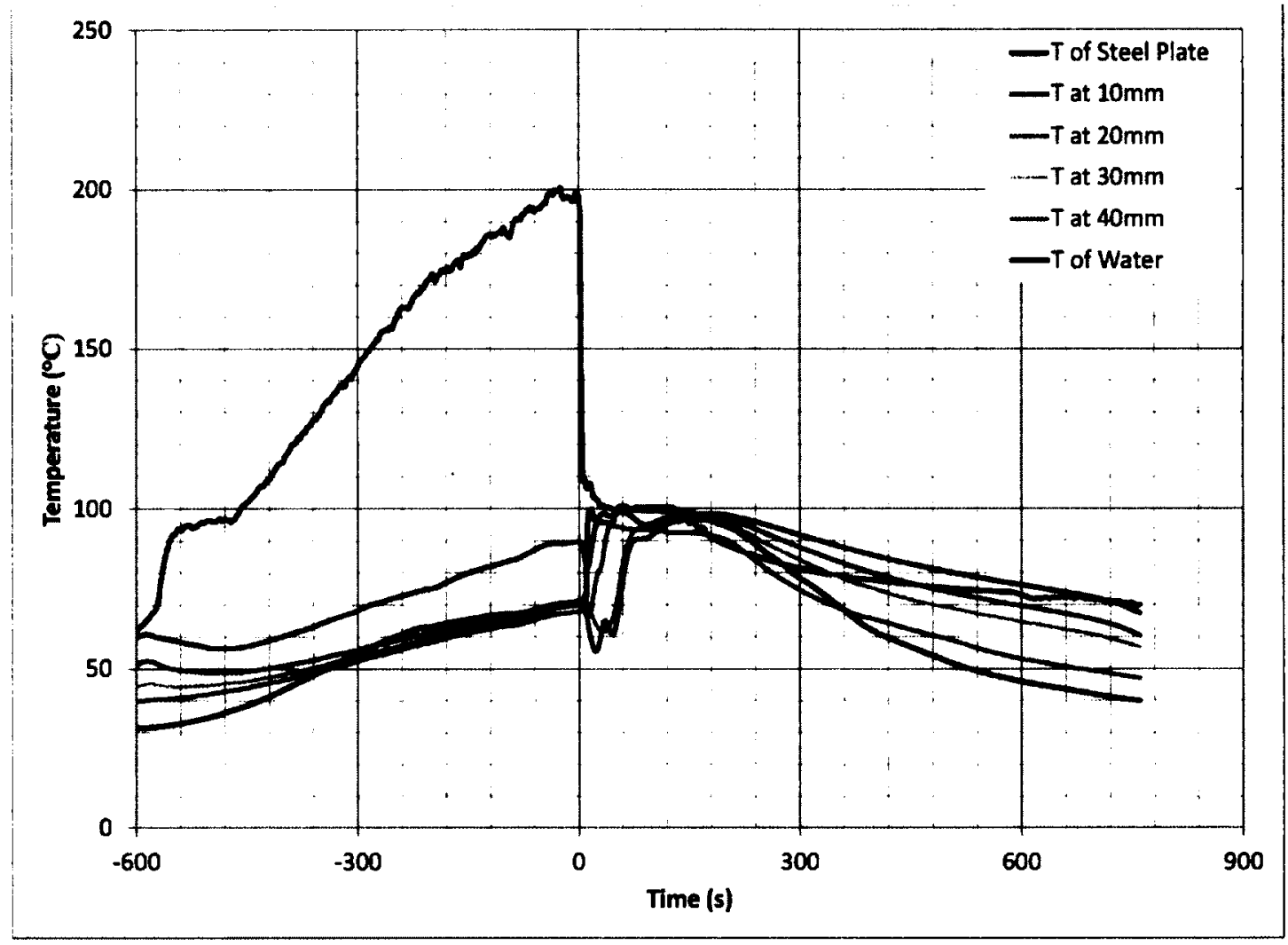

Fig. 5.4.5-1 Test $1 \mathrm{E}-600$ cc of AFFF AR, 2\%, expansion ratio 1:8.7, $200^{\circ} \mathrm{C}$ 
Fig. 5.4.5-2 shows the drainage recorded during Test $1 \mathrm{E}$ and Fig. 5.4.5-3 shows the calculated rate of drainage. As the amount of foam concentrate was increased from 400 $\mathrm{cc}$ in Test $1 \mathrm{D}$ to $600 \mathrm{cc}$ in Test $1 \mathrm{E}$, the maximum drainage rate was also increased substantially.

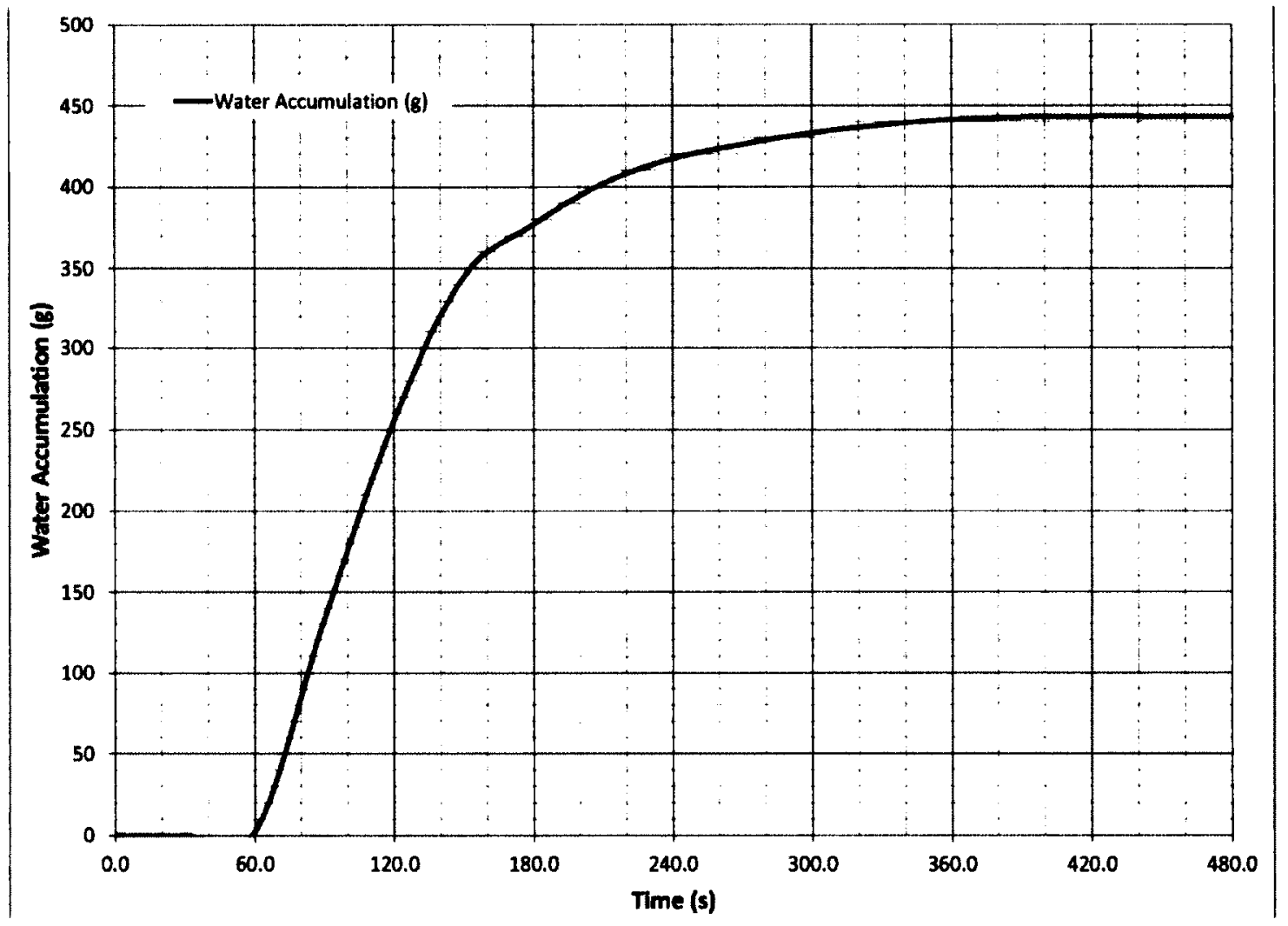

Fig. 5.4.5-2 Test 1E - Water accumulation 


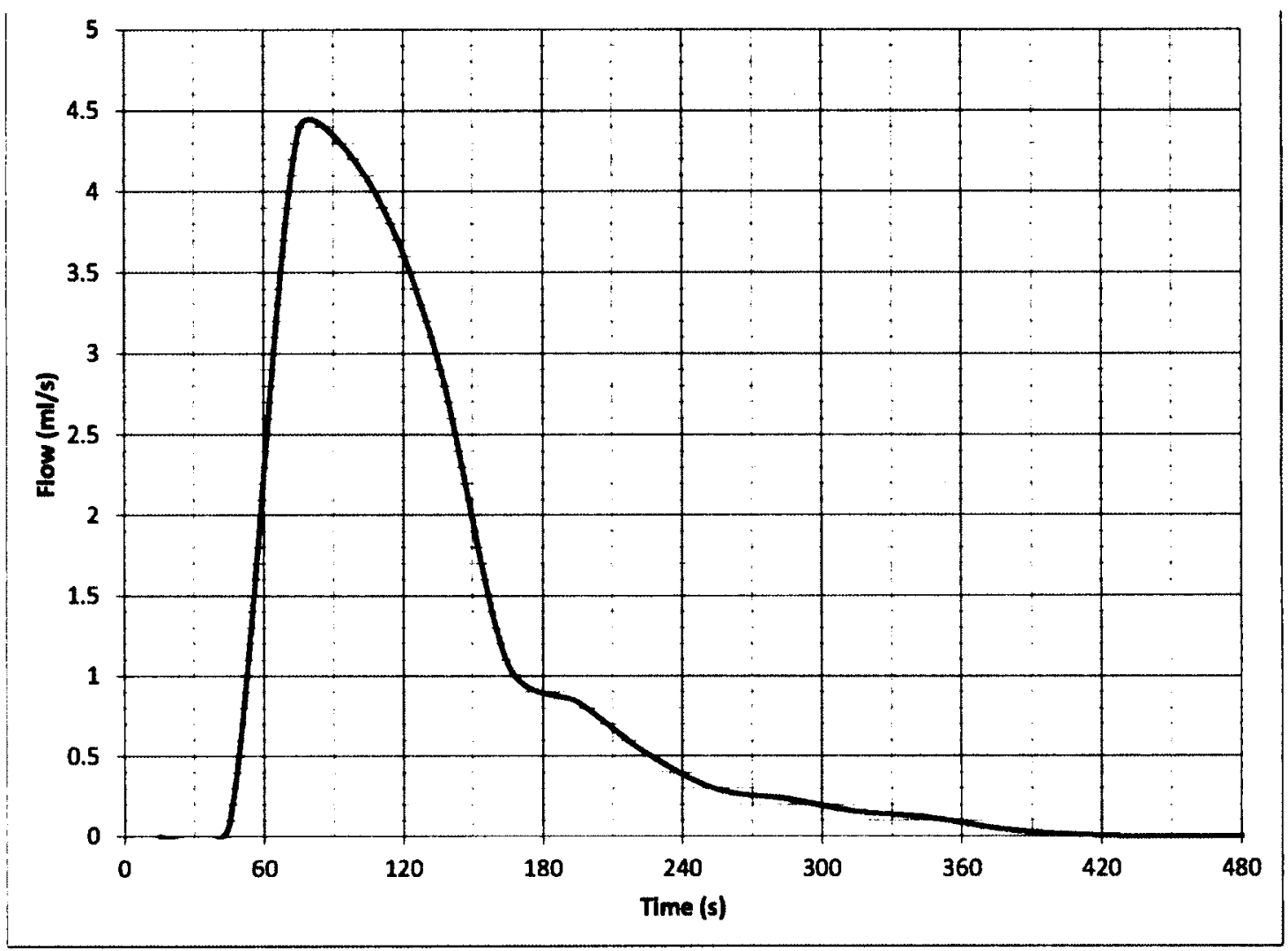

Fig. 5.4.5-3 Test 1E - Foam water drainage rate

The mass of the drained water that was collected was $443.2 \mathrm{~g}$. The initial mass of the liquid was $597.7 \mathrm{~g}$ and the escaped vapour mass was $154 \mathrm{~g}$.

\subsubsection{Test 2A}

In Tests $2 \mathrm{~A}, 2 \mathrm{~B}$ and $2 \mathrm{C}$, the initial temperature was $175^{\circ} \mathrm{C}$. Foam used in Test $2 \mathrm{~A}$ had $200 \mathrm{cc}$ of solution with $3 \%$ AFFF AR of foam concentrate and expansion ratio of 1:25. The foam was sprayed over the $6.35 \mathrm{~mm}$ steel plate that was at $175^{\circ} \mathrm{C}$ at the time that the foam was inserted. The following graph (Fig. 5.4.6-1) shows the temperatures recorded 
during the test. The burner was stopped at $t=-210$ seconds and the foam was inserted at $t$ $=5$ seconds. The cooling of the steel plate is more gradual when compared to Test $1 \mathrm{~A}$. This can be attributed to the foam drainage rate that was affected by the surface temperature of the steel plate. As the initial surface temperature was lower, the rate of evaporation was also lower and the drainage started before the temperature of the top of the steel plate dropped to $100^{\circ} \mathrm{C}$. Any significant drainage started at approximately $\mathrm{t}=75$ seconds as can be seen on Fig 5.4.6-2 but few water droplets were noticed at approximately $t=45$ seconds. This explains the sharp increase of temperature of the curve "T of water" on Fig. 5.4.6-1.

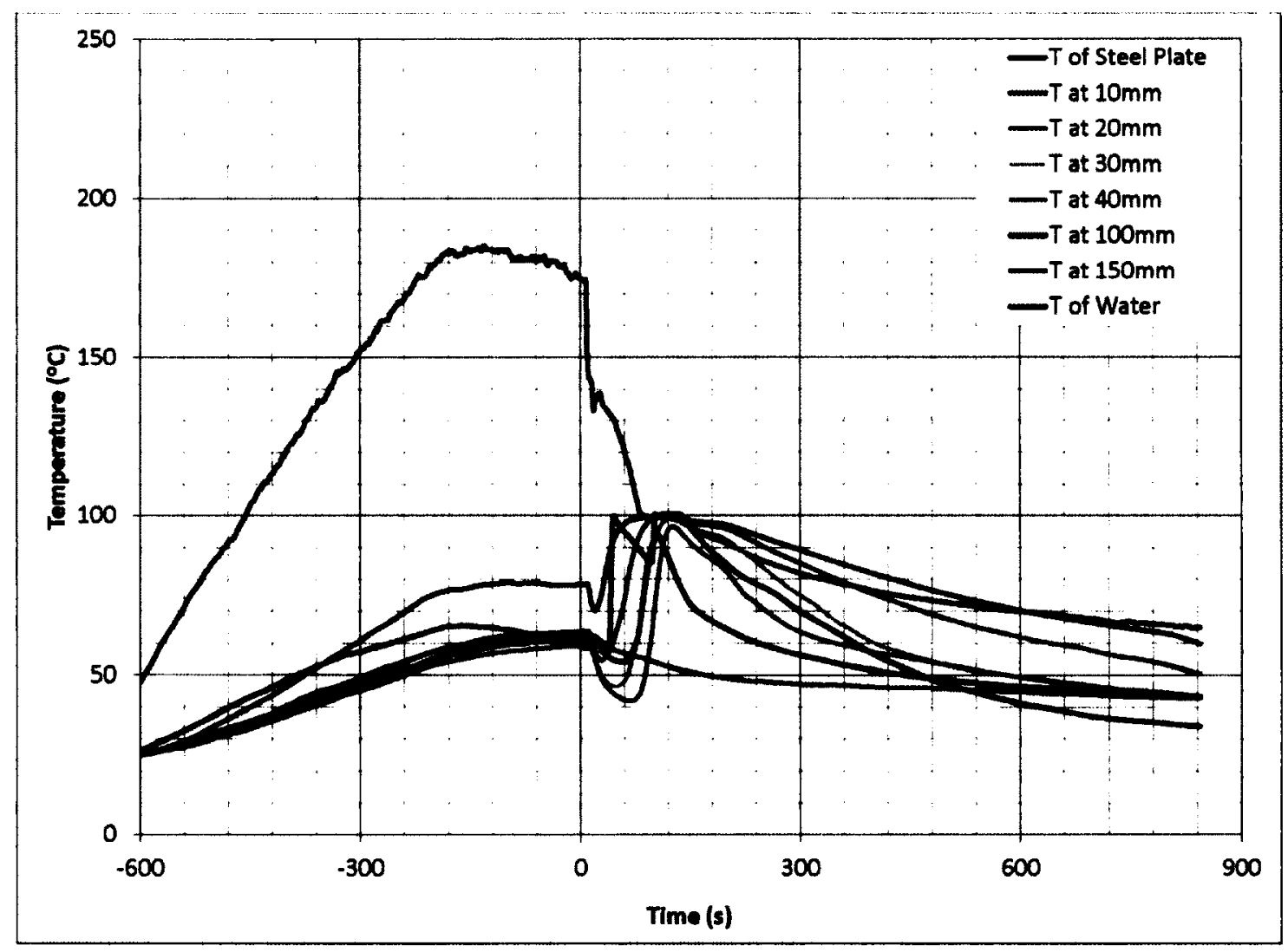

Fig. 5.4.6-1 Test $2 \mathrm{~A}-200$ ce of AFFF AR, 3\%, expansion ratio 1:25, $175^{\circ} \mathrm{C}$ 
The readings of the mass of the drained water beyond $t=165$ seconds was corrupted and could not be recorded. The curve on Fig. 5.4.6-2 represents a flow rate between $t=0$ to $t=165$ seconds.

The mass of the drained water that was collected was measured at $74.4 \mathrm{~g}$. The initial mass of the liquid was $198.6 \mathrm{~g}$ and the escaped vapour mass was calculated to be $124 \mathrm{~g}$.

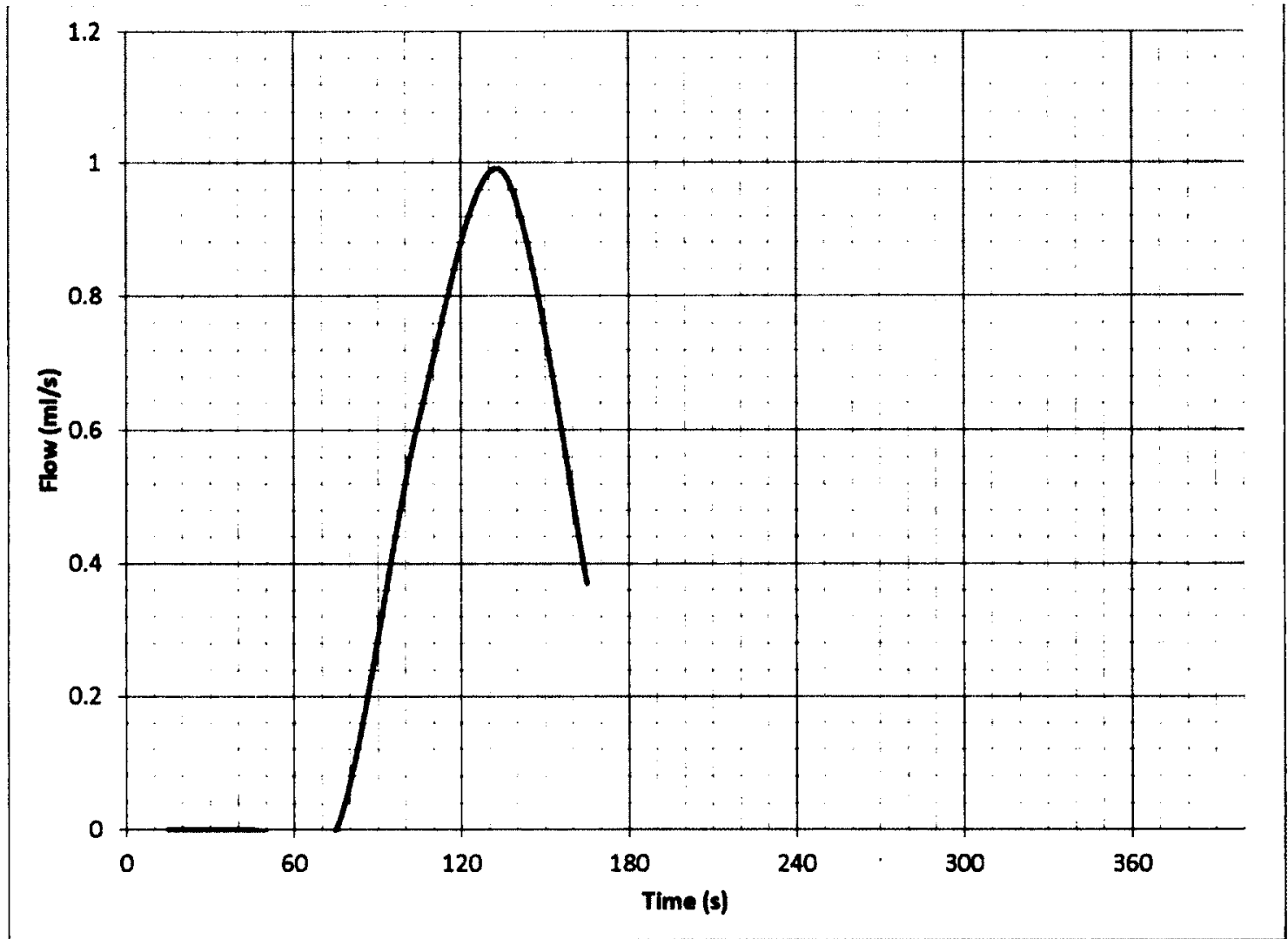

Fig. 5.4.6-2 Test 1E - Foam water drainage 


\subsubsection{Test 2B}

In Test $2 \mathrm{~B}$, the foam used was $400 \mathrm{cc}$ of solution with $3 \%$ AFFF AR foam concentrate and an expansion ratio of 1:25. The foam was sprayed over the $6.35 \mathrm{~mm}$ steel plate that was at $175^{\circ} \mathrm{C}$ at the time that the foam was inserted. The following graph (Fig. 5.4.7-1) shows the temperatures recorded during the test. The burner was stopped at $t=-120$ seconds and the foam was inserted at $t=-10$ seconds. The cooling rate seemed to increase as more foam was available to drain when compared to Test $2 \mathrm{~A}$. This can be seen by a sharp temperature fluctuation between $130^{\circ} \mathrm{C}$ to $150^{\circ} \mathrm{C}$ measured at the top of the steel plate. This is similar to the fluctuations seen in Tests 1A, 1B and 1C. These fluctuations were caused by limited availability of water drained from the foam. When all this drained water was evaporated, the steel plate surface temperature increased due to heat conduction through the steel plate and as the foam decomposed, water was drained and evaporated and reduced the surface temperature of the steel plate. 


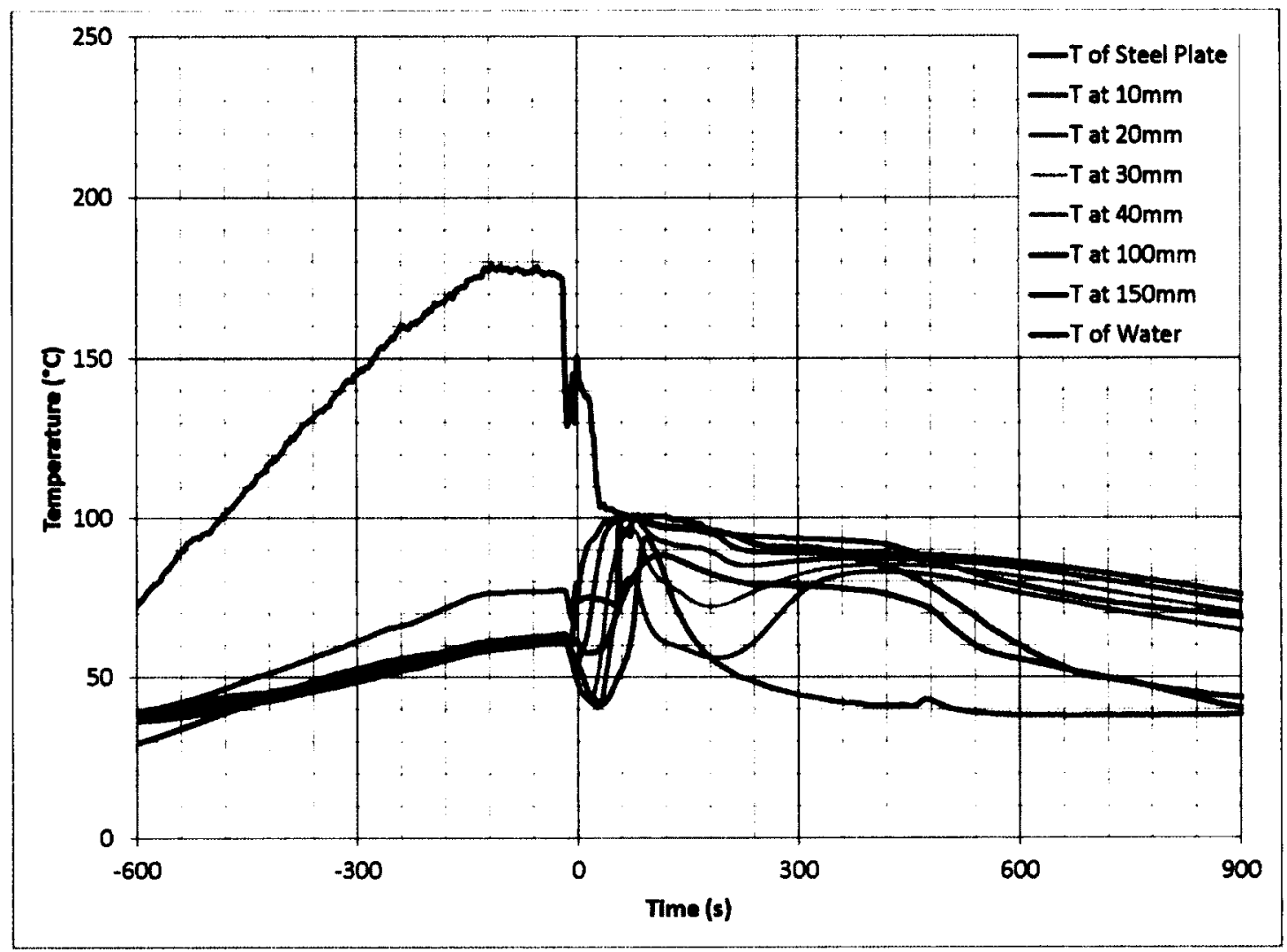

Fig. 5.4.7-1 Test $2 B-400$ ce of AFFF AR, $3 \%$, expansion ratio $1: 25,175^{\circ} \mathrm{C}$

Similarly to the previous experiments, any significant water drainage started when the steel surface temperature dropped to $100^{\circ} \mathrm{C}$ as can be observed in Fig. 5.4.7-2.

The mass of the drained water that was collected was measured to be $271.2 \mathrm{~g}$. The initial mass of the liquid was $394.8 \mathrm{~g}$ and the escaped vapour mass was calculated to be $124 \mathrm{~g}$. 


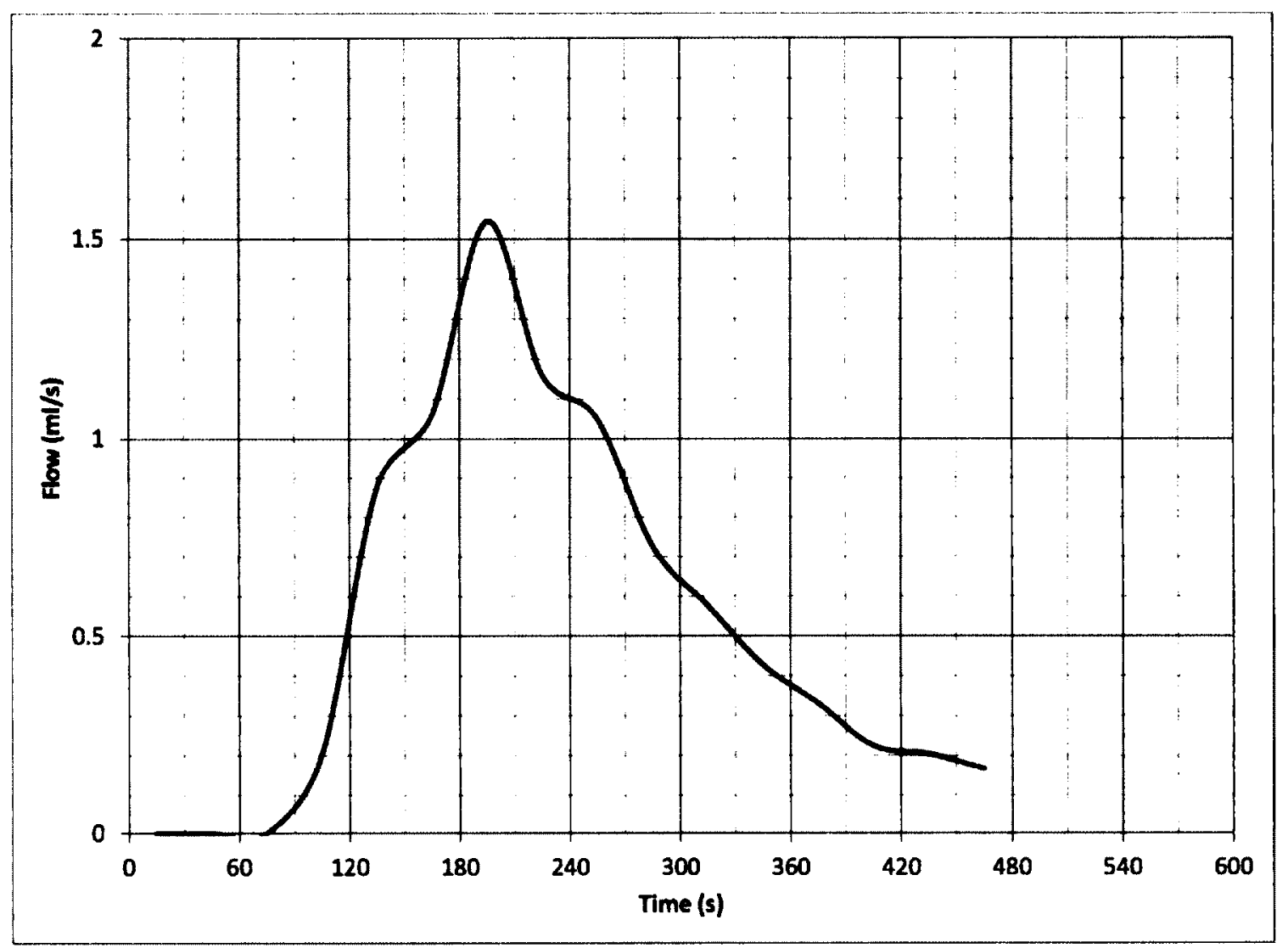

Fig. 5.4.7-2 Test 2B - Foam water drainage rate

\subsubsection{Test 2C}

In Test $2 \mathrm{C}$, the foam used was $600 \mathrm{cc}$ of solution with $3 \% \mathrm{AFFF}$ AR foam concentrate and expansion ratio of $1: 25$. The foam was sprayed over the $6.35 \mathrm{~mm}$ steel plate that was at $175^{\circ} \mathrm{C}$ at the time that the foam was inserted. The following graph (Fig. 5.4.8-1) shows the temperatures recorded during the test. The start of temperature fluctuation measured on top of the steel plate is at a lower temperature than in Test 2B. The amount of foam in Test $2 \mathrm{C}$ is $50 \%$ greater and therefore a larger amount of water could drain and evaporate. This temperature fluctuation zone seemed to be dependent on the available water 
drainage. As the rate of drainage increased, the average temperature of the fluctuation zone decreased. In the case of Test $2 \mathrm{C}$, the average temperature of the fluctuation zone was approximately $115^{\circ} \mathrm{C}$ as compared to $143^{\circ} \mathrm{C}$ in Test $2 \mathrm{~B}$.

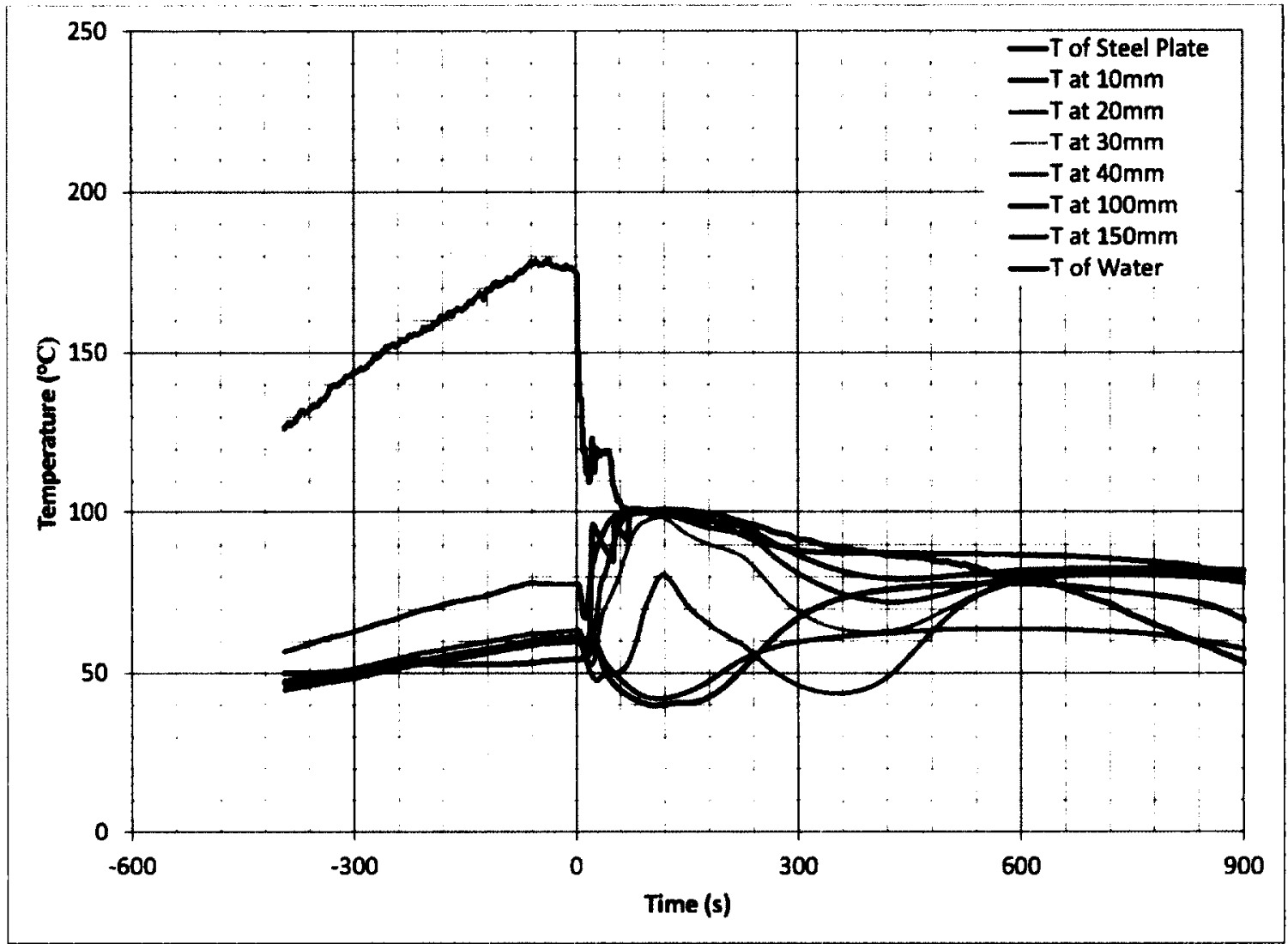

Fig. 5.4.8-1 Test $2 \mathrm{C}-600$ ce of AFFF AR, 3\%, expansion ratio $1: 25,175^{\circ} \mathrm{C}$

The rate of drainage can be observed in Fig. 5.4.8-2. As in the previous tests, the sharp increase in the measurement of drain water temperature was due to a few drops of water but any significant water drainage started when the surface temperature of the steel plate dropped to $100^{\circ} \mathrm{C}$. 


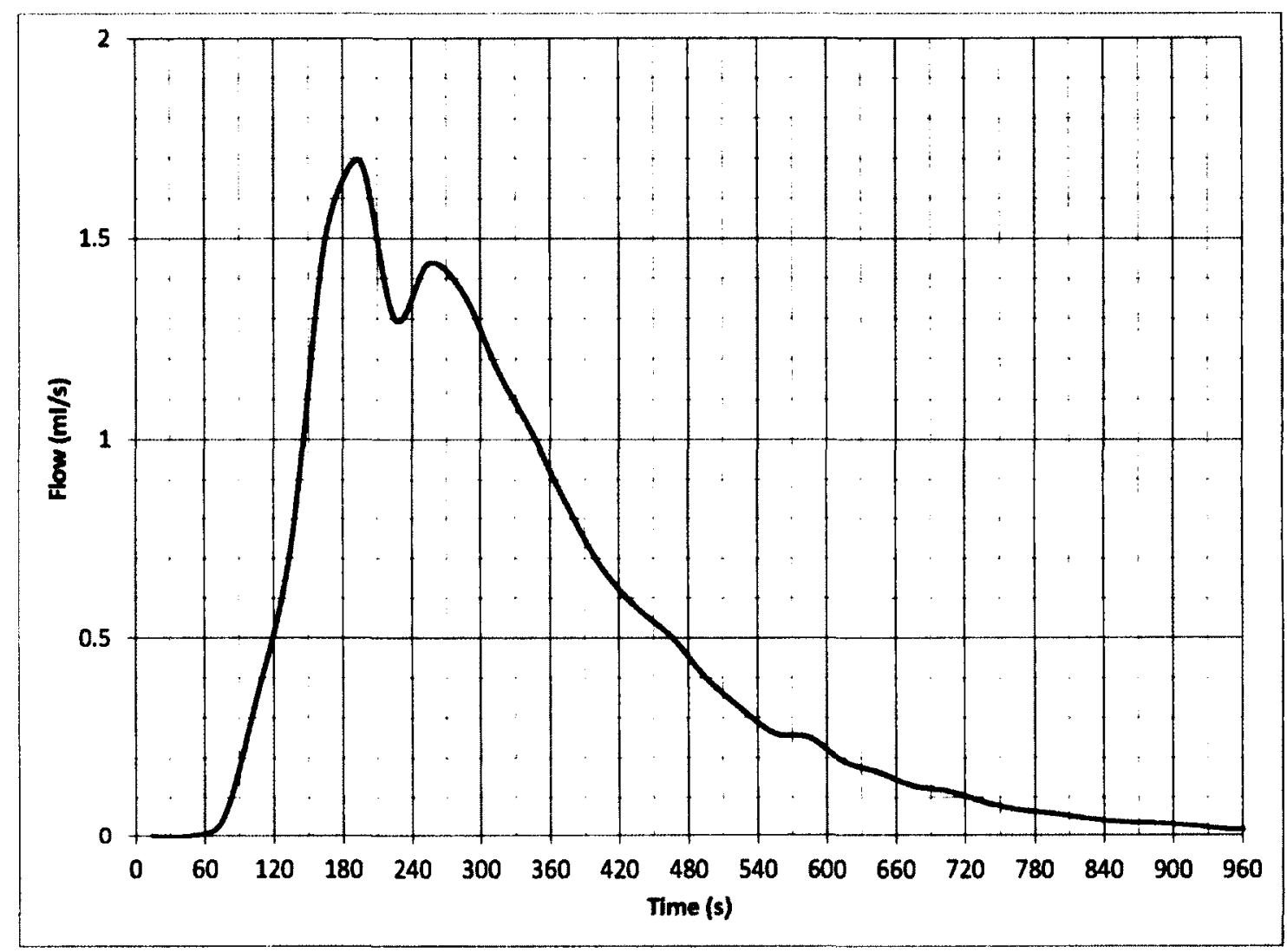

Fig. 5.4.8-2 Test 2C - Foam water drainage

The mass of the drained water that was collected was measured at $478.1 \mathrm{~g}$. The initial mass of the liquid was $594.6 \mathrm{~g}$ and the escaped vapour mass was calculated to be $116 \mathrm{~g}$.

\subsubsection{Test 3A}

In tests $3 \mathrm{~A}$ and $3 \mathrm{~B}$ the initial steel plate temperature when foam was inserted was at $150^{\circ} \mathrm{C}$. In Test $3 \mathrm{~A}$, the foam used was $200 \mathrm{cc}$ of solution with $3 \%$ AFFF AR foam concentrate and expansion ratio of $1: 25$. The foam was sprayed over the $6.35 \mathrm{~mm}$ steel plate that was at $150^{\circ} \mathrm{C}$ at the time that the foam was inserted. The following graph 
(Fig. 5.4.9-1) shows the temperatures recorded during the test. Similarly to Test $2 \mathrm{~A}$, the fluctuation of the temperature measured at the top of the steel plate is minimal and the rate of the temperature drop of the steel plate was less than the temperature drops in previous tests. This is attributed to the smaller amount of the water drainage until the time the steel plate surface temperature descended to $100^{\circ} \mathrm{C}$.

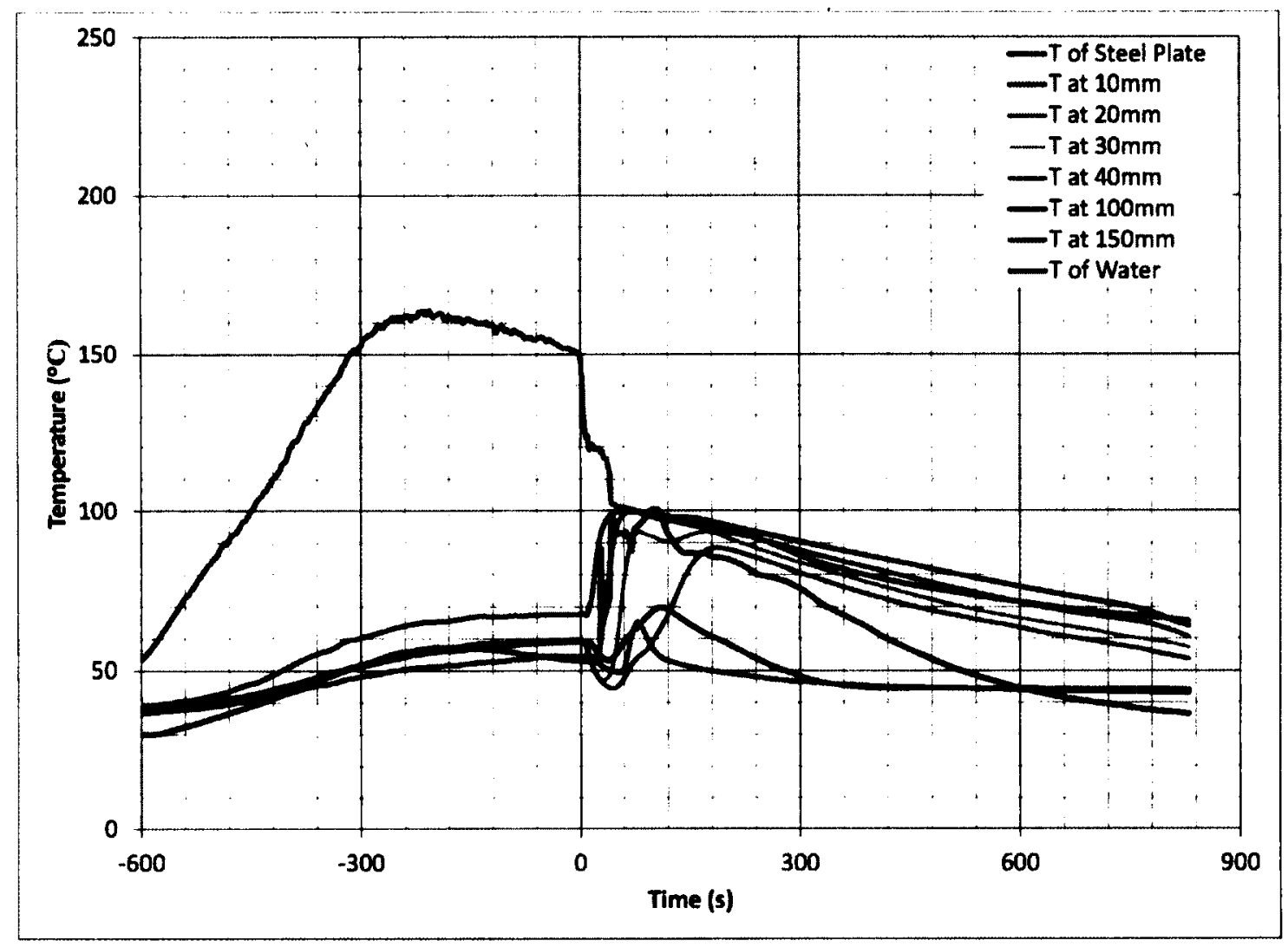

Fig. 5.4.9-1 Test $3 \mathrm{~A}-200$ cc of AFFF AR, $3 \%$, expansion ratio $1: 25,150^{\circ} \mathrm{C}$

Again as in the previous tests, a few drops of water were drained from the container before the top of the steel plate temperature dropped to $100^{\circ} \mathrm{C}$. In this test, the amount of initial drained water was slightly higher as can be seen in Fig. 5.4.9-2 at $\mathrm{t}=30$ seconds. 
It shows the rate of drainage in Test 3A. Any significant drainage occurred after the temperature of the top of the steel plate dropped to $100^{\circ} \mathrm{C}$.

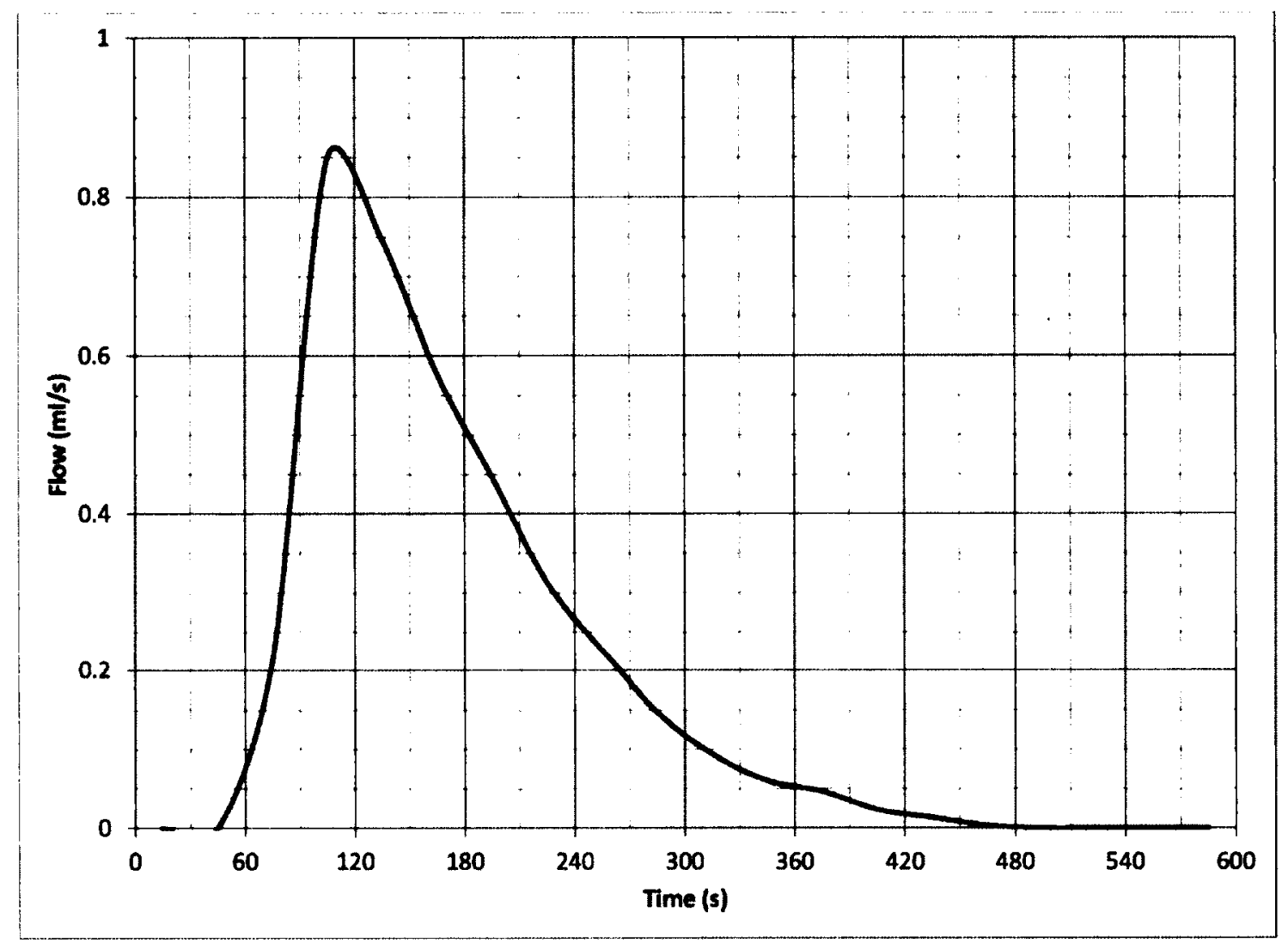

\section{Fig. 5.4.9-2 Test 3A - Foam water drainage rate}

The mass of the drained water that was collected was measured at $112.6 \mathrm{~g}$. The initial mass of the liquid was $197.6 \mathrm{~g}$, so the mass of the vapour that escaped was calculated to be $85.0 \mathrm{~g}$. 


\subsubsection{Test 3B}

In Test 3B, the foam used was $400 \mathrm{cc}$ of solution with $3 \%$ AFFF AR foam concentrate and expansion ratio of 1:25. The foam that was sprayed over the $6.35 \mathrm{~mm}$ steel plate that was at $150^{\circ} \mathrm{C}$ at the time that the foam was inserted. The burner was stopped at $\mathrm{t}=-300$ seconds and the foam was inserted at $t=0$ seconds. The following graph (Fig. 5.4.10-1) shows the temperatures recorded during the test. As the vapours escaped from the surface of the foam, the temperature above the foam layer increased and was relatively steady as can be seen on the curve " $T$ at $100 \mathrm{~mm}$ " from $t=80$ seconds to $t=600$ seconds.

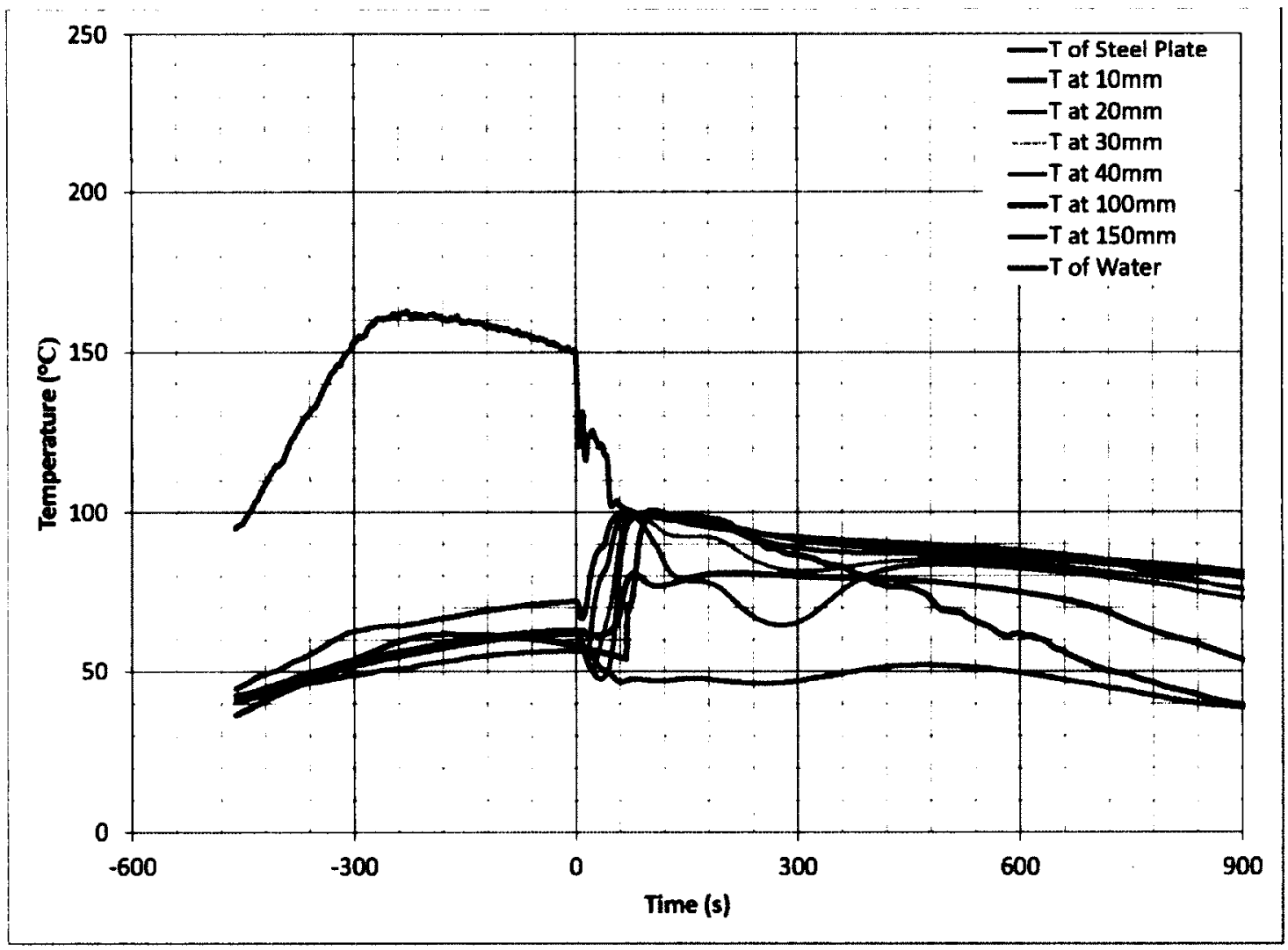

Fig. 5.4.10-1 Test 3B - 400 cc of AFFF AR, 3\%, expansion ratio 1:25, $150^{\circ} \mathrm{C}$ 
The drained foam water mass was recorded and the rate of water drained was calculated and is represented in Fig. 5.4.10-2. As the temperature at the time of the foam insertion was reduced, the liquid drained from the foam was not completely evaporated during the time period that the steel plate was above $100^{\circ} \mathrm{C}$ (reached at $\mathrm{t}=70$ seconds). Any significant drainage started at $\mathrm{t}=40$ seconds.

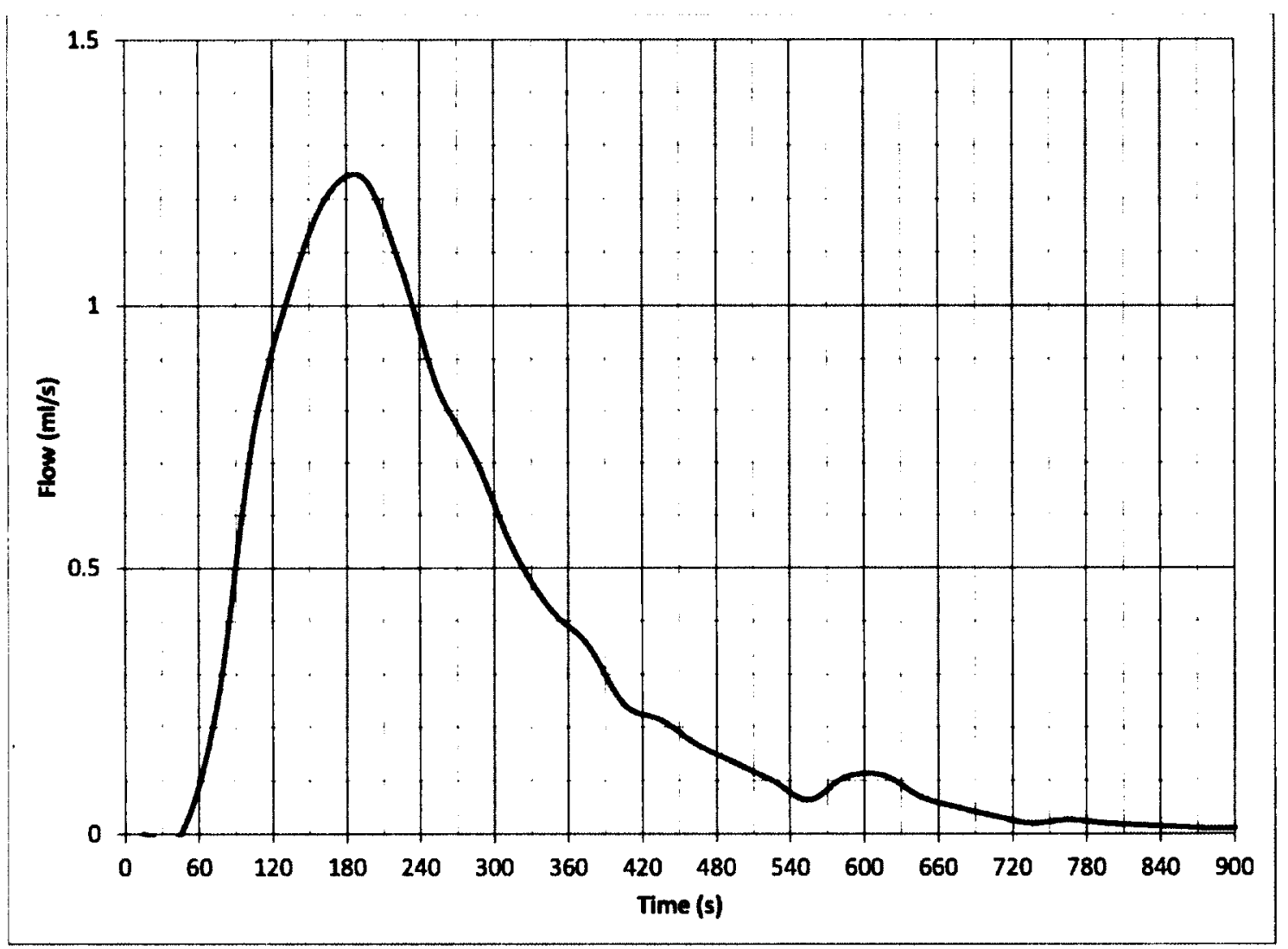

Fig. 5.4.10-2 Test 3B - Foam water drainage

The mass of the drained water that was collected was measured at $298.4 \mathrm{~g}$. The initial mass of the liquid was $397.0 \mathrm{~g}$ and the escaped vapour mass was calculated to be $99.6 \mathrm{~g}$. 


\subsubsection{Test 4A}

In Test 4A, the foam used was $200 \mathrm{cc}$ of solution with $3 \%$ AFFF AR foam concentrate and expansion ration of 1:25. The foam was sprayed over the $6.35 \mathrm{~mm}$ steel plate that was at $125^{\circ} \mathrm{C}$ at the time that the foam was inserted. The burner was stopped at $\mathrm{t}=-540$ seconds and the foam was inserted at $t=0$ seconds. The following graph (Fig. 5.4.11-1) shows the temperatures recorded during the test. As the initial steel plate temperature was reduced, the rate of cooling of the steel plate was reduced. The time to reduce the temperature at the top of the steel plate to $100^{\circ} \mathrm{C}$ was over 60 seconds. The vapour generated was less significant than in the tests where the initial temperature was higher.

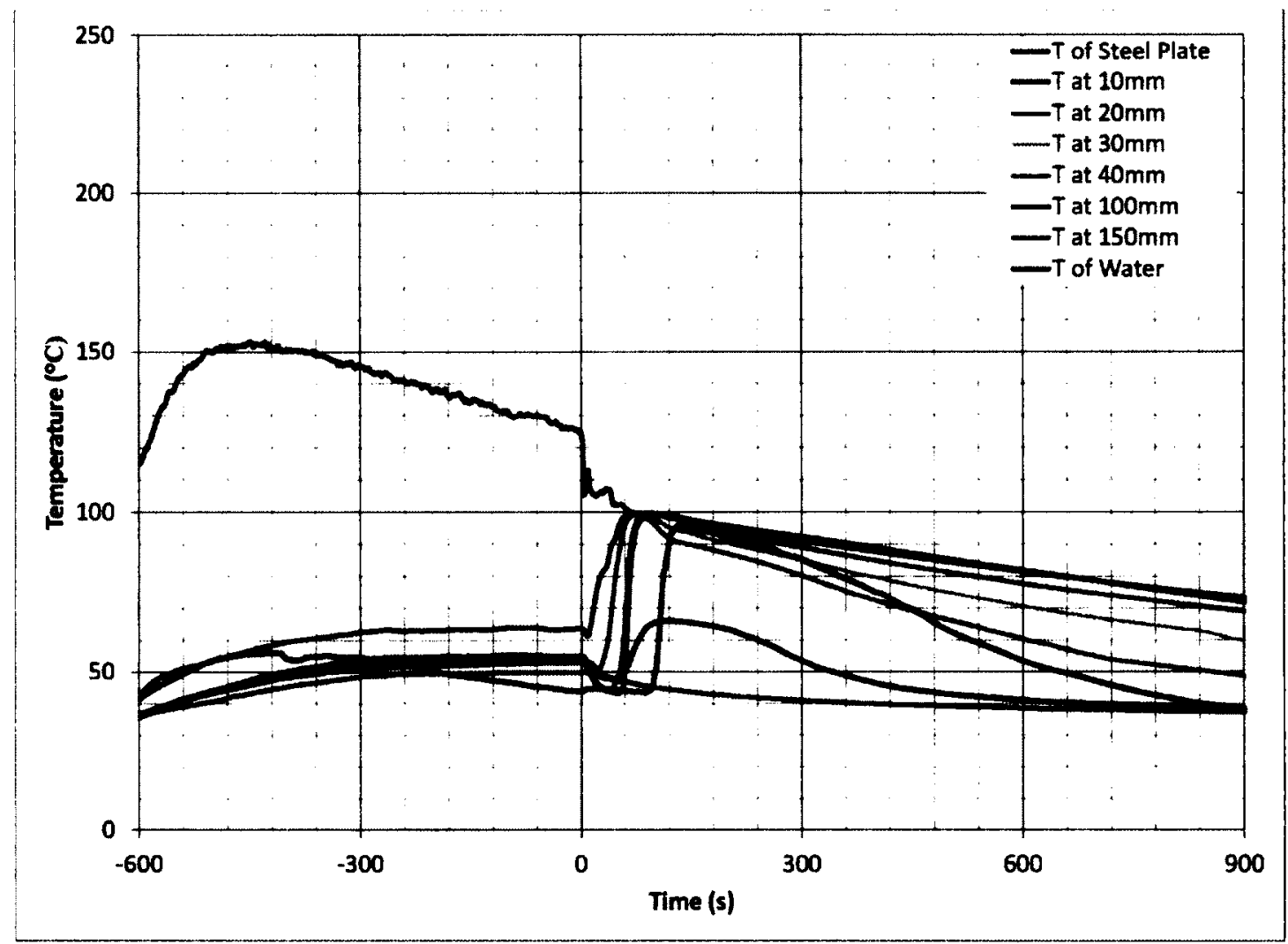

Fig. 5.4.11-1 Test 4A - 200 ce of AFFF AR, 3\%, expansion ratio 1:25, $125^{\circ} \mathrm{C}$ 
As the initial temperature of the steel plate was lowered, the vapour generation decreased and a negligible amount of vapour remained trapped by the foam. This was reflected by temperatures taken within the foam layer that were no longer higher than the temperatures of the steel plate. The mass of the drained liquid that was not evaporated was recorded, and the rate of drainage was calculated and graphed. See Fig. 5.4.11-2.

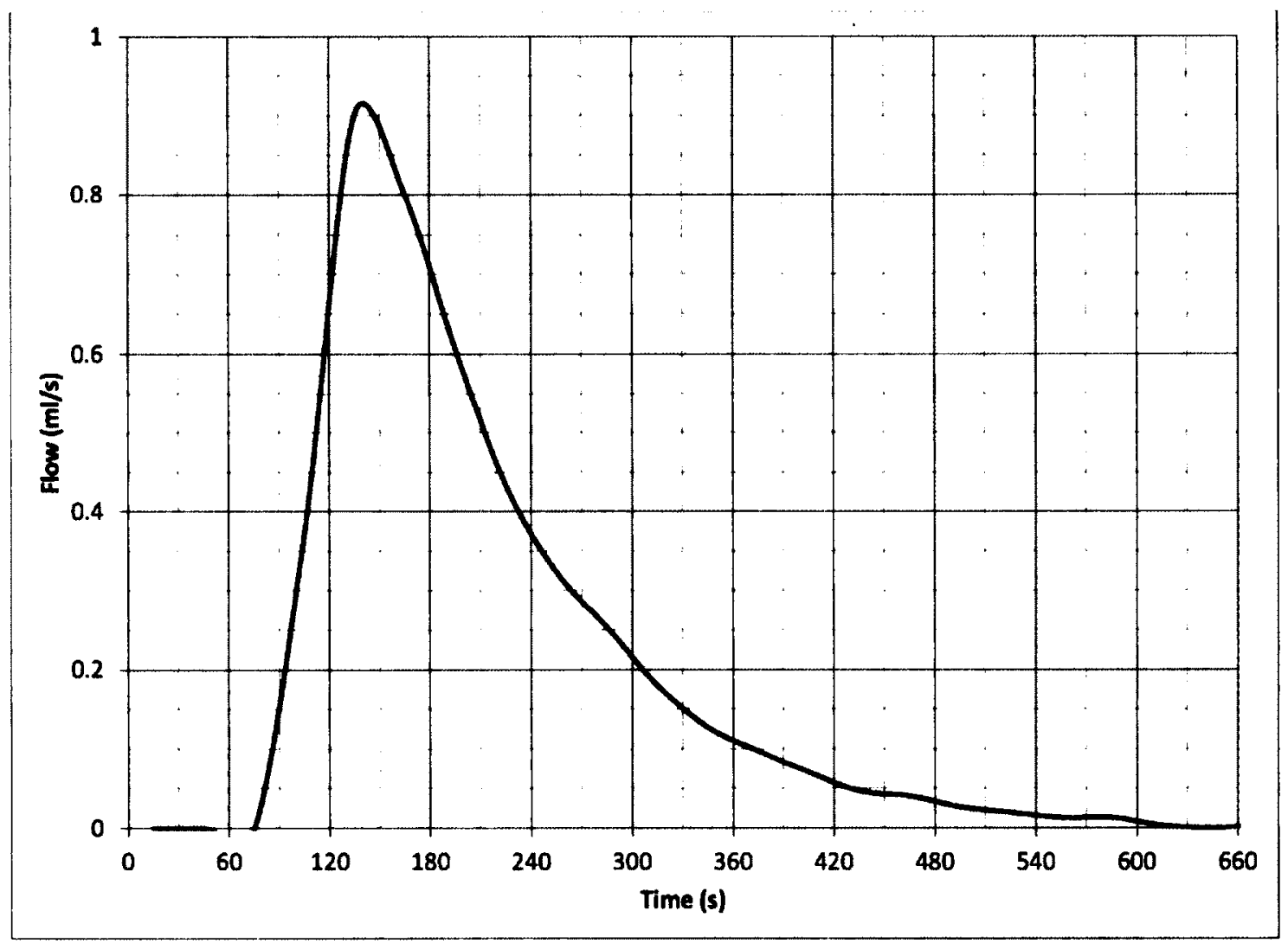

\section{Fig. 5.4.11-2 Test 4A - Foam water drainage}

When the top of the steel plate temperature was above $100^{\circ} \mathrm{C}$, small amounts of water drainage were seen during the initial cooling of the steel plate. 
The mass of the drained water that was collected was measured at $130.1 \mathrm{~g}$. The initial mass of the liquid was $197.6 \mathrm{~g}$ and the escaped vapour mass was calculated to be $67.5 \mathrm{~g}$.

\subsubsection{Test 4B}

In Test 4B, the foam used was $400 \mathrm{cc}$ of solution with $3 \%$ AFFF AR foam concentrate and expansion ratio of $1: 25$. The foam was sprayed over the $6.35 \mathrm{~mm}$ steel plate that was at $125^{\circ} \mathrm{C}$ at the time that the foam was inserted. The burner was stopped at $\mathrm{t}=-540$ seconds, restarted at $t=-480$ seconds and stopped again at $t=-300$ seconds. The foam was inserted at $\mathrm{t}=0$ seconds. The following graph Fig. (5.4.12-1) shows the temperatures recorded during the test. 


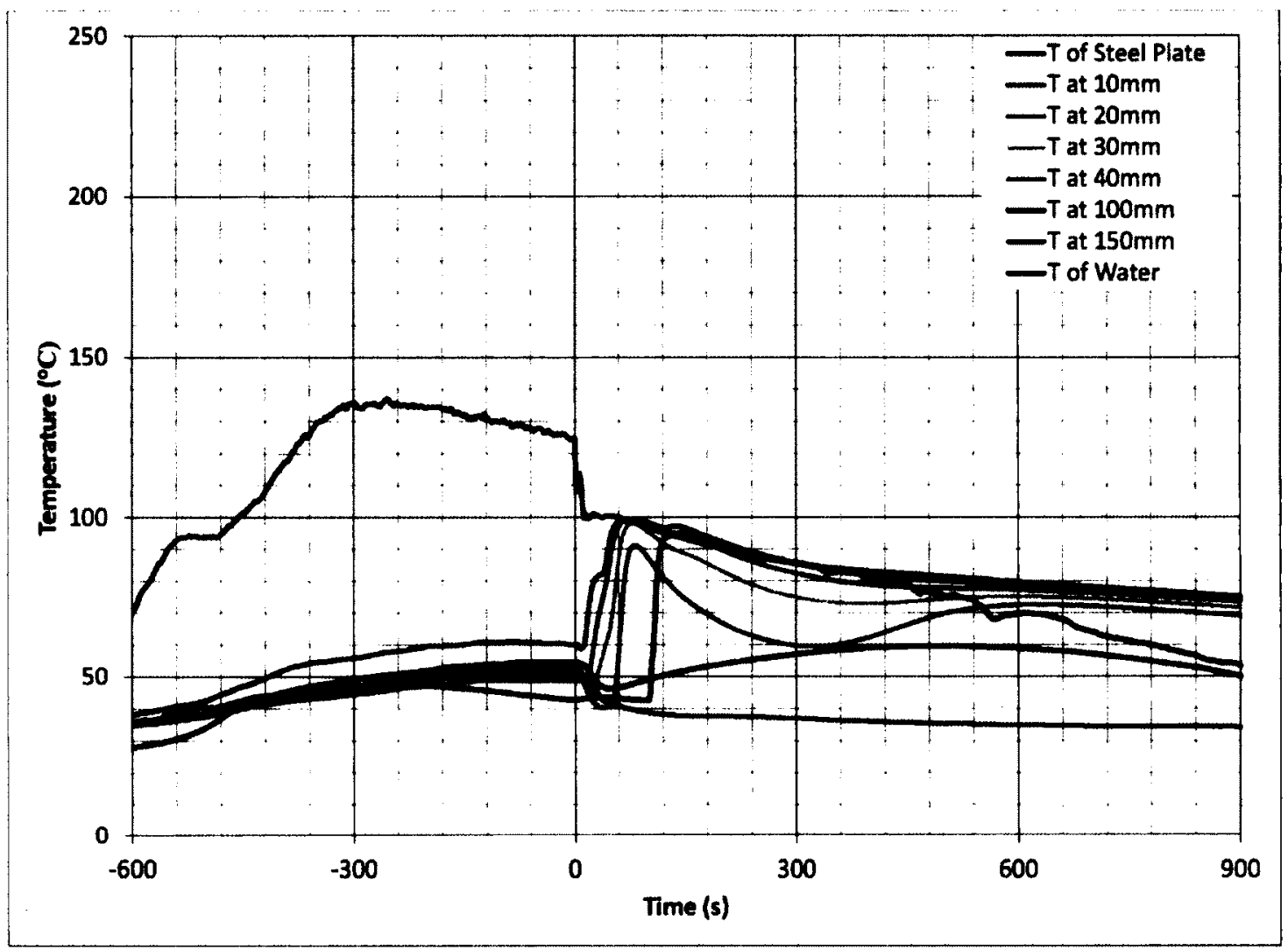

Fig. 5.4.12-1 Test $4 B-400$ ce of AFFF AR, 3\%, expansion ratio $1: 25,125^{\circ} \mathrm{C}$

As the amount of foam was doubled from Test $4 \mathrm{~A}$, the time for the temperature at the top of the steel plate drop to $100^{\circ} \mathrm{C}$ was reduced from 65 seconds to 10 seconds. This is attributed to the larger amount of liquid drained from the foam. As in the previous tests, the mass of water drained from the container was recorded and the rate of water drainage was calculated and graphed. See Fig. 5.4.12-2. 


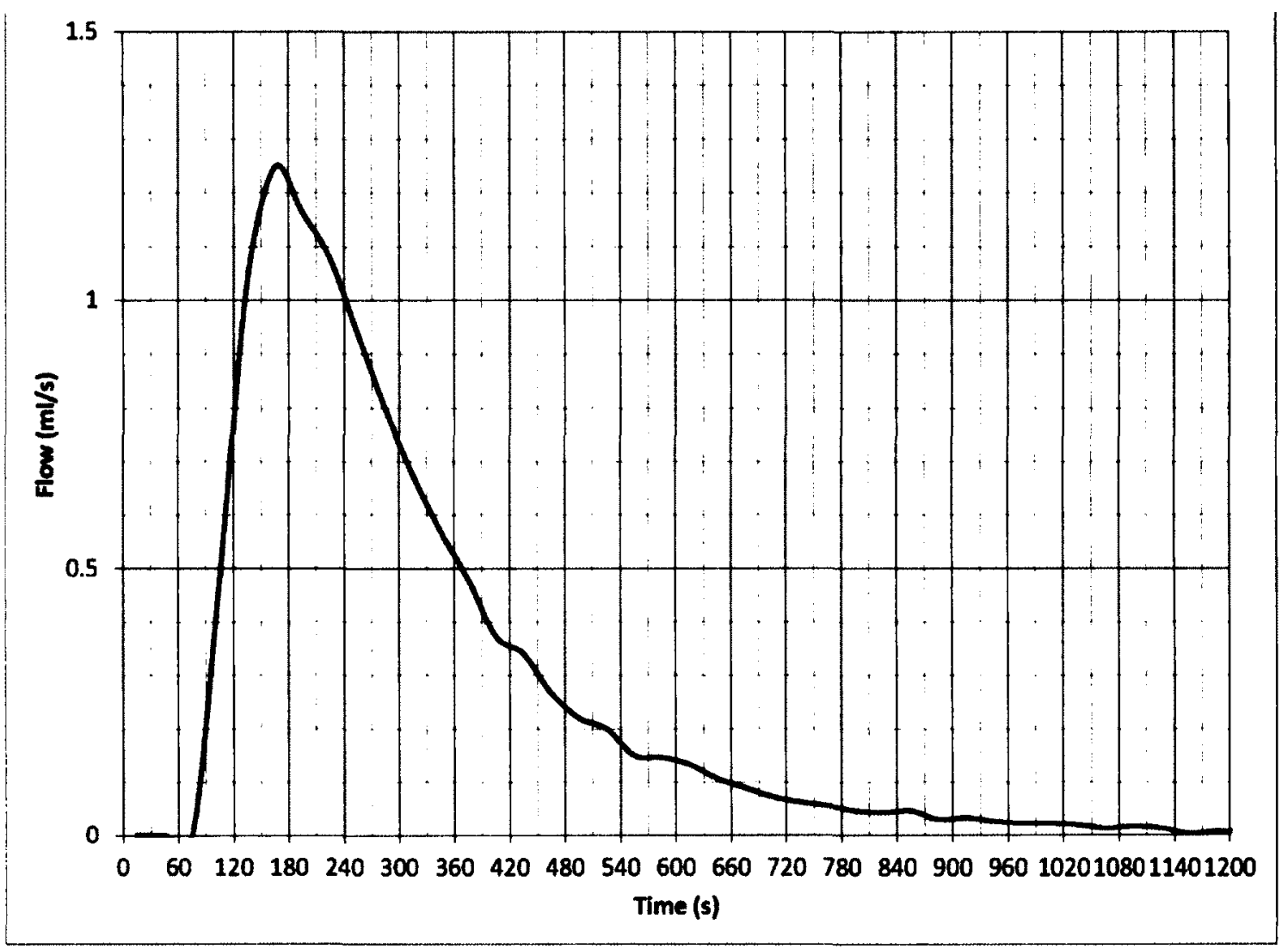

Fig. 5.4.12-2 Test 4B - Foam water drainage

As expected, the rate of water drainage was higher than in Test $4 \mathrm{~A}$ due to twice the amount of foam.

The mass of the drained water that was collected was measured at $331.8 \mathrm{~g}$. The initial mass of the liquid was $397.5 \mathrm{~g}$ and the escaped vapour mass was calculated to be $65.7 \mathrm{~g}$. 


\subsubsection{Test 5A}

In Test $5 \mathrm{~A}$, the foam used was $200 \mathrm{cc}$ of solution with $3 \%$ AFFF AR foam concentrate and expansion ration of 1:25. The foam was sprayed over the $6.35 \mathrm{~mm}$ steel plate that was at $100^{\circ} \mathrm{C}$ at the time that the foam was inserted. The burner was stopped at $\mathrm{t}=580$ seconds, restarted at $t=490$ seconds and stopped again at $t=-350$ seconds. The following graph Fig. (5.4.13-1) shows the temperatures recorded during the test. As small amount of vapour that was generated was noticed during the test and some vapour was noticed to escape across the foam layer.

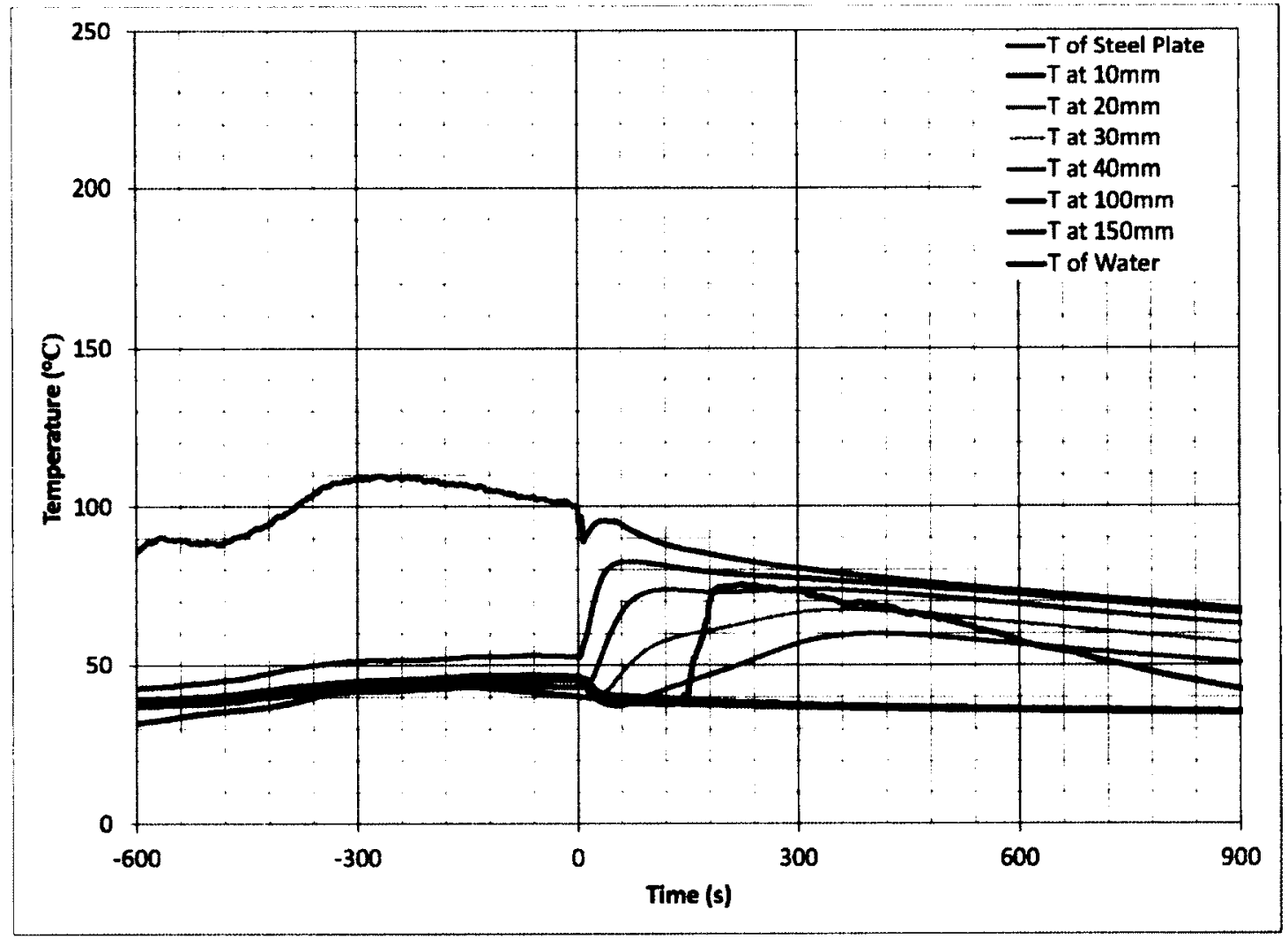

Fig. 5.4.13-1 Test 5A - 100 ce of AFFF AR, 3\%, expansion ratio 1:25, $100^{\circ} \mathrm{C}$ 
Any significant drainage started after 120 seconds as can be seen in Fig. 5.4.13-2. This coincides with the increase of temperature shown on curve "T of water" in Fig. 5.4.13-1. The increase in temperature measured at the top of the steel plate from $t=5$ seconds to $t=60$ seconds was due to the conduction of heat across the steel plate.

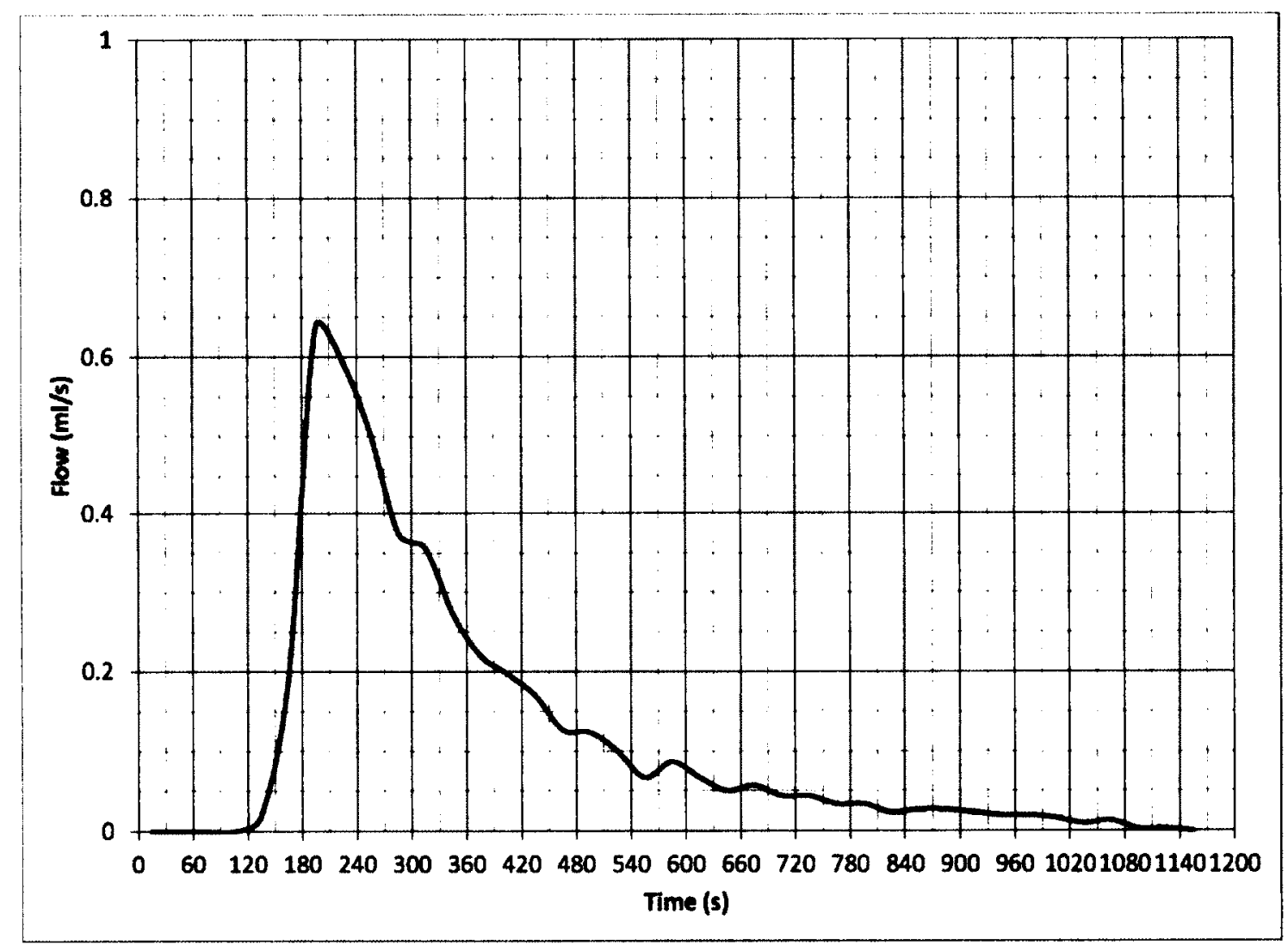

Fig. 5.4.13-2 Test 5A - Foam water drainage

The mass of the drained water that was collected was measured at $137.4 \mathrm{~g}$. The initial mass of the liquid was $197.7 \mathrm{~g}$ and the escaped vapour mass was calculated to be $60.3 \mathrm{~g}$. 
In Test $5 \mathrm{~A}$, a relatively large amount of vapour was released considering that the initial temperature of the top of the steel plate was $100^{\circ} \mathrm{C}$. This is attributed to the thermal mass of the steel plate. The temperatures under the floor and at the bottom of the floor were estimated at $560^{\circ} \mathrm{C}$ and $440^{\circ} \mathrm{C}$ respectively at $\mathrm{t}=0$ seconds by interpolating the temperatures measured under the floor and at the bottom of the floor in Test 1 at $t=480$ seconds (Fig. 5.2-1).

\subsection{Condensation of vapour in the foam laver analyses}

For mass conservation, the vapour that escaped into the atmosphere equals the initial mass of the foam concentrate and water, minus the mass of the liquid collected.

$\mathrm{M}_{\mathrm{v}}=\mathrm{M}_{\mathrm{fwi}}-\mathrm{M}_{\mathrm{fwc}}$

Where:

$$
\begin{aligned}
& M_{v}=\text { mass of vapour that escaped }(\mathrm{kg}) \\
& M_{\mathrm{fwi}}=\text { initial mass of foam concentrate and water }(\mathrm{kg}) \\
& M_{\mathrm{fwc}}=\text { collected mass of foam concentrate and water }(\mathrm{kg})
\end{aligned}
$$

The energy absorbed by the foam equals the energy to increase the temperature of the liquid and air in the foam, and to convert a portion of the liquid in the foam to vapour.

As not all parameters could be measured, the following approximations and assumptions were made:

- The energy to increase the air temperature in the foam was considered negligible. 
- The energy to increase the temperature of the liquid left in the foam and that did not drain was considered negligible. If the water evaporates and then condensates, then the energy is accounted for by the energy transferred to the foam. If the water is drained then this energy is accounted for in the average temperature of the drained water.

- The collected drained water average temperature was approximated to be $95^{\circ} \mathrm{C}$. This was based on the data obtained during the experiments. As most of the water drained between 90 seconds and 300 seconds, an average temperature of the draining water during this time period was approximately $95^{\circ} \mathrm{C}$

- The vapour temperature and evaporation temperature were approximated to be $100^{\circ} \mathrm{C}$.

The results for Test $2 \mathrm{~B}$ were used in the following analyses:

$Q=Q_{V}+Q_{W}$

Where:

$Q=$ energy absorbed by foam (kJ)

$Q_{V}=$ energy absorbed to convert liquid to vapour (kJ)

$Q_{W}=$ energy absorbed by draining water that was collected (kJ)

The average temperature of the air and the water-foam concentrate was $25^{\circ} \mathrm{C}$. The energy required to increase the temperature from $25^{\circ} \mathrm{C}$ to $100^{\circ} \mathrm{C}\left(\Delta \mathrm{T}_{1}\right)$, evaporate $124 \mathrm{~g}$ of water and to increase the temperature of $271 \mathrm{~g}$ of water from $25^{\circ} \mathrm{C}$ to $95^{\circ} \mathrm{C}\left(\Delta \mathrm{T}_{2}\right)$ is: 
$Q=Q_{V}+Q_{W}=\left(\Delta T_{1}\left(c_{P W}\right) M_{v}\right)+\left(h_{f g} M_{v}\right)+\left(\Delta T_{2}\left(c_{P W}\right) M_{f u c}\right)$

$Q=(75 \times 4.18 \times 0.124)+(2270 \times 0.124)+(70 \times 4.18 \times 0.271)=$

$38.87+281.48+79.29=399.64(K J)$

Table 5.5-1 provides the summary of similar calculations done for all the tests:

Table 5.5-1 Condensation of vapour experiments data

\begin{tabular}{|c|c|c|c|c|c|c|c|c|}
\hline Test & $\begin{array}{l}\text { Expansion } \\
\text { ratio }\end{array}$ & $\begin{array}{l}\text { steel surface } \\
\text { temperature }\end{array}$ & $\begin{array}{l}M_{\text {wwi }} \\
(g)\end{array}$ & $\begin{array}{c}M_{\text {fwc }} \\
(g)\end{array}$ & $\begin{array}{l}M_{v} \\
\text { (g) }\end{array}$ & $\begin{array}{l}Q_{w} \\
(\mathrm{KJ})\end{array}$ & $\begin{array}{c}Q_{V} \\
(K J)\end{array}$ & $\begin{array}{c}Q \\
(K J)\end{array}$ \\
\hline $1 \mathrm{~A}$ & $1: 25$ & $200^{\circ} \mathrm{C}$ & 197.8 & 51.2 & 146.6 & 15.0 & 378.7 & 393.7 \\
\hline $1 \mathrm{~B}$ & $1: 25$ & $200^{\circ} \mathrm{C}$ & 396.1 & 255.4 & 140.7 & 74.7 & 363.5 & 438.2 \\
\hline $1 \mathrm{C}$ & $1: 25$ & $200^{\circ} \mathrm{C}$ & 591.7 & 431.4 & 160.3 & 126.2 & 414.1 & 540.4 \\
\hline $1 D$ & $1: 8.7$ & $200^{\circ} \mathrm{C}$ & 399.4 & 232.9 & 166.5 & 68.1 & 430.2 & 498.3 \\
\hline $1 E$ & $1: 8.7$ & $200^{\circ} \mathrm{C}$ & 597.7 & 443.2 & 154.5 & 129.7 & 399.2 & 528.8 \\
\hline $2 A$ & $1: 25$ & $175^{\circ} \mathrm{C}$ & 198.6 & 74.4 & 124.2 & 21.8 & 320.9 & 342.6 \\
\hline $2 \mathrm{~B}$ & $1: 25$ & $175^{\circ} \mathrm{C}$ & 394.8 & 271.2 & 123.6 & 79.4 & 319.3 & 398.7 \\
\hline $2 \mathrm{C}$ & $1: 25$ & $175^{\circ} \mathrm{C}$ & 594.6 & 478.1 & 115.5 & 139.9 & 301.0 & 440.9 \\
\hline $3 A$ & $1: 25$ & $150^{\circ} \mathrm{C}$ & 197.6 & 112.6 & 85 & 32.9 & 219.6 & 252.5 \\
\hline $3 B$ & $1: 25$ & $150^{\circ} \mathrm{C}$ & 397 & 298.4 & 99.6 & 87.3 & 254.7 & 342.0 \\
\hline $4 A$ & $1: 25$ & $125^{\circ} \mathrm{C}$ & 197.6 & 130.1 & 67.5 & 38.1 & 174.4 & 212.5 \\
\hline $4 B$ & $1: 25$ & $125^{\circ} \mathrm{C}$ & 397.5 & 331.8 & 65.7 & 97.1 & 169.7 & 266.8 \\
\hline $5 A$ & $1: 25$ & $100^{\circ} \mathrm{C}$ & 197.7 & 137.4 & 60.3 & 40.2 & 155.8 & 196.0 \\
\hline \multicolumn{9}{|c|}{$\begin{array}{l}\text { Miwi is mass of foam concentrate and water mix } \\
M_{\text {iwc }} \text { is mass of foam concentrate and water drained and collected } \\
M_{\mathrm{y}} \text { is calculated mass of escaped vapour }\end{array}$} \\
\hline
\end{tabular}


As expected, a portion of the energy was absorbed by raising the water temperature to $100^{\circ} \mathrm{C}$. A significantly greater amount of energy was absorbed by changing the state of some of this water from liquid to gas.

If a large amount of water vapour was absorbed by the foam, then it would be expected higher the foam layer, the rate of vapour condensation in the foam layer would increase. Therefore if a significant amount of vapour condenses in the foam layer, the vapour loss to the atmosphere should decrease as the amount of foam is increased for the same initial steel plate temperature. Based on the data collected from the above-mentioned experiments, it can be concluded that there is no significant change of the vapour loss to the atmosphere for the same initial temperature of the steel plate. This can be observed in the results listed in Table 5.5-1 for Test 2A that in which $124 \mathrm{~g}$ of vapour escaped, Test 2B in which $123 \mathrm{~g}$ of vapour escaped and Test 2C in which $115 \mathrm{~g}$ of vapour escaped. Additionally, it can be concluded that there is no major change in the mass of the liquid evaporated when compared to the amount of foam used.

In fact, it was found that most of the vapour escaped into the atmosphere and the "heat pump" effect was found to be negligible.

By comparing the results of escaped vapour listed in Table 5.5-1 for Test 1C that had an expansion ratio of 1:25 and had $160 \mathrm{~g}$ of escaped vapour to Test $1 \mathrm{E}$ that had an expansion ratio of 1:8.7 and had $154 \mathrm{~g}$ of escaped vapour, it can also be concluded that 
the vapour condensation in the foam layer is negligible regardless of the foam expansion ratio.

Since most of the energy is absorbed by the water content of the foam as it is converted to vapour, the energy absorbed by the foam (vapour) can be calculated. This finding is a very significant factor in determining the amount of foam required in extinguishing fires.

\subsection{Newton's Law of Cooling}

From the absorption of vapour experiments, it can be concluded that most of the energy transfer from the hot surface to the foam will be used to convert the liquid in the foam to vapour when comparing the energy absorbed by heating the foam or heating the draining water up to temperatures of $95^{\circ} \mathrm{C}$ to $100^{\circ} \mathrm{C}$. This is based on the energy calculations in section 5.2 and comparing the results with Test $1 \mathrm{C}$.

One of the important objectives of this study is to establish and validate a method to predict the cooling ability of the CAF and to determine the optimal foam discharge density in order to use a minimum amount of foam and still provide maximum cooling.

As the foam is made up of liquid and air, the heat transfer between the hot steel plate surface and the foam will be in a form of convection. The following analyses are based on the scenario where a steel plate is heated and the surface of the steel plate is above $100^{\circ} \mathrm{C}$ when the foam is sprayed on top of the hot plate. 
As the foam comes in contact with the hot surface, the bubbles that are affected by the hot surface burst, and the liquid (water foam concentrate) that was forming the bubble surface either evaporates or drains as was demonstrated in the previous section of this study. The vapour moves upward through the foam and causes an accelerated breakage of the surrounding bubbles and causes drainage of the foam. This is documented in a study by Magrabi, Dlugogorski and Jameson. [37]

If the heat transfer between the hot surface and the foam could be determined, it would be possible to predict the foam's ability to cool the surface and also to predict the fire extinguishing performance of the foam.

In general, heat transfer due to convection can be calculated using Newton's Law of Cooling where the heat flux is proportional to the difference between the surface and the fluid temperatures and the proportionality is known as the convective heat transfer coefficient [60].

$\dot{q}=h A\left(T_{0}-T_{\infty}\right)$

Where

$$
\begin{aligned}
& \dot{q}=\text { rate of energy (heat) flow }(\mathrm{kJ} / \mathrm{s}) \\
& h=\text { convective heat transfer coefficient }\left(\mathrm{W} / \mathrm{m}^{2} \mathrm{~K}\right) \\
& T_{0}=\text { temperature of the surface }\left({ }^{\circ} \mathrm{C}\right) \\
& T_{\infty}=\text { temperature of the gas } / \text { liquid }\left({ }^{\circ} \mathrm{C}\right)
\end{aligned}
$$




$$
A=\text { surface } \operatorname{area}\left(\mathrm{m}^{2}\right)
$$

From observation of the foam's behaviour, it can be determined that there are two different phases of heat transfer:

- Phase 1 is when the foam is in contact with a surface having a temperature at or above $100^{\circ} \mathrm{C}$ and a rapid evaporation of the water content in the foam takes place, and

- Phase 2 is when the surface is below $100^{\circ} \mathrm{C}$ and the water content in the foam drains.

To determine the convective heat transfer coefficient using the foam properties and the heat transfer across the steel plate is extremely difficult. This is due to the decomposition of the foam and due to the transient state of the heat transfer across the steel plate. The following section describes a simplified method used to get the heat transfer coefficient between the steel surface and foam when the steel temperature is above $100^{\circ} \mathrm{C}$.

\subsection{Convective Heat Transfer Coefficient for Surface Temperature above $100^{\circ} \mathrm{C}$}

A series of experiments was conducted to determine the convective heat transfer coefficient for conditions when the surface temperature is at or above $100^{\circ} \mathrm{C}$. In equation 5.6-1, $T_{\infty}$ represents the ambient fluid temperature. The initial temperature of the foam when the foam was sprayed over the hot steel plate surface was approximately $25^{\circ} \mathrm{C}$. The foam drain flow only starts after the floor surface (steel plate) is at or below $100^{\circ} \mathrm{C}$. In the 
initial stages of the foam application, most of the liquid that is in contact with the hot surface evaporates.

If the fluid temperature changes with time, equation 5.5-1 would take the following form:

$$
\dot{q}(t)=h_{f} A\left(T_{s}(t)-T_{\infty}(t)\right)
$$

Where:

$h_{f}$ is the steel to foam convective heat transfer coefficient

$T_{s}$ is the surface temperature in ${ }^{\circ} \mathrm{K}$ that varies with time

$T_{\infty}$ is the temperature of the fluid that varies with time

\subsubsection{Theory}

Heat transfer from the plate to the foam when the plate temperature is above $100^{\circ} \mathrm{C}$ can be calculated using equation $5.7-1$

$\dot{q}(t)=h_{f} A\left(T_{s}(t)-T_{\infty}(t)\right)$

By integrating the rate of energy from the start of evaporation to the end of evaporation the energy absorbed by the foam can be calculated as follows:

$$
Q=\int_{t_{0}}^{t_{1}} \dot{q} d t=\int_{t_{0}}^{t_{1}} h_{f} A\left(T_{s}(t)-T_{\infty}(t)\right) d t
$$

Where:

$\mathrm{Q}=$ Energy absorbed by foam and converted to vapour

$t_{0}=$ time at the insertion of the foam

$t_{t}=$ time at the end of evaporation 
Assuming that $h_{f}$ is a constant with respect to time, equation 5.7.1-2 can be re-written as:

$$
Q=\int_{t_{0}}^{t_{1}} \dot{q} d t=h_{f} A \int_{t_{0}}^{t_{1}}\left(T_{s}(t)-T_{\infty}(t)\right) d t
$$

The heat transfer coefficient can be used to estimate the heat flow that is absorbed by the foam to convert the water content of the foam to vapour.

If $100 \%$ of the foam is evaporated, then the energy absorbed by the foam can be calculated and the energy absorbed would be:

$$
Q=\left(\Delta T\left(c_{P W}\right) M_{W}\right)+\left(h_{f g} M_{W}\right)
$$

Where:

$$
\begin{aligned}
& Q=\text { energy absorbed by the foam }(\mathrm{KJ}) \\
& \Delta T=\text { change of temperature of liquid from insertion temperature to evaporation } \\
& \text { temperature. }\left({ }^{\circ} \mathrm{K}\right) \\
& c_{p w}=\text { specific heat of water }=4.18(\mathrm{~kJ} / \mathrm{kgK}) \\
& M_{w}=\text { mass of liquid }(\mathrm{kg}) \\
& h_{f \mathcal{g}}=\text { latent heat of evaporation }=2,270(\mathrm{~kJ} / \mathrm{kg})
\end{aligned}
$$

The time that it takes for all of the foam to evaporate can be measured. Based on the absorption of vapour experiments 1A, 1B and 1C, for an initial steel plate temperature of $200^{\circ} \mathrm{C}$, when a foam consisting of only $80 \mathrm{cc}$ of water foam concentrate is discharged over the steel plate at $200^{\circ} \mathrm{C}$, then it is expected that $100 \%$ of the foam will evaporate and no drainage water will be collected. In this case, the energy absorbed by the foam would be:

- increase the temperature of $80 \mathrm{cc}$ of water from $25^{\circ} \mathrm{C}$ to $100^{\circ} \mathrm{C}$, and 
- evaporate $80 \mathrm{cc}$ of water.

$Q=(75 \times 4.18 \times 0.080)+(2270 \times 0.080)=206.7(\mathrm{~kJ})$

As stated in Fundamentals of Heat Transfer: "The transfer coefficient is an attempt to encompass in a single quantity all of the effects that influence the convection. The calculations to determine the heat transfer coefficient are complex and provide only an estimate as some of the conditions will vary" [60]. The heat transfer coefficient includes a number of parameters and based on the literature review, the evaporation of the liquid on the surface is a major factor.

As the time period of the evaporation is relatively short, the foam temperature did not increase. The foam surface temperature was measured and remained at $25^{\circ} \mathrm{C}$ during the first 3 minutes of the experiment in the area that was not affected by the vapour penetration. It was observed during the experiments that the duration of Phase 1 (when the surface temperature is at or above $100^{\circ} \mathrm{C}$ ) is relatively short. See the figures in section 5.3. It was also observed that the foam temperature near the floor surface varied due to the vapour lifting sections of the foam. Vapour bubbles were noticed near the thermocouples measuring the foam temperature. These "vapour tunnels" were observed during the tests and were noticed at different locations. 
The locations of the vapour bubbles were not consistent among tests and this affected the temperature readings inside the foam layer, which were also not consistent among tests. This variation of temperature where the vapour was escaping from the foam was also manually measured at the foam surface.

The foam temperature, that was not affected by vapour, was found to be approximately $25^{\circ} \mathrm{C}$ within two minutes of the foam's insertion while the surface temperature of the steel plate temperature was at or above $100^{\circ} \mathrm{C}$. This indicated that the area within the foam layer, where the temperature was $25^{\circ} \mathrm{C}$, was above the boundary layer. Hence $25^{\circ} \mathrm{C}$ was used for $T_{\infty}$.

Equation 5.7.1-3 requires to integrate a function that varies with time. The integral can be approximated by the following equation replacing the integral by summation:

$$
Q=h_{f} A \sum_{i=t_{0}}^{t_{1}}\left(\frac{T_{s}(i)-T_{s}(i+1)}{2}-T_{\infty}\right) \Delta t
$$

Where

$$
\begin{aligned}
& t_{0}=\text { time at foam insertion } \\
& t_{1}=\text { time at end of evaporation }
\end{aligned}
$$

As the measurements were taken at every 2 seconds, the time step is 2 and the equation 5.7.1-5 is modified to:

$$
Q=h_{f} A \sum_{i=t_{0}}^{t / 2}\left(\frac{T_{s}(2 i)-T_{s}(2 i+2)}{2}-T_{\infty}\right) \Delta t
$$


To solve for $h_{f}$ :

$\left.h_{f}=Q / A \sum_{i=t_{0}}^{t_{t}^{\prime 2}}\left(\frac{T_{s}(2 i)+T_{s}(2 i+2)}{2}\right)-T_{\infty}\right) \Delta t$

Using the surface temperature of the steel plate which was recorded every 2 seconds from the time that the foam is introduced onto the steel plate until the time the foam has completely disintegrated, the value of the foam heat transfer coefficient was computed.

\subsubsection{Experiments}

To test the above theory, an experiment (6-1) was conducted, using $80 \mathrm{cc}$ of foam concentrate with AFFF AR at 3\%. The water mix was measured and then poured into the foam generator. The foam expansion ratio was 1:25.

The heat transfer foam holding tank described in section 4.2 .3 was used. A $6.35 \mathrm{~mm}$ thick steel plate was placed directly on the floor of the heat transfer foam holding tank. A thermocouple was attached to the top surface of the steel plate. The floor of the tank was heated with a gas burner and the top of the steel plate temperature was monitored. When a temperature of $200^{\circ} \mathrm{C}$ was reached, the burner was shut off. The top of the steel plate temperature still climbed several degrees. After reaching the maximum temperature, the steel plate surface temperature decreased, and when the surface temperature dropped to $200^{\circ} \mathrm{C}$, all the foam produced from the pre-measured water and foam concentrate mix was sprayed over the hot steel plate. See Fig 5.7.2-1 and Fig 5.7.2-2 for details. 


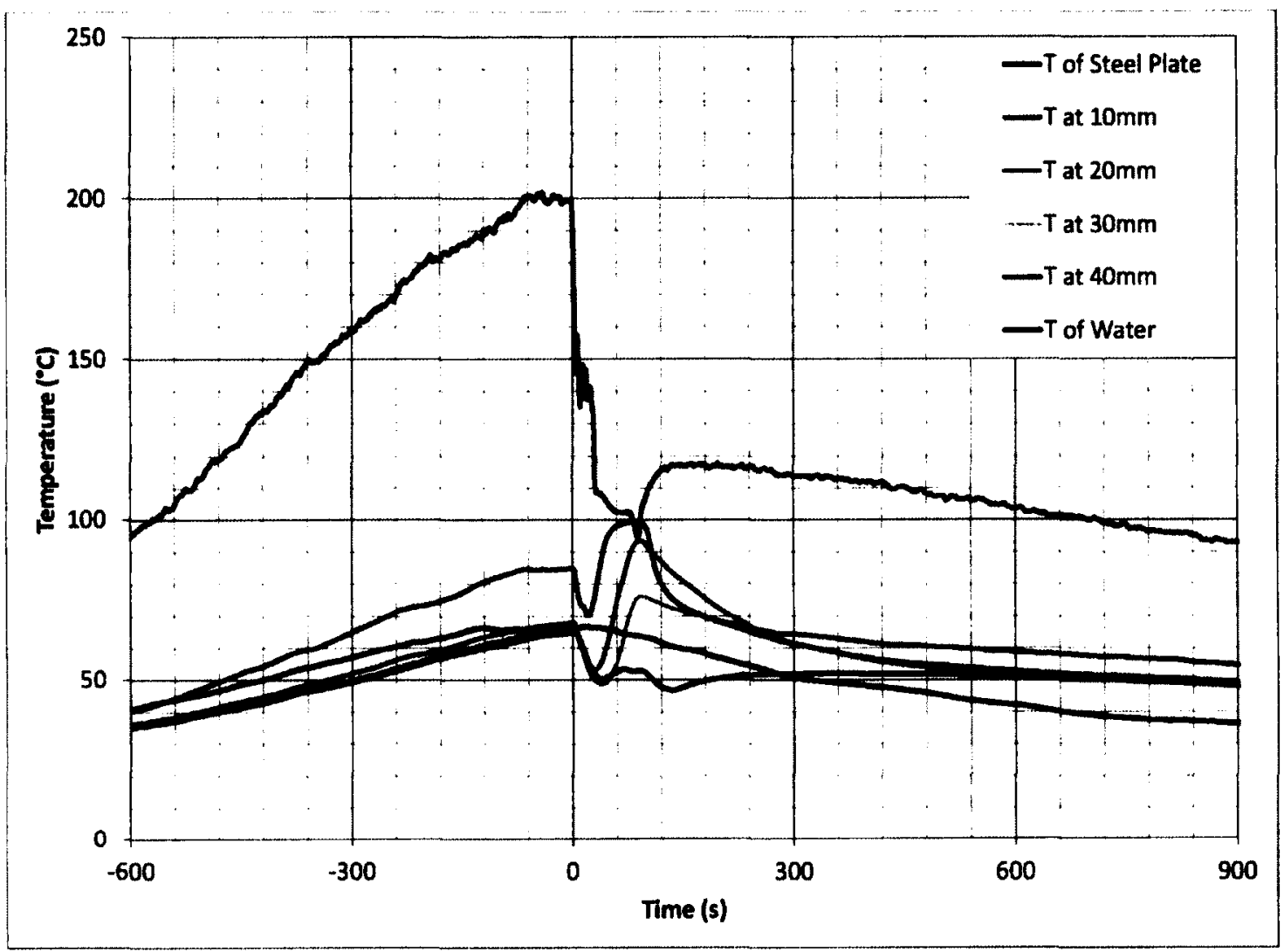

Fig. 5.7.2-1 Test 6-1 - 80cc of foam over steel plate at $200^{\circ} \mathrm{C}$, expansion ratio 1:25 


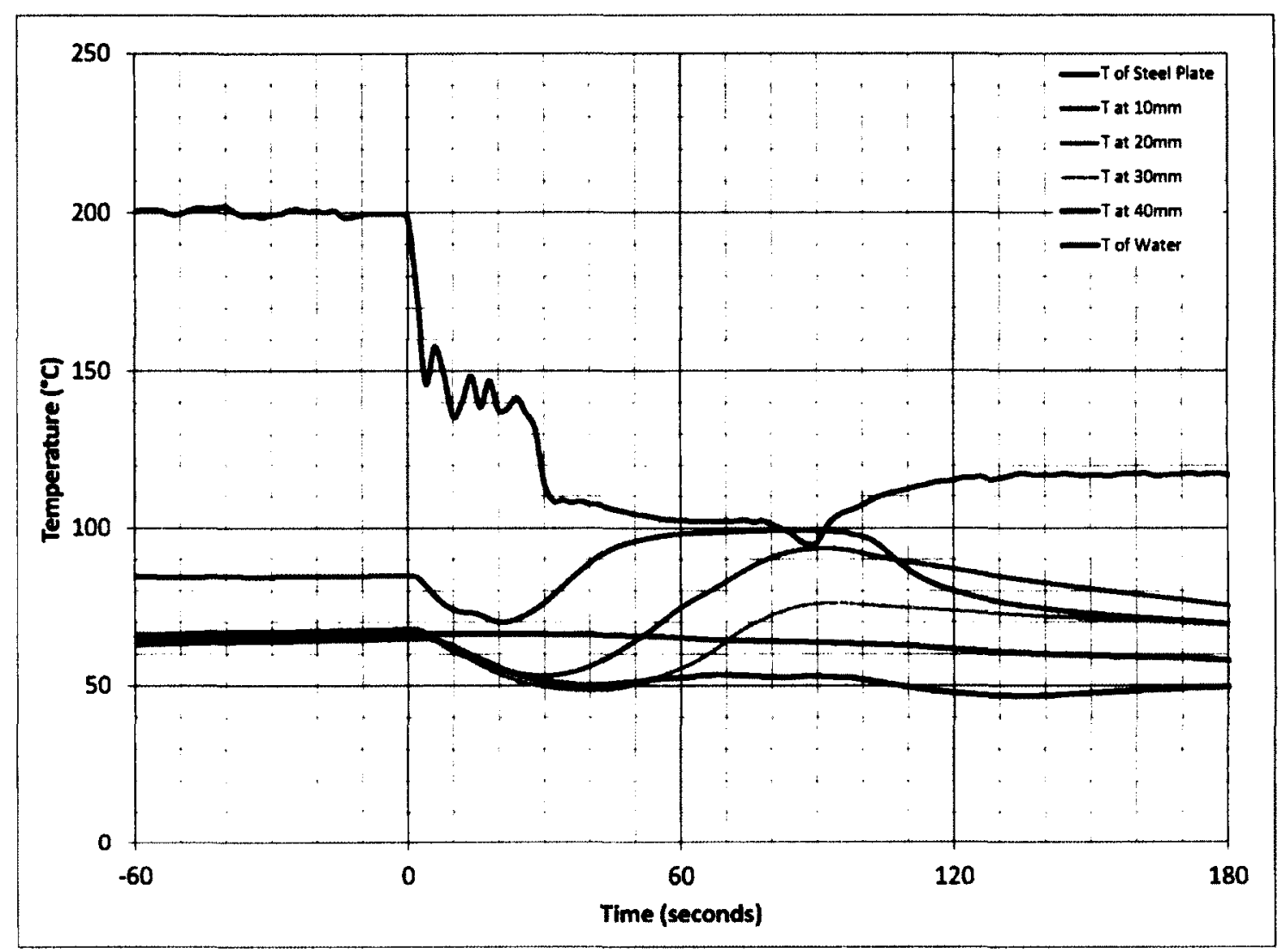

Fig. 5.7.2-2 Test 6-1 - 80cc of foam over steel plate at $200^{\circ} \mathrm{C}$ detailed

The temperature of the steel plate was monitored and recorded every two seconds. The foam was left to disintegrate and completely evaporate. For the first 30 seconds, massive vapour generation was observed; during that time, the temperature of the top of steel plate dropped sharply and then fluctuated. As all the available drained water had evaporated, the surface temperature of the steel increased slightly and then dropped as more drainage water was released from the foam. 
At approximately $\mathrm{t}=80$ seconds, the remaining foam disintegrated and caused a small liquid accumulation near the thermocouple measuring the temperature at the top of the steel plate. The foam completely evaporated at $t=88$ seconds.

There was no water (foam solution) drained from the foam container and all of the foam evaporated. As all of the foam evaporated, there was no vapour bubbles that could affect the temperature measured above the steel plate and the temperature above the steel plate was lower than the temperature measured at the top of the steel plate.

Using the Labview software and transferring the data to an Excel spread sheet, the following results shown in Table 5.7.2-1 were obtained. 
Table 5.7.2-1 Test 6-1 - Calculation of convective steel to foam heat transfer

Calculation of $h$ using foam made of $80 c c$ of water foam concentrate on a plate with initial temperature of 200 des $C$

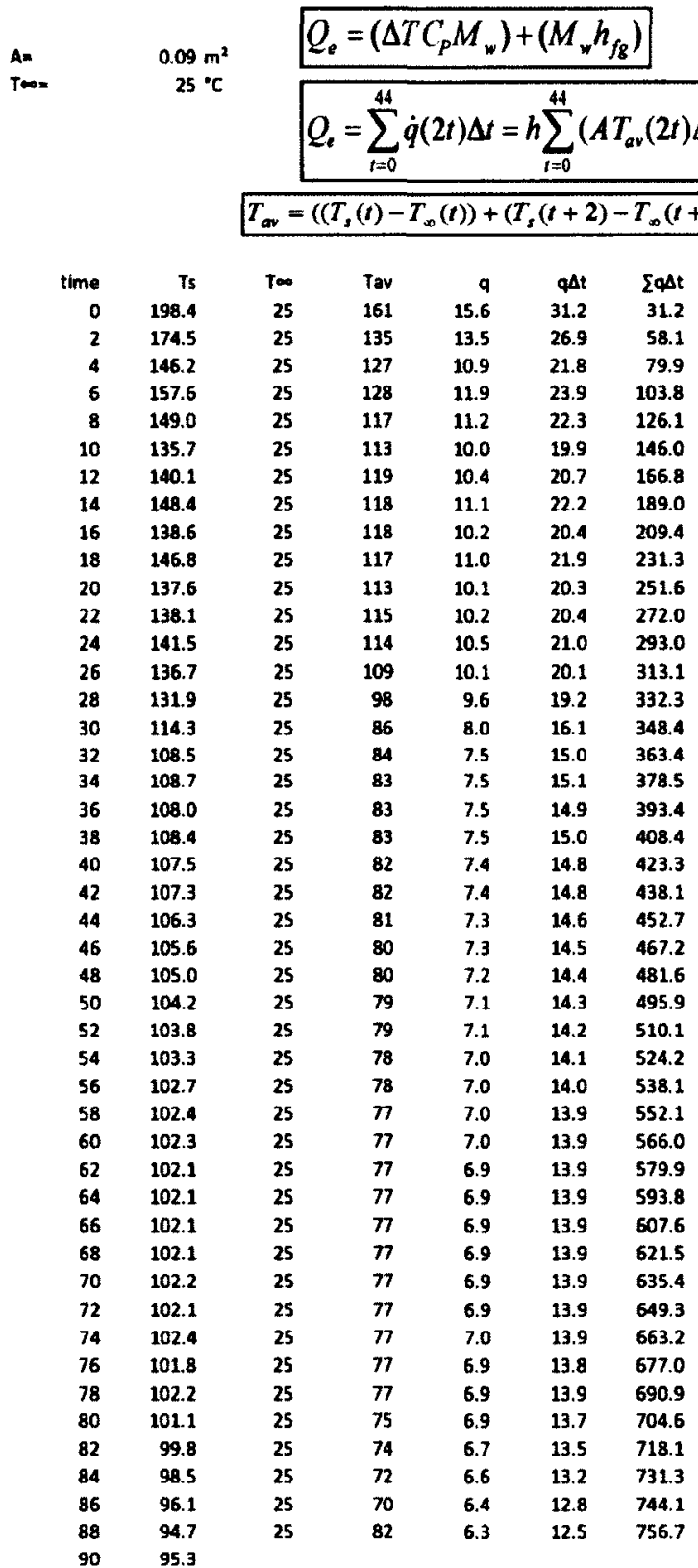




$$
\begin{aligned}
& Q_{e}=\left(\Delta T C_{P} M_{w}\right)+\left(M_{w} h_{f g}\right)
\end{aligned}
$$

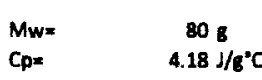

$$
\begin{aligned}
& \text { htg= } \quad 2270 \mathrm{~d} / \mathrm{s} \\
& \begin{array}{ll}
\Delta T= & 75^{\circ} \mathrm{C} \\
\text { Qe* } \quad 206680 \mathrm{~J}
\end{array} \\
& Q_{e}=\sum_{t=0}^{44} \dot{q}(2 t) \Delta t=h \sum_{t=0}^{44}\left(A T_{a v}(2 t) \Delta t\right) \\
& h=\frac{Q}{\sum_{t=0}^{44}\left(A T_{a v}(2 t) \Delta t\right)} \\
& \sum_{t=0}^{44}\left(A T_{a v}(2 t) \Delta t\right)=756.692 \\
& \text { h* } 273
\end{aligned}
$$

The convective heat transfer coefficient was calculated to be $273 \mathrm{~kW} / \mathrm{m}^{2} \mathrm{~K}$.

\subsubsection{Verification of the validity of the convective heat transfer coefficient}

Four additional experiments (6-2, 6-3, 6-4 and 6-5) were completed to verify the validity of the model to obtain the convective heat transfer coefficient.

These experiments were similar to Test 6-1 described above, but the amount of foam and the initial temperature of the steel plate were varied. The following Table 5.7.3-1 provides the summary of the test configurations. 
Table 5.7.3-1 Tests to determine the steel to foam convective heat transfer coefficient

\begin{tabular}{|c|c|c|c|c|c|c|c|}
\hline Test & Foam type & $\begin{array}{c}\text { Concentrate } \\
\%\end{array}$ & $\begin{array}{l}\text { Expansion } \\
\text { ratio }\end{array}$ & $\begin{array}{l}\text { steel surface } \\
\text { temperature }\end{array}$ & $\begin{array}{l}M_{\text {fwi }} \\
\text { (g) }\end{array}$ & $\begin{array}{l}Q_{\theta} \\
(K J)\end{array}$ & $\begin{array}{c}Q_{h} \\
(K J)\end{array}$ \\
\hline $6-1$ & AFFF - AR & 3 & $1: 25$ & $200^{\circ} \mathrm{C}$ & 80 & 208 & 208 \\
\hline $6-2$ & AFFF - AR & 3 & $1: 25$ & $200^{\circ} \mathrm{C}$ & 100 & 260 & 253 \\
\hline $6-3$ & AFFF - AR & 3 & $1: 25$ & $200^{\circ} \mathrm{C}$ & 60 & 156 & 166 \\
\hline $6-4$ & AFFF - AR & 2 & $1: 8.7$ & $175^{\circ} \mathrm{C}$ & 60 & 156 & 160 \\
\hline $6-5$ & AFFF - AR & 2 & $1: 8.7$ & $150^{\circ} \mathrm{C}$ & 60 & 156 & 167 \\
\hline $\begin{array}{l}M_{\text {twi }} \\
Q_{\theta}= \\
Q_{h}=\end{array}$ & $\begin{array}{l}\text { mass of foam } \\
\text { nergy absorb } \\
\text { nergy calcula }\end{array}$ & $\begin{array}{l}\text { that was inser } \\
\text { d calculated } \\
\text { ed using heat }\end{array}$ & ig equation & $\begin{array}{l}6.1-1 \\
\text { ent of } 273(\end{array}$ & & & \\
\hline
\end{tabular}

\section{Validation Test 6-2}

$100 \mathrm{cc}$ of foam concentrate using 3\% AFFF AR with an expansion ratio of 1:25 was used. The initial steel plate temperature at the insertion of the foam was $200^{\circ} \mathrm{C}$. The foam mass was slightly higher in this experiment than in Test 6-1 so more water was available for drainage. This resulted in fewer fluctuations after the initial drop of the surface temperature of the top of the steel plate. The recorded temperatures of the top of steel plate and the foam at $10 \mathrm{~mm}$ height between $\mathrm{t}=70$ seconds to 100 seconds are the same. This was mostly due to the vapour that was affecting the thermocouple located $10 \mathrm{~mm}$ from the floor. The vapour escaping from the foam was visible during this time. All the foam had evaporated by $t=104$ seconds. 


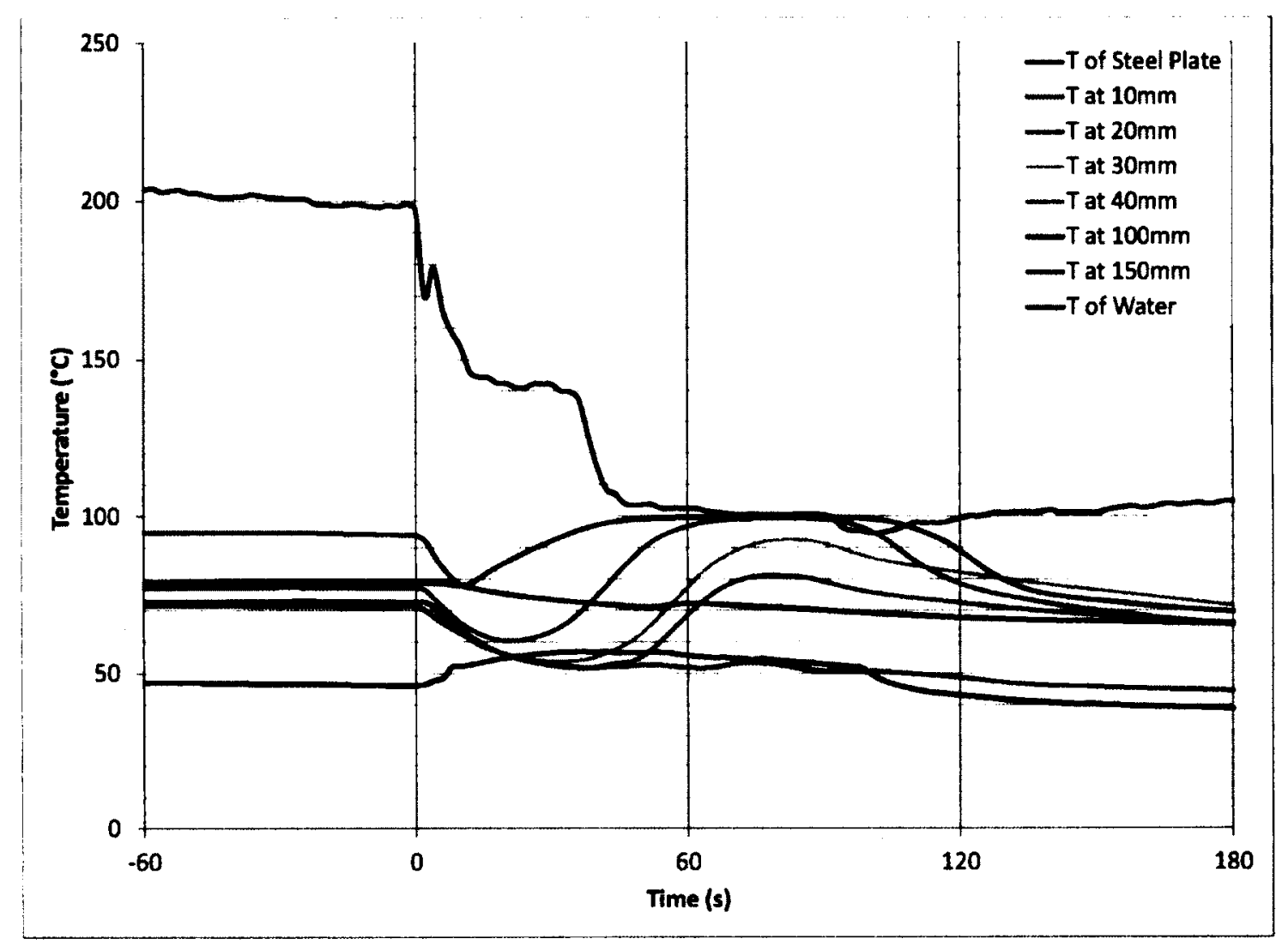

Fig. 5.7.3-1 Test 6-2 - 100cc of foam over steel plate at $200^{\circ} \mathrm{C}$ expansion 1:25

The graph of the data collected is shown in Fig. 5.7.3-1 and the details of calculations are shown in Table 5.7.3-2. 
Table 5.7.3-2 Test 6-2 - 100cc of foam over steel plate at $200^{\circ} \mathrm{C}$ expansion 1:25

\begin{tabular}{|c|c|c|c|c|c|c|c|}
\hline \multirow{3}{*}{$\begin{array}{l}n= \\
\text { Aone } \\
\text { time }\end{array}$} & \multirow{3}{*}{$\begin{array}{c}273 \\
0.09 \mathrm{~m}^{2} \\
25^{\circ} \mathrm{C} \\
\\
73\end{array}$} & & \multicolumn{5}{|c|}{$Q_{h}=\sum_{t=0}^{52} \dot{q}(2 t) \Delta \mathrm{U}=h \sum_{t=0}^{52}\left(A T_{a v}(2 t) \Delta v\right)$} \\
\hline & & \multicolumn{6}{|c|}{$T_{a v}=\left(\left(T_{s}(t)-T_{\infty}(t)\right)+\left(T_{s}(t+2)-T_{\infty}(t+2)\right) / 2\right.$} \\
\hline & & $7 \infty$ & h & Tav & $q$ & $\Phi \Delta t$ & IQAt \\
\hline 0 & 198.8 & 25 & 273 & 173 & 4273 & 8545 & 8545 \\
\hline 2 & 197.2 & 25 & 273 & 159 & 4234 & 8468 & 17013 \\
\hline 4 & 169.9 & 25 & 273 & 149 & 3561 & 7122 & 24136 \\
\hline 6 & 178.9 & 25 & 273 & 147 & 3783 & 7566 & 31701 \\
\hline 8 & 165.6 & 25 & 273 & 137 & 3456 & 6911 & 38612 \\
\hline 10 & 158.6 & 25 & 273 & 131 & 3285 & 6570 & 45183 \\
\hline 12 & 153.8 & 25 & 273 & 125 & 3166 & 6331 & 51514 \\
\hline 14 & 145.9 & 25 & 273 & 120 & 2973 & 5946 & 57460 \\
\hline 16 & 144,4 & 25 & 273 & 119 & 2936 & 5872 & 63332 \\
\hline 18 & 144.2 & 25 & 273 & 118 & 2931 & 5862 & 69193 \\
\hline 20 & 142.5 & 25 & 273 & 117 & 2889 & 5779 & 74972 \\
\hline 22 & 142.4 & 25 & 273 & 117 & 2887 & 5774 & 80746 \\
\hline 24 & 141.2 & 25 & 273 & 116 & 2856 & 5712 & 86458 \\
\hline 26 & 140.9 & 25 & 273 & 117 & 2850 & 5700 & 92158 \\
\hline 28 & 142.3 & 25 & 273 & 117 & 2882 & 5765 & 97923 \\
\hline 30 & 142.2 & 25 & 273 & 117 & 2881 & 5762 & 103685 \\
\hline 32 & 142.1 & 25 & 273 & 116 & 2879 & 5759 & 109444 \\
\hline 34 & 140.0 & 25 & 273 & 115 & 2826 & 5653 & 115097 \\
\hline 36 & 139.7 & 25 & 273 & 113 & 2819 & 5639 & 120736 \\
\hline 38 & 137.2 & 25 & 273 & 106 & 2758 & 5515 & 126251 \\
\hline 40 & 125.8 & 25 & 273 & 96 & 2477 & 4955 & 131206 \\
\hline 42 & 115.9 & 25 & 273 & 87 & 2233 & 4467 & 135673 \\
\hline 44 & 108.6 & 25 & 273 & 83 & 2055 & 4110 & 139783 \\
\hline 46 & 107.1 & 25 & 273 & 81 & 2019 & 4038 & 143821 \\
\hline 48 & 104.1 & 25 & 273 & 79 & 1944 & 3888 & 147709 \\
\hline 50 & 103.3 & 25 & 273 & 78 & 1926 & 3851 & 151560 \\
\hline 52 & 103.5 & 25 & 273 & 79 & 1930 & 3861 & 155421 \\
\hline 54 & 103.7 & 25 & 273 & 78 & 1935 & 3869 & 159291 \\
\hline 56 & 102.5 & 25 & 273 & 77 & 1906 & 3812 & 163103 \\
\hline 58 & 102.4 & 25 & 273 & 77 & 1904 & 3807 & 166910 \\
\hline 60 & 102.5 & 25 & 273 & 77 & 1904 & 3908 & 170719 \\
\hline 62 & 102.3 & 25 & 273 & 77 & 1901 & 3803 & 174521 \\
\hline 64 & 102.4 & 25 & 273 & $n$ & 1902 & 3803 & 178325 \\
\hline 66 & 101.6 & 25 & 273 & 76 & 1882 & 3764 & 182088 \\
\hline 68 & 101.2 & 25 & 273 & 76 & 1874 & 3748 & 185837 \\
\hline 70 & 100.9 & 25 & 273 & 76 & 1866 & 3732 & 189568 \\
\hline 72 & 100.6 & 25 & 273 & 76 & 1857 & 3715 & 193283 \\
\hline 74 & 100.5 & 25 & 273 & 75 & 1855 & 3710 & 196993 \\
\hline 76 & 100.5 & 25 & 273 & 75 & 1856 & 3711 & 200704 \\
\hline 78 & 100.5 & 25 & 273 & 75 & 1856 & 3711 & 204015 \\
\hline 80 & 100.5 & 25 & 273 & 75 & 2856 & 3711 & 208127 \\
\hline 82 & 100.5 & 25 & 273 & 75 & 1855 & 3711 & 211838 \\
\hline 84 & 100.5 & 25 & 273 & 75 & 1856 & 3712 & 215550 \\
\hline 86 & 100.5 & 25 & 273 & 75 & 1856 & 3711 & 219261 \\
\hline 88 & 100.5 & 25 & 273 & 76 & 1855 & 3711 & 222972 \\
\hline 90 & 100.6 & 25 & 273 & 75 & 1858 & 3716 & 226588 \\
\hline 92 & 100.3 & 25 & 273 & 75 & 1852 & 3704 & 230393 \\
\hline 94 & 99.3 & 25 & 273 & 73 & 1826 & 3652 & 234045 \\
\hline 96 & 96.6 & 25 & 273 & 71 & 1761 & 3522 & 237566 \\
\hline 98 & 95.3 & 25 & 273 & 70 & 1729 & 3459 & 241025 \\
\hline 100 & 95.3 & 25 & 273 & 70 & 1728 & 3456 & 244481 \\
\hline 102 & 94.7 & 25 & 273 & 70 & 1714 & 3427 & 247909 \\
\hline 104 & 94.6 & 25 & 273 & 82 & 1710 & 3419 & 251328 \\
\hline
\end{tabular}




$$
\begin{aligned}
& Q_{s}=\left(\Delta T C_{p} M_{w}\right)+\left(M_{w} h_{f g}\right) \\
& M w=\quad 100 \mathrm{~g} \\
& C p=\quad 4.18 \mathrm{~J} / \mathrm{g}^{\circ} \mathrm{C} \\
& \text { hfg }=\quad 2270 \mathrm{~J} / \mathrm{g} \\
& \text { Qee } 258350 \text { J } \\
& Q_{h}=\sum_{t=0}^{52} \dot{q}(2 t) \Delta t=h \sum_{t=0}^{52}\left(A T_{a v}(2 t) \Delta t\right) \\
& Q_{h}=\quad 251328 \\
& \text { Difference between } Q e \text { and } Q h \text { in } \% \\
& \text { ((Qe-Qh)/Qe) } 100 \quad 2.7 \%
\end{aligned}
$$

The difference between the results calculated using the energy absorption equation 5.7.1-4, which is based on increasing the liquid temperature and on evaporation, and the results calculated using equation $5.7 .1-5$ is $2.72 \%$.

\section{Validation Test 6-3}

$60 \mathrm{cc}$ of foam concentrate using 3\% AFFF AR with an expansion ratio of 1:25 was used in Test 6-3. The initial steel plate temperature at the insertion of the foam was $200^{\circ} \mathrm{C}$.

As the amount of foam was reduced, the rate of drainage also decreased and the energy absorption was reduced. This was represented by a lower rate of temperature drop measured at the top of the steel plate. See Fig. 5.7.3-2. The foam was completely evaporated by $\mathrm{t}=68$ seconds. The details of calculations are shown in Table 5.7.3-3. 


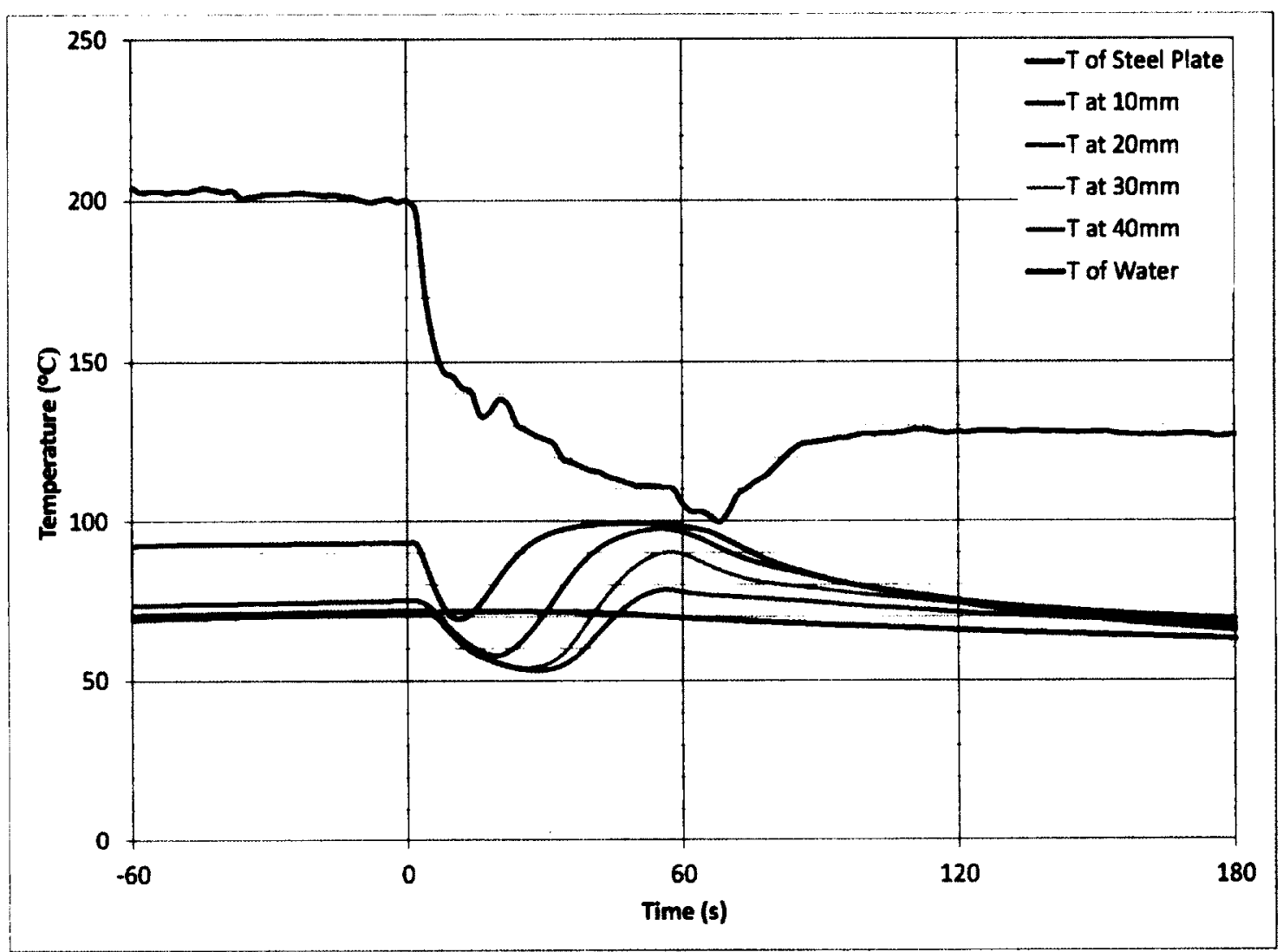

Fig. 5.7.3-2 Test 6-3 - 60c of foam over steel plate at $200^{\circ} \mathrm{C}$ expansion 1:25 
Table 5.7.3-3 Test 6-3 - 60ce of foam over steel plate at $200^{\circ} \mathrm{C}$ expansion 1:25

Calculation of Q using foam made of $60 \mathrm{cc}$ of water fosm concentrate on a plate with initial temperature of 200 deg $C$

\begin{tabular}{|c|c|c|c|c|c|c|c|}
\hline \multicolumn{2}{|r|}{$\begin{array}{l}273 \\
0.09 \mathrm{~m}^{2} \\
25^{\circ} \mathrm{C}\end{array}$} & & \multicolumn{5}{|c|}{$Q_{h}=\sum_{t=1}^{34} \dot{q}(2 t) \Delta t=h \sum_{t=1}^{34}\left(A T_{s}(2 t) \Delta t\right.$} \\
\hline $\begin{array}{l}h= \\
A= \\
T \infty=\end{array}$ & \multicolumn{7}{|c|}{$T_{a v}=\left(\left(T_{s}(t)-T_{\infty}(t)\right)+\left(T_{s}(t+2)-T_{\infty}(t+2)\right) / 2\right.$} \\
\hline time & $T+\infty$ & h & Tav & $q$ & $q \Delta t$ & & $q \Delta t$ \\
\hline 2 & 196.6 & 25 & 273 & 159 & 4217 & 8435 & 8435 \\
\hline 4 & 170.6 & 25 & 273 & 138 & 3579 & 7159 & 15593 \\
\hline 6 & 155.1 & 25 & 273 & 126 & 3197 & 6394 & 21987 \\
\hline 8 & 147.0 & 25 & 273 & 121 & 2998 & 5997 & 27984 \\
\hline 10 & 145.4 & 25 & 273 & 119 & 2961 & 5921 & 33906 \\
\hline 12 & 141.9 & 25 & 273 & 116 & 2873 & 5747 & 39652 \\
\hline 14 & 140.6 & 25 & 273 & 112 & 2843 & 5685 & 45338 \\
\hline 16 & 133.3 & 25 & 273 & 109 & 2662 & 5324 & 50661 \\
\hline 18 & 134.3 & 25 & 273 & 111 & 2687 & 5374 & 56036 \\
\hline 20 & 138.2 & 25 & 273 & 112 & 2783 & 5566 & 61601 \\
\hline 22 & 136.7 & 25 & 273 & 109 & 2746 & 5493 & 67094 \\
\hline 24 & 130.4 & 25 & 273 & 105 & 2592 & 5184 & 72278 \\
\hline 26 & 128.7 & 25 & 273 & 103 & 2549 & 5097 & 77376 \\
\hline 28 & 127.0 & 25 & 273 & 101 & 2508 & 5017 & 82392 \\
\hline 30 & 125.9 & 25 & 273 & 100 & 2480 & 4960 & 87352 \\
\hline 32 & 124.4 & 25 & 273 & 97 & 2444 & 4888 & 92240 \\
\hline 34 & 119.7 & 25 & 273 & 94 & 2327 & 4654 & 96894 \\
\hline 36 & 118.6 & 25 & 273 & 93 & 2300 & 4600 & 101494 \\
\hline 38 & 117.2 & 25 & 273 & 92 & 2268 & 4535 & 106029 \\
\hline 40 & 116.1 & 25 & 273 & 91 & 2239 & 4479 & 110508 \\
\hline 42 & 115.5 & 25 & 273 & 90 & 2225 & 4450 & 114958 \\
\hline 44 & 114.0 & 25 & 273 & 89 & 2187 & 4373 & 119332 \\
\hline 46 & 113.3 & 25 & 273 & 88 & 2169 & 4339 & 123670 \\
\hline 48 & 112.1 & 25 & 273 & 87 & 2142 & 4284 & 127954 \\
\hline 50 & 111.3 & 25 & 273 & 86 & 2123 & 4245 & 132199 \\
\hline 52 & 111.3 & 25 & 273 & 86 & 2122 & 4244 & 236443 \\
\hline 54 & 111.1 & 25 & 273 & 86 & 2116 & 4233 & 140676 \\
\hline 56 & 110.7 & 25 & 273 & 85 & 2106 & 4212 & 144888 \\
\hline 58 & 110.1 & 25 & 273 & 83 & 2092 & 4183 & 149072 \\
\hline 60 & 105.4 & 25 & 273 & 79 & 1977 & 3954 & 153025 \\
\hline 62 & 102.9 & 25 & 273 & 78 & 1914 & 3829 & 156854 \\
\hline 64 & 103.0 & 25 & 273 & 77 & 1917 & 3834 & 160688 \\
\hline 66 & 101.5 & 25 & 273 & 76 & 1882 & 3763 & 164451 \\
\hline 68 & 99.7 & 25 & 0 & 76 & 0 & 0 & 164451 \\
\hline 70 & 102.7 & 25 & & & & & \\
\hline
\end{tabular}

$$
\begin{aligned}
& Q_{.}=\left(\Delta T C_{p} M_{v}\right)+\left(M_{v} h_{f_{g}}\right) \\
& \begin{array}{lc}
M w= & 60 \mathrm{~g} \\
\mathrm{Cp}= & 4.18 \mathrm{~J} / \mathrm{g}^{\circ} \mathrm{C} \\
\mathrm{hfg}= & 2270 \mathrm{~J} / \mathrm{g} \\
\Delta T= & 75 \mathrm{~J}^{\circ} \mathrm{C} \\
\mathrm{Qe}= & 155010 \mathrm{~J}
\end{array}
\end{aligned}
$$$$
Q_{h}=\sum_{t=1}^{34} \dot{q}(2 t) \Delta t=h \sum_{t=1}^{34}\left(A T_{s}(2 t) \Delta t\right)
$$

$Q_{n}=\quad 164451$

Difference between Qe and $Q$ h in $\%$ 
The difference between the results calculated using the energy absorption equation 5.7.1-4, which is based on increasing the liquid temperature and on evaporation is $6 \%$ lower than the results calculated using the equation 5.7.1-5 that uses the convective heat transfer coefficient.

\section{Validation Test 6-4}

$60 \mathrm{cc}$ of foam concentrate using $2 \%$ AFFF AR with an expansion ratio of 1:8.7 was used in Test 6-4. The initial steel plate temperature at the insertion of the foam was $175^{\circ} \mathrm{C}$. The graph of the collected data is shown in Fig. 5.7.3-3 and the details of calculations are shown in Table 5.7.3-4.

The foam was inserted at $t=4$ seconds. The initial rate of temperature drop measured on top of the steel plate shown in Figure 5.7.3-3 was much higher when compared to Test 63. This was due to the lower expansion ratio and therefore resulted in an increased rate of water drainage from the foam. As the foam started to dry (water drained from the foam), the rate of drainage decreased. This is represented by the reduced rate of temperature decrease measured at the top of the steel plate (from $t=4$ seconds to $t=60$ seconds). The foam was completely evaporated by $t=70$ seconds. 


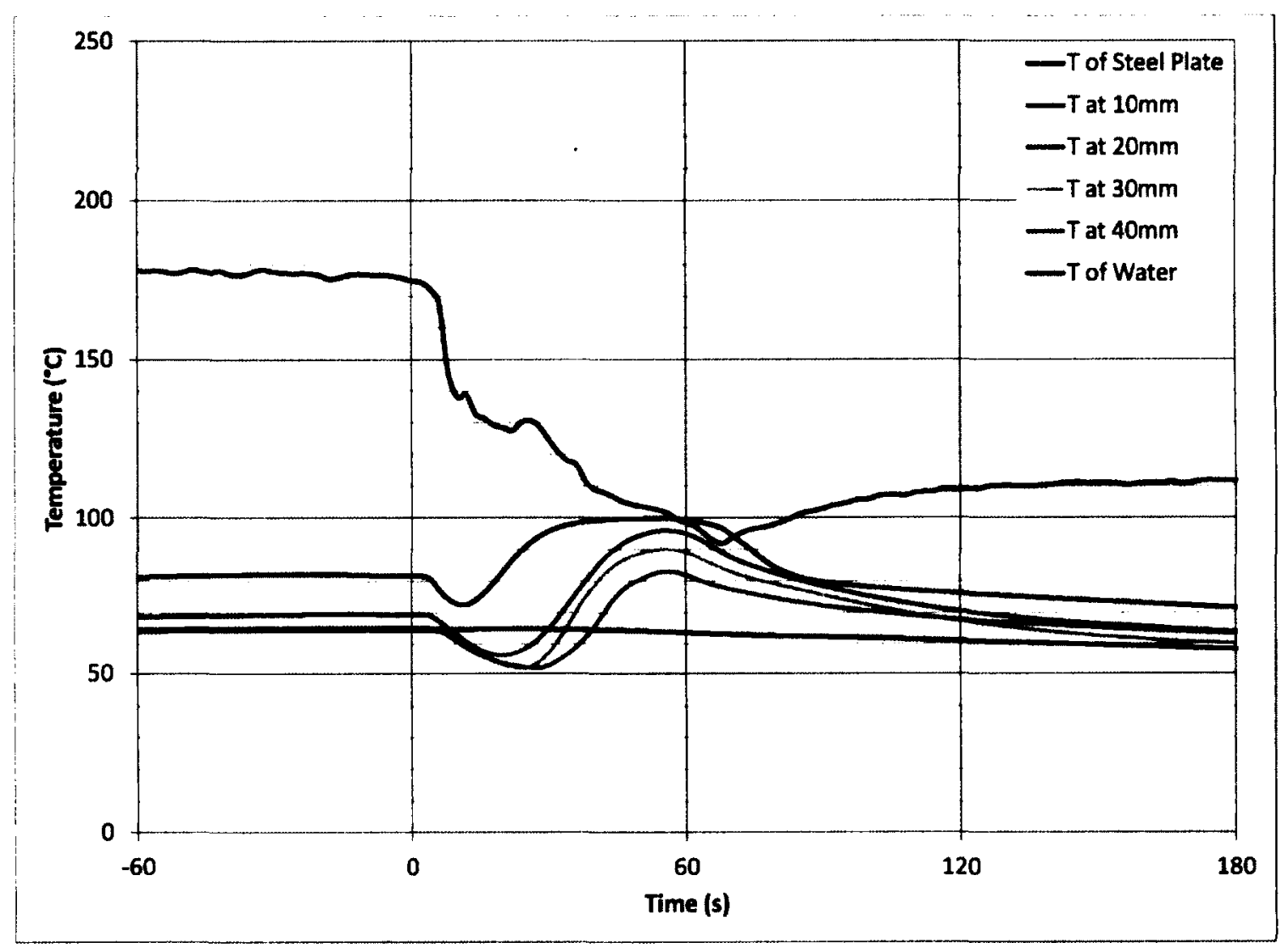

Fig. 5.7.3-3 Test 6-4 - 60cc of foam over steel plate at $175^{\circ} \mathrm{C}$ expansion 1:8.7 
Table 5.7.3-4 Test 6-4 - 60cc of foam over steel plate at $175^{\circ} \mathrm{C}$ expansion $1: 8.7$

Calculation of $Q$ using foam made of $60 \mathrm{cc}$ of water foam concentrate on a plate whith inltial temperature of 175 deg

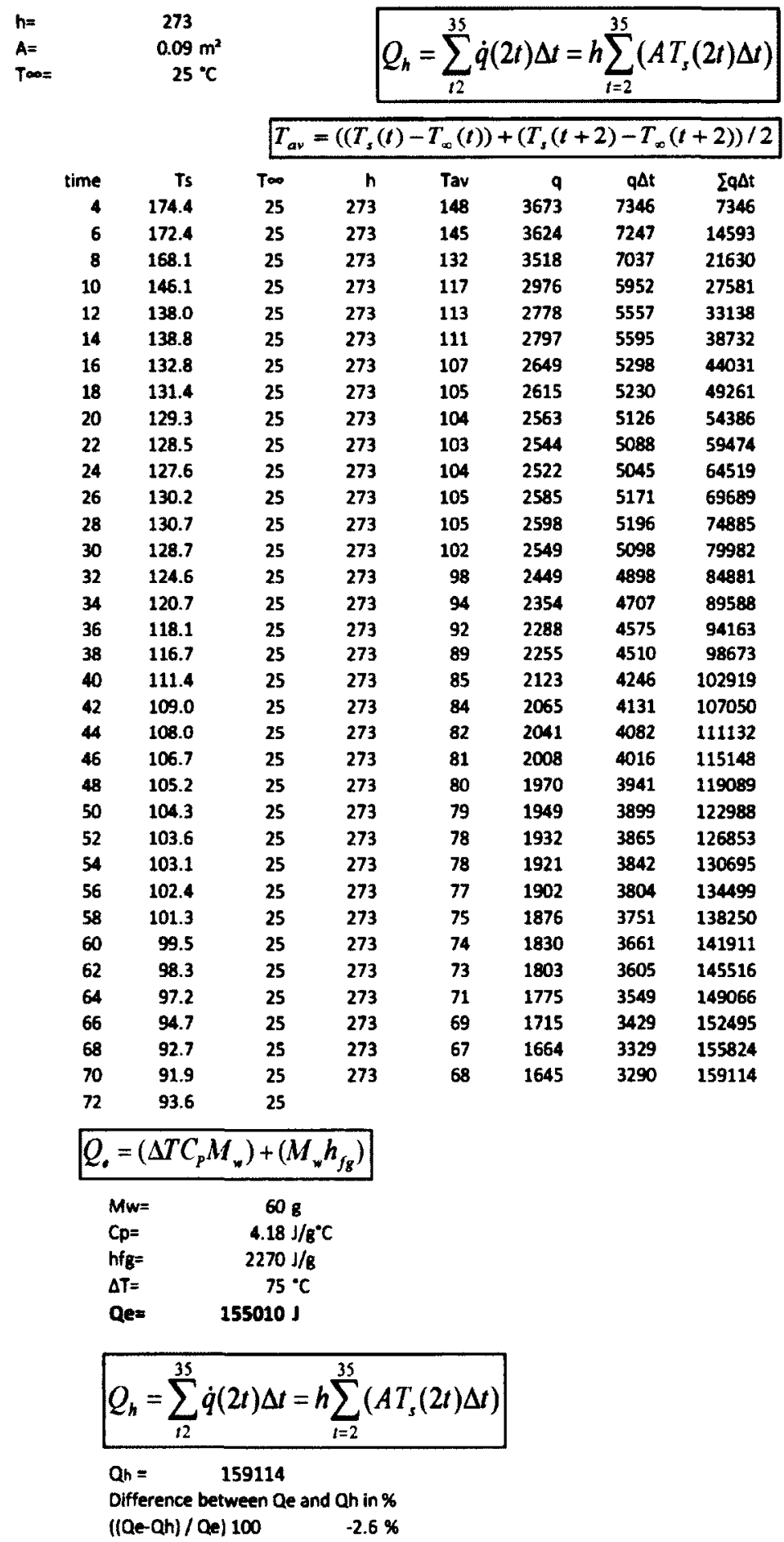


The difference between the results calculated using the energy absorption equation 5.7.1-4, which is based on increasing the liquid temperature and on evaporation is $2.7 \%$ lower than the results calculated using the equation 5.7.1-5 that uses the convective heat transfer coefficient.

\section{Validation Test 6-5}

$60 \mathrm{cc}$ of foam concentrate using $2 \%$ AFFF AR with expansion ratio of 1:8.7 was used in Test 6-5. The initial steel plate temperature at the insertion of the foam was $150^{\circ} \mathrm{C}$. As the initial temperature of the top of the steel plate was lower than in Test 6-4, the rate of the water drainage was also reduced. This caused a reduced rate of temperature decrease measured on top of the steel plate when compared to Test 6-4. All the foam evaporated by $\mathrm{t}=80$ seconds.

The graph of the collected data is shown on Fig. 5.7.3-4 and the details of calculations are shown in Table 5.7.3-5. 


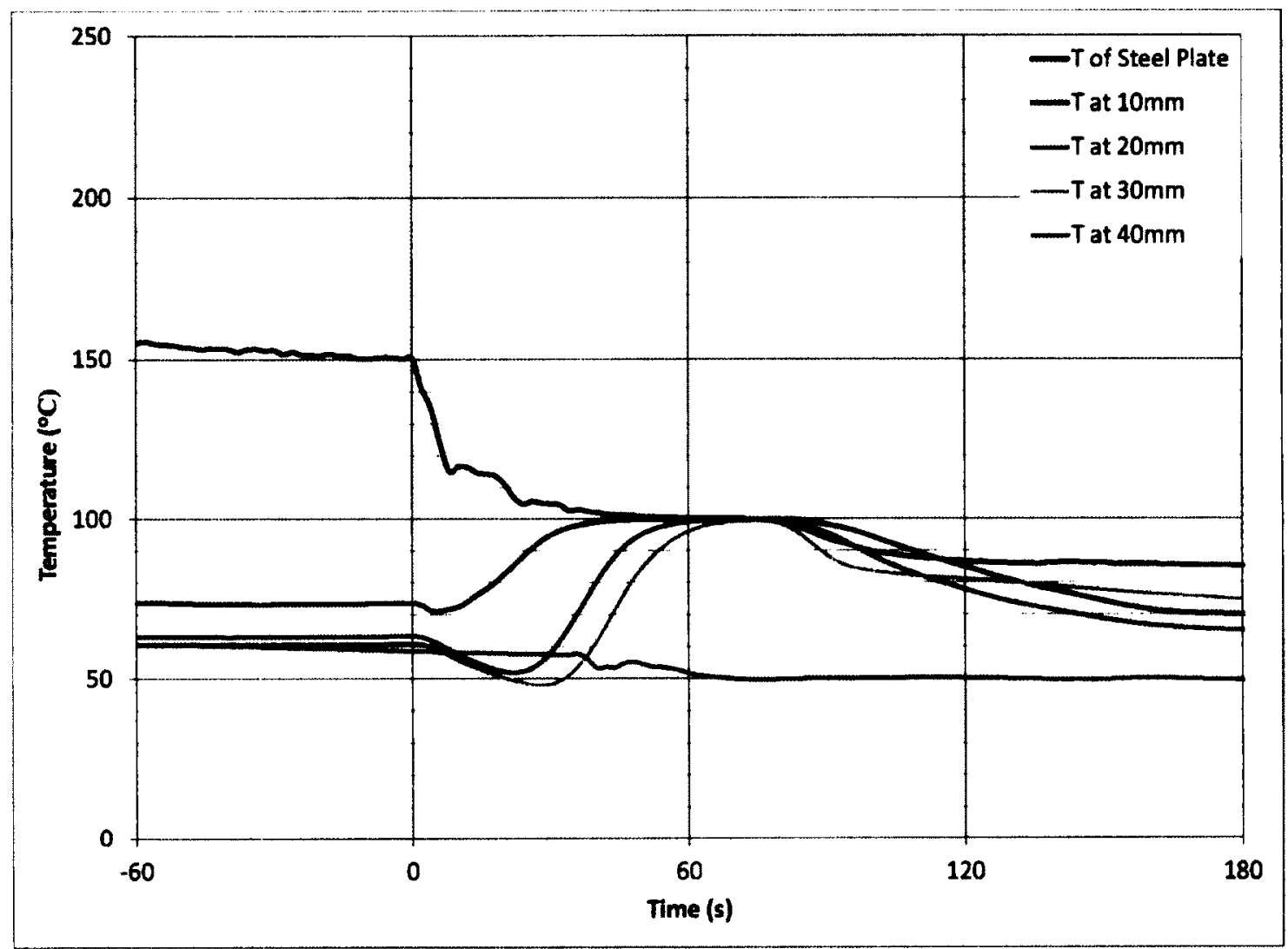

Fig. 5.7.3-4 Test 6-5 - 60cc of foam over steel plate at $150^{\circ} \mathrm{C}$ expansion 1:8.7 
Table 5.7.3-5 Test 6-5 - 60cc of foam over steel plate at $150^{\circ} \mathrm{C}$ expansion 1:8.7

\begin{tabular}{|c|c|c|c|c|c|c|c|c|}
\hline \multirow{3}{*}{$\begin{array}{l}h= \\
A= \\
T=0=\end{array}$} & \multicolumn{2}{|r|}{273} & & & & & & \\
\hline & \multicolumn{2}{|r|}{$0.09 \mathrm{~m}^{2}$} & & & & & & \\
\hline & \multicolumn{2}{|r|}{$25^{\circ} \mathrm{C}$} & & & & & & \\
\hline \multirow[b]{2}{*}{ time } & \multirow[b]{2}{*}{$\mathbf{T}$} & \multirow[b]{2}{*}{ To } & \multicolumn{6}{|c|}{$T_{a v}=\left(\left(T_{s}(t)-T_{a b}(t)\right)+\left(T_{s}(t+2)-T_{\infty}(t+2)\right) / 2\right.$} \\
\hline & & & h & Tav & $\mathbf{q}$ & $q \Delta t$ & \multicolumn{2}{|c|}{$\sum q \Delta t$} \\
\hline & 0 & 150.4 & 25 & 273 & 121 & 3083 & 6165 & 6165 \\
\hline & 2 & 141.1 & 25 & 273 & 113 & 2855 & 5709 & 11874 \\
\hline & 4 & 135.1 & 25 & 273 & 105 & 2706 & 5411 & 17286 \\
\hline & 6 & 124.2 & 25 & 273 & 95 & 2438 & 4876 & 22162 \\
\hline & 8 & 115.3 & 25 & 273 & 91 & 2219 & 4438 & 26600 \\
\hline & 10 & 116.7 & 25 & 273 & 92 & 2255 & 4510 & 31111 \\
\hline & 12 & 116.5 & 25 & 273 & 91 & 2249 & 4499 & 35610 \\
\hline & 14 & 114.8 & 25 & 273 & 90 & 2209 & 4417 & 40027 \\
\hline & 16 & 114.5 & 25 & 273 & 89 & 2199 & 4398 & 44425 \\
\hline & 18 & 113.8 & 25 & 273 & 87 & 2182 & 4365 & 48789 \\
\hline & 20 & 111.1 & 25 & 273 & 84 & 2118 & 4235 & 53025 \\
\hline & 22 & 106.8 & 25 & 273 & 81 & 2011 & 4022 & 57047 \\
\hline & 24 & 104.7 & 25 & 273 & 80 & 1959 & 3917 & 60964 \\
\hline & 26 & 105.4 & 25 & 273 & 80 & 1977 & 3955 & 64919 \\
\hline & 28 & 105.0 & 25 & 273 & 80 & 1967 & 3934 & 68852 \\
\hline & 30 & 104.7 & 25 & 273 & 80 & 1960 & 3920 & 72772 \\
\hline & 32 & 104.4 & 25 & 273 & 78 & 1952 & 3904 & 76676 \\
\hline & 34 & 102.6 & 25 & 273 & 78 & 1906 & 3813 & 80489 \\
\hline & 36 & 102.9 & 25 & 273 & 78 & 1915 & 3829 & 84318 \\
\hline & 38 & 102.3 & 25 & 273 & 77 & 1901 & 3802 & 88120 \\
\hline & 40 & 102.0 & 25 & 273 & 77 & 1893 & 3785 & 91906 \\
\hline & 42 & 101.5 & 25 & 273 & 76 & 1881 & 3762 & 95667 \\
\hline & 44 & 101.3 & 25 & 273 & 76 & 1876 & 3752 & 99420 \\
\hline & 46 & 101.2 & 25 & 273 & 76 & 1873 & 3746 & 103166 \\
\hline & 48 & 101.0 & 25 & 273 & 76 & 1869 & 3738 & 106904 \\
\hline & 50 & 100.8 & 25 & 273 & 76 & 1864 & 3727 & 110631 \\
\hline & 52 & 100.6 & 25 & 273 & 76 & 1859 & 3717 & 114348 \\
\hline & 54 & 100.5 & 25 & 273 & 75 & 1856 & 3712 & 118060 \\
\hline & 56 & 100.4 & 25 & 273 & 75 & 1854 & 3708 & 121767 \\
\hline & 58 & 100.3 & 25 & 273 & 75 & 1851 & 3702 & 125470 \\
\hline & 60 & 100.2 & 25 & 273 & 75 & 1849 & 3698 & 129168 \\
\hline & 62 & 100.2 & 25 & 273 & 75 & 1849 & 3697 & 132865 \\
\hline & 64 & 100.2 & 25 & 273 & 75 & 1850 & 3699 & 136564 \\
\hline & 66 & 100.2 & 25 & 273 & 75 & 1848 & 3697 & 140261 \\
\hline & 68 & 100.2 & 25 & 273 & 75 & 1848 & 3696 & 143957 \\
\hline & 70 & 100.2 & 25 & 273 & 75 & 1848 & 3695 & 147652 \\
\hline & 72 & 100.1 & 25 & 273 & 75 & 1847 & 3694 & 151346 \\
\hline & 74 & 100.1 & 25 & 273 & 75 & 1846 & 3691 & 155037 \\
\hline & 76 & 100.1 & 25 & 273 & 75 & 1846 & 3693 & 158730 \\
\hline & 78 & 100.0 & 25 & 273 & 75 & 1844 & 3688 & 162418 \\
\hline & 80 & 99.8 & 25 & 273 & 87 & 1838 & 3676 & 166094 \\
\hline & 82 & 98.9 & & & & & & \\
\hline
\end{tabular}




$$
\begin{aligned}
& Q_{.}=\left(\Delta T C_{p} M_{w}\right)+\left(M_{w} h_{f g}\right) \\
& 608 \\
& 4.18 \mathrm{~J} / \mathrm{B}^{\circ} \mathrm{C} \\
& 2270 \mathrm{~J} / \mathrm{B} \\
& 155010 \mathrm{~J} \\
& Q_{h}=\sum_{t=0}^{40} \dot{q}(2 t) \Delta t=h \sum_{t=0}^{40}\left(A T_{s}(2 t) \Delta t\right) \\
& a_{n}=166094 \\
& \text { Difference between } Q \text { a and } Q \text { ah in } \% \\
& \text { ((Qe-ah) / Qe) } 100 \quad-7.2 \%
\end{aligned}
$$

The difference between the results calculated using the energy absorption equation 5.7.1-4, which is based on increasing the liquid temperature and on evaporation is $7.2 \%$ lower than the results calculated using the equation 5.6.1-5 that uses the convective heat transfer coefficient.

The above-mentioned method provides a relatively accurate value for determining the convective heat transfer coefficient of CAF. The experimental values are within $10 \%$ of the actual values of energy absorbed by raising the liquid temperature to $100^{\circ} \mathrm{C}$ and evaporating the liquid. As the variations between the results calculated using energy absorption and the results using the heat transfer foam coefficient are relatively small, the method of calculating the heat transfer foam coefficient provides a reasonable approximation and can be used to predict the foam's rate of heat absorption. 
As the heat transfer coefficient was verified using different temperatures and different foam expansion ratios, the value calculated for the heat transfer coefficient of $273\left(\mathrm{~kW} / \mathrm{m}^{2} \mathrm{~K}\right)$ provides a valid approximation for the CAF. The heat transfer coefficient is valid for different expansion ratios of compressed-air foam.

It should be noted that typical values for convection with phase change for boiling and condensation are in the range of 250 to $1000\left(\mathrm{~kW} / \mathrm{m}^{2} \mathrm{~K}\right)[60]$.

\subsection{Heat Transfer for Surface Temperature below $100^{\circ} \mathrm{C}$}

Foam is made mostly of air. When the foam is in contact with the surface that has a temperature above $100^{\circ} \mathrm{C}$, a large percentage of the liquid in the foam evaporates and some of the vapour (insignificant amount) can be absorbed by the foam.

When the hot surface temperature drops just below $100^{\circ} \mathrm{C}$, the rate of energy loss from the steel plate is expected to be lower with the presence of foam than in the absence of foam. This is due to the formation of a vapour layer, created when the surface temperature was at or above $100^{\circ} \mathrm{C}$, on top of the steel surface held in place by the foam. Once this vapour layer escapes, the foam comes in contact with the steel surface, it breaks up and drains water. This causes an increase of the heat transfer rate.

In Test 1, the holding tank with a $6.3 \mathrm{~mm}$ steel plate at the bottom of the tank was heated above $200^{\circ} \mathrm{C}$ and was allowed to cool without the insertion of the foam. 
The time for the surface temperature to drop from $100^{\circ} \mathrm{C}$ to $80^{\circ} \mathrm{C}$ was 540 seconds. See Fig 5.8-1

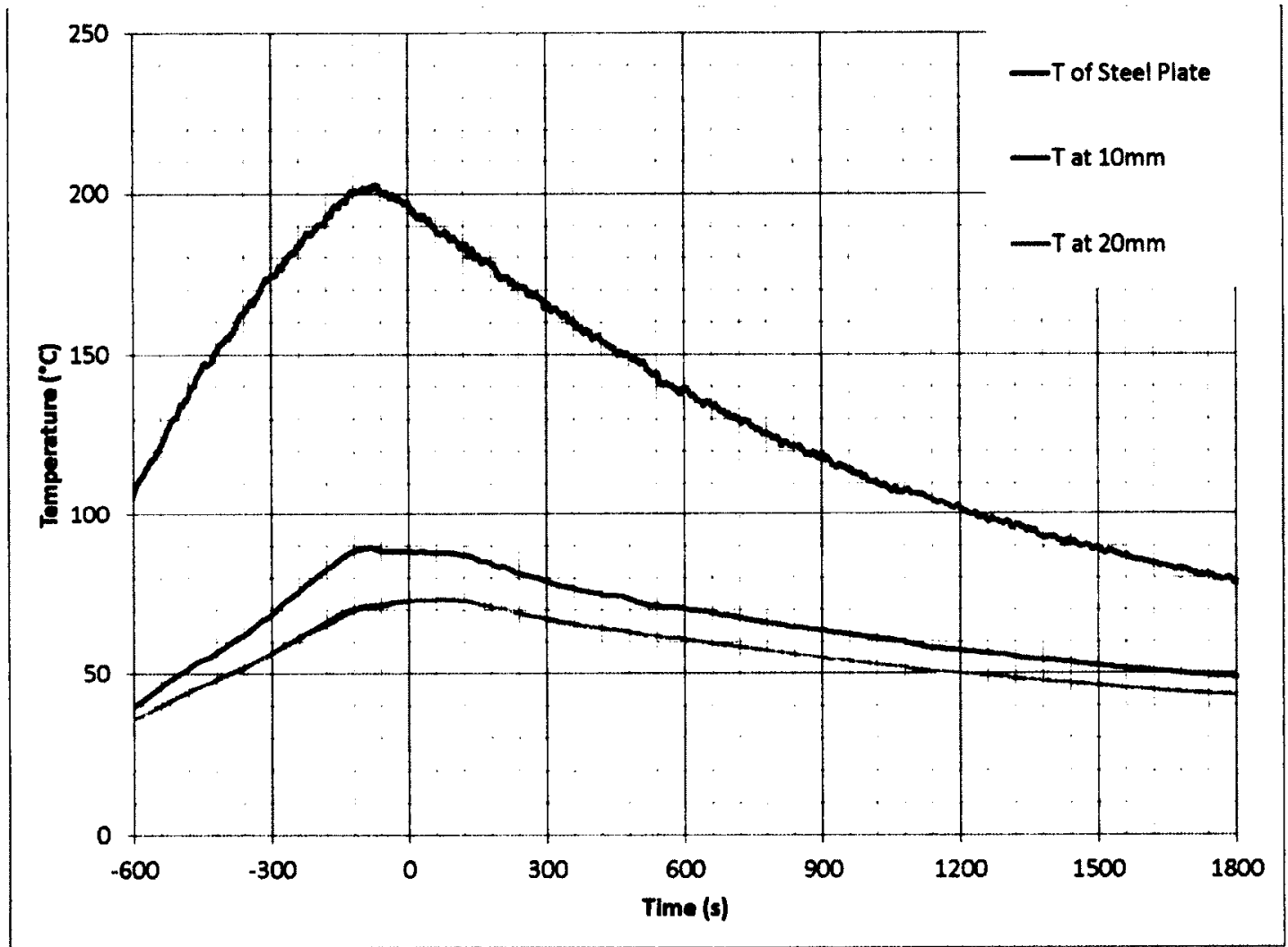

Fig. 5.8-1 Test 7-1 - temperature without foam

The temperature curves for the surface temperature of the steel plate were compared for Tests 1, 1A, 1B, 1C, 1D and 1E and the time was set at 0 seconds when the temperature of the surface of the steel plate dropped to $100^{\circ} \mathrm{C}$. See Fig 5.8-2. 


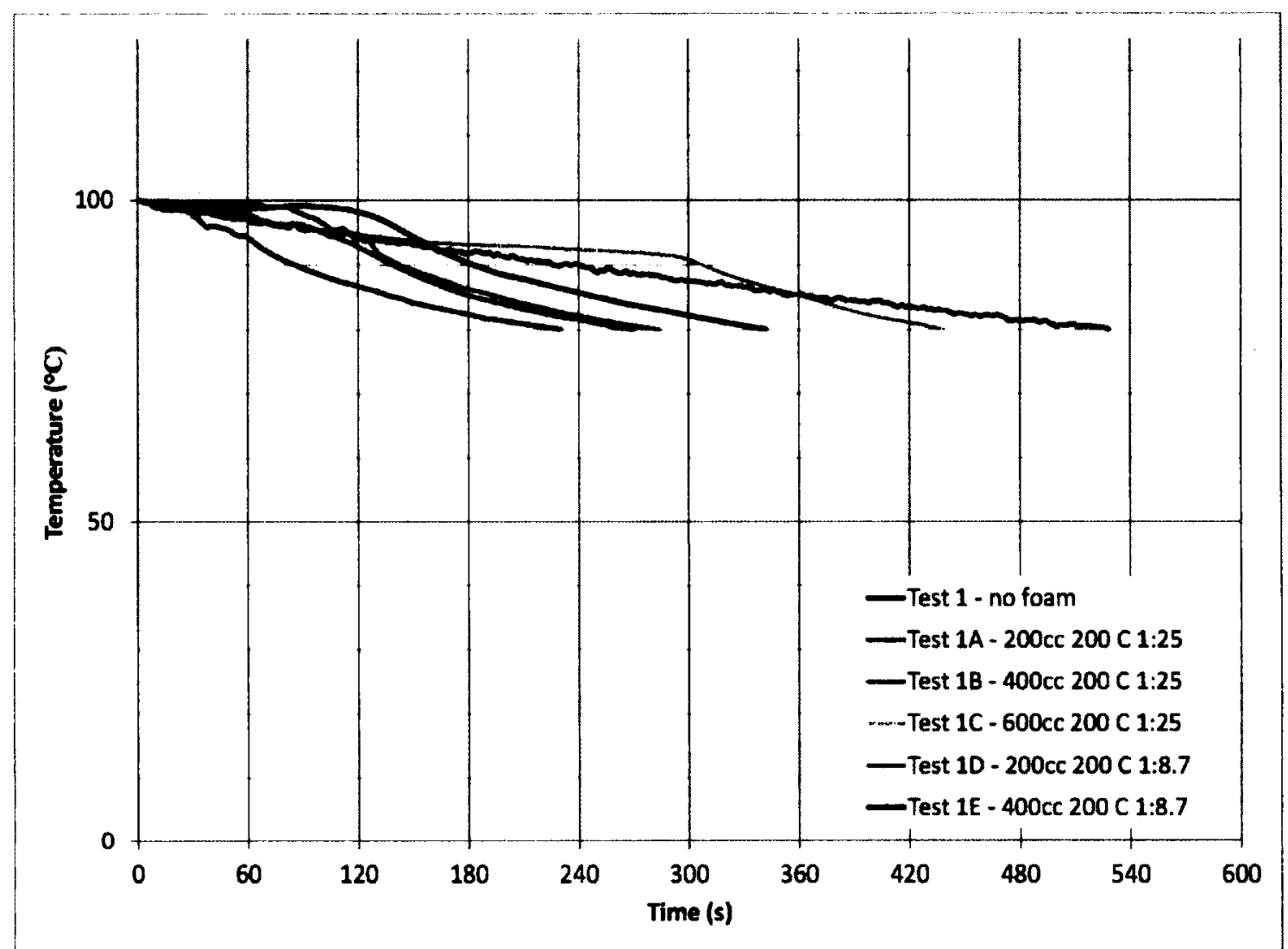

Fig. 5.8-2 Temperature drop of top of steel plate from $100^{\circ} \mathrm{C}$ to $80^{\circ} \mathrm{C}$ for Tests 1 , 1A, 1B, 1C, 1D and 1E

From Figure 5.8-2 it can be seen that when the steel plate surface temperature drops to $100^{\circ} \mathrm{C}$ and is covered with foam, the temperature at the top of the steel plate drops slower than the rate of temperature drop without the foam due to the trapped vapour layer. As the foam disintegrated, the vapour bubbles were released, and foam started to drain. The draining water from the foam increased the cooling rate of the steel plate surface. When the amount of applied foam was increased, the time required for the foam to disintegrate and allow the vapour to escape also increased as can be seen when steel temperature from Tests 1A, 1B and 1C are compared in Figure 5.8-2. 
Fig. 5.8-3 compares the temperature drops for Tests 1, 2A, 2B and 2C. The results for test $2 \mathrm{~A}$ and $2 \mathrm{~B}$ were consistent with the results obtained for Tests $1 \mathrm{~A}, 1 \mathrm{~B}$ and $1 \mathrm{C}$. In test 2C, a larger amount of foam was used and an initial temperature drop was assumed to be caused by drainage before the vapour release. The top of the steel plate temperature between 200 and 600 seconds was relatively steady until the vapour escape at approximately 600 seconds.

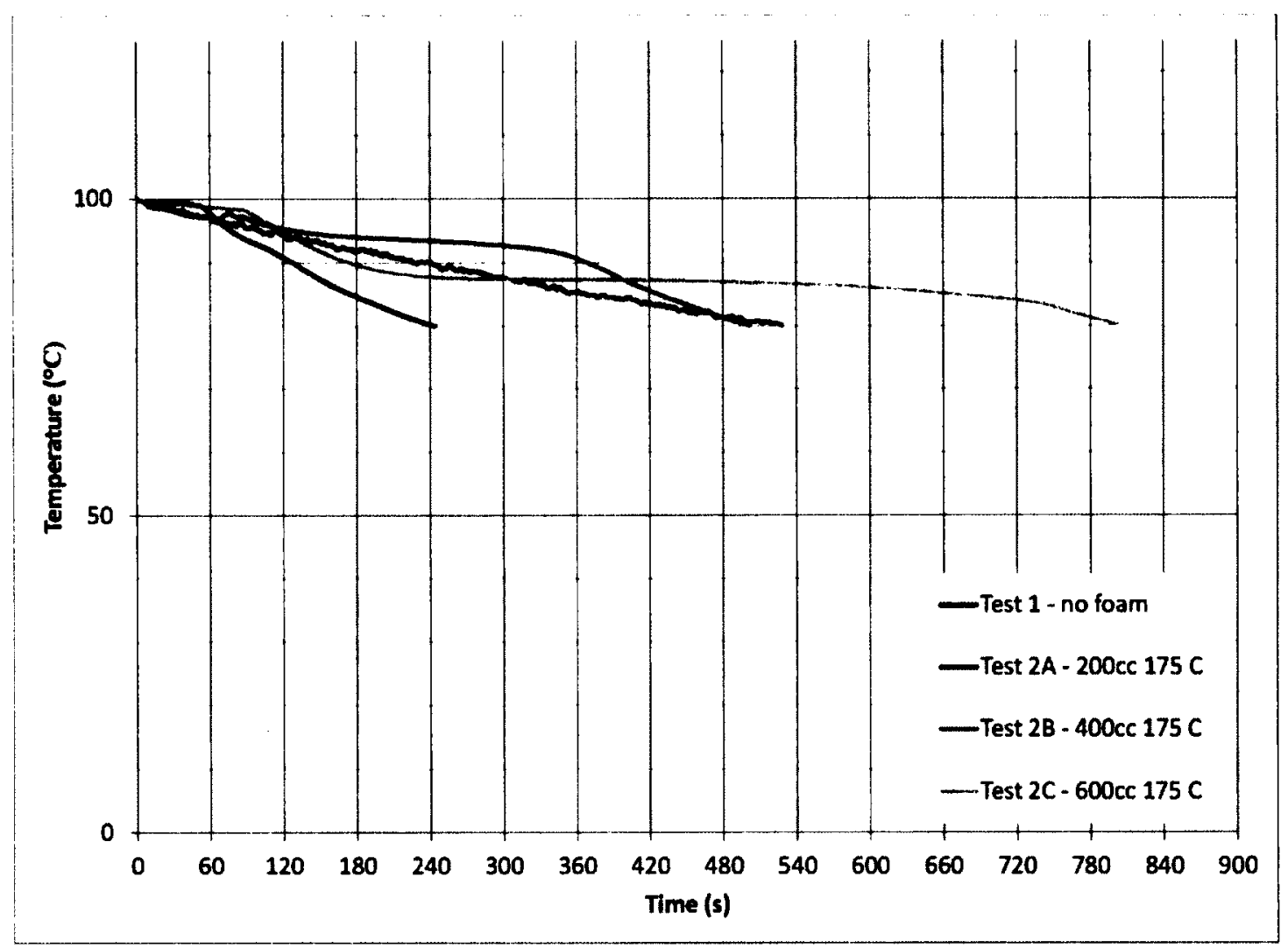

Fig. 5.8-3 Temperature drop of top of steel plate from $100^{\circ} \mathrm{C}$ to $80^{\circ} \mathrm{C}$ for Tests 1 , 2A, 2B and 2C

Fig. 5.8-4 compares the temperature drops for Tests 1, 3A, 3B, 4A, 4B and 5A. As the initial temperature of the steel plate was lowered, the time required for the draining water to start affecting the temperature of the top of the steel plate also increased when 
compared to Tests with higher initial temperature. For example, in Fig. 5.8-3, the vapour release for Test $2 \mathrm{~B}$, that was performed with initial steel plate temperature of $175^{\circ} \mathrm{C}$, occurred at 360 seconds and for Test $3 \mathrm{~B}$, that was performed with initial steel plate temperature of $150^{\circ} \mathrm{C}$, the vapour release occurred at 600 seconds as can be seen in Fig. 5.8-4.

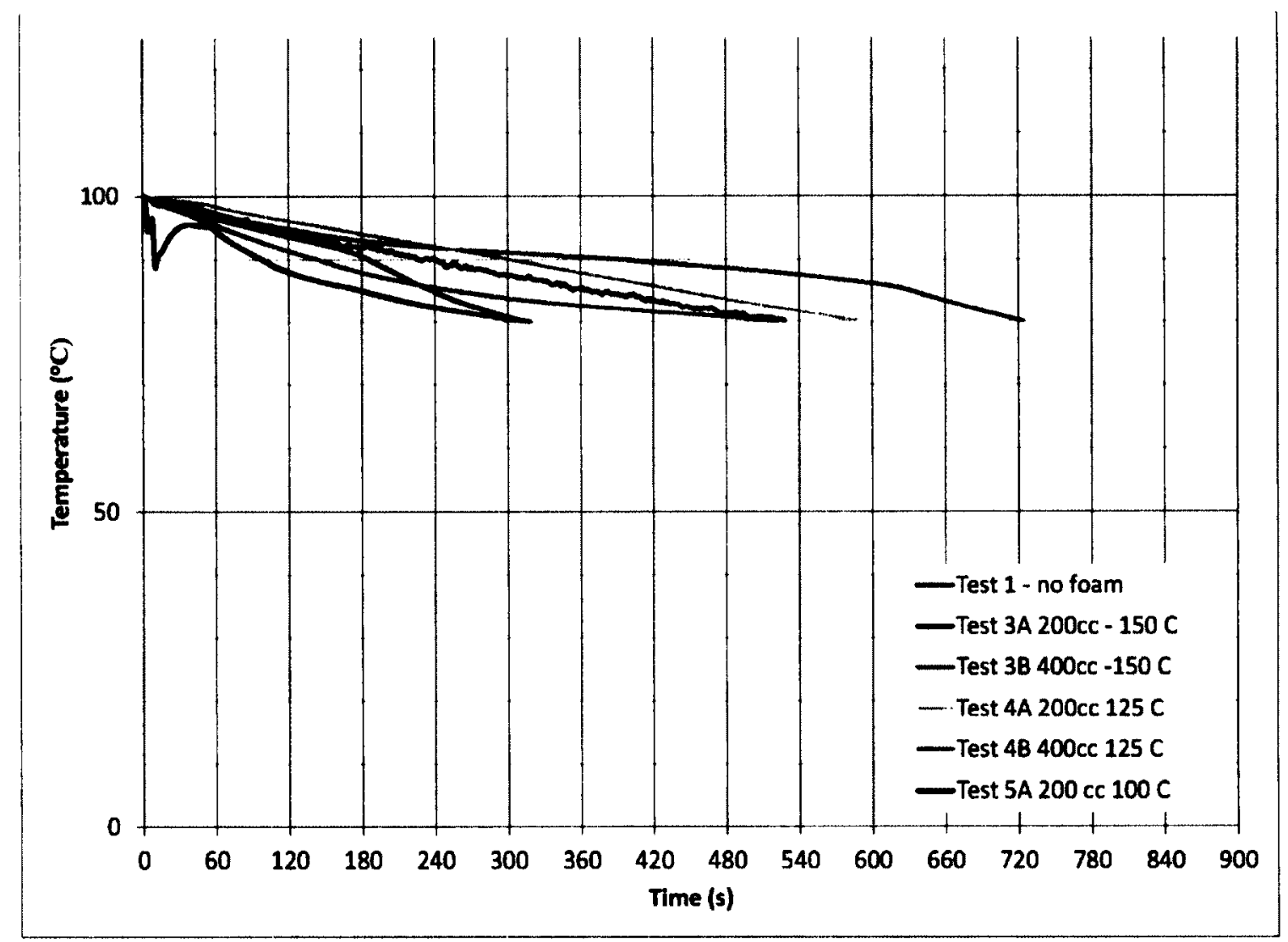

Fig. 5.8-4 Temperature drop of top of steel plate from $100^{\circ} \mathrm{C}$ to $80^{\circ} \mathrm{C}$ for Tests 1 , $3 A, 3 B, 4 A, 4 B$ and $5 A$

In Test $5 \mathrm{~A}$, the foam was inserted when the surface temperature dropped to $100^{\circ} \mathrm{C}$. This caused an initial temperature drop of the steel plate at approximately 10 seconds. 


\subsection{Use of steel to foam convective heat transfer coefficient}

The maximum energy that can be absorbed by foam is when the all the liquid in the foam has been evaporated. In a typical application of a foam extinguishing system, the foam is distributed over a relatively large area. The application rate of foam over a given surface $\left(D_{w}\right)$ is normally expressed in $(\ell / s) / \mathrm{m}^{2}$ or $\mathrm{gpm} / \mathrm{ft}^{2}$ where the volume is the volume of the concentrate used to make foam, rather than the volume of the expanded foam (although the volume of expanded foam is used in high expansion foam).

As the application density is in $(\ell / s) / \mathrm{m}^{2}$ to calculate the energy rate, the units have to be converted to $(\mathrm{kg} / \mathrm{s}) / \mathrm{m}^{2}$.

$$
\begin{aligned}
& 1000 l=m^{3} \\
& M_{W}=\frac{D_{W} \rho_{W} t A}{1000}
\end{aligned}
$$

Assuming a constant rate of application, the maximum energy absorption rate for an area is:

$$
\begin{aligned}
& \dot{q}=\left(\Delta T\left(c_{P W}\right) M_{W}\right) / t+\left(h_{f g} M_{W}\right) / t \quad(\mathrm{~kJ} / \mathrm{s}) \\
& \dot{q}=\left(\Delta T\left(c_{P W}\right) D_{W} \rho_{W} t A\right) / 1000 t+\left(h_{f g} D_{W} \rho_{W} t A\right) / 1000 t \quad(\mathrm{~kJ} / \mathrm{s}) \\
& \dot{q}=\left(\Delta T\left(c_{P W}\right) D_{W} \rho_{W} A\right)+\left(h_{f g} D_{W} \rho_{W} A\right) \quad(\mathrm{J} / \mathrm{s})
\end{aligned}
$$


For example, using an application of foam density (D) of $0.0068(1 / \mathrm{s}) / \mathrm{m}^{2}\left(0.01 \mathrm{gpm} / \mathrm{ft}^{2}\right)$ (these are typical application rates for CAF [2]), the energy absorbed by the foam per an area of $1 \mathrm{~m}^{2}$ per $\mathrm{s}$ will:

Increase the temperature from $20^{\circ} \mathrm{C}$ to $100^{\circ} \mathrm{C}$ for $0.0068 \ell$ of water, and Evaporate $0.0068 \ell$ of water $\dot{q}^{\prime \prime}=(80 x 4.18 x 0.0068)+(2270 x 0.0068)=17.71\left(\mathrm{~kJ} / \mathrm{s} \mathrm{m}^{2}\right)$

If the surface temperature is $200^{\circ} \mathrm{C}$ and the $h_{f}$ of $273\left(\mathrm{~kW} / \mathrm{m}^{2} \mathrm{~K}\right)$ is used, the rate of energy absorbed per $\mathrm{m}^{2}$ by the foam can be calculated using equation 5.6-1

$\dot{q}^{\prime \prime}=h_{f}\left(T_{s}-T_{\infty}\right)=273(200-25)=47,775 \mathrm{~J} / \mathrm{s} \mathrm{m}^{2}=47.775 \mathrm{~kW} / \mathrm{m}^{2}$

This represents the maximum rate of cooling by the foam. Note that the equation contains surface temperature of the object $\left(\mathrm{T}_{\mathrm{S}}\right)$ to be cooled. Therefore, the maximum rate of cooling also depends on the object's surface temperature that is a function of the rate of energy flow across the object and the thermal mass of the object.

This demonstrates that due to the low application rates of the foam, required by the codes, the rate of energy absorption of the foam is limited by the foam supply and does not provide the optimum cooling of hot surfaces. 
If the expected surface temperature is known, the $h_{f}$ can be used to determine the optimum application density $D_{W O}$ that can be calculated as:

$$
\begin{aligned}
& \dot{q}=\left(\Delta T\left(c_{P W}\right) D_{W O} \rho_{W} A\right) / 1000+\left(h_{f g} D_{W O} \rho_{W} A\right) / 1000=h_{f}\left(T_{s}-T_{\infty}\right) \\
& D_{W O}=\frac{1000 h_{f}\left(T_{s}-T_{\infty}\right)}{A \rho_{W}\left(\left(\Delta T\left(c_{P W}\right)\right)+h_{f g}\right)} \quad\left(\ell / \mathrm{s} \mathrm{m}^{2}\right) \\
& D_{W O}=\frac{1000 h_{f}\left(T_{s}-T_{\infty}\right)}{A \rho_{W}\left(\left(100-T_{\infty}\right)\left(c_{P W}\right)+h_{f g}\right)} \quad\left(\ell / \mathrm{s} \mathrm{m}^{2}\right)
\end{aligned}
$$

The optimal application density $D_{\mathrm{wo}}\left(/ / \mathrm{s}^{2}\right)$ represents the minimum foam application density that will provide the maximum cooling. Even if the application density is increased, the heat absorption rate of the foam will not change.

The surface temperature of the object to be cooled can be estimated based on the heat flow to the surface by conduction and from the surface by convection. The optimum application density for cooling can therefore be calculated.

In cases where the application density rate provides a cooling rate lower than the maximum cooling rate, then the total amount of foam required to cool the surface of object to $100^{\circ} \mathrm{C}$ can be determined by calculating the energy required to lower the temperature of the object to $100^{\circ} \mathrm{C}$. 
$Q=\left(T_{S-o}-100\right) c_{o} M_{o} \quad(\mathrm{~kJ})$

The amount of energy absorbed by the foam will be

$$
Q=\left(\Delta T\left(c_{P W}\right) D_{W} \rho_{W} A\right) t+\left(h_{f g} D_{W} \rho_{W} A\right) t \quad(\mathrm{~J} / \mathrm{s})
$$

The amount of foam required to cool the object would be:

$$
D_{W} t A=\frac{1000\left(T_{S-o}-100\right) c_{o} M_{o}}{\rho_{W} \operatorname{At}\left(\Delta T\left(c_{P W}\right)+h_{f g}\right)}
$$

Where :

$\mathrm{T}_{\mathrm{S}-\mathrm{O}}=$ initial temperature of the object $\left({ }^{0} \mathrm{C}\right)$

$c_{O}=$ specific heat of the object $(\mathrm{kJ} / \mathrm{kg} \mathrm{K})$

$\mathrm{M}_{\mathrm{O}}=$ mass of the object $(\mathrm{kg})$

Calculated for foam inserted at $20^{\circ} \mathrm{C}$ gives:

$$
D_{W} t A=\frac{\left(T_{S-O}-100\right) c_{O} M_{O}}{((80 \times 4.18)+2270)}=\frac{\left(T_{S-O}-100\right) c_{O} M_{O}}{2604.4}
$$

Equation 5.7.1-5, for calculating the heat absorption by the foam, uses the temperature of the surface of the material being cooled as one of the factors. This temperature depends on the thermal mass of the body being cooled, the thermal conductivity and the thickness of the body. If the rate of the heat flow to the surface is reduced, the rate of surface temperature drop is increased, and therefore, the rate of foam application can also be reduced.

If the characteristics of the material subjected to cooling by the foam are known, and the heat flow to the surface in the transient condition caused by the cooling is known, then 
the rate of cooling by the foam and the required rate of application of the foam can be calculated. If the thermal conductivity of the material is lower than that of steel, the expected optimal application density of the foam would also be lower.

If the foam is used at its maximum cooling capacity, all of the foam on top of the hot surface is evaporated and provides the maximum cooling rate. If the rate of application of the foam is higher than the optimum application rate, then the foam accumulates on top of the hot surface but the rate of cooling is not increased. The total amount of energy absorbed by the cooling of the foam can be attributed to the evaporation of the water content of the foam.

The use of CAFS provides extinguishing of the fire and cooling of the surrounding area to reduce the possibility of re-ignition. Based on the experiments by NRC, when CAF is used, most of the fires are extinguished within 2 minutes. The data developed in this thesis, may lead to an application of two densities - density in the initial stage of foam discharge that would be based on the extinguishing capacity and density that would be used in the secondary stage when the foam is used for cooling and protecting from reignition.

The data obtained in this research on the cooling ability of the foam may lead to the reduction of the required duration of foam discharge. 


\section{EXPERIMENTAL - GAS PROPAGATION}

\subsection{General}

The objective of this series of experiments was to investigate the CAF's ability to mitigate gas propagation. The experiments were done by spraying CAF onto a grated floor, placing a propane gas burner under the floor and measuring the $\mathrm{CO}_{2}$ generated by the burning propane that penetrated the foam layer.

\subsection{Equipment}

\subsubsection{Foam}

The same foam concentrates were used in these experiments as were used in the heat radiation experiments. See section 4.2 .1 for details.

\subsubsection{Foam generator}

The same foam generator was used as for the heat radiation experiments. See section 4.2.2 for details.

\subsubsection{Foam tank - open}

The foam-holding tank for the tests to determine the products of combustion attenuation was similar to the holding tank for the heat transfer (see section 4.2.3) and had the same dimensions (see Figs. 6.2.3-1 and 6.2.3-2). The difference was that the "floor" of the tank was grated instead of a solid plate. 
See Fig. 6.2.3-3. A circular deflector plate of $250 \mathrm{~mm}$ diameter was attached below the open-grate to minimize draining water from affecting the flames. The flames did not directly impact the foam.

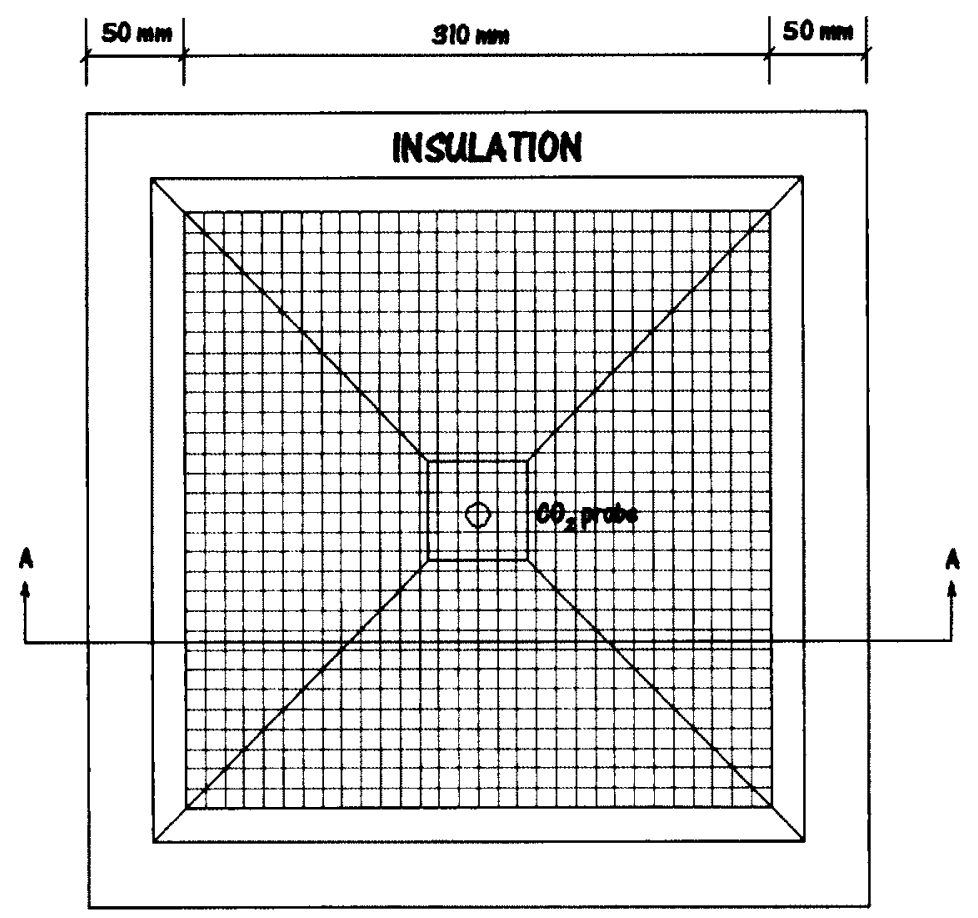

Fig. 6.2.3-1 Foam tank - open floor - plan view 


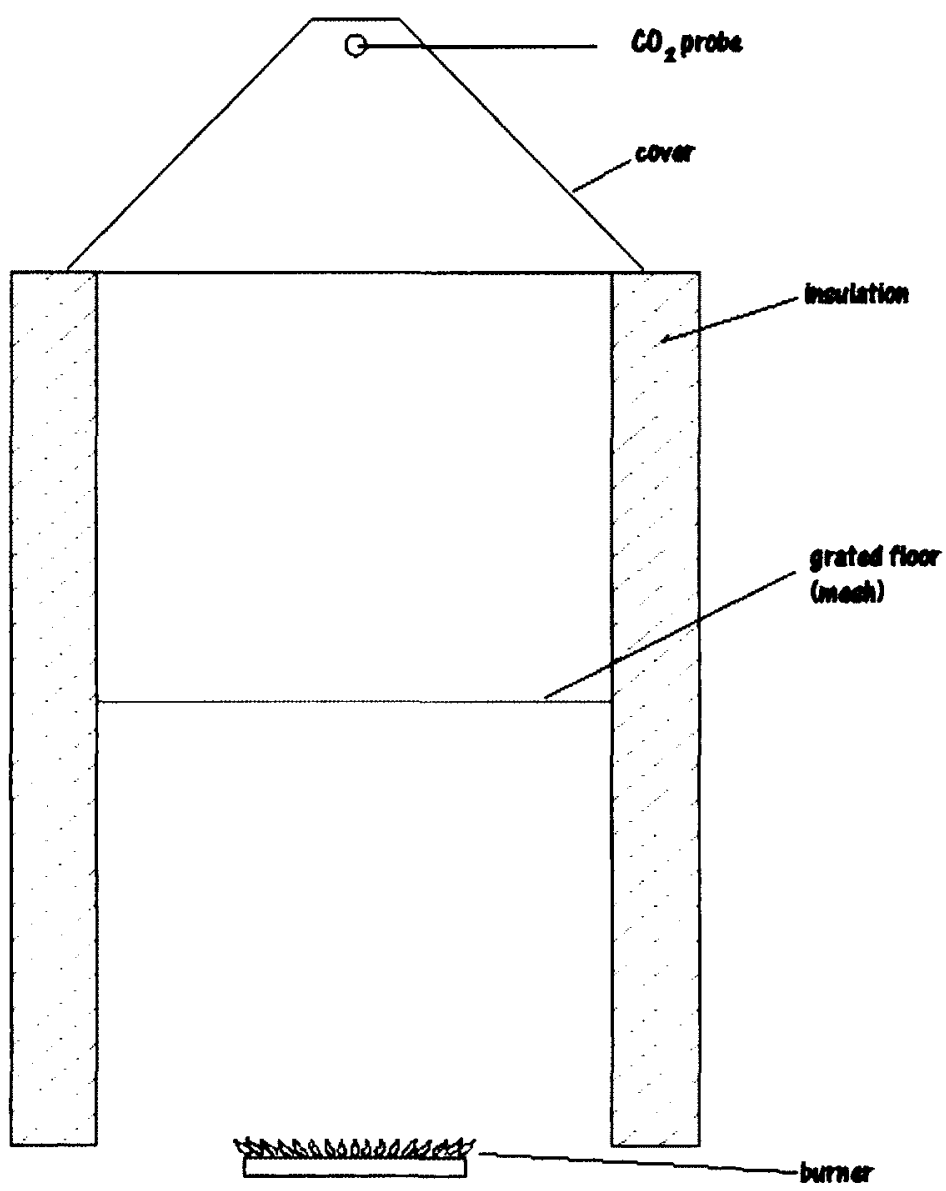

Fig. 6.2.3-2 Foam tank - open floor - cross section AA 


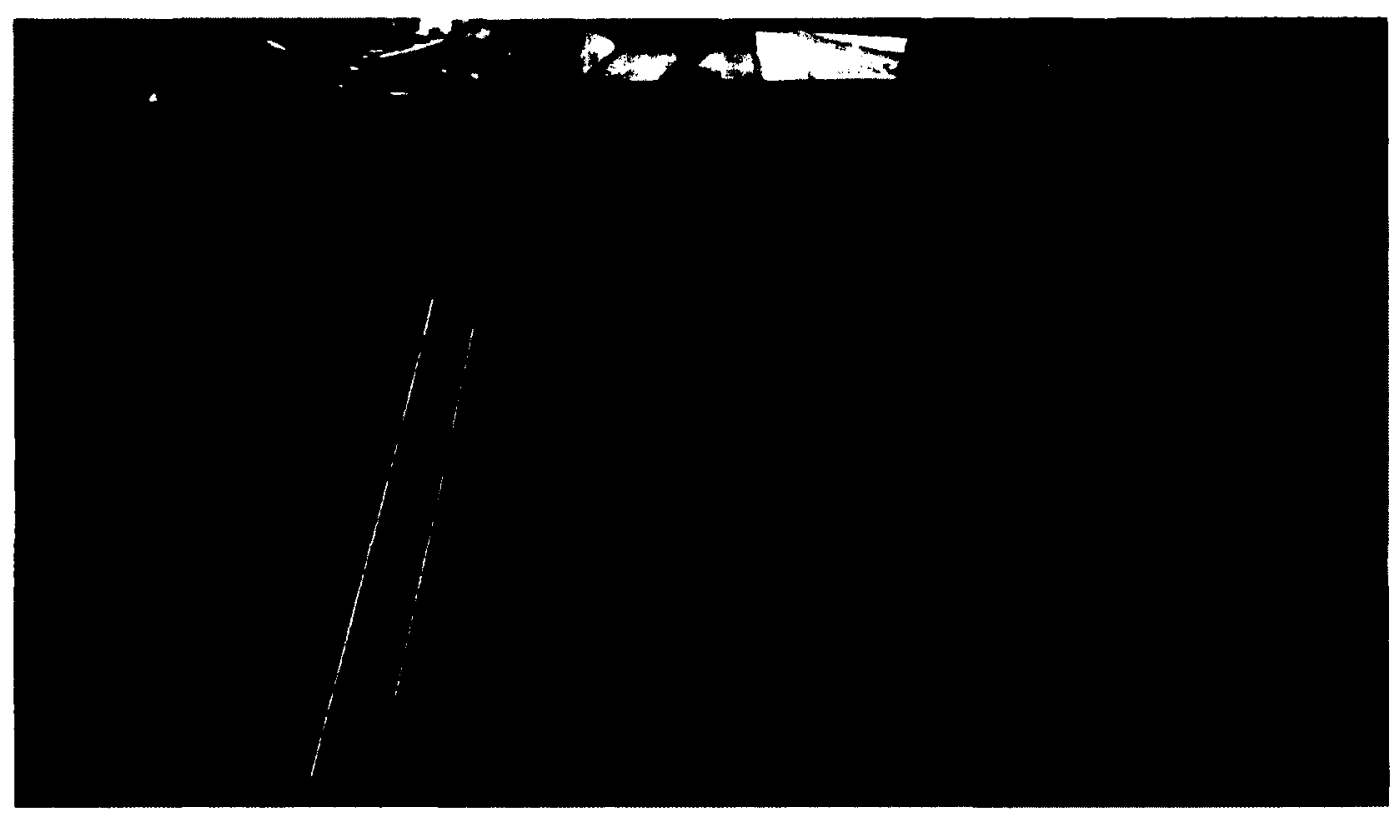

Fig. 6.2.3-3 Foam tank - with open floor grate

Two pyramid-like hoods were built that were placed on top of the container to prevent ambient air from mixing with the $\mathrm{CO}_{2}$ generated by the propane fuelled fire. The hoods had a $30 \times 30 \mathrm{~mm}$ opening at the top and copper piping was installed to take air samples from inside the hood.

One hood was made of plywood and the other plywood and plexiglass. The all plywood hood was used to take measurements without the foam due to high temperatures of the gas. See Fig. 6.2.3-4. The second hood was used with the foam to be able to observe the foam during the test. See Fig.6.2.3-5. 


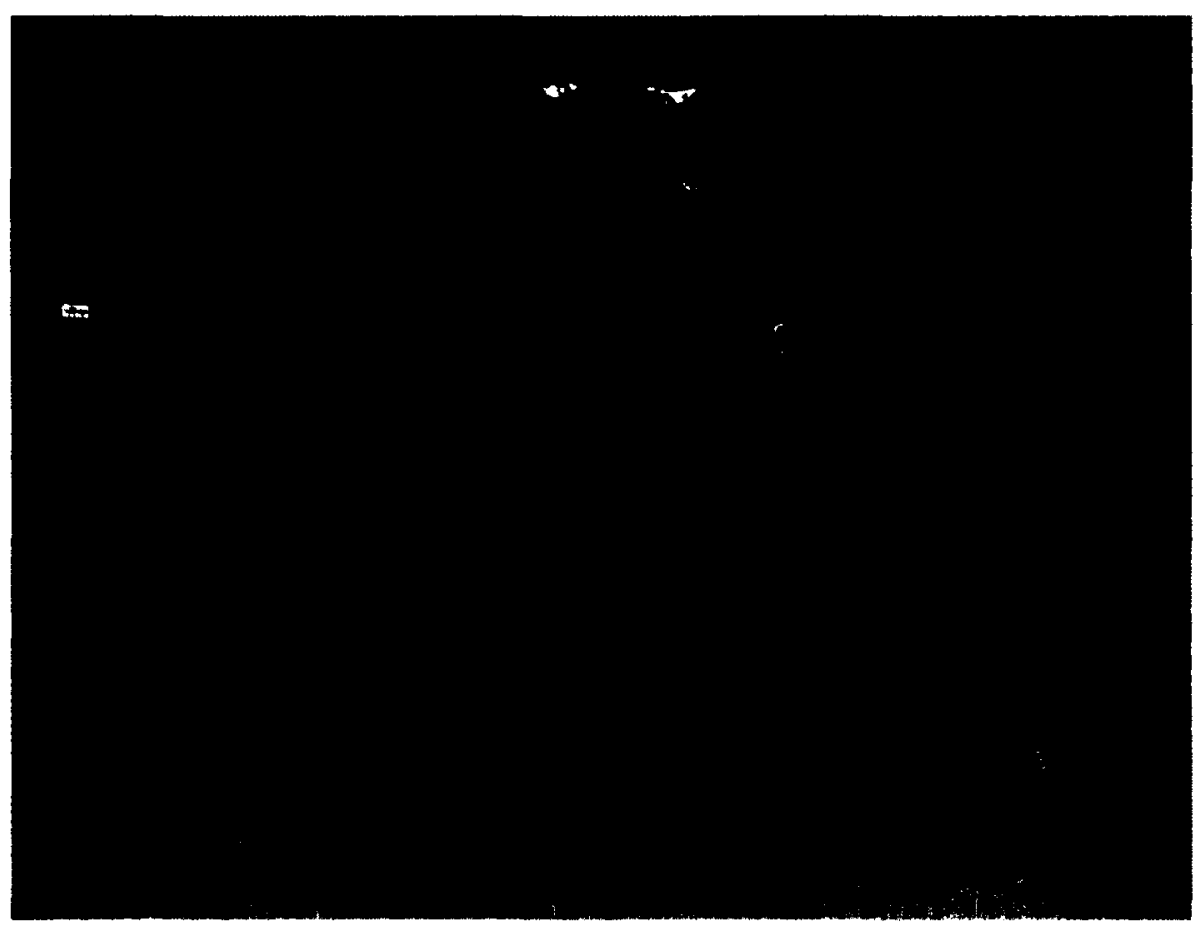

Fig. 6.2.3-4 Plywood hood for high temperature tests

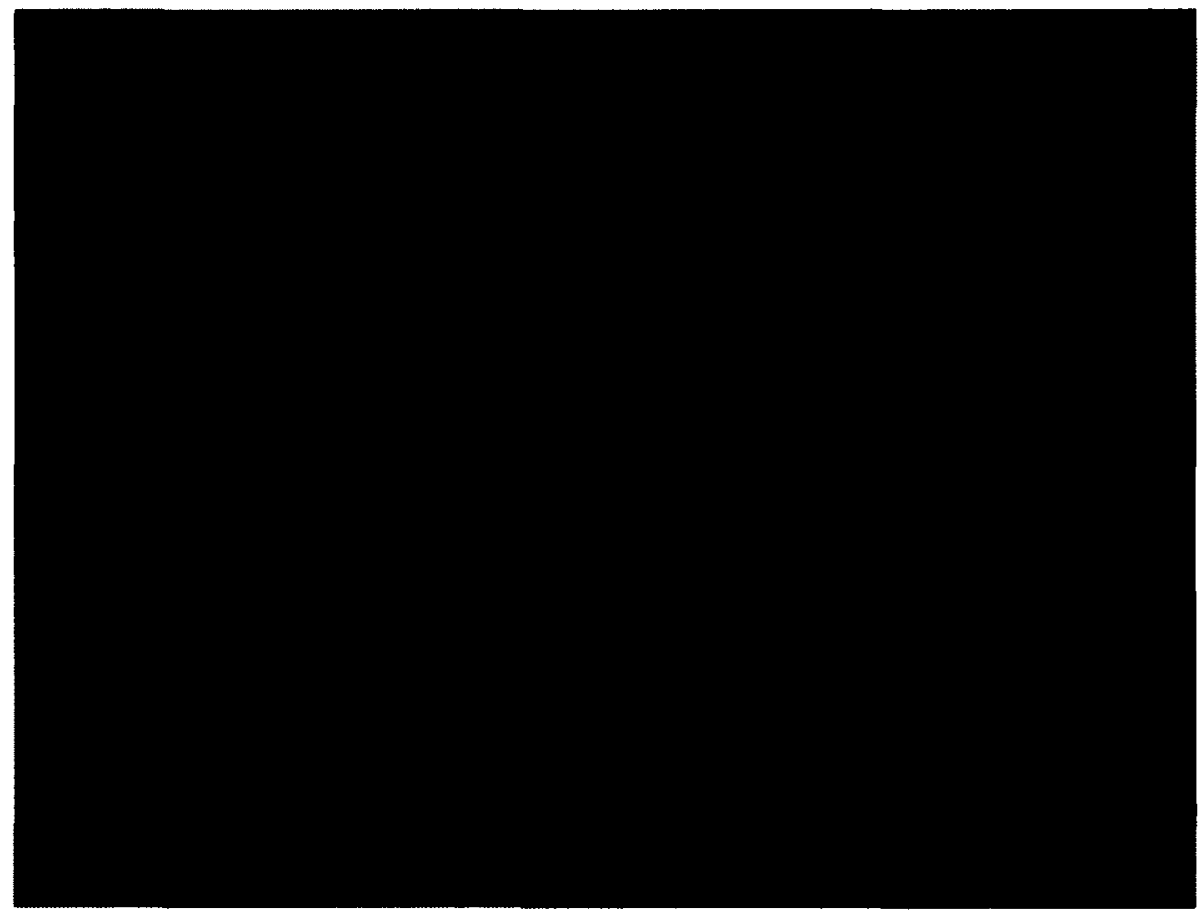

Fig. 6.2.3-5 Plywood hood with plexiglass windows 
This series of experiments was designed to simulate fires where the foam layer provides a continuous barrier that the products of combustion have to cross. To investigate the ability of foam to mitigate the flow of gases, the following measurements were made: ambient $\mathrm{CO}_{2}$ concentration, $\mathrm{CO}_{2}$ concentration under fire conditions without the foam layer and $\mathrm{CO}_{2}$ concentration with the foam layer.

\subsubsection{Thermocouples}

The same temperature monitoring devices, multiplex reader and software (Labview) used in the heat transfer experiments were used for these experiments.. For details see section 4.2.4.

\subsubsection{Heat source}

The same burner as in the heat transfer experiments was used. For details see section 4.2.5.

\subsubsection{Scale}

The same scale as in the heat transfer experiments was used. See section 4.2 .6 for details.

\subsection{7 $\mathrm{CO}_{2}$ detection}

Two $\mathrm{CO}_{2}$ probes were used. One had the capacity to measure $\mathrm{CO}_{2}$ concentrations up to $30 \%$ and the second probe had the ability to measure $\mathrm{CO}_{2}$ concentrations up to $1 \%$. The probes were connected to the copper tubing with flexible tubing that was connected to a humidity filter and an air pump. See Fig. 6.2.7-1 
The $\mathrm{CO}_{2}$ probes were sampling data every two seconds and the results were recorded in a computer using Labview software.

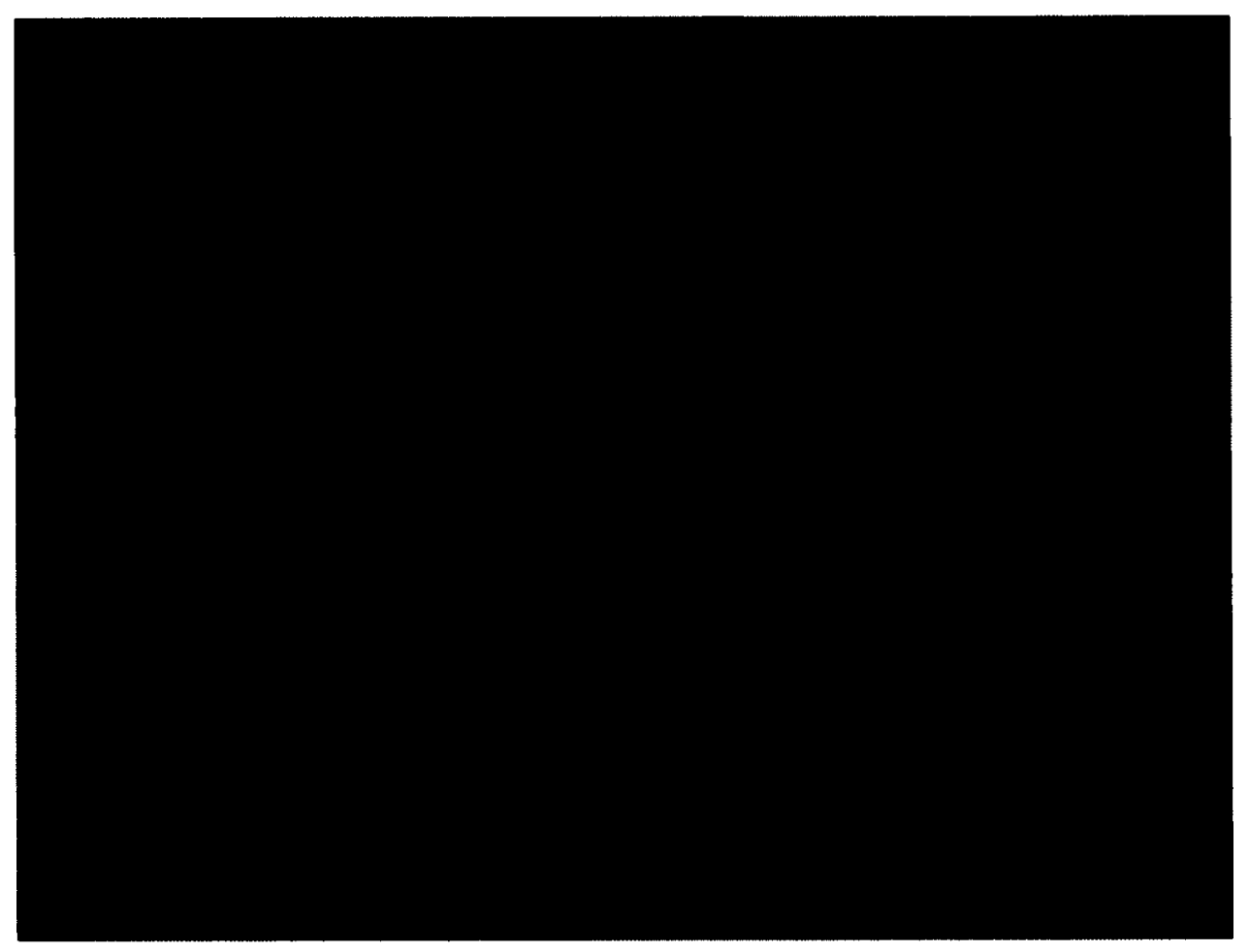

\section{Fig. 6.2.7-1 $\mathrm{CO}_{2}$ probes with accessories}

A $50 \mathrm{~mm}$ foam depth was used for the gas mitigation test. To study the gas penetration through the foam layer, it is important to measure the products of combustion with acceptable precision. As $\mathrm{CO}_{2}$ is generated in relatively large quantities from the combustion of propane, the measurements of $\mathrm{CO}_{2}$ concentration can provide information on the $\mathrm{CO}$ concentration with acceptable precision. The mitigation of $\mathrm{CO}_{2}$ movement by the foam layer could also be used to estimate the mitigation of the flow of other ability of 
the foam to mitigate the flow of other gases and soot. The use of the results for soot is expected to be conservative due to the relatively large size of soot particles.

\subsection{Calibration}

\subsubsection{Foam water - foam concentrate calibration}

For details about calibration, see section 4.3.1

\subsubsection{Expansion rate verification}

For details about the verification of the expansion ratio, see section 4.3.1

\subsection{Gas mitigation experiment - procedure}

Gas mitigation experiments were set up to measure the CAF's capacity to control the propagation of gases.

By measuring the ambient $\mathrm{CO}_{2}$ concentration and $\mathrm{CO}_{2}$ concentration during the operation of the burner without and with the foam, the reduction of gas transfer across the CAF can be calculated. 


\subsection{Gas mitigation experiments}

\subsubsection{Gas mitigation experiment - reference test - G1}

The reference test was setup to determine the ambient $\mathrm{CO}_{2}$ concentration and to determine the $\mathrm{CO}_{2}$ concentration in the foam container when the burner was operating without the presence of the foam.

The solid floor foam container was replaced with a grated (mesh) floor container. See Fig. 6.5.1-1 for the typical setup.

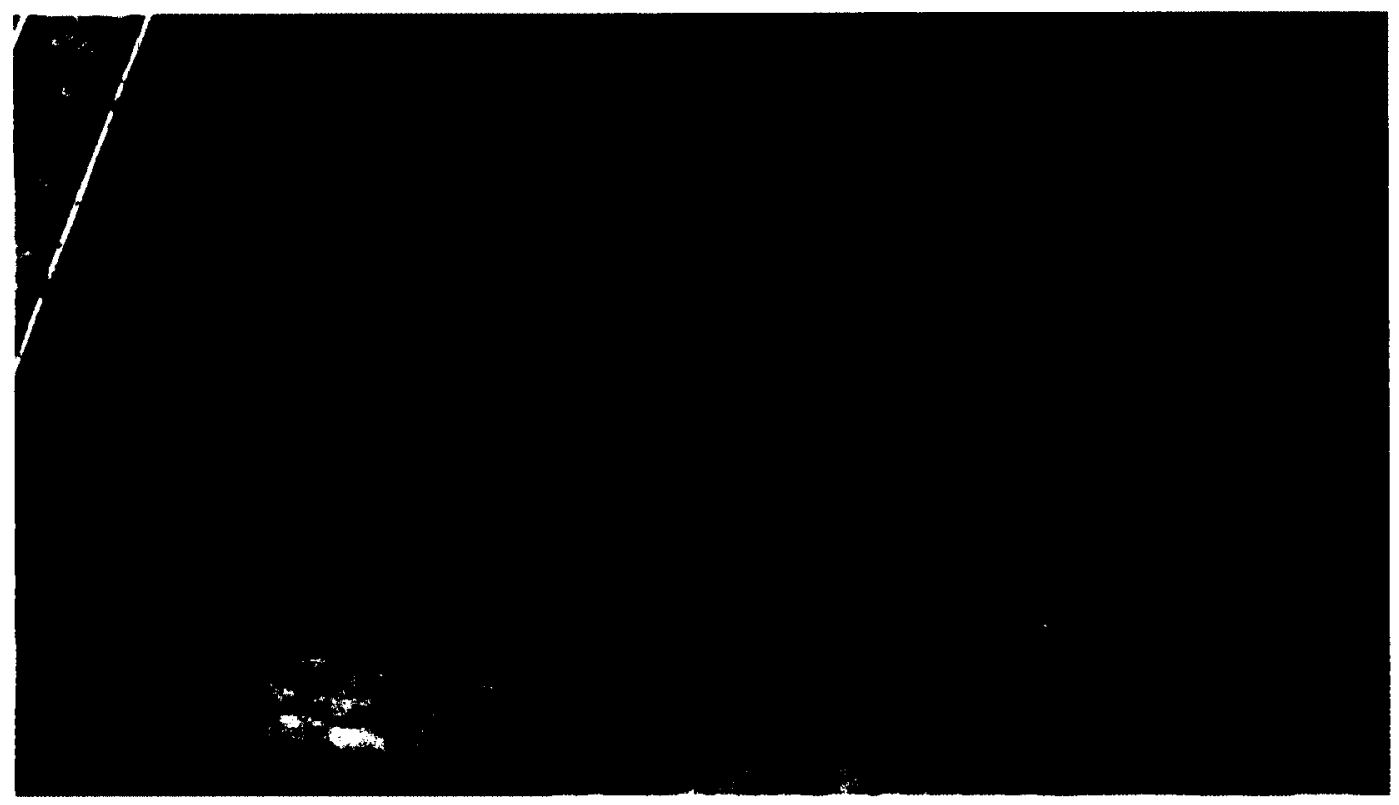

Fig. 6.5.1-1 The $\mathrm{CO}_{2}$ foam container setup.

Two different $\mathrm{CO}_{2}$ probes were used during these experiments: a high sensitivity sensor with a maximum reading of $1 \% \mathrm{CO}_{2}$ concentration and a high concentration sensor with 
a maximum reading of $30 \%$. The $\mathrm{CO}_{2}$ sensors were connected to the computer running Labview software..

Thermocouples were located at $10 \mathrm{~mm}, 20 \mathrm{~mm}, 30 \mathrm{~mm}$ and $40 \mathrm{~mm}$ above the grated floor. The thermocouples were connected to a multiplexer and data were recorded simultaneously with the $\mathrm{CO}_{2}$ data on Labview software every 2 seconds.

The following procedure was used for the tests:

1. The ambient $\mathrm{CO}_{2}$ concentration was measured.

2. The burner was activated and the foam container with the plywood hood was installed on top of the apparatus. The concentration of $\mathrm{CO}_{2}$ was measured until a steady state was attained.

3. The hood was removed and the burner was extinguished. The subsequent experiments were not started until the $\mathrm{CO}_{2}$ level was reduced to the originally measured ambient level.

The ambient concentration of $\mathrm{CO}_{2}$ measured was $0.052 \%$, and the $\mathrm{CO}_{2}$ concentration with the burner on, without the foam was $3.2 \%$.

\subsubsection{Gas mitigation experiments - Test G2, G3, G4 and G5}

Test G2 - Foam - Class A - concentrate mix at 1\% and expansion ratio 1:23

Class A foam mixed at $1 \%$ with an expansion ratio of $1: 23$ was used for this test. 
The foam was sprayed into the container to a depth of $50 \mathrm{~mm}$. The hood with plexiglass windows was installed on top of the container. The burner was ignited. The $\mathrm{CO}_{2}$ concentration and temperature were measured at 2 seconds intervals. Figure 6.5.2-1 shows the experimental setup.

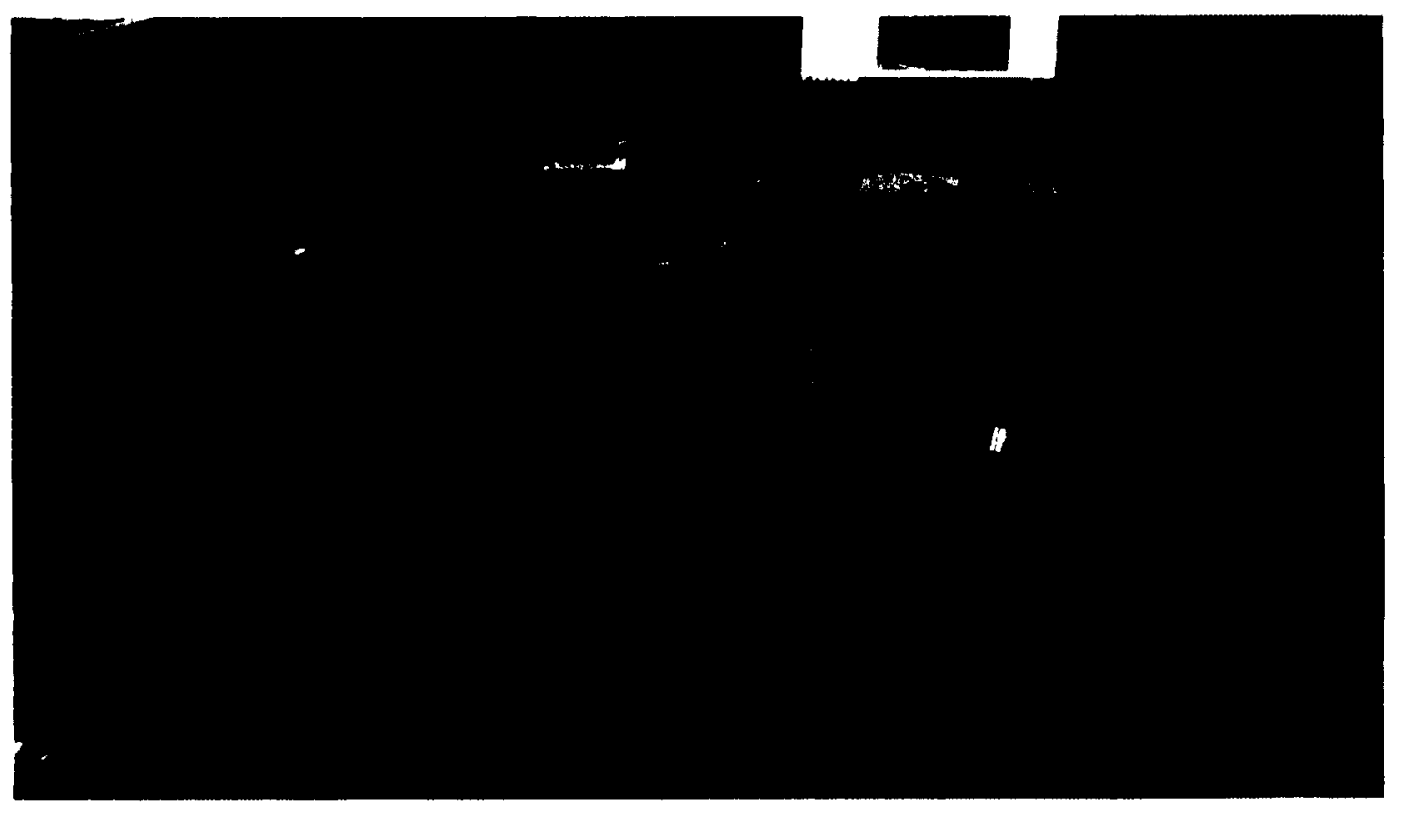

Fig. 6.5.2-1 Gas mitigation experiment set up.

The experiment was stopped when the foam no longer covered the entire surface of the floor.

The following graph (Fig. 6.5.2-2) illustrates the $\mathrm{CO}_{2}$ concentration measured with respect to time. The foam was inserted at $t=-20$ seconds and the burner was ignited at $t=0$. The hood was removed at approximately $t=820$ seconds 
At $t=770$ seconds, the foam coverage was no longer complete. A sudden increase in $\mathrm{CO}_{2}$ concentration was observed as shown in Fig. 6.5.2-2.

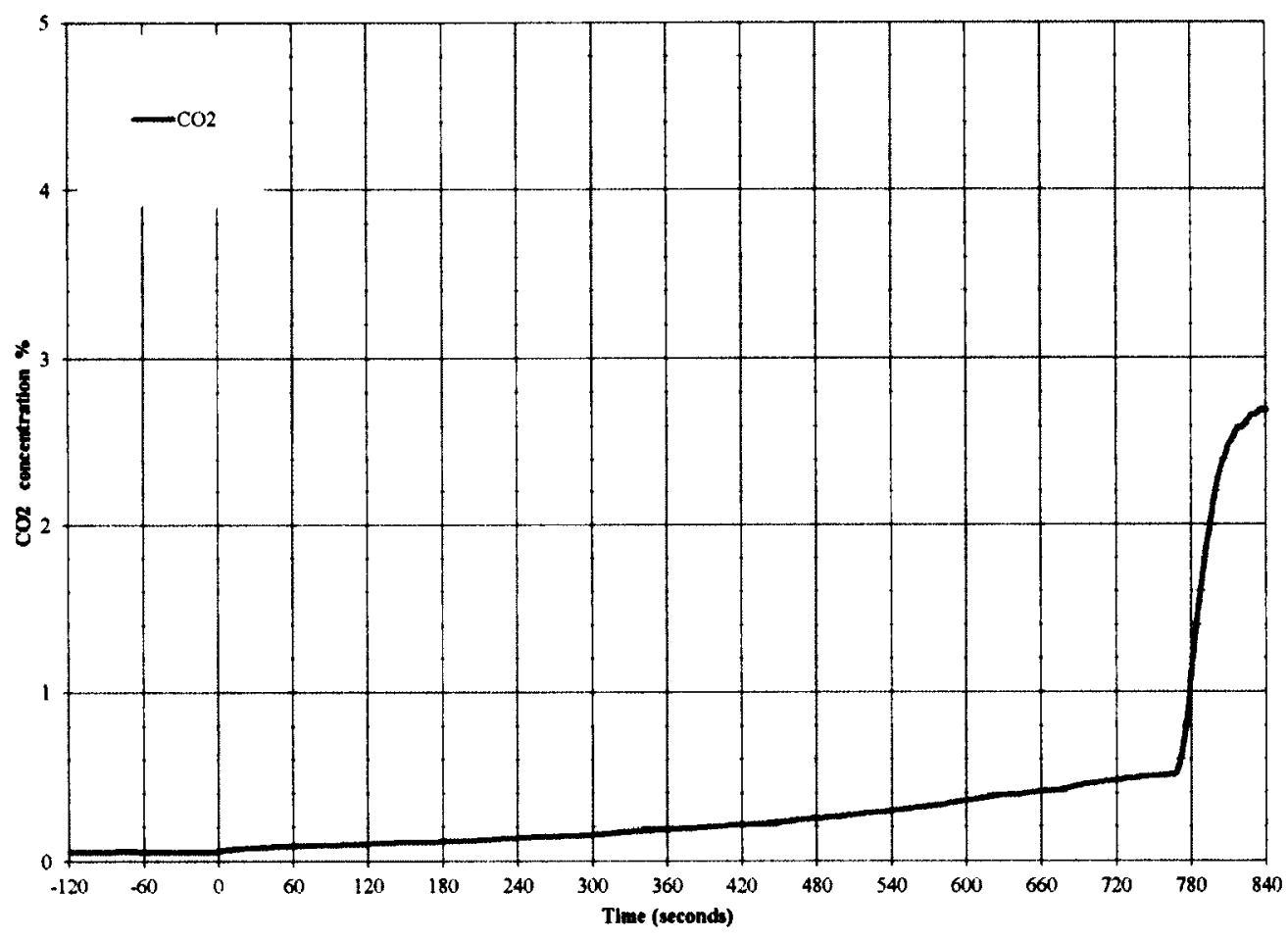

Fig. 6.5.2-2 Test G2- $\mathrm{CO}_{2}$ concentration vs Time - Foam A expansion 1:25

Test G3 - Foam Class B - concentrate mix at 3\% and expansion ratio 1 : 25

Test G3 was conducted using Class B (AFFF-AR) foam at $3 \%$ foam concentrate with an expansion ratio of 1:25. There was a small percentage of gas crossing the foam layer that increased as the foam was getting thinner. This can be observed in Fig. 6.5.2-2 that 
illustrates the recorded $\mathrm{CO}_{2}$ concentration. As the foam coverage became incomplete, the $\mathrm{CO}_{2}$ concentration increased sharply $(\mathrm{t}=770 \mathrm{sec}$. $)$

The foam behaviour was similar to Test G2. It was observed that Class A foam takes considerably less time (approximately $30 \%$ less) to disintegrate than Class B foam. When Class $\mathrm{B}$ foam was used, the measured $\mathrm{CO}_{2}$ concentration was less than when Class $\mathrm{A}$ foam was used. The foam was introduced into the container at $t=300$ seconds and the burner was started at $\mathrm{t}=320$ seconds. A sudden increase in $\mathrm{CO}_{2}$ concentration was observed at $t=1080$ seconds as shown in Fig. 6.5.2-3. The foam coverage was not full at that time. The hood was removed at approximately $\mathrm{t}=1120$ seconds. 


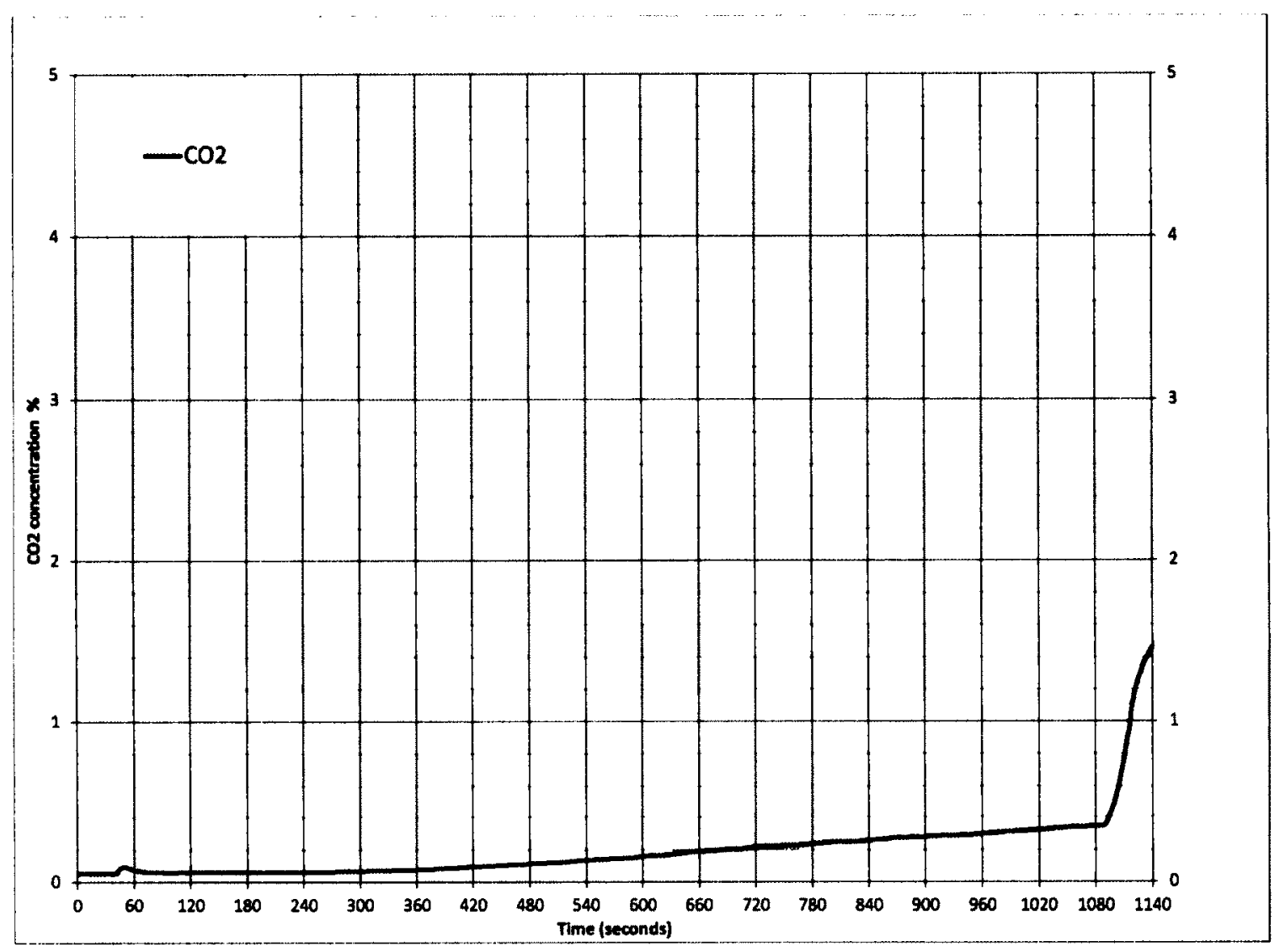

Fig. 6.5.2-3 Test $\mathrm{G3}-\mathrm{CO}_{2}$ concentration vs Time

Test G4 - Foam Class A - concentrate mix at $0.3 \%$ and expansion ratio 1:8.7

Test G4 used Foam Class A mixed at $0.3 \%$ with an expansion ratio of 1:8.7.

The foam water content was relatively high and drained very quickly. The following Figure 6.5.2-4 shows the results for Test G4. The foam was introduced into the container at $\mathrm{t}=70$ seconds. The burner was ignited at $\mathrm{t}=100$ seconds causing an increase of the $\mathrm{CO}_{2}$ concentration. A small opening in the foam coverage occurred when the burner was ignited and the foam was immediately redistributed to cover the entire floor surface. This 
explains a small peak in $\mathrm{CO}_{2}$ concentration at $\mathrm{t}=120$ seconds. An opening in the foam coverage occurred at $\mathrm{t}=560$ seconds. A sudden increase in $\mathrm{CO}_{2}$ concentration can be observed in Fig. $6.5 .2-4$ at that time. The hood was removed at $t=$ approximately 600 seconds.

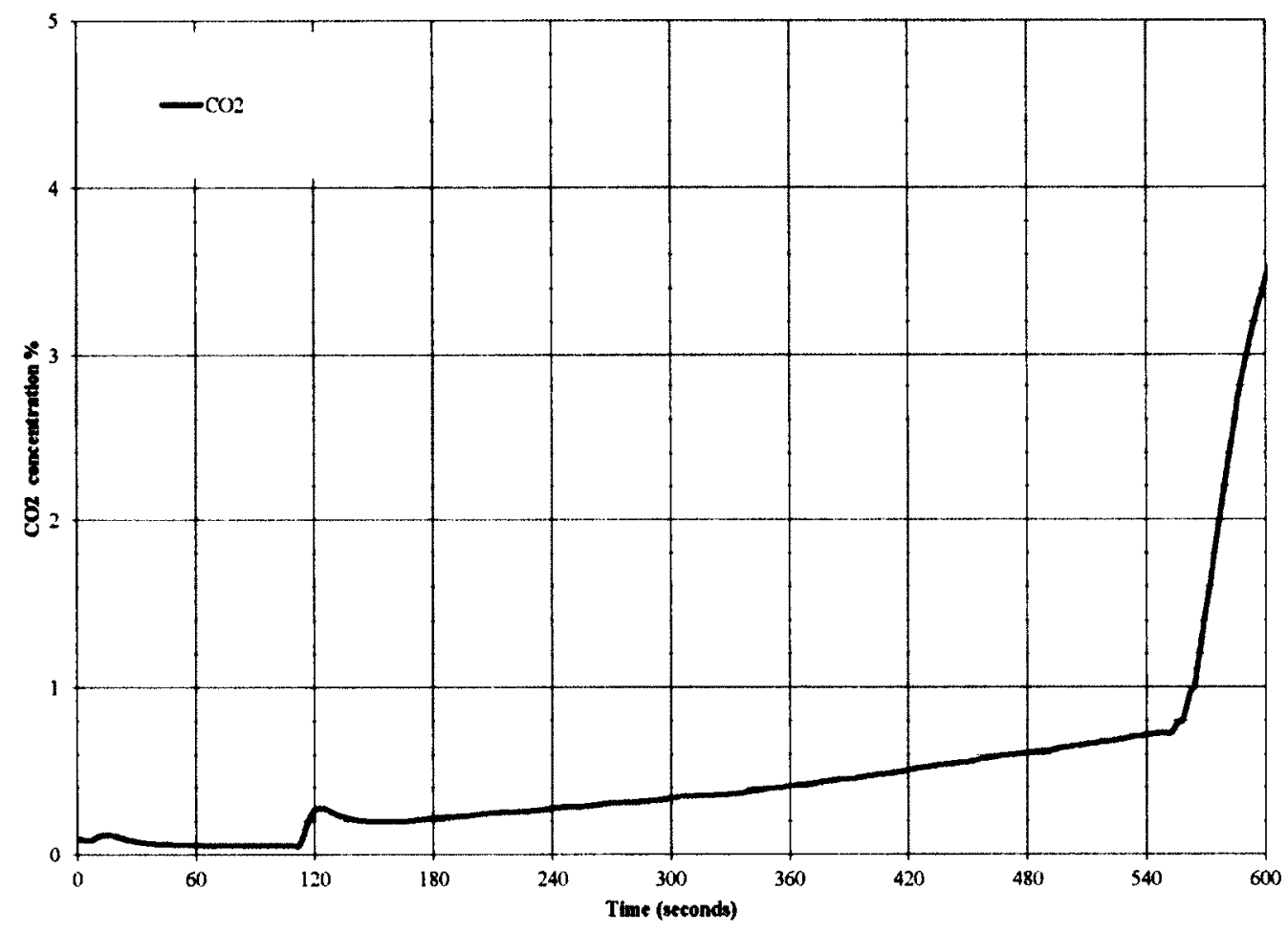

Fig. 6.5.2-4 Test $\mathrm{G} 4-\mathrm{CO}_{2}$ concentration vs Time

Due to the rapid disintegration of the foam, the use of foam with this expansion ratio is not recommended to control gas propagation. 
Test G5 - Foam Class B - concentrate mix at 2\% and expansion ratio 8.7:1

The foam was Class B (AFFF-AR) mixed at $2 \%$ with an expansion ratio of 1:8.7.

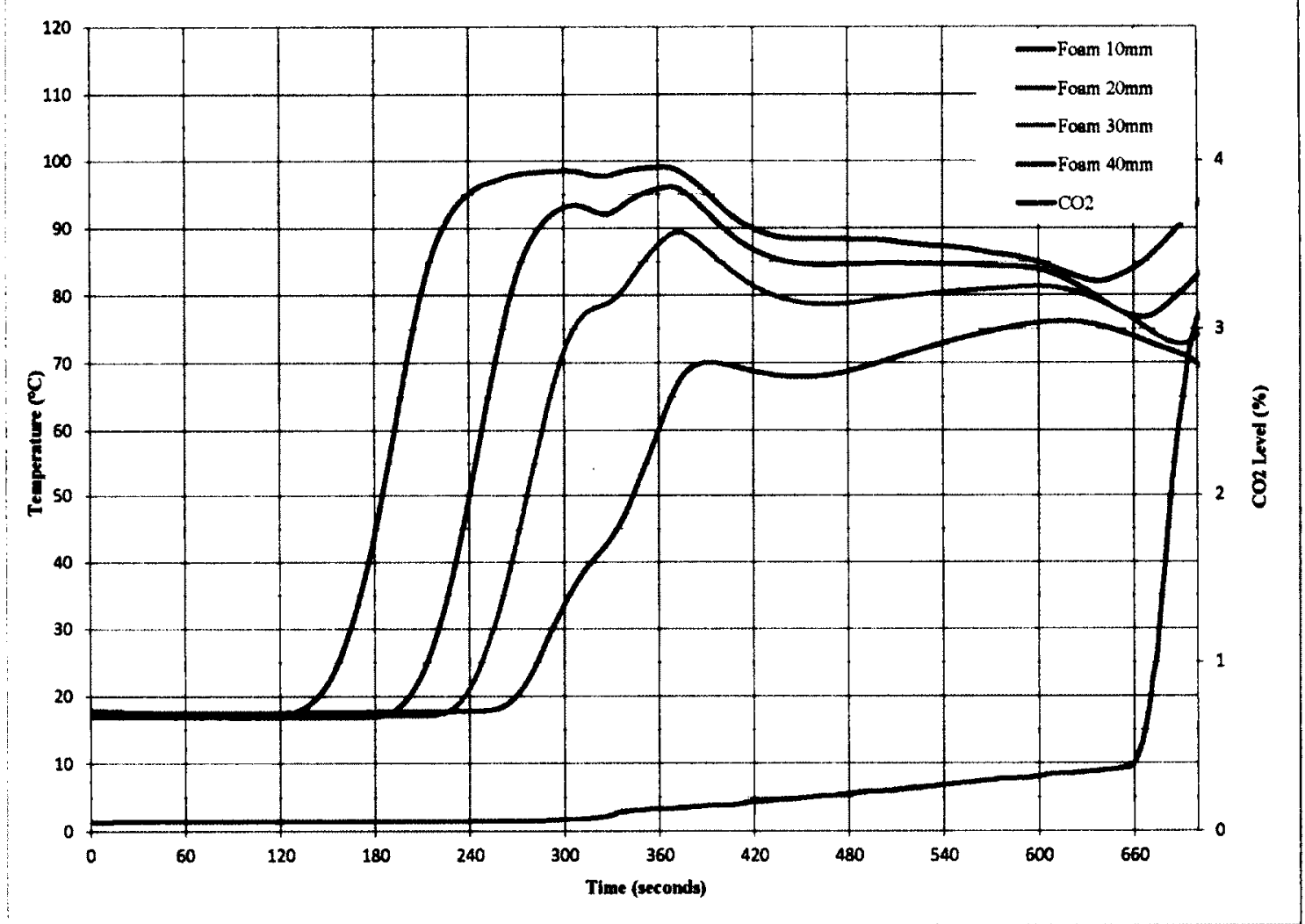

Fig. 6.5.2-5 Test $\mathrm{G5}$ - Temperature and $\mathrm{CO}_{2}$ concentration vs Time

The test results and observations were similar to Test G4. Figure 6.5.2-5 shows the results for Test G5. The foam was introduced at $t=0$ seconds. The hood was put on top of the container and the $\mathrm{CO}_{2}$ probes were installed. The fire was started at $\mathrm{t}=120$ seconds. Until $\mathrm{t}=330$ seconds the $\mathrm{CO}_{2}$ concentration did not change and then the concentration increased slowly until the foam coverage was broken at $t=660$ seconds. 


\subsubsection{Unheated foam experiments - Test G6}

In order to compare the foam behaviour without exposure to heat, the foam was monitored in Test G6 without the operation of the burner.

The foam generator was filled with the foam solution using Class B (AFFF-AR) $3 \%$ foam concentrate with expansion ratio of $1: 25$.

The foam was discharged into the foam container with a solid floor instead of the grated floor. The height level of the foam was recorded every minute until the foam no longer covered the entire surface of the container.

The foam disintegration was very slow and the surface cover was intact for 3 hours. The experiment was stopped after 3 hours when the foam cover was less than $10 \mathrm{~mm}$. The foam height dropped approximately $25 \%$ in the first 8 minutes and then the rate of decrease in height stabilized. The experiment demonstrated the exceptional stability of the $\mathrm{CAF}$ and the possibility to use the foam in preventive measures. 


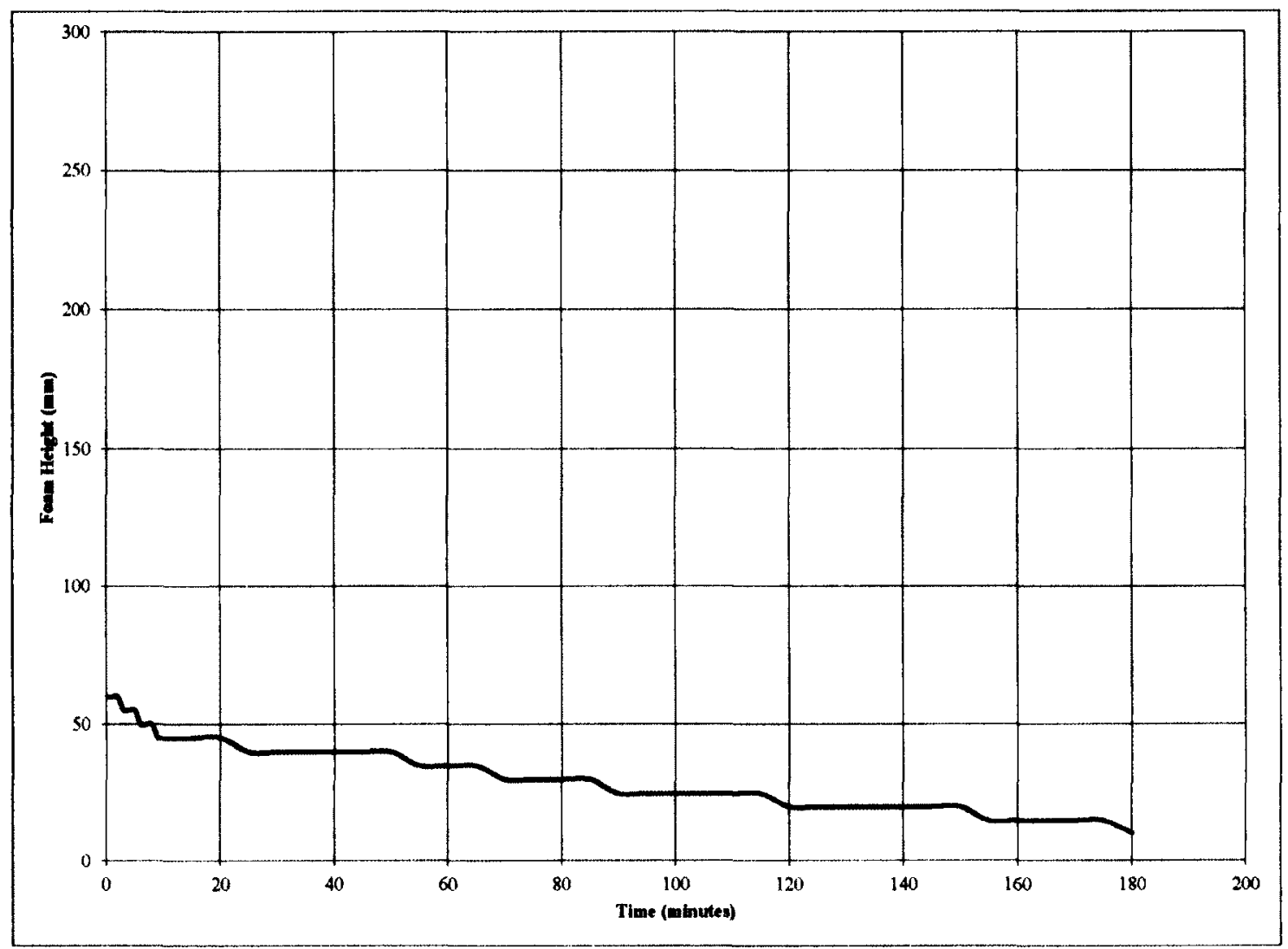

Fig. 6.5.3-1 Test G6 - Foam height vs Time

When the foam height decreased to $10 \mathrm{~mm}$ the experiment was terminated.

\subsubsection{Test summary}

Table 6.5.4-1 provides comparative summary of the test results. 
Table 6.5.4-1 Gas mitigation data

\begin{tabular}{|c|c|c|c|c|}
\hline Test & Foam type & Expansion & Time to break cover & $\mathbf{C O}_{2}$ concentration at break of cover \\
\hline G2 & Class A & $1: 25$ & $775 \mathrm{~s}$ & $2.5 \%$ \\
\hline G3 & Class B & $1: 25$ & $1080 \mathrm{~s}$ & $1.8 \%$ \\
\hline G4 & Class A & $1: 8.7$ & 500 & $3.5 \%$ \\
\hline G5 & Class B & $1: 8.7$ & 660 & $2 \%$ \\
\hline
\end{tabular}

From the results illustrated in Table 6.5.4-1, it can be concluded that CAF made of ARFFF concentrate with expansion ratio of 1:25 provided the most effective gas mitigation. 


\section{GAS MITIGATION ANALYSES}

\subsection{Products of combustion}

In order to determine the gas mitigation capacity of the $\mathrm{CAF}$, the gas that crosses the foam layer must be measured. $\mathrm{CO}_{2}$ generated by a fire was used to study the foam's ability to mitigate the movement of the products of combustion.

The following section provides the chemistry of complete combustion of propane gas. The complete combustion of propane gas in air is given by the following reaction.

$$
\mathrm{C}_{3} \mathrm{H}_{8}+9.335 \mathrm{O}_{2}+35.119 \mathrm{~N}_{2} \longrightarrow 3 \mathrm{CO}_{2}+4 \mathrm{H}_{2} \mathrm{O}+4.335 \mathrm{O}_{2}+35.119 \mathrm{~N}_{2}
$$

In general, the perfect combustion of one molecule of propane $\left(\mathrm{C}_{3} \mathrm{H}_{8}\right)$ will generate 3 molecules of carbon dioxide $\left(\mathrm{CO}_{2}\right)$. This stoichiometric equation applies only to ideal conditions. [59]

In reality, well-ventilated combustion of propane will also generate other products of combustion. Well-ventilated combustion of one gram of propane will generate 0.005 grams of carbon monoxide (CO), 0.001 grams of hydrocarbons, 0.024 grams of soot and 2.85 grams of carbon dioxide [61].

Normally the amount of carbon dioxide in air is expressed as a \% by volume. The molecular weight of air at $20^{\circ} \mathrm{C}$ prior to combustion is 28.95 and the density of air prior 
to combustion is $1203 \mathrm{~g} / \mathrm{m}^{3}$ so that $1 \mathrm{~m}^{3}$ of air contains 41.55 moles. One mole of gas will occupy 24.11 at $20^{\circ} \mathrm{C}$. One mole of $\mathrm{CO}_{2}$ has a mass of 44 grams.

\subsection{Analyses of amounts of gas penetration}

Carbon dioxide concentration measurements above the foam $\left(\mathrm{CO}_{2 \mathrm{~m}}\right)$ were used to determine the gas penetration across the foam layer. It was assumed that the foam layer will not act as a filter that allows some gases to pass through but block others.

As soot will probably have more difficulty to cross the foam layer, the use of $\mathrm{CO}_{2}$ penetration across the foam layer should provide conservative results for soot. The penetration of $\mathrm{CO}_{2}$ across the foam layer is expected to be similar to that of $\mathrm{CO}$.

As observed in the experiments described in Chapter 5, when large quantities of vapour were generated below the foam, the vapour formed large bubbles that penetrated the foam layer. When the vapour was generated slowly, the foam was able to contain approximately three times its volume of vapour. The foam was not able to contain any rapid generation of vapour.

The following equation can be used to determine the change in $\mathrm{CO}_{2}$ concentration (\%):

$$
\begin{aligned}
& \Delta C O_{2 f}=C O_{2 f}-C O_{2 a} \\
& \Delta C O_{2 m}=C O_{2 m}-C O_{2 a}
\end{aligned}
$$


Reduction of $\mathrm{CO}_{2}$ percentage $=\frac{\Delta C \mathrm{O}_{2 f}-\Delta C \mathrm{O}_{2 m}}{\Delta C O_{2 f}} 100(\%)$

Where:

$\mathrm{CO}_{2 \mathrm{a}}$ is $\mathrm{CO}_{2}$ ambient concentration \% in air without fire

$\mathrm{CO}_{2 \mathrm{f}}$ is $\mathrm{CO}_{2}$ concentration \% near the top of the enclosure under fire conditions without foam

$\mathrm{CO}_{2 \mathrm{~m}}$ is $\mathrm{CO}_{2}$ measured concentration \% near the top of the enclosure under fire conditions with foam

By measuring the concentration of $\mathrm{CO}_{2 m}$, the amount of gas volume $(\dot{m})$ that is penetrating the foam layer can be estimated.

By considering the volume (V) above the foam as a control volume, the mass of gas entering the control volume will be same as the mass of gas exiting the control volume within a time period $(\Delta t)$. The measured concentration of $\mathrm{CO}_{2}$ at $\mathrm{t}+\Delta \mathrm{t}$ is approximated by concentration of $\mathrm{CO}_{2}$ in the control volume at $\mathrm{t}$, that is increased by the portion of $\mathrm{CO}_{2}$ generated by the fire.

$\dot{m}_{\mathrm{CO}_{2}}=\dot{g} \rho\left(\mathrm{CO}_{2} \%\right)$

where $\dot{m}_{\mathrm{CO}_{2}}=$ flow of $\mathrm{CO}_{2}$ (mass)

$\dot{g}=$ flow of gas volume

$\rho V\left(\mathrm{CO}_{2 m} \%(t+\Delta t)-\mathrm{CO}_{2 m} \%(t)=\dot{\mathrm{g}} \rho\left(\mathrm{CO}_{2 f} \%-\mathrm{CO}_{2 m} \%\right)\right.$ 
The amount of $\mathrm{CO}_{2 \mathrm{f}}$ as the percentage of the control volume $=\frac{\dot{\mathrm{g}}(t) \Delta t}{V} \mathrm{CO}_{2 f}(t)$

The amount of $\mathrm{CO}_{2 \mathrm{f}}$ as the percentage of the control volume $=\frac{\dot{g}(t) \Delta t}{V} \mathrm{CO}_{2 m}(t)$

$C O_{2 m}(t+\Delta t) \cong C O_{2 m}(t)+\frac{\dot{g}(t) \Delta t}{V} \mathrm{CO}_{2 f}(t)-\frac{\dot{g}(t) \Delta t}{V} \mathrm{CO}_{2 m}(t)$

As the concentration of $\mathrm{CO}_{2 \mathrm{~m}}$ is measured, the actual flow of gas $(\ell / \mathrm{s})$ can be calculated and is given by equation $7.2-3$

$$
\begin{aligned}
& \frac{\dot{g} \Delta t}{V}\left(C O_{2 f}-C O_{2 m}(t)\right)=C O_{2 m}(t+\Delta t)-C O_{2 m}(t) \\
& \dot{g}=\frac{\left(C O_{2 m}(t+\Delta t)-C O_{2 m}(t) V\right.}{\left(C O_{2 f}-C O_{2 m}(t)\right) \Delta t}
\end{aligned}
$$

Where

$\mathrm{CO}_{2 m}(t)$ represents $\mathrm{CO}_{2}$ concentration measured at time $\mathrm{t}$

$\dot{g}(t)$ represents flow rate of gas at time $t(\ell / s)$

Based on the measurements the following data was obtained:

$\mathrm{CO}_{2 \mathrm{a}}=0.052(\%)$

$\mathrm{CO}_{2 \mathrm{~F}}=3.2(\%)$

\section{Test G2 Foam Class B expansion ratio $1: 25$}

Test G2 was used for detailed analyses as Class B foam with expansion ratio 1:25 is most suited for mitigation of gas due to decomposition resistance and low spreadability. 
$\mathrm{CO}_{2 \mathrm{~m}}$ varies from $0.055 \%$ at the insertion of the foam to $0.33 \%$ when the foam layer was less than $10 \mathrm{~mm}$ thick.

Reduction of $\mathrm{CO}_{2}$ ratio $=\frac{\Delta C \mathrm{O}_{2 f}-\Delta C \mathrm{CO}_{2 m}}{\Delta C \mathrm{O}_{2 f}} 100(\%)$

Reduction of $\mathrm{CO}_{2}$ ratio near the end of the foam cover is:

$$
\frac{\Delta C O_{2 f}-\Delta C O_{2 m}}{\Delta C O_{2 f}} 100=\frac{(3.2-0.052)-(0.33-0.052)}{(3.2-0.052)} 100=91.2 \%
$$

Fig. 7.2-1 shows the measured $\mathrm{CO}_{2}$ concentration above the foam and the calculated flow of gas $(\ell / \mathrm{min})$ crossing the foam layer. The flow across the foam layer was calculated using Formula 7.2-3 and the time period $\Delta t$ used was 30 seconds. The fluctuation in the gas flow are probably due to the gas forming bubbles of different sizes that work their way across the foam layer. 


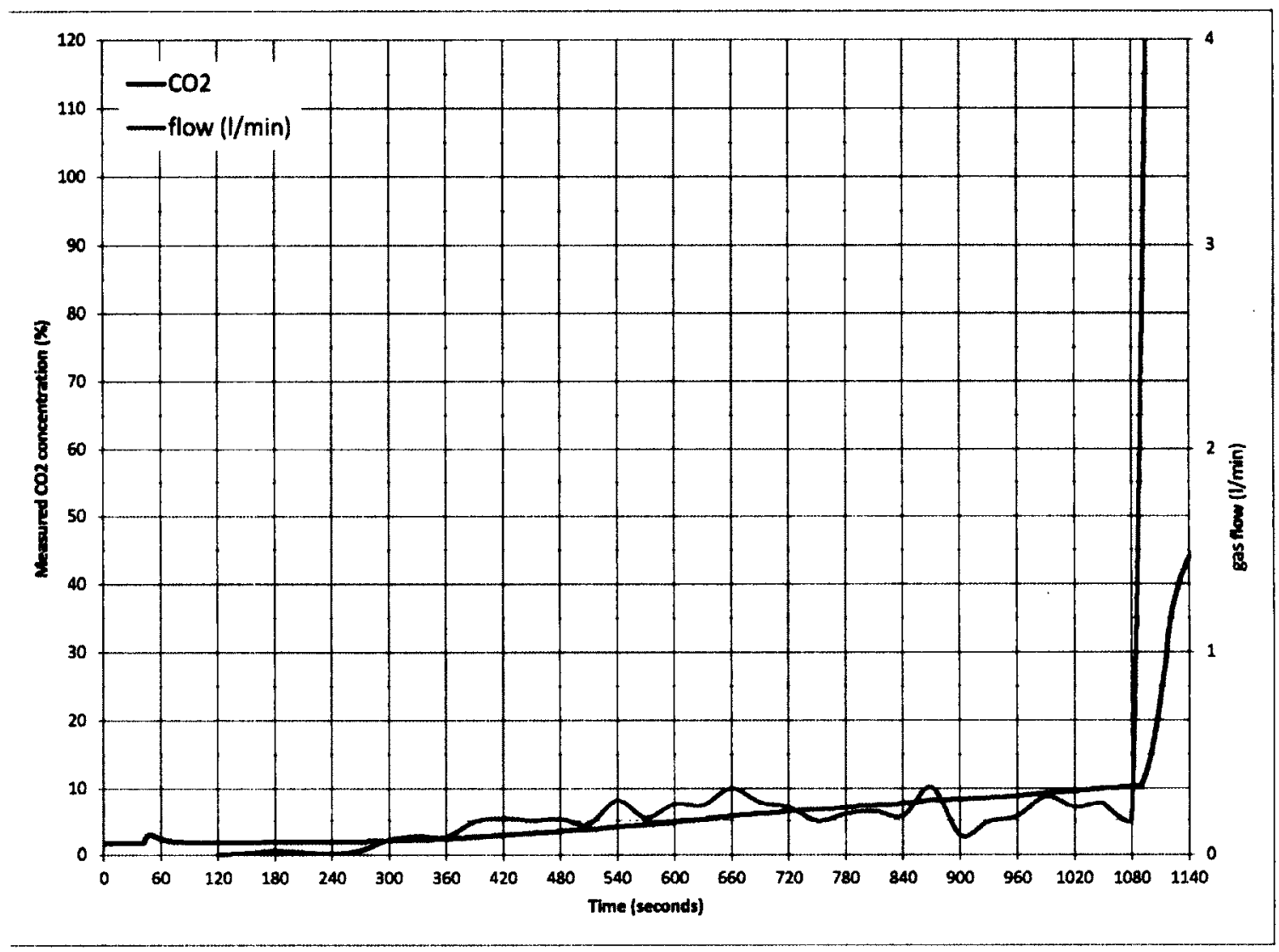

Fig. 7.2-1 Test G2 - Gas flow across the foam layer

Using a Class A foam with an expansion ratio of $1: 23$, in Test $\mathrm{G} 3$ the $\mathrm{CO}_{2 \mathrm{~m}}$ varied from $0.6 \%$ at the beginning of the foam cover to $0.54 \%$ at the end of the foam cover. By comparing the results of Test G3 with Test G2, it was concluded that the Class A foam did not provide as long a protection as the Class B foam due to the faster disintegration of the foam. The reduction of $\mathrm{CO}_{2}$ passage was also slightly higher for the Class $\mathrm{B}$ foam. 
Tests G4 and G5 used low-expansion foam; the disintegration of the foam was faster than for foams with higher expansion ratios. The use of CAF with low expansion (less than $1: 20$ ) is not suitable for use in controlling gas propagation.

When the foam was exposed to heat the foam provided a good control of gas propagation for 12 minutes using Class B foam and 10 minutes using Class A foam. When the Class B foam was not exposed to heat in Test G6, the foam decomposition was substantially slower and the foam cover was complete for over 3 hours.

In Tests G2, G3, G4 and G5, vapour penetration across the foam layer, observed during the tests with solid floor, did not occur as the liquid from the foam drained through the grated floor to the ground or evaporated.

Based on the experiments described in Chapter 5, where the foam was in contact with surface having a temperature above $100^{\circ} \mathrm{C}$, the vapour escaped across the foam. When the foam was evaporating at higher rate, the mitigation of gas flow across the foam layer was expected to be minimal. As soon as the temperature of the surface dropped below $100^{\circ} \mathrm{C}$, the gas mitigation is expected to be similar to the tests described in this section. As the temperature of the surface is expected to drop below $100^{\circ} \mathrm{C}$ within few minutes, the expected gas mitigation was still considered more effective than any other fire prevention or fire fighting system available today. 


\section{CONCLUSIONS AND RECOMMENDATIONS}

\subsection{Summary}

The objectives of the research described in this thesis were to:

- determine the heat absorption capacity of compressed-air foam, and

- determine the foam's ability to mitigate gas propagation.

\subsection{Heat absorption capacity of CAF}

A theory to find the convective heat transfer coefficient between a steel plate and compressed-air foam was developed and experiments were prepared and completed to obtain the required data to calculate the heat transfer coefficient between steel and compressed-air foam.

The validity of the obtained heat transfer coefficient was verified using different compressed-air foam expansions, different initial temperatures of the target (steel), and using different amounts of foam coverage.

The experiments demonstrated that the water released from the foam (vaporized), constitutes major portion of the energy absorbed by the foam. A method was developed using the heat transfer coefficient to calculate the optimum rate of foam delivery to provide the most efficient cooling. 
This method will help develop new standards for required foam delivery density as well as the duration of the foam delivery. As a result, these findings may reduce the extinguishing time and the required quantity of CAF used to extinguish a fire.

In the experiments described in this thesis the heat was applied to the bottom of the foam, whereas in similar experiments described in the literature review the foam was applied to cold surface that is to be protected and the foam was exposed to radiation.

The tests by Lattimer [13] show that the vaporization is relatively low and seem to be constant when the foam is exposed to radiation. Contrary to Lattimer's tests, typical application of foam in fire-fighting is by applying the foam over the fire area. It is expected that the burning surface is hot.

This study demonstrates that there is a significant vaporization when the surface that the foam is applied to is above $100^{\circ} \mathrm{C}$ and that the vaporization is minimal when the surface temperature is below $100^{\circ} \mathrm{C}$. If the rate of vaporization is to be used in models that can predict extinguishment using foam, this study shows that using only a radiation source located above the foam layer could produce wrong results. Furthermore, the foam that was used in experiments by Lattimer was not CAF. 
The idea of testing CAF in both extinguishing and cooling of the surface was tested by NRC where the CAF was used in extinguishing fire and combustible liquids were preheated. No data on the cooling ability was collected.

\subsection{Foam's ability to mitigate gas propagation}

It was found that compressed-air foam has the ability to efficiently control gas spread. For example, a flammable liquid spill can be covered by a layer of compressed-air foam and the foam will prevent the propagation of flammable liquid vapours when the surface temperature is below $100^{\circ} \mathrm{C}$.

The experiments described in Chapter 5 demonstrated that when a large amount of vapour was generated the vapour penetrated the foam layer. As vapour volume is approximately 1,600 times the volume of water, the amounts of vapour generated greatly exceeded the foam capacity to contain large amounts of gas.

The location of spills of flammable liquids or the potential release of toxic gas is not easily predictable. Control with CAF can be used in both automatic and manual systems and its effectiveness will depend on the duration of the full coverage of the foam layer. As CAFSs are now being adopted by fire departments, the use of CAF in the control of flammable liquid vapours or toxic gases should be considered and be a part of the standard operating procedures of fire departments that are equipped with CAFS. 


\subsection{Future application of CAF}

Present codes require that automatic fire protection be provided with water-based automatic sprinklers. The main reason is the reliability of sprinkler systems and the unlimited duration (still depends on water supplies) of the operation of the system.

Similar to gas extinguishing systems, CAF is a one-time limited discharge operation whereby if the foam supply is exhausted and the fire has not been extinguished, the fire is no longer controlled. By providing more information on CAF's behaviour under exposure to heat, it will be possible to determine the quantities of foam required to extinguish a fire and to provide adequate reliability to replace sprinkler systems in certain applications.

The use of CAF will help reduce the amount of water that is required to fight a fire and to reduce the adverse effects of fire on the environment. Additional information and continued research on the CAF's ability to extinguish fire and to control heat may eventually lead to the acceptance of a CAFS in building codes as the prime fire protection system.

In this study, it was demonstrated that CAF can provide an efficient barrier for gas propagation and mitigation for an extended period of time. It could become a standard practice to spray CAF over flammable liquid spills to prevent vapour propagation and 
possible explosion or fire until the decontamination equipment can be delivered to the site.

The use of CAF in the marine industry would be the ideal solution as CAF requires small amounts of water (will not sink the boat) and does not require a sealed environment as is the case of gas-based fire protection systems.

\subsection{Recommendations for future research}

The foam density covering the target may be affected by the foam having to penetrate the fire plume and by air movement. It would be beneficial to determine these effects on foam density while using typical foam delivery nozzles.

The storage of flammable liquids and dangerous liquids in plastic totes (containers with dimensions of 27 to $64 \mathrm{ft}^{3}$ that contain 700 to $1000 \ell$ of liquids) is becoming more and more prevalent in industry even though the fire protection of these large plastic containers is still outside of the scope of current fire protection codes.

Research in the protection of flammable and dangerous goods in large containers using CAFSs should be pursued and used to develop a new fire protection standard that could increase the safety in the industry and reduce environmental hazards. 


\section{REFERENCES}

1. National Fire Protection Association. NFPA 10 - Standard for Portable Fire Extinguishers. Quincy (MA): NFPA; 2010.

2. National Fire Protection Association. NFPA 11, Standard for Low-, Medium, and High-Expansion Foam. Quincy (MA): NFPA; 2010.

3. Persson H. Fire Extinguishing Foams - Resistance Against Heat Radiation. Swedish National Testing and Research Institute - Fire Technology SP Report $54 ; 1992$.

4. Workman M. Foam Systems - Low-expansion, Medium-expansion, Highexpansion. Viking Corporation; 2006.

5. Sheinson RS, Williams BA, Green C, Fleming JW, Anleitner R, Ayers S, Maranghides A. The Future of Aqueous Film Forming Foam (AFFF): Performance Parameters and Requirements. Washington (DC): Navy Technology Center for Safety and Survivability, Combustion Dynamics Section, Naval Research Laboratory.

6. Cortina TA. Fact Sheet on AFFF Fire Fighting Agents. Arlington (VA): Fire Fighting Foam Coalition.

7. McLaughlin WL. Properties of Compressed Air Foam. Washington: San Juan County Fire District \#3; 2001.

8. Taylor RG. Compressed-Air Foam Systems in Limited Staffing Conditions. Morristown (NJ): Morristown Fire Bureau; 1997.

9. Jastrzebski Z. Entrance effect and wall effects in an extrusion rheometer during the flow of concentrated suspensions. Ind. Eng. Chem. Res 1967; p. 6:445-5.4

10. Mooney M. Explicit formulas for slip and fluidity. J Rheol 1931; p. 2:210-22

11. Gardiner BS, Dlugogorski BZ, Jameson GJ. Rheology of fire-fighting foams. Fire Safety Journal $31 ; 1998 ;$ p. 61-75

12. Gardiner BS, Dlugogorski DZ, Jameson GJ, Chhabra RP. Yield stress measurements of aqueous foams in the dry limit. The society of Rheology; 1998; p. S0148-6055(98)01006-2. 
13. Lattimer BY, Hanauska CP, Scheffey JL, Williams FW. The use of small-sacale test data to characterize some aspects of fire fighting foam for suppression modeling. Fire Safety Journal 38; 2003; p. 117-146.

14. National Fire Protection Association. NFPA 30, Flammable and Combustible liquid Code. Quincy (MA): NFPA; 2012.

15. National Fire Protection Association. NFPA 13, Standards for the Installation of Sprinkler Systems. Quincy (MA): NFPA; 2010.

16. FM Global. Flammable Liquid Storage in Portable Containers - Property Loss Prevention Data Sheets 7-29. West Glocester (R.I): FM Global Research; 2009.

17. National Research Council of Canada. National Fire Code of Canada 2005. Ottawa (ON): Canadian Commission on building and fire Codes; 2006; art. 4.1.6.

18. Lhotsky P, Mastroberardino C. Study of fire effects on telecommunication equipment. Report. Montreal (QC): Civelec Consultants Inc; 2009.

19. National Fire Protection Association. NFPA 76, Standard for the Fire Protection of Telecommunications Facilities, Annex D - Smoke management. Quincy (MA): NFPA; 2010.

20. FM Global. Flammable Liquid Operations - Property Loss Prevention Data Sheets 7-32. West Glocester (RI): FM Global Research; 2010

21. National Research Council of Canada. National Fire Code of Canada 2010. Ottawa (ON): Canadian Commission on building and fire Code. Art. 3.2

22. National Research Council of Canada. National Fire Code of Canada 2010. Ottawa (ON): Canadian Commission on building and fire Code. Art. 1.2

23. Kim A. Overview of recent progress in fire suppression technology (publication NRCC-45690). Ottwa (ON): National Research Council of Canada.

24. Grant CC. Halon design calculations. In: DiNenno PJ, Beyler CL, Custer RLP, Walton WD, Watts JM, Drysdale D, Hall JR. Fire Protection Handbook, $18^{\text {th }}$ th ed. Quincy(MA): National Fire Protection Associations; 1995.

25. Sumi K, Tsuchiya Y. Toxic Gases and Vapours Produced at Fires (publication CBD-144). Ottawa (ON): National Research Council of Canada; 1971.

26. National Fire Protection Association. NFPA 412 Standard for Evaluating Aircraft Rescue and Fire-Fighting Foam Equipment. Quincy (MA): NFPA; 2009. Art. 3.3. 
27. National Fire Protection Association. NFPA 409 - Standard on Aircraft Hangers. Quincy (MA): NFPA; 2011. Art. 6.24

28. Lhotsky P, Mastroberardino C. Design of fire protection system for Air Transant. Plans. Montreal (QC): Civelec Consultants; 2003.

29. Viking Corporation. Viking Grate Nozzle - Viking Technical Data - Foam 141 a. Hastings MI: The Viking Corporation; 2010.

30. Lhotsky P, Mastroberardino C. Design of fire protection system for CalmAir. Plans. Montreal (QC): Civelec Consultants; 2005.

31. Lhotsky P, Mastroberardino C. Design of fire protection system for Air Tassili Plans. Montreal (QC): Civelec Consultants; 2007.

32. Lhotsky P, Mastroberardino C. Alternative Solution - Flammable Liquid Protection - AkzoNobel - Delta B.C. Report. Montreal (QC): Civelec Consultants; 2008.

33. Crampton G. Rotary Foam Nozzle NRC - Patent \# 6328225. US Pattent Office; 2001.

34. FireFlex Systems Inc. ICAF News - INL 061211. Boisbriand, (QC): FireFlex Systems Inc.; 2006.

35. Gardiner BS, Dlugogorski BZ, Jameson GJ. Prediction of Pressure Losses in Pipe Flow of Aqueous Foams. Ind. Eng. Chem. Res.; 199, 38, p. 1099-1106.

36. Gardiner BS, Dlugogorski BZ, Jameson GJ. The steady shear of the threedimensional wet polydisperse foams. Journal of non-Newtonian Fluid Mechanics; 1992; p. 151-166.

37. Magrabi SA, Dlugogorski BZ, Jameson GJ. Bubble size distribution and coarsening of aqueous foams. Chemical Engineering Science 54; 1999; p. 4007 4022 .

38. Magrabi SA, Dlugogorski BZ, Jameson GJ. A comparative study of drainage characteristics in AFFF and FFFP compressed-air fire-fighting foams. Fire Safety Journal $37 ; 2002 ;$ p. 21-52.

39. Magrabi SA, Dlugogorski BZ, Jameson GJ. Free Drainage in Aqueous Foams: Model and experimental study. AIChE Vol 47, No2.; 2001. 
40. Saint-Jalmes A, Dominique Langevin D. Time evolution of aqueous foams: drainage and coarsening. Journal of Physics: Condensed Matter 14; 2002; p. 9397-9412.

41. Kim AK, Dlugogorski BZ. Multipurpose Overhead Compressed-Air Foam System and it's Fire Suppression Performance. Journal of Fire Protection Engineering; 8(3); 1997; p. 133-150

42. Kim AK, Crampton G. Use of Compressed-air foam Technology to Protect Subfloor and Cable Trays against Class C fires. (publication B4143). Ottawa (ON): National Research Council of Canada

43. Kim AK, Crampton G. Use of Compressed-air foam Technology to Provide Fire Protection for Power Transformers (publication B4142). Ottawa (ON): National Research Council of Canada.

44. Kim AK, Crampton G. Feasibility Study and Development of a Prototype CAF System for Fire Protection of Housing Units in Remote Areas (publication B4164). Ottawa (ON): National Research Council of Canada.

45. Kim AK, Crampton G, Asselin JP. A Comparison of the Fire Suppression Performance of Compressed-Air Foam and Foam-Water Sprinkler Systems for Class B Hazards (publication IRC-RR 146). Ottawa (ON): National Research Council of Canada; 2004

46. Underwriters Laboratories Inc. UL 162 - UL Standard for Safety for Foam Equipment and Liquid Concentrates, Seventh Edition. Northbrook (IL): Underwriters Laboratories Inc.; 1994

47. Crampton G. Fire Extinguishing Performance of the ICAF system with Synchronous Operation of Sprinklers (publication IRC-RR 237). Ottawa (ON): National Research Council of Canada; 2007

48. Crampton G. The Determination of a Safety Factor for Application Density of Compressed Air Foam on Flammable Liquid Fires (publication RR 180). Ottawa (ON): National Research Council of Canada; 2004

49. Crampton G, Kim AK. The Comparism of the Fire Suppression Performance of Compressed-Air Foam with Foam Water Sprinklers on Free-Flowing Heptane Spill Fires (publication IRC-RR 174). Ottawa (ON): National Research Council of Canada; 2004 
50. Kim AK, Crampton G. Evaluation of the Fire Suppression Effectiveness of Manually Applied Compressed Air Foam (CAF) System. Fire Technology, 48; 2012; p. 549-564.

51. Fleming JW, Sheinson RS. Development of a Cup Burner Apparatus for Fire Suppression Evaluation of High-Expansion Foams. Fire Techology, 48; 2012; p. 615-623.

52. Laundess AJ, Rayson MS, Dlugogorski BZ, Kennedy EM. Suppression Performance Comparison for Aspirated, Compressed-Air and In Situ Chemically Generated Class B Foams. Fire Technology, 48; 2012; p. 625-640.

53. Magrabi SA, Dlugogorski BZ, Jameson GJ. The Performance of Aged Aqueous Foams for Mitigation of Thermal Radiation. Dev. Chem. Eng. Mineral Process, 8 (1/2); 2000; p. 93-112

54. Society of Fire Protection Engineers. Uncertainty Analyses - Reference Manual for the P.E. Exam in Fire Protection Engineering. Boston (MA): SFPE; 1996; p. $47-49$

55. Boyed CF, Di Marzo M. The behaviour of a fire-protection foam exposed to radiant heating. Elsvier Science ltd. Vol 41, No12; 1998; p. 1799-1728.

56. DiNenno PJ, Beyler CL, Custer RLP, Walton WD, Watts JM, Drysdale D, Hall JR. Fire Protection Handbook, $18^{\text {th }}$ ed. Quincy(MA): National Fire Protection Association

57. Drysdale DD. Thermochemistry. In: DiNenno PJ, Beyler CL, Custer RLP, Walton WD, Watts JM, Drysdale D, Hall JR. Fire Protection Handbook, $18^{\text {th }}$ th ed. Quincy(MA): National Fire Protection Associations; 1995.

58. Hodges B. Heat budget and thermodynamics at free surface. University of Western Australia; 1998

59. Mehaffey J. Heat Transfer - Convection and Radiation - Fire Dynamics 1 Lecture 4, Ottawa (ON): Carleton University; 2009

60. Incropera FP, De Witt DP. Fundamentalsof Heat Transfer. Toronto (ON): John Wiley \& Sons, Inc.; 1981

61. Clarke BF. Fire Hazards of Materials an Overview. In: DiNenno PJ, Beyler CL, Custer RLP, Walton WD, Watts JM, Drysdale D, Hall JR. Fire Protection Handbook, $18^{\text {th }}$ th ed. Quincy(MA): National Fire Protection Association; 1995. 